Exploring windows of opportunities of smallholder

farmers in the Indo-Gangetic Plains of India

Roos de Adelhart Toorop

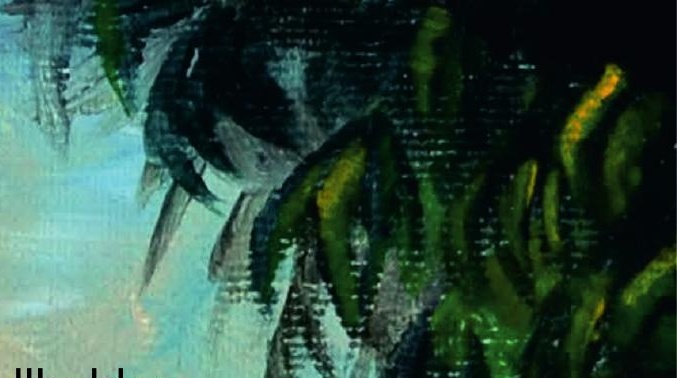




\section{Propositions}

1. Positive deviant behavior is more important than outstanding performance. (this thesis)

2. Farmers' autonomy is indispensable in achieving antifragile food systems. (this thesis)

3. The effects on public health should be taken into account when agronomists promote practices and technologies.

4. Practical but less scientifically sound decisions made in the research design should be discussed openly in publications.

5. Marathon running should be a category in the training and supervision plan for $\mathrm{PhD}$ candidates.

6. Many drops in the ocean are a more sustainable way of transformation than revolutions.

Propositions belonging to the thesis entitled

Exploring windows of opportunities of smallholder farmers in the Indo-Gangetic Plains of India

Roos de Adelhart Toorop

Wageningen, 12 October 2021 
Exploring windows of opportunities of smallholder farmers in the Indo-Gangetic Plains of India 


\section{Thesis committee}

\section{Promotor}

Dr J.C.J. Groot

Associate professor, Farming Systems Ecology Group

Wageningen University \& Research

\section{Co-promotor}

Dr S. López-Ridaura

Senior Scientist

International Maize and Wheat Improvement Center (CIMMYT), Mexico City, Mexico

\section{Other members}

Prof. Dr M.K. van Ittersum, Wageningen University \& Research

Dr A. van Paassen, Wageningen University \& Research

Dr A. Riar, Research Institute for Organic Agriculture (FiBL), Frick, Switzerland

Dr M. Kozicka, International Institute for Applied Systems Analysis (IIASA), Austria

This research was conducted under the auspices of the C.T. de Wit Graduate School for Production Ecology and Resource Conservation. 


\title{
Exploring windows of opportunities of smallholder farmers in the Indo-Gangetic Plains of India
}

\author{
Roos de Adelhart Toorop
}

\section{Thesis}

submitted in fulfillment of the requirements for the degree of doctor

$$
\text { at Wageningen University }
$$

by the authority of the Rector Magnificus,

$$
\begin{aligned}
& \text { Prof. Dr. A.P.J. Mol, } \\
& \text { in the presence of the }
\end{aligned}
$$

Thesis Committee appointed by the Academic Board

to be defended in public

on Tuesday 12 October 2021

at 11 a.m. in the Aula 
Roos de Adelhart Toorop

Exploring windows of opportunities of smallholder farmers in the Indo-Gangetic Plains of India 192 pages

PhD thesis, Wageningen University, Wageningen, the Netherlands (2021)

With references, with summary in English

ISBN: 978-94-6395-950-6

DOI: https://doi.org/10.18174/552227 


\section{Table of Contents}

Chapter 1 General Introduction 7

Chapter 2 Challenges experienced by smallholder farmers shape the window of opportunities for farm development in northern India

Chapter 3 Farm-level exploration of economic and environmental impacts of sustainable intensification of rice-wheat cropping systems in the Eastern Indo-Gangetic plains

Chapter 4 Using a positive deviance approach to inform farming systems redesign: a case study from Bihar, India

Chapter 5 Analysing antifragility among smallholder farmers in Bihar, India: an assessment of farmers' vulnerability and the strengths of positive deviants $\mathbf{1 1 3}$

Chapter 6 General Discussion

Summary | Samenvatting | सारांश

Acknowledgements 181

About the author

Selected Publications 189

Education Statement 


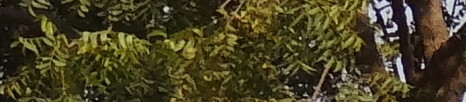

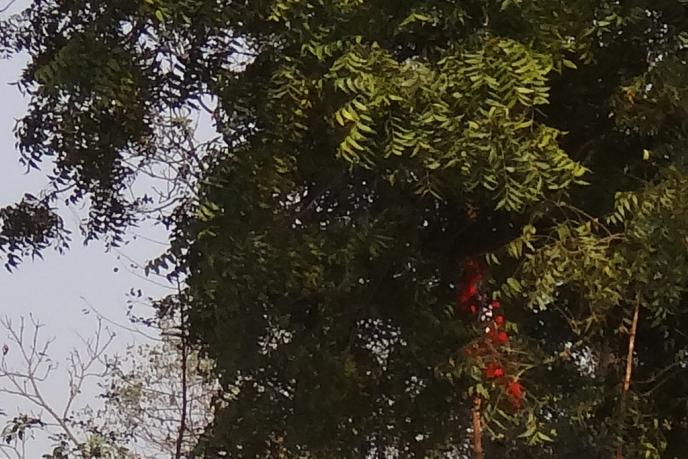




\section{Chapter 1}

General Introduction 



\section{Need for Systems Redesign}

Humanity faces a challenge to simultaneously improve human wellbeing whilst remaining within ecological planetary boundaries. There is a growing recognition that 'development' and environmental challenges need to be intertwined in order to reach global prosperity (Pereira et al., 2015; Steffen et al., 2015). Agriculture is being questioned for its biophysical and socio-economic sustainability: while intensification, homogenization, and specialization were seen as a sign of progress since the 1950s (Erenstein and Thorpe, 2011), industrial agriculture is now being associated with a strong focus on productivity maximization with its adverse effects on the environment (soils, water, biodiversity), animal welfare, exploitive labor demands and power of multi-national companies (Giller et al., 2021). To maintain high productivity, farmers depend and rely on inputs (e.g. seeds, fertilizers, pesticides, veterinary medicines), secured access to markets and value chains, subsidies and governmental interventions. These dependencies create power asymmetries within the food-system: the larger entities, such as (multi-national) input providers, banks and governments, have gained the power to direct the smaller entities, control the supply-chain and (directly and indirectly) have a disproportionate influence on decision making (Nyström et al., 2019). Enterprises that trade and process food, for example, collect farmers' products at predefined moments and set the price. Such a position makes farmers fragile and dependent on the larger entities. While global connectivity increased over the past century, local connectivity is weakening. Intensification of agricultural production reduces feedback within and among farming systems and often leads to decoupling: cycles (of e.g. nutrients, organic matter, crops as feed) and biological processes (e.g. natural pest suppression) that used to be present within the farming system are being replaced by external inputs (fertilizers, pesticides and feed) (Hodbod and Eakin, 2015; Meuwissen et al., 2019).

These are also among the prevalent challenges in South Asia. The Indo-Gangetic Plains (IGP), encompassing the northern regions of the Indian subcontinent (Pakistan, India, Nepal, Bangladesh), are traditionally characterized by fertile soils, favorable climate to cultivate cereals and abundant water availability (Aggarwal et al., 2004). Rapid population growth puts pressure on the land that is suitable for production while the impacts of climate change are experienced strongly (M. L. Jat et al., 2020) and continuous cereal production under the current resource management strategies leads to degradation of natural resources (Erenstein and Thorpe, 2011). Climatic and socio-economic perturbations affect the food system and increase the vulnerability of farmers and the resource poor population (Aggarwal et al., 2004). 
In times of global change, volatility and disturbances should be expected. Floods, droughts, unpredictable rainfall patterns, hurricanes, earthquakes, wildfires, ice storms, market disruptions, fluctuating input and output prices are amongst the challenges for 21 st century farmers (IPCC, 2019). Therefore, farming systems need to be designed to thrive rather than survive, when facing volatility and uncertainty. This requires a shift from systems-optimization, with a narrow range of conditions in which the system can exist (i.e. vulnerable, fragile systems), towards systems that are resilient, adaptive and transformative. These 'future proof' systems are not indifferent to disturbances, or return to the status quo after a disturbance, but take advantage of the disturbance to evolve (Darnhofer, 2021; de Bruijn et al., 2020; Tendall et al., 2015). In other words: these systems do not resist inevitable change. Although there has been an increasing social and political pressure to enhance robustness (withstanding) and resilience (recovery) of farming systems, it can be questioned whether the current systems need enhancement or a thorough transformation (Hendrickson, 2015). In this thesis I investigate ways to shift from the dominant business-as-usual food production towards systems that do not harm the environment and improve social structures.

\section{Moving Away From Fragility}

\subsection{Improving 'the average'}

Farming systems are composed of subsystems, which are characterized by diversity. A mixed farm is comprised of crops and animals as subsystems. Within the subsystem crops, we can distinguish various cropping patterns and within the component animals, we can distinguish different types of animals. If elements in farming systems do not fit with other elements and within the socio-ecological context, they will not perform. As first step towards a systems transformation, system elements that do not fit the socio-ecological context can be identified and adapted while strong, fitting system elements can be nurtured.

A common way to obtain insight in the diversity of farming systems in a similar context is to group farms based on their resources and livelihood activities, as well as their agricultural management practices (Berre et al., 2016; Lopez-Ridaura et al., 2018; Tittonell, 2014; Tittonell et al., 2010). Such a farm typology aims to find commonalities within groups and diversity between groups, and in that way represent the average, most dominant, farming systems within 
a community. Farm systems with a unique set-up in the community are usually omitted from the analysis and treated as outliers.

A farm typology can be used to select representative farms for in-depth analysis per group (i.e. farm type) (Alvarez et al., 2018). Subsequently, model-based analysis can help to gain systems understanding, by identifying fitting and unsuitable system elements and explore windows of opportunities (Groot and Rossing, 2011) for a variety of farm types. In addition to identification of unsuitable system elements that do not contribute to achieving farmer objectives, insight in trade-offs and synergies among objectives helps to identify suitable development strategies and trajectories. Moreover, ex-ante impact assessments can give insight in possible differentiated potential to improve systems' performance for different farm types: expansion of the window of opportunities implies that there are promising development options which are associated with increased adaptive capacity (Groot et al., 2016).

\subsection{Stepping away from 'the average': Positive deviants}

In addition to looking at ways to improve the average, most dominant farming systems within a community, looking beyond the average, at positively deviating examples may yield insights into suitable development directions. Positive deviants are individuals within a community who manage to do better than their peers, despite being part of the same context. Understanding 'what works' within the narrowed setting of a farm, might give useful hints for the broader context of a farming system. This focus on real-life examples may bridge the divide between research and practice. While researchers are often delineated by (quantitative) performance indicators to evaluate system performance, farmers are driven by their goals, values and opportunities, and often only implicitly evaluate performance indicators. Positive deviants' farming practices are assumed accessible, affordable, tailored to local conditions and possibly transferable to other farmers (Bradley et al., 2009; Marsh et al., 2004; Pant and Odame, 2009). Understanding, and where possible even mimicking, the political and social context that enabled the trajectory of change could benefit the transferability of the practices and behaviour (S. Biggs, 2008). Positive deviants are often very connected in their social networks and show high levels of engagement and self-organization (Clancy, 2010). Insights in positive deviants' trajectories, practices, activities, drivers and networks, within and beyond the farm level, may give concrete examples of locally adapted, resilient farming systems. 
There is no standardized selection procedure to assign individuals as positive deviants. Most studies have used normative approaches to identify the 'best' farms, and relied on expert knowledge for the final selection (e.g. the community or local researchers) without quantitative verification whether the performance is indeed better than the average (Amankwah et al., 2012; S. D. Biggs et al., 2004; Ochieng, 2007; Pant and Odame, 2009). Modernel et al. (2018) and Steinke et al. (2019) applied a quantitative approach and selected positive deviants based on Pareto-optimality.

\subsection{Towards antifragility}

Improving farm performance as assessed by performance indicators may be important as part of a transition towards 'future proof' farming systems, especially when facing (food) insecurity and scarcity. However, as stressed in the previous section, the context enabling system transitions is of importance to secure the realisation of livelihood aspirations and to become adaptive. When 'future proof' systems are resilient, adaptive and transformative, they may become the opposite from fragile (i.e. vulnerable to collapse): antifragile. They evolve and gain from volatility. System properties of resilient systems, as described in the social-ecological literature, come close to this definition (Berkes et al., 2003; Folke, 2006; Folke et al., 2010; Folke et al., 2002; Holling, 1996; Walker et al., 2004). Folke (2006) describes socio-ecological resilience as “1) the amount of disturbance a system can absorb and still remain within the same state or domain of attraction, 2) the degree to which the system is capable of self-organization (versus lack of organization, or organization forced by external factors), and 3) the degree to which the system can build and increase the capacity for learning and adaptation." In this thesis, I explicitly focus on resilience with as properties adaptability and transformability to arrive at systems that benefit from disturbances and evolve as a result. As not all definitions of resilience focus on evolution, I here introduce this form of resilience as antifragility.

Antifragility was first introduced by Taleb (2012) and was described in a business-oriented and entrepreneurial way: fragile systems perish in a world full of volatility making the average system stronger. Although the principles hold stake when transferring this concept to the food system, farming systems and to subsystems of farms, this transfer needs to be made with caution as the focus at systems-level should be on support and sustainable development rather than on selection. 


\section{Box 1: Definitions of concepts}

Adaptive capacity: Ability to deal with perturbations and increase the extent of variability that can be coped with (Urruty et al., 2016)

Antifragility: Ability to 'bounce back better' after a disturbance. The disturbance triggers reconfiguration of the system (Taleb, 2012).

Cropping pattern: Sequence of crops grown on a plot in subsequent seasons (e.g. wheat-mung bean-rice in rabi, kharif (monsoon) and zaid)

Farm system: A decision making unit consisting of farm components (e.g. soil, crop, animals, manure, household) that transforms resources into products that can be consumed or sold (Fresco and Westphal, 1988)

Farming system: A population of individual farm systems that may have widely differing resource bases, enterprise patterns, household livelihoods and constraints (Giller, 2013).

Fragility: Being prone to collapse in case of a disturbance (Taleb, 2012).

Optionality: Having multiple options and the flexibility to change practice when the opportunity arises, not being locked-in (Taleb, 2012).

Positive deviant: An individual who positively deviates from the average despite operating in a similar context (Pant and Odame, 2009).

Resilience: Ability to ‘bounce back' (i.e. recover) after a disturbance (Van Der Werf et al., 2014).

Robustness: Withstanding disturbances and maintaining system functioning (Urruty et al., 2016).

Vulnerability: The degree to which a system is likely to experience harm due to exposure to a undesirable situation (disturbance, shock, stress) (Turner II et al., 2003).

Typology: A categorization of farm diversity in terms of their resources and livelihood activities, as well as agricultural management practices (Lopez-Ridaura et al., 2002).

Window of opportunities: Set of potential farm configurations that differ from each other in performance in terms of selected objectives. The configurations are possibilities that are not currently enacted. In literature also referred to as outcome space or opportunity space (Groot et al., 2012; Timler et al., 2020).

\section{Study Area}

This thesis focuses on northern India, with an emphasis on a the IGP. The area hosts a population of 375 million ( $36 \%$ of the total population of India) on a surface area of $518.000 \mathrm{~km} 2$ (16\% of India) (Erenstein and Thorpe, 2011). The area is characterized by a high degree of socio-economic diversity. The North-Western plains are associated with higher levels of assets and livelihood outcomes (i.e. more wealth) compared to the Eastern plains. Punjab and Haryana are referred to as the 'granary' of India, and are associated with larger herds of bovines and farm sizes, and better access to irrigation water. Uttar Pradesh, Bihar and West-Bengal are among the most populous states of the country. Bihar, in the Eastern plains, is one of 
the poorest states, with $90 \%$ of the inhabitants living in rural areas. Although $81 \%$ of the population is active in farming, food insecurity is still common (Lopez-Ridaura et al., 2018). The state is challenged by unfavourable biophysical and climatic conditions, high degrees of land fragmentation, inadequate infrastructure and weak institutions and markets.

Wheat and rice are traditionally cultivated in the IGP, both irrigated and unirrigated. Population pressure, limited land resources, need for more irrigation and a shortening growing season for rice have already been reported as problems for decades (E. Huke and R. Huke, 1992). During the Green Revolution, modern technologies including high yielding variety seeds, chemical fertilisers, irrigation facilities, and improved crop protection measures were promoted together with considerable policy support (Singh, 2000). These efforts led to self-sufficiency in food grain production at the national level but also caused depletion of natural resources, and stagnating yields.

Productivity stagnation and environmental challenges led to a strong advocacy for technologies based on principles of Conservation Agriculture (H. S. Jat et al., 2021; M. L. Jat et al., 2020; R. Jat et al., 2018). These principles - minimal soil disturbance, crop rotations and permanent soil cover - have been widely tested and promoted. Another development direction especially promoted for small farms ( $<2 \mathrm{ha}$ ) is integrated farming systems. Integrated farming systems link components or enterprises which become subsystems of the farm. They typically cycle nutrients through the subsystems and are space efficient. Integrated farming systems are characterized by an abundance of optionality, leading to less risks if managed efficiently (Behera and France, 2016). Both conservation agriculture and integrated farming systems are being tested on-station and on-farm in a wide variety of settings and contexts along the IGP. Adoption, especially of full packages of principles, however still remains limited.

\section{Study Objectives and Questions}

General objective:

- This thesis aims to understand and capture the diversity of farming systems based on their main components, characteristics, and interrelationships in order to identify windows of opportunities to inform redesign towards better whole-system farm performance for smallholder farms in the Indo Gangetic Plains. 
Research questions:

- How do farm characteristics, challenges and objectives compare and to what extent do these affect the window of opportunities and trade-offs for smallholder farmers across the Indo-Gangetic Plains (Chapter 2)?

- What are sustainable intensification alternatives for different types of smallholder farmers in cereal-based farming systems (Chapter 3)?

- How can positive deviant practices from a community inform farming systems redesign (Chapter 4)?

- What drives and limits antifragility among smallholder farmers (Chapter 5)?

Specific research objectives were to:

- Understand and distinguish farm characteristics, objectives and challenges perceived by smallholder farmers across the Indo-Gangetic Plains (Chapter 2).

- Assess sustainable intensification options in cereal-based farming systems for different types of smallholders (Chapter 3).

- Redesign farming systems based on positive deviant practices (Chapter 4).

- Assess the drivers and challenges for smallholder farmers to become more antifragile (Chapter 5).

\section{Research Methods}

\subsection{DEED-cycle as approach for systems analysis}

This thesis adopts the iterative Describe-Explain-Explore-Design (DEED) research cycle, combining analysis and design-oriented approaches (Descheemaeker et al., 2019; Giller et al., 2008; Rossing et al., 2021). The cycle begins with a description of the components of the system and the farm characteristics including drivers and challenges followed by an explanation of processes in terms of biophysical and socio-economic performance. After these analysis-oriented phases, focus can shift towards exploration to gain insight in trade-offs and synergies between objectives, and for ex-ante impact assessments. The next step is to (re)design the farming system based on the information gained from the previous phases, in close collaboration with stakeholders to ensure a redesign that is relevant to the farm context. The DEED-cycle supports systems-analysis and is often combined with whole-farm models (Descheemaeker et al., 2019; 
Giller et al., 2008; Le Gal et al., 2011). The cycle is typically iterative, as the (model-based) results from the exploration phase need feedback from stakeholders which inform a new (re)design cycle.

\subsection{Farmers' drivers and challenges}

As part of the Describe and Explain phases of the DEED cycle, a deeper understanding of drivers and challenges was aimed for. While farmers are often assumed to primarily be profit maximisers, in India where farming is for most farmers their livelihood strategy, multiple objectives shape their decision making (Behera and France, 2016). Their goals, values, intentions, attitude, preferences, beliefs and motivations all influence their behavior (Bergevoet et al., 2004; Gosnell et al., 2019; Ondersteijn et al., 2003), and are therefore important to grasp. Moreover, farmers' perceptions and how they perceive risks are important in the identification of ways to increase adaptive capacity. As we can expect an increasingly volatile world, the vulnerability and adaptive capacity of a farm system depends largely on the farmers' ability to change (Huet et al., 2020). Drivers and challenges were assessed through ranking exercises wherein farmers were asked to rank predefined objectives and challenges, and through Focus Group Discussions (FGD) which elaborated on strategies to cope with challenges.

\subsection{Whole-farm modelling}

The whole-farm model FarmDESIGN (Ditzler et al., 2019; Groot et al., 2012; Timler et al., 2020) was used to analyse (i.e. Describe and Explain) the current farming systems' functioning and to Explore trade-offs, synergies and suitable directions for systems (re)Design. The model follows the structure of the DEED-cycle, and offers a structured way to assess a farming system. The model yields theoretical windows of opportunities, i.e. outcome spaces, based on the economic, agronomic, environmental and/or social objectives set, delineated by decision variables and constraints. These windows of opportunities can be used as "discussion support" to inform the dialogue between farmers, advisors, researchers and policymakers.

\section{Thesis Outline}

The outline of this thesis is graphically represented in Figure 1.1. Chapter 2 focuses on describing and explaining the whole-farm functioning, and assesses the objectives and challenges of farmers throughout the IGP. Chapter 3 zooms in to Bihar and explains and explores options to 
sustainably intensify the five dominant farm types. Chapter 4 steps away from average farms by identifying positive deviants and positive deviance practices and suggests a model-based methodology for positive deviance informed redesign. Chapter 5 describes the drivers and constraints for average farmers and addresses the farm designs of positive deviant farms that are likely to be more antifragile than the average farms.

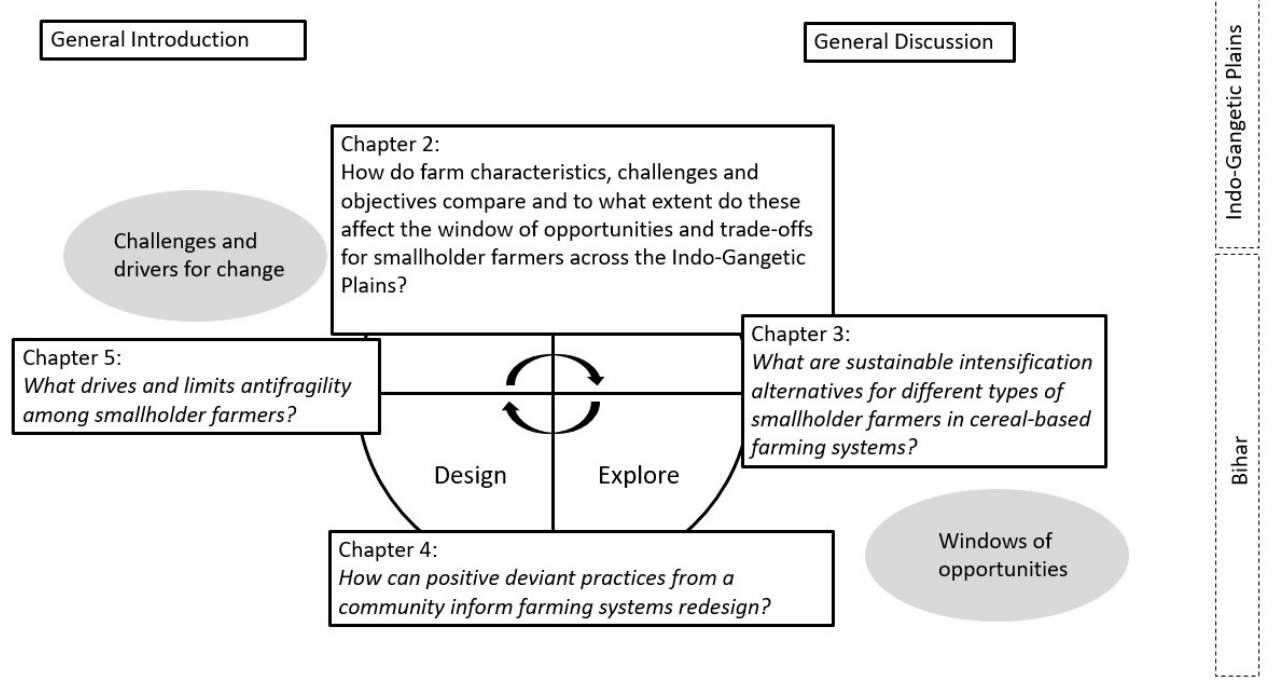

Figure 1.1: Schematic overview of chapters with research questions. Chapter 2, the general introduction and general discussion focus on the IGP whereas Chapter 3, 4 and 5 zoom in to the Eastern IGP state Bihar.

Chapter 2 gives an overview of farm characteristics across the Indo-Gangetic Plains and addresses farmers' challenges and objectives. In a case study we illustrate to what extent the perceived challenges could affect the window of opportunities and trade-offs that farmers must navigate.

Chapter 3 zooms in on five farms from different farm types in Bihar. For each type we explore the potential to improve economic and environmental systems' performance with and without the sustainable intensification option to grow mung bean in the usually fallow zaid (summer) season. Trade-offs and synergies were identified for four performance indicators.

Chapter 4 introduces a methodology for positive deviance informed redesigns of farming systems. The best farms (positive deviants) and best practices (positive deviance practices) from a community are identified and recombined to arrive at promising development options 
for different farm types. To tailor the development options for each of the farm types, feedback was received in focus group discussions.

Chapter 5 focuses on vulnerability and antifragility of smallholder farmers. We identify main challenges and coping strategies and describe the strengths of positive deviants, which transformed their farming systems towards more antifragile systems. In this way we define the scope and first attention points to make farming systems more antifragile.

In Chapter 6 the outcomes of the four research chapters are synthesized and discussed. This final chapter puts the findings on this thesis in a broader context, reflects on the methodologies used and addresses points for future research. 


\section{References}

Aggarwal, P. K., Joshi, P. K., Ingram, J. S. I., and Gupta, R. K. (2004), Adapting food systems of the Indo-Gangetic plains to global environmental change: key information needs to improve policy formulation. Environmental Science \& Policy. 7(6): p. 487-498.

Alvarez, S., Timler, C. J., Michalscheck, M., Paas, W., Descheemaeker, K., Tittonell, P., Andersson, J. A., and Groot, J. C. (2018), Capturing farm diversity with hypothesis-based typologies: An innovative methodological framework for farming system typology development. PLoS ONE. 13(5): p. 1-24.

Amankwah, K., Klerkx, L., Oosting, S. J., Sakyi-Dawson, O., Van Der Zijpp, A. J., and Millar, D. (2012), Diagnosing constraints to market participation of small ruminant producers in northern Ghana: An innovation systems analysis. NJAS - Wageningen Journal of Life Sciences. 60-63: p. 37-47.

Behera, U. K. and France, J. (2016), Integrated Farming Systems and the Livelihood Security of Small and Marginal Farmers in India and Other Developing Countries. Advances in Agronomy. 138: p. 235-282.

Bergevoet, R. H., Ondersteijn, C. J., Saatkamp, H. W., Van Woerkum, C. M., and Huirne, R. B. (2004), Entrepreneurial behaviour of dutch dairy farmers under a milk quota system: Goals, objectives and attitudes. Agricultural Systems. 80(1): p. 1-21.

Berkes, F., Colding, J., and Folke, C. (2003), Navigating Social-Ecological Systems - Building Resilience for Complexity and Change. Cambridge University Press, p. 388.

Berre, D., Baudron, F., Menale, K., Craufurd, P., and Lopez-Ridaura, S. (2016), Different ways to cut a cake: Comparing expert-based and statistical typologies to target sustainable intensification technologies, a case-study in Southern Ethiopia. Experimental Agriculture. (2014): p. 1-17.

Biggs, S. (2008), Learning from the positive to reduce rural poverty and increase social justice: Institutional innovations in agricultural and natural resources research and development. Experimental Agriculture. 44(1): p. 37-60.

Biggs, S. D., Gurung, S. M., and Messerschmidt, D. (2004), An exploratory study of gender, social inclusion and empowerment through development groups and group-based organizations in Nepal: Building on the positive. Version 2. Tech. rep.

Bradley, E. H., Curry, L. A., Ramanadhan, S., Rowe, L., Nembhard, I. M., and Krumholz, H. M. (2009), Research in action: using positive deviance to improve quality of health care. Implement. Sci. 4(1): p. 25.

De Bruijn, H., Größler, A., and Videira, N. (2020), Antifragility as a design criterion for modelling dynamic systems. Systems Research and Behavioral Science. 37(1): p. 23-37.

Clancy, T. R. (2010), Diamonds in the rough: Positive deviance and complexity. Journal of Nursing Administration. 40(2): p. 53-56.

Darnhofer, I. (2021), Resilience or how do we enable agricultural systems to ride the waves of unexpected change ? Agricultural Systems. 187(November 2020): p. 102997.

Descheemaeker, K., Ronner, E., Ollenburger, M., Franke, A. C., Klapwijk, C. J., Falconnier, G. N., Wichern, J., and Giller, K. E. (2019), Which Options Fit Best? Operationalizing the Socio-Ecological Niche Concept. Experimental Agriculture. 55(S1): p. 169-190.

Ditzler, L., Komarek, A. M., Chiang, T.-W., Alvarez, S., Chatterjee, S. A., Timler, C., Raneri, J. E., Carmona, N. E., Kennedy, G., and Groot, J. C. J. (2019), A model to examine farm household trade-offs and synergies with an application to smallholders in Vietnam. Agric. Syst. 173(1): p. 49-63.

Erenstein, O. and Thorpe, W. (2011), Livelihoods and agro-ecological gradients: A meso-level analysis in the Indo-Gangetic Plains, India. Agricultural Systems. 104(1): p. 42-53.

Folke, C. (2006), Resilience: The emergence of a perspective for social-ecological systems analyses. Global Environmental Change. 16(3): p. 253-267.

Folke, C., Carpenter, S. R., Walker, B., Scheffer, M., Chapin, T., and Rockström, J. (2010), Resilience thinking: Integrating resilience, adaptability and transformability. Ecology and Society. 15(4).

Folke, C., Carpenter, S., Elmqvist, T., Gunderson, L., Holling, C. S., and Walker, B. (2002), Resilience and Sustainable Development: Building Adaptive Capacity in a World of Transformations. AMBIO: A Journal of the Human Environment. 31(5): p. 437-440.

Fresco, L. and Westphal, E. (1988), A hierarchical classification of farm systems. Experimental Agriculture. 24.

Giller, K. E., Hijbeek, R., Andersson, J. A., and Sumberg, J. (2021), Regenerative Agriculture : An agronomic perspective.

Giller, K. E. (2013), Guest editorial: Can we define the term 'farming systems'? A question of scale. Outlook on Agriculture. 42(3): p. 149-153.

Giller, K. E., Leeuwis, C., Andersson, J. A., Andriesse, W., Brouwer, A., Frost, P., Hebinck, P., Heitkönig, I., Van Ittersum, M. K., Koning, N., Ruben, R., Slingerland, M., Udo, H., Veldkamp, T., Van de Vijver, C., Van Wijk, M. T., and Windmeijer, P. (2008), Competing claims on natural resources: What role for science? Ecology and Society. $13(2)$. 
Gosnell, H., Gill, N., and Voyer, M. (2019), Transformational adaptation on the farm : Processes of change and persistence in transitions to ' climate-smart ' regenerative agriculture. Global Environmental Change. 59(August): p. 101965.

Groot, J. C. J., Cortez-Arriola, J., Rossing, W. A. H., Améndola Massiotti, R. D., and Tittonell, P. (2016), Capturing agroecosystem vulnerability and resilience. Sust. 8(11): p. 1206.

Groot, J. C. J., Oomen, G. J. M., and Rossing, W. A. H. (2012), Multi-objective optimization and design of farming systems. Agric. Syst. 110: p. 63-77.

Groot, J. C. J. and Rossing, W. A. H. (2011), Model-aided learning for adaptive management of natural resources: an evolutionary design perspective. Methods Ecol. Evol. 2(6): p. 643-650.

Hendrickson, M. K. (2015), Resilience in a concentrated and consolidated food system. Journal of Environmental Studies and Sciences. 5(3): p. 418-431.

Hodbod, J. and Eakin, H. (2015), Adapting a social-ecological resilience framework for food systems. Journal of Environmental Studies and Sciences. 5(3): p. 474-484.

Holling, C. S. (1996), Engineering resilience versus ecological resilience. Engineering within ecological constraints. (1996): p. 31-43.

Huet, E. K., Adam, M., Giller, K. E., and Descheemaeker, K. (2020), Diversity in perception and management of farming risks in southern Mali. Agricultural Systems. 184: p. 102905.

Huke, E. and Huke, R. (1992), Rice / Wheat Atlas of South Asia: p. 55.

IPCC (2019), Climate change and land grabbing. Tech. rep., p. 423-449.

Jat, H. S., Datta, A., Choudhary, M., Sharma, P. C., and Jat, M. L. (2021), Conservation Agriculture: factors and drivers of adoption and scalable innovative practices in Indo-Gangetic plains of India- a review. International Journal of Agricultural Sustainability. 19(1): p. 40-55.

Jat, M. L., Chakraborty, D., Ladha, J. K., Rana, D. S., Gathala, M. K., McDonald, A., and Gerard, B. (2020), Conservation agriculture for sustainable intensification in South Asia. Nature Sustainability. 3(4): p. 336-343.

Jat, R., Singh, R. G., Kumar, M., Jat, M., Parihar, C. M., Bijarniya, D., Sutaliya, J. M., Jat M.K, Parihar, M., Kakraliya, S. K., and Gupta, R. K. (2018), Ten years of conservation agriculture in a rice-maize rotation of Eastern Gangetic Plains of India: Yield trends, water productivity and economic profitability. Field Crops Research. 232(April 2018): p. $1-10$.

Le Gal, P. Y., Dugué, P., Faure, G., and Novak, S. (2011), How does research address the design of innovative agricultural production systems at the farm level? A review. Agricultural Systems. 104(9): p. 714-728.

Lopez-Ridaura, S., Frelat, R., Van Wijk, M. T., Valbuena, D., Krupnik, T. J., and Jat, M. L. (2018), Climate smart agriculture, farm household typologies and food security: An ex-ante assessment from Eastern India. Agric. Syst. 159(September 2016): p. 57-68.

Lopez-Ridaura, S., O., M., and Astier, M. (2002), Evaluating the sustainability of com-plex socio-environmental systems. Ecological Indicators. 2((1-2)): p. 135-148.

Marsh, D. R., Schroeder, D. G., Dearden, K. A., Sternin, J., and Sternin, M. (2004), The power of positive deviance. Br. Med. J. 329(7475): p. 1177.

Meuwissen, M. P., Feindt, P. H., Spiegel, A., Termeer, C. J., Mathijs, E., de Mey, Y., Finger, R., Balmann, A., Wauters, E., Urquhart, J., Vigani, M., Zawalińska, K., Herrera, H., Nicholas-Davies, P., Hansson, H., Paas, W., Slijper, T., Coopmans, I., Vroege, W., Ciechomska, A., Accatino, F., Kopainsky, B., Poortvliet, P. M., Candel, J. J., Maye, D., Severini, S., Senni, S., Soriano, B., Lagerkvist, C. J., Peneva, M., Gavrilescu, C., and Reidsma, P. (2019), A framework to assess the resilience of farming systems. Agricultural Systems. 176(June): p. 102656.

Modernel, P., Dogliotti, S., Alvarez, S., Corbeels, M., Picasso, V., Tittonell, P., and Rossing, W. (2018), Identification of beef production farms in the Pampas and Campos area that stand out in economic and environmental performance. Ecological Indicators. 89(May 2017): p. 755-770.

Nyström, M., Jouffray, J. B., Norström, A. V., Crona, B., Søgaard Jørgensen, P., Carpenter, S. R., Bodin, Galaz, V., and Folke, C. (2019), Anatomy and resilience of the global production ecosystem. Nature. 575(7781): p. 98-108.

Ochieng, C. M. O. (2007), Development through positive deviance and its implications for economic policy making and public administration in Africa: The case of Kenyan agricultural development, 1930-2005. World Development. 35(3): p. 454-479.

Ondersteijn, C. J. M., Beldman, A. C. G., Daatselaar, C. H. G., Giesen, G. W. J., and Huirne, R. B. M. (2003), Farm structure or farm management: effective ways to reduce nutrient surpluses on dairy farms and their financial impacts. Livest. Prod. Sci. 84(2): p. 171-181.

Pant, L. P. and Odame, H. H. (2009), The promise of positive deviants: bridging divides between scientific research and local practices in smallholder agriculture. Knowl. Manag. Dev. J. 5(2): p. 160-172.

Pereira, L., Karpouzoglou, T., Doshi, S., and Frantzeskaki, N. (2015), Organising a safe space for navigating social-ecological transformations to sustainability. International Journal of Environmental Research and Public Health. 12(6): p. 6027-6044. 
Rossing, W. A. H., Marta, M., Aguerre, V., Leoni, C., Ruggia, A., and Dogliotti, S. (2021), Crafting actionable knowledge on ecological intensification : Lessons from co-innovation approaches in Uruguay and Europe. Agricultural Systems. 190(October 2020): p. 103103.

Singh, R. B. (2000), Environmental consequences of agricultural development: a case study from the Green Revolution state of Haryana, India. Tech. rep.

Steffen, W., Broadgate, W., Deutsch, L., Gaffney, O., and Ludwig, C. (2015), The trajectory of the anthropocene: The great acceleration. Anthropocene Review. 2(1): p. 81-98.

Steinke, J., Mgimiloko, M. G., Graef, F., Hammond, J., van Wijk, M. T., and van Etten, J. (2019), Prioritizing options for multi-objective agricultural development through the Positive Deviance approach. PLoS ONE. 14(2): p. 1-20.

Taleb, N. N. (2012), Antifragile - things that gain from disorder. Vol. 53. 9, p. 1689-1699. arXiv: arXiv: 1011.1669v3.

Tendall, D. M., Joerin, J., Kopainsky, B., Edwards, P., Shreck, A., Le, Q. B., Kruetli, P., Grant, M., and Six, J. (2015), Food system resilience: Defining the concept. Global Food Security. 6: p. 17-23.

Timler, C., Alvarez, S., DeClerck, F., Remans, R., Raneri, J., Estrada Carmona, N., Mashingaidze, N., Abe Chatterjee, S., Chiang, T. W., Termote, C., Yang, R. Y., Descheemaeker, K., Brouwer, I. D., Kennedy, G., Tittonell, P. A., and Groot, J. C. (2020), Exploring solution spaces for nutrition-sensitive agriculture in Kenya and Vietnam. Agricultural Systems. 180(1): p. 102774.

Tittonell, P. (2014), Livelihood strategies, resilience and transformability in African agroecosystems. Agricultural Systems. 126: p. 3-14.

Tittonell, P., Muriuki, A., Shepherd, K. D., Mugendi, D., Kaizzi, K. C., Okeyo, J., Verchot, L., Coe, R., and Vanlauwe, B. (2010), The diversity of rural livelihoods and their influence on soil fertility in agricultural systems of East Africa-A typology of smallholder farms. Agric. Syst. 103(2): p. 83-97.

Turner II, B., Kasperson, R. E., Matson, P. A., Mccarthy, J. J., Corell, R. W., Christensen, L., Eckley, N., Kasperson, J. X., Luers, A., Martello, M. L., Polsky, C., Pulsipher, A., and Schiller, A. (2003), A framework for vulnerability analysis in sustainability science. Tech. rep.

Urruty, N., Tailliez-Lefebvre, D., and Huyghe, C. (2016), Stability, robustness, vulnerability and resilience of agricultural systems. A review. Agronomy for Sustainable Development. 36(1): p. 1-15.

Van Der Werf, H. M., Garnett, T., Corson, M. S., Hayashi, K., Huisingh, D., and Cederberg, C. (2014), Towards eco-efficient agriculture and food systems: Theory, praxis and future challenges. Journal of Cleaner Production. 73: p. 1-9.

Walker, B., Holling, C. S., Carpenter, S. R., and Kinzig, A. (2004), Resilience, adaptability and transformability in social-ecological systems. Ecology and Society. 9(2). 


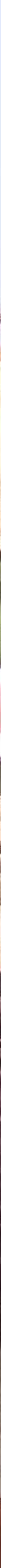




\section{Chapter 2}

Challenges experienced by smallholder farmers shape the window of opportunities for farm development in northern India

Roos de Adelhart Toorop, Santiago Lopez-Ridaura, Mangi Lal Jat, Jeroen C.J. Groot 


\section{Abstract}

Intensified crop cultivation in northern India has resulted in large gains in productivity with considerable externalities. Large concerns exist over resource depletion, environmental pollution, and farm viability. It is anticipated that farmers will have to redesign their farms to arrive at more sustainable farm systems. To obtain an overview of the farm diversity and its main characteristics we surveyed ca. 600 marginal and smallholder farmers in six districts in northern India (Patiala (Punjab), Karnal (Haryana), Muzaffarnagar (Western Uttar Pradesh), Faizabad (Easters Utter Pradesh), Patna (Bihar) and Kota (Rajasthan)). In each district a subset of farmers was interviewed to assess their objectives and perceived challenges. Furthermore, we conducted a model-based exploration to determine the potential effects of anticipated constraints, reflected in reduced product prices and productivity and higher hired labor costs, on their options to improve profitability, soil quality, labor use and water use. The differences in objectives between the six districts were correlated to the differences in climatic conditions (Mantel test, $\mathrm{r}=0.5714, \mathrm{p}=0.0125$ ). In contrast, the challenges were not correlated with climate, demography, or farm structure, but were uniform over five out of the six districts. The most frequently mentioned challenges that were seen as acute problems were related to low labor availability, fluctuating market prices, low soil fertility and high seed prices. The model-based analysis showed that the anticipated, associated changes of lower product prices and productivity and higher prices of hired labor could aggravate the trade-offs of farm profitability with water use and soil quality. We conclude that, due to continued farm fragmentation and increased price volatility and resource constraints, the window of opportunities for smallholder farmers in northern India is strongly reduced and more fundamental changes in farming and supporting policies are needed to address the challenges that farmers are facing.

Keywords: FarmDESIGN, multi-objective optimization, trade-offs, Indo-Gangetic Plains 


\section{Introduction}

The Indo-Gangetic Plains (IGP) in the north of India are the breadbasket of the country. Since the Green Revolution, the agricultural systems are dominated by rice-wheat double cropping with high levels of inputs such as fertilizers, pesticides, and irrigation water (Singh, 2000). This has enhanced productivity at plot level, but has also created negative externalities due to inefficient use of these inputs, leading to pollution due to dissipation of pesticides and nutrients, depletion of water resources and degradation of soils (Davis et al., 2019; Laik et al., 2014). Simultaneously, the demographical development has led to fragmentation of farms, so that a large proportion of the farmers are currently considered as small and marginal farmers with a farm area of less than two ha (Kuchimanchi et al., 2019; Manjunatha et al., 2013). These developments have compromised the livelihoods of farmers and made them more vulnerable for economic and climatic volatility.

Despite the large-scale specialisation and homogenization that has occurred, there is still considerable variability across the farming systems in the IGP. There are biophysical gradients from west to east that result in differences in resource availability (e.g. water) and in additional crop choices besides the dominating rice-wheat systems (Erenstein and Thorpe, 2011). The area covers different states, which have different policies to incentivise farmers to contribute to national food security, and to support their livelihoods, for example by schemes of implementing minimum support prices. Moreover, demographic gradients and the relations between urban and rural areas within the IGP affect the configuration and performance of cropping systems, and the relations with value chains and markets, which directly impact the opportunities and livelihoods of farmers (Erenstein et al., 2010).

The inherently large disparities in the population were not mitigated by Green Revolution progress, and farmers are also affected differentially by the emerging problems in farming (e.g., productivity stagnation, dependency on inputs and subsidies), the environment (e.g., depletion of water, pollution of water and air) and the dynamics in policies. Given the diversity in biophysical conditions, policies, farmer communities, resource endowment and socio-economic opportunities, considerable differences can be anticipated in the perceived challenges and development objectives of farmers between communities in different parts of the IGP, but also within communities in a certain locality.

The contextual setting in terms of biophysical and socio-economics conditions, and prevailing policies, in combination with the farmers' production choices, resource endowment and 
managerial capabilities will shape the window of opportunities for improving relevant farm performance indicators (Timler et al., 2020). These are reflected in a range of available options for farm reconfiguration. The eventual direction of development can be considered as a pathway through the outcome space that is guided by farmer priorities, objectives and decision making. Bio-economic farm models can support the exploration of outcome spaces and the visualisation of required adjustments in farms to achieve the aspired improvement in farm performance (Ditzler et al., 2019; Groot and Rossing, 2011).

Here we aim to inventory smallholder farmer perceptions in terms of the different objectives that farmers have and the various problems, threats and challenges they may face. We will analyse whether the socio-economic and biophysical contrasts between localities are reflected in these differences in inventoried perceptions. Moreover, we assess to what extent the perceived challenges could affect the outcome spaces and trade-offs that farmers must navigate.

\section{Methodology}

\subsection{Study area}

This study area encompasses most of the IGP in India, ranging from the semi-arid Northwest to the sub-humid middle Gangetic plains in Bihar (Figure 2.1). Kota (Rajasthan) is also situated in northern India, but not part of the IGP. The IGP comprises 0.47 million $\mathrm{km} 2$ and has 280 million rural inhabitants (Erenstein et al., 2010). The major crops grown in the area are wheat, rice and sugarcane (Table 2.1). To capture differentiated contexts and types of farming systems, we sampled six districts in five different states across a gradient from west to east in Northern India: Kota (Rajasthan), Patiala (Punjab), Karnal (Haryana), Muzaffarnagar (Western Uttar Pradesh, UP-West), Faizabad (Eastern Uttar Pradesh, UP East) and Patna (Bihar).

The North-western states Punjab and Haryana, the heart of the Green Revolution efforts, are typically associated with lower poverty incidence and compare with middle income countries when looking at rural development indicators. In contrast, the eastern IGP are characterized by a higher degree of poverty and food insecurity (Erenstein et al., 2010; Erenstein and Thorpe, 2011; Lopez-Ridaura et al., 2018). Study districts were selected based on their vicinity to a research and prototyping station of the Indian Council for Agricultural Research (ICAR), where farming systems demonstrations and researcher-led extension aim to increase development opportunities for farmers. 


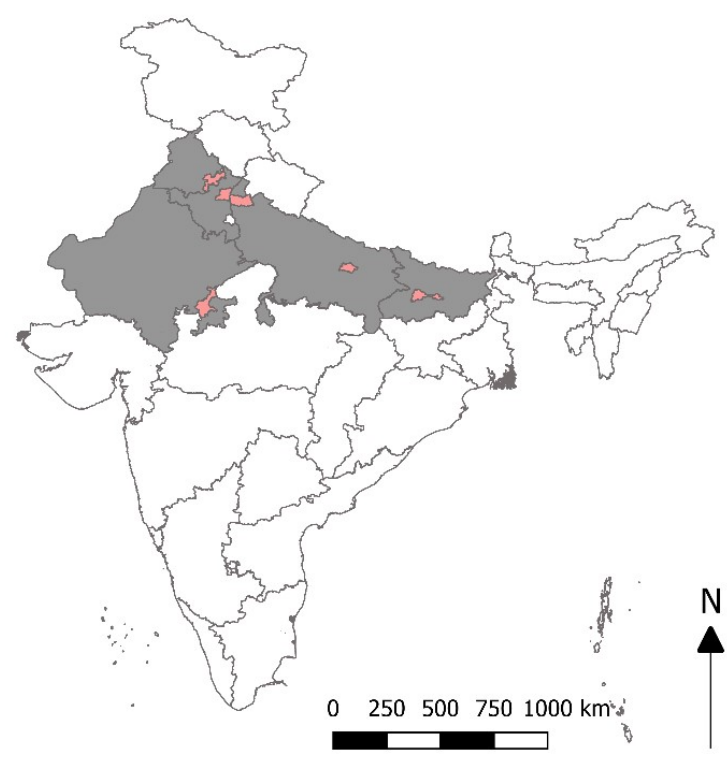

Figure 2.1: Map of India with the studied states (grey) and districts (pink).

\subsection{Data collection \& methods}

Quick surveys of 638 marginal and small farms were conducted (between 84-147 farmers per district, see Table 2.1), followed by interviews with subsets of farmers to reveal their objectives and challenges. The acquired data was supplemented with a detailed household survey with 15 farmers per district. The potential impacts of challenges on the outcome spaces of farms were modeled using the whole-farm model FarmDESIGN.

\subsubsection{Quick surveys}

In each district a quick survey was done to acquire an overview of the diversity of farm characteristics. Where possible, the villages were divided into three parts and surveys were done along the (Y-shaped) borders to get a random sample from ca. 100 households. Based on the major farm features in the district, the survey was slightly adjusted for each district to ask relevant questions. The surveys took about 5-10 minutes per household. Based on the quick survey a typology was made of farms in each district (not presented in this study) and representative farms from each type were interviewed for the ranking of objectives and labelling of challenges. 


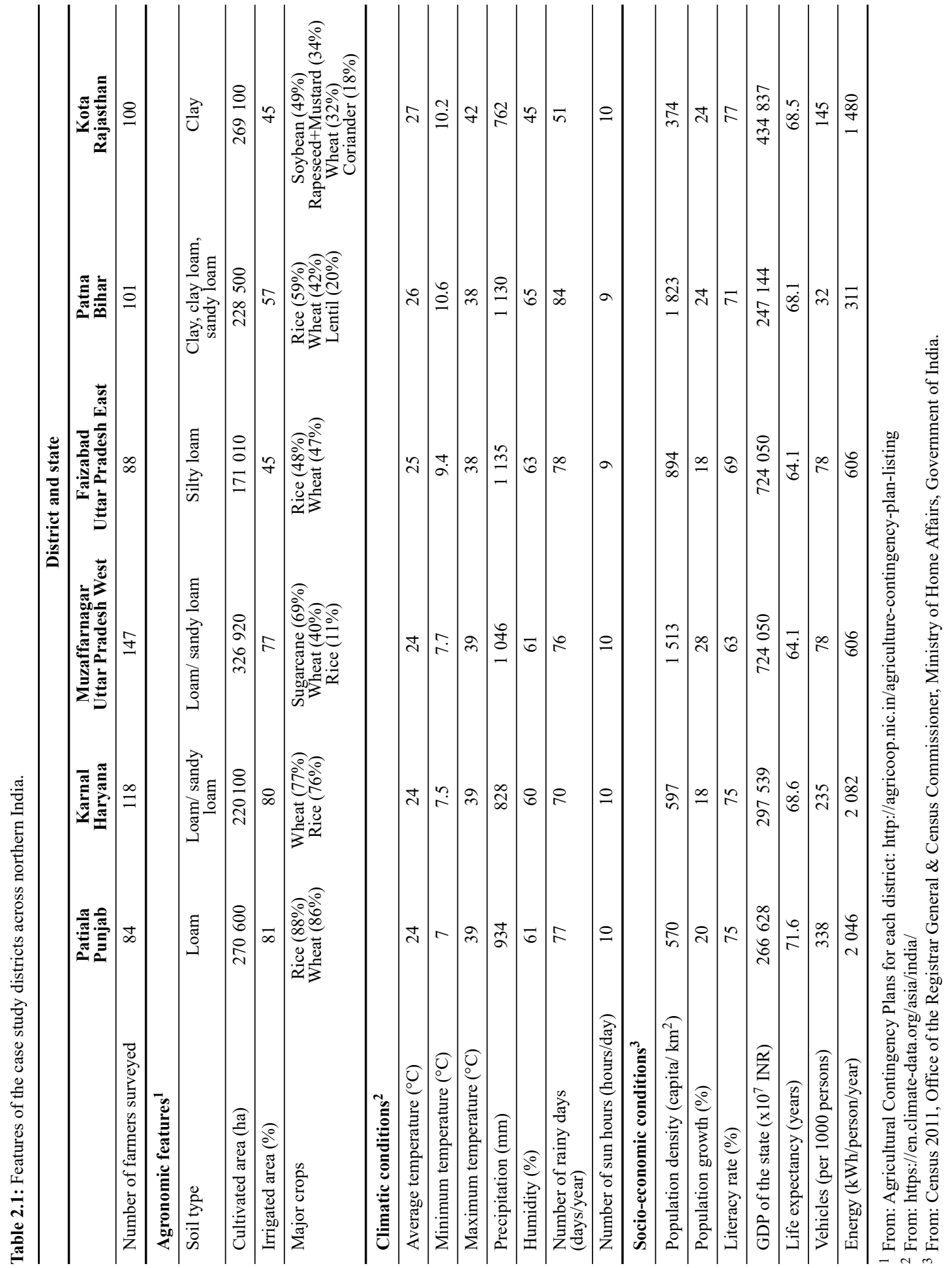




\subsubsection{Objectives \& Challenges}

In collaboration with local researchers, eight objectives and 19 challenges were formulated. Farmers were asked to rank each of the objectives in order of importance and to assign the challenges the labels 'problem', 'threat' and 'no problem'.

The objectives were to improve soil quality; water availability; income; animal health; family labor balance; food self-sufficiency; off farm labor opportunities; and free time. The challenges were: limited access to market; limited access to extension services; limited access to credits; lack of processing equipment; limited availability of good seeds; lack of fertilizers; high price of fertilizers; high price of good seeds; fluctuating market prices; incidence of livestock pests and diseases; incidence of crop pests and diseases; low soil fertility; land fragmentation; limited labor availability; limited water availability; limited land availability; large post-harvest losses; unpredictable climate; and damage caused by wildlife.

\subsection{Statistical analysis}

For both the objectives and the challenges a Kruskal Wallis test was done for continuous ordinal variables. In case of significance, a Dunn test was used to determine which groups differentiated. To indicate differences among the six districts, an analysis of dissimilarities was done. R function Daisy from package Cluster was used to compute dissimilarity through Euclidian distance. Subsequentially, dissimilarities were compared with a Mantel test using the package Vegan in $\mathrm{R}$.

\subsection{Model based analysis}

To illustrate the relation between farmer-perceived challenges and their potential effects on development options in outcome spaces, a farm from Punjab was selected for whole-farm analysis with multi-optimization model FarmDESIGN (Ditzler et al., 2019; Groot et al., 2012), in which we aimed to maximize soil organic matter balance and farm operating profit, and to minimize water use. The configuration of the farm is presented in Supplementary Materials 2A. In addition to the existing cropping activities that reflect the importance of cereal-based double-cropping patterns, two innovative three-season cropping patterns were included as new options (Adelhart Toorop et al., 2020b; Adelhart Toorop et al., 2020a): wheat-mung bean-maize and wheat-yam-yam (a yam crop cultivated during two seasons). Input data for the model was collected in on-farm interviews with the household head using a customized version of 
the IMPACTLite survey tool that facilitates the collection of household information on key farm-household performance and livelihoods indicators (Rufino et al., 2013).

FarmDESIGN is a static bio-economic whole-farm model that describes the farm configuration in terms of production activities (cropping, animal husbandry, etc.) and resource allocation (manure, fertilizers, pesticides, labor, products and residues, etc.). Subsequently, farm performance is quantified in terms of annual resource flows and balances. The model is equipped with an evolutionary algorithm (Differential Evolution, DE; Price and Storn (1997)) which is expanded to allow Pareto-based multi-objective optimization (Deb et al., 2002), to explore options to improve performance compared to the baseline farm based on four objectives.

The optimization algorithm is parameterized with decision variables, constraints and objectives, and parameters that are specific to DE (Supplementary Materials 2A). These parameters can be added and adjusted in the user-interface of the FarmDESIGN model. The decision variables indicate which adjustments in the farm could be made, for instance in crop areas, animal numbers and the allocation of crop and animal products to different destinations in the farm. The constraints limit the allowed values of selected indicators to certain ranges and are used to for instance define the area of the farm or maximum levels of nutrient mining or emissions. Multiple objectives can be selected from a large array of indicators that are quantified, and the direction of optimization (minimization or maximization) is specified (Ditzler et al., 2019; Estrada-Carmona et al., 2020; Groot et al., 2012).

Optimizations were conducted for 1000 iterations of recombination, evaluation (i.e., indicator quantification), and Pareto-based selection. The recombination in DE entails uniform cross-over of alleles within a genotype that represents the decision variables and is parameterized with cross-over probability $(\mathrm{CR}=0.85)$ and amplitude $(\mathrm{F}=0.15)$. The model exploration yielded 1000 outcomes that represented alternative farm reconfigurations with differences in proportions of production activities and resource allocation.

To determine how the farmer-perceived challenges could affect their farms and livelihoods, the optimizations were run for different scenarios. These scenarios represented changes in farm parameters reflected the most prominent challenges that the farmers identified. The consequences of these challenges were related to increased cost of hired labor, reduced prices of farm products and lower productivity of crops. In the scenarios the related farm parameters 
were gradually adjusted by up to $25 \%$ deterioration, while also effects of improvement scenarios by up to $15 \%$ were created (Supplementary Materials $2 \mathrm{~A}$ ).

\section{Results}

\subsection{Farm and household characteristics}

An overview of the main farm features is presented in Figure 2.2. The farms in Patiala (Punjab) and Karnal (Haryana) districts had on average large farm areas (5.60-7.37 ha), farm incomes (417 357-997 357 INR, equal to 5 843-13 963 USD) and livestock numbers (4.6-10.8 TLU). In contrast, the farms in the selected districts in UP West, UP East and Bihar were smaller (0.96-1.23 ha) with comparatively low farm incomes (45 571-122 428, equal to 638-1 714 USD $^{1}$ ) and livestock numbers (2.2-2.7 TLU). Farms in Kota district in Rajasthan took an intermediate position for these variables. In Patiala and Karnal, the land shares of wheat and rice were for almost all farms close to $100 \%$, indicating that hardly other crops were cultivated in the rabi and kharif seasons. In the other districts wheat and rice made up between $36-65 \%$ of the area, apart from Muzaffarnagar (UP West) and Kota (Rajasthan) districts where rice was virtually absent. Household size and milk yield per animal ranged across the districts, with large inter-quartile ranges in the districts of Karnal (Haryana), Faizabad (UP East) and Patna (Bihar).

\subsection{Farmer objectives and challenges}

The primary objectives identified by farmers were improving income, water availability, family labor balance and animal health (Figure 2.3 and Supplementary Materials 2B). For all districts, income was within the top three highest ranked objectives while off-farm labor and free time were ranked lowest. Increasing off-farm labor opportunities and free time were perceived least important.

Improving water availability and soil quality were deemed as most important objectives in Kota district located in the more arid state of Rajasthan, while these objectives were perceived as less important in Patiala (Punjab) and Muzaffarnagar (UP West) districts (Figure 2.3). Water availability also received high priority in Karnal (Haryana) and Faizabad (UP East) districts.

\footnotetext{
${ }^{1} 1$ Indian Rupee (INR) was equal to 0.014 US dollar (USD) on 16 June 2021
} 
In Muzaffarnagar (UP West) and Patna (Bihar), improving animal health was considered as important.

A

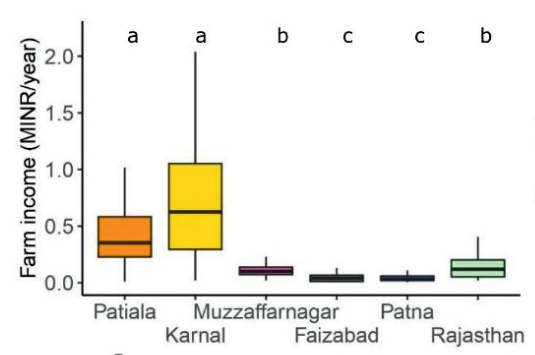

c

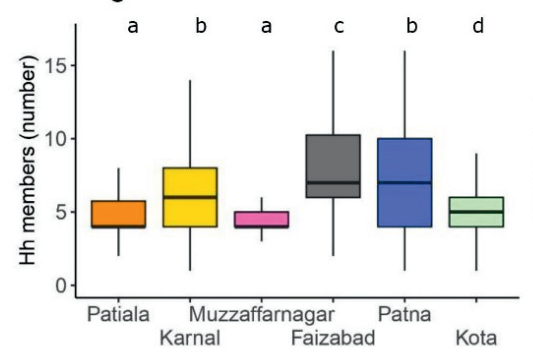

E
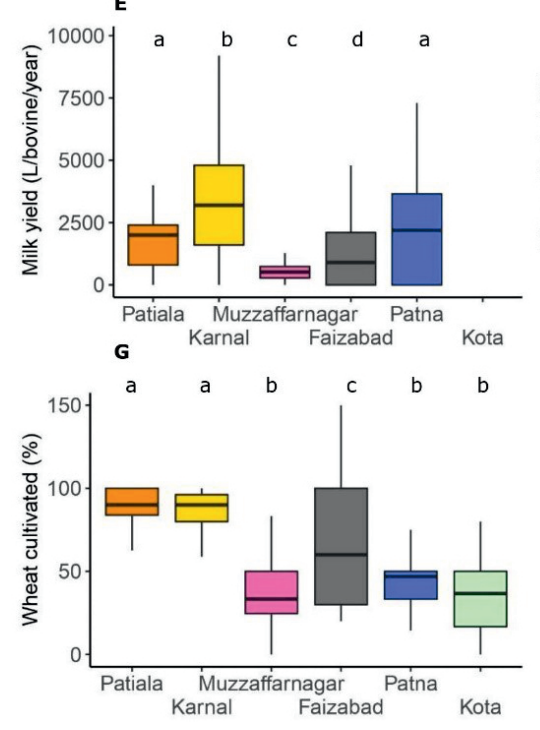
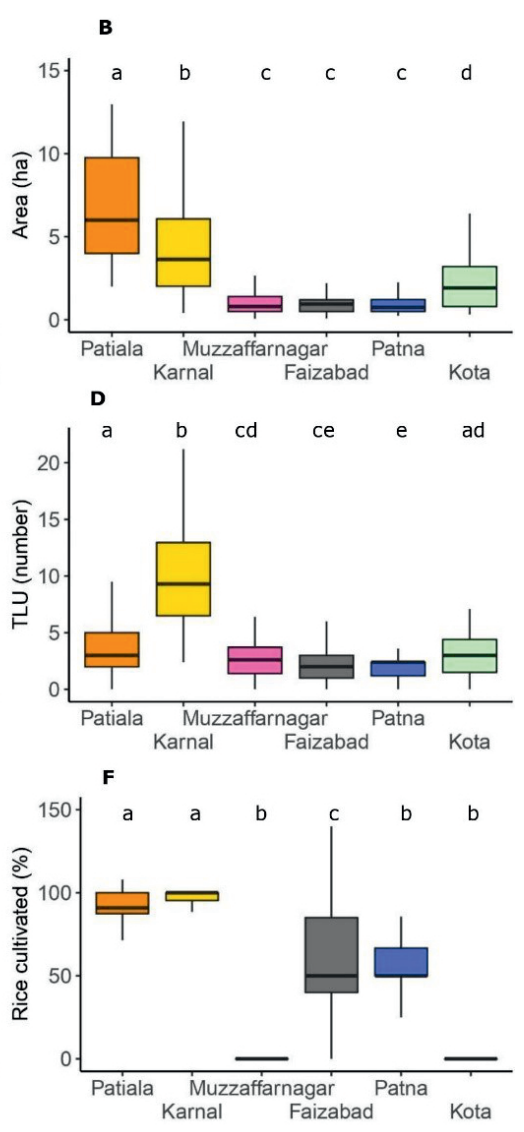

Figure 2.2: Farm and household characteristics of smallholder farms in case study areas in Patiala (Punjab), Karnal (Haryana), Muzaffarnagar (UP West), Faizabad (UP East), Patna (Bihar) and Kota (Rajasthan). Note that outliers were not displayed. 


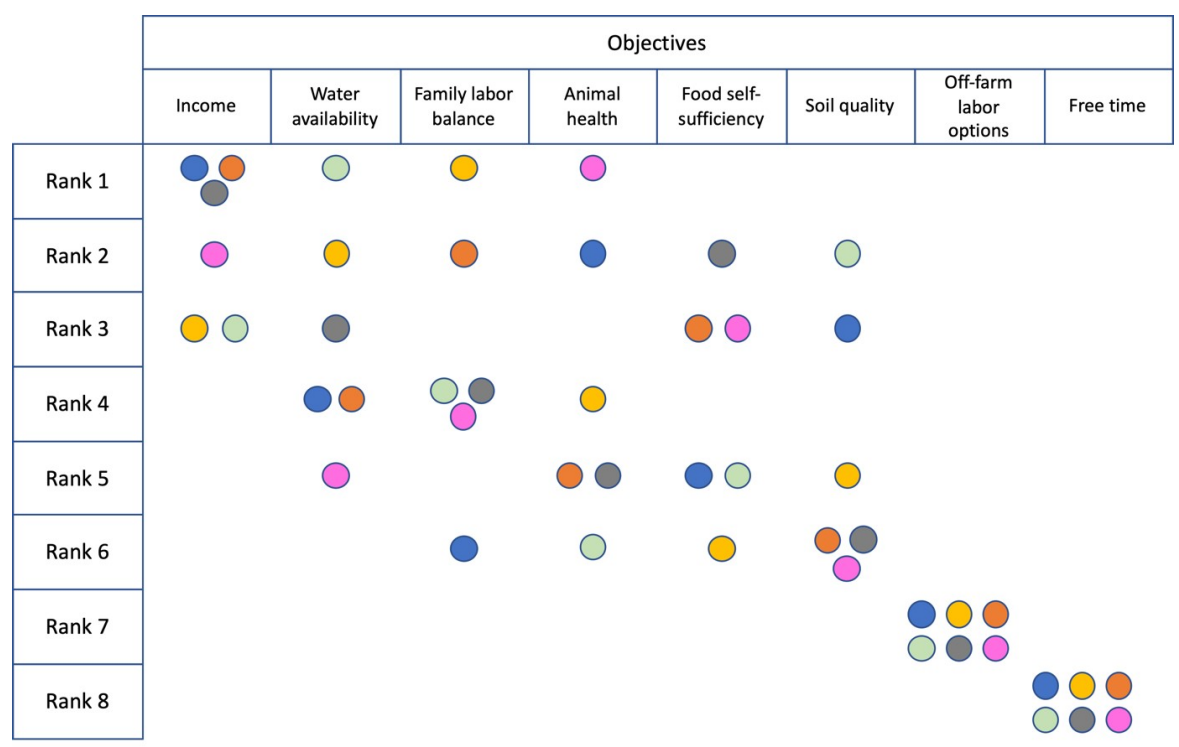

\begin{tabular}{lll}
\hline Patna (Bihar) & Patiala (Punjab) & Faizabad (UP East) \\
Karnal (Haryana) & Kota (Rajasthan) & Kuzaffanagar (UP West)
\end{tabular}

Figure 2.3: Ranking of eight objectives by 48 farmers from six districts in northern India. Objectives were ordered in sequence of declining average rank from left to right.

Farmer perceptions of common challenges are shown in Table 2.2 and Supplementary Materials 2B. Most of the challenges that were seen as a 'problem' by more than $40 \%$ of the respondents were associated with the internal set-up and resources available within the farm (labor availability, low soil fertility, unpredictable climate, land fragmentation, land availability, crop pests and diseases and water availability). Land fragmentation, water availability and unpredictable climate were identified as the most important threats. External services were often assigned the label 'no problem' (access to market, access to extension services, high post-harvest losses, availability of good seeds, processing equipment).

For ten out of 17 challenges there was a significant difference in response among the districts (Table 2.2). Farmers in Faizabad district (UP East) assigned consistently lower scores for the challenges than farmers in the other districts, while in Kota district (Rajasthan) the more problems were experienced. 
Table 2.2: Rating of challenges by 49 farmers from six districts in northern India. A score of 1 corresponded with 'no problem', 2 with 'treat' and 3 with 'problem'. Districts were ordered in sequences of descending average score from left to right and challenges were ordered in descending average score from top to bottom. Challenges with significantly different scorings between districts are indicated with $*(\mathrm{p}<0.05)$.

\begin{tabular}{|c|c|c|c|c|c|c|}
\hline & $\begin{array}{c}\text { Kota } \\
\text { (Rajasthan) }\end{array}$ & $\begin{array}{l}\text { Muzaffarnagar } \\
\text { (UP West) }\end{array}$ & $\begin{array}{c}\text { Patiala } \\
\text { (Punjab) }\end{array}$ & $\begin{array}{l}\text { Patna } \\
\text { (Bihar) } \\
\end{array}$ & $\begin{array}{c}\text { Karnal } \\
\text { (Haryana) }\end{array}$ & $\begin{array}{l}\text { Faizabad } \\
\text { (UP East) }\end{array}$ \\
\hline Labour availability * & 2.8 & 3.0 & 3.0 & 2.7 & 2.8 & 1.9 \\
\hline Fertilizer price & 3.0 & 2.7 & 2.5 & 2.7 & 2.8 & 1.8 \\
\hline Fluctuating market prices* & 2.4 & 3.0 & 2.8 & 2.6 & 2.6 & 1.8 \\
\hline Unpredictable climate & 2.8 & 2.7 & 2.8 & 2.4 & 2.2 & 1.9 \\
\hline Low soil fertility* & 2.8 & 3.0 & 3.0 & 2.4 & 1.9 & 1.6 \\
\hline Price good seeds* & 2.8 & 3.0 & 2.5 & 2.4 & 2.6 & 1.3 \\
\hline Land availability* & 3.0 & 2.5 & 3.0 & 1.9 & 1.4 & 1.9 \\
\hline Water availability & 2.3 & 2.0 & 2.5 & 2.2 & 2.0 & 2.0 \\
\hline Crop pests and diseases & 2.0 & 2.3 & 1.4 & 2.6 & 2.4 & 1.9 \\
\hline Wildlife & 1.5 & 1.7 & 2.3 & 2.6 & 2.6 & 1.9 \\
\hline Lack of access to credits & 2.0 & 1.7 & 1.8 & 2.3 & 2.0 & 1.4 \\
\hline Livestock pest and disease* & 2.8 & 1.5 & 1.4 & 2.3 & 2.1 & 1.1 \\
\hline Lack of fertilizers* & 3.0 & 1.5 & 2.8 & 1.7 & 1.1 & 1.0 \\
\hline Availability good seeds* & 1.8 & 2.3 & 1.8 & 1.3 & 1.0 & 1.1 \\
\hline Lack of processing equipment* & 2.8 & 1.0 & 1.0 & 1.8 & 1.4 & 1.2 \\
\hline High post-harvest losses* & 1.4 & 1.5 & 1.1 & 1.0 & 1.7 & 1.8 \\
\hline Access to extension services & 1.3 & 1.3 & 1.3 & 1.4 & 1.8 & 1.1 \\
\hline Average score & 2.4 & 2.2 & 2.2 & 2.1 & 2.0 & 1.6 \\
\hline
\end{tabular}

\subsection{Analysis of dissimilarities}

The dissimilarities between the six districts in climatic and socio-economic conditions at district level (see Table 2.1) are presented in Figure 2.4. The climatic conditions in Kota district (Rajasthan) differed strongly from the other districts, due to higher temperatures and less rainfall (Supplementary Materials 2C). Also, the contrast in climate between Patna (Bihar) on the one hand and Karnal (Haryana) and Patiala (Punjab) on the other hand were strong. Similarly, the socio-economic conditions in Karnal and Patiala districts were similar, but these differed considerably from the district of Patna, but also the West and East UP districts.

The Mantel test was used to determine whether correlations existed between dissimilarities among districts for climatic and socio-economic conditions with farm structure, farmer objectives and challenges (Figure 2.4f). The relation between dissimilarities of districts in climatic variables and objectives was significant $(r=0.5714, p=0.0125)$. The dissimilarities of objectives and challenges between districts were negatively correlated, mostly due to the low scoring of challenges in UP East (Table 2.2). 

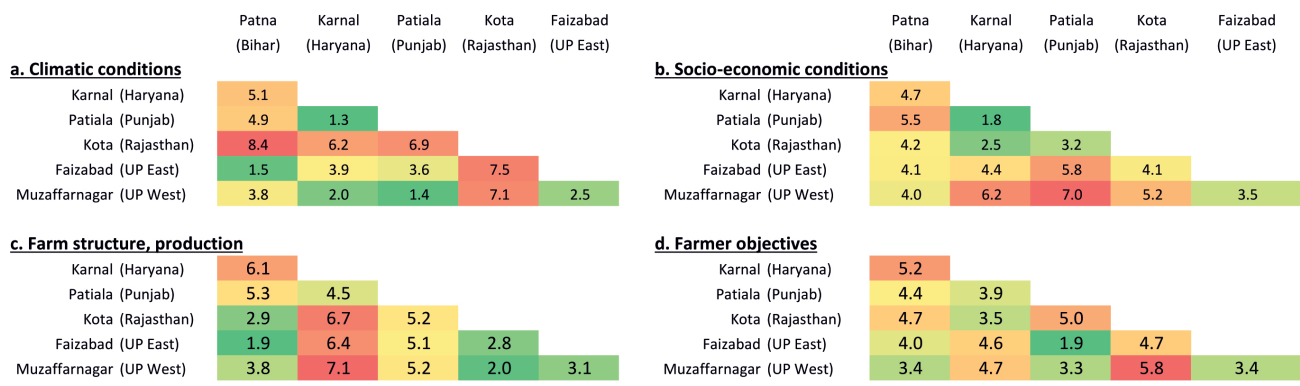

d. Farmer objectives
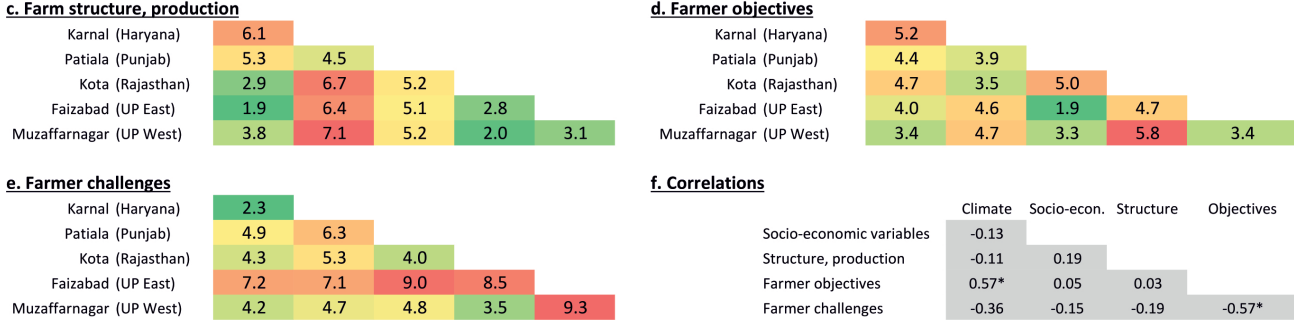

Figure 2.4: Dissimilarity matrices indicating patterns of differences among six districts in Northern India, measured as the Euclidean distance between districts in climatic conditions (a.), socio-economic variables (b.), farm features (c.), farmer objectives (d.) and challenges (e.) (standardized), and the Mantel correlation coefficient among dissimilarity matrices.

\subsection{Impact of challenges on window of opportunities}

Based on the importance assigned to the farm-internal problems and challenges (labor availability, low soil fertility, unpredictable climate, land fragmentation, land availability, crop pests and diseases and water availability) by the farmers, the sensitivity of an example farm to increased cost of hired labor, reduced prices of farm products and lower productivity of crops was analyzed with whole-farm modelling (Figure 2.5). With the existing farm configuration (crop areas, animal numbers, allocation of products etc.), both profitability and soil quality (as reflected in the organic matter balance) would be affected by the changes in product prices and crop productivity (Figure 2.5a). Inputs of organic matter to the soil would be influenced by productivity because proportional changes in residue yield and root- and stubble production are expected. Due to this proportionality, although the scope for improvement in both profit and $\mathrm{OM}$ balance relative to the original situation would decrease under unfavorable scenarios $(-15 \%$ and $-25 \%)$ and increase under favorable conditions $(+15 \%)$, the trade-off between profit and OM balance would remain virtually unchanged (Figure $2.5 \mathrm{a}$ ).

Synergistic improvements of an increase in profit combined with reduction in water use would be feasible (Figure 2.5b), but this relationship was different between the baseline and different scenarios of change, under unfavorable conditions lower profit increase could be realized per quantity of reduction in water use. Between water use and OM balance there was a trade-off, reductions in water use would be associated with lower organic matter inputs, but this trade-off 
would become less pronounced under less favorable conditions (scenarios $-15 \%$ and $-25 \%$ ) (Figure 2.5c).

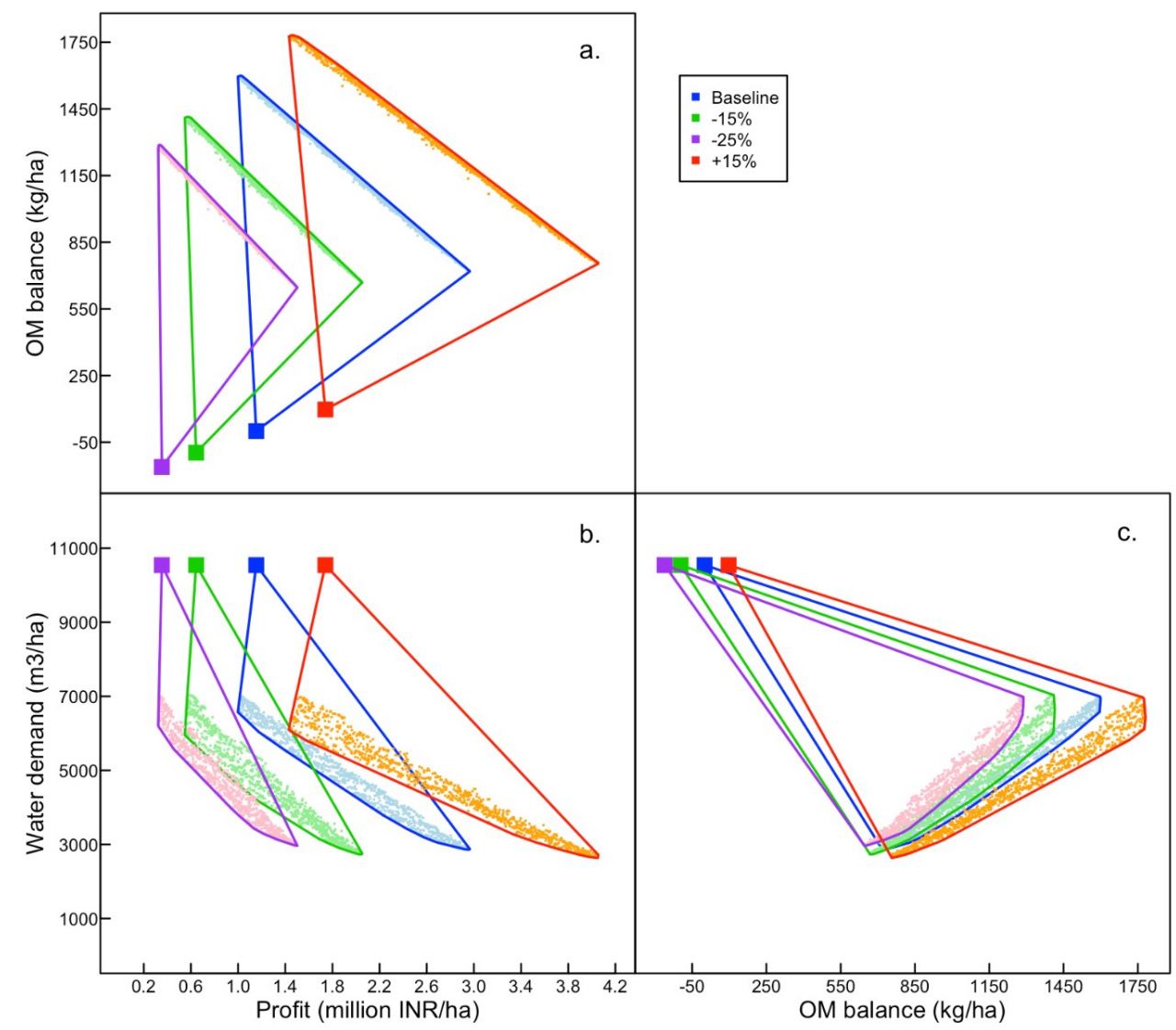

Figure 2.5: Relations among objectives to maximize profit and organic matter (OM) balance, and to minimize the water demand at farm level. Comparison of baseline conditions and scenarios with $15 \%$ and $25 \%$ decline, and $15 \%$ increase in crop productivity, product prices and increase in hired labor costs.

\section{Discussion}

In this study we aimed to inventory smallholder farmer perceptions in terms of the different objectives that farmers have, and the various problems, threats and challenges they may face. We analysed whether the socio-economic and biophysical contrasts between localities were reflected in these differences in stated perceptions. Moreover, we assessed to what extent the perceived challenges could affect the outcome spaces and trade-offs that farmers must navigate. 
The differences in objectives between the six districts were correlated to the differences in climatic conditions, but not with demography or farm structure. The challenges were not correlated with climate, demography, or farm structure, but were uniform over five out of the six districts. The most frequently mentioned challenges that were seen as acute problems were related to low labor availability, fluctuating market prices, low soil fertility and high seed prices. The model-based analysis showed that the anticipated, associated changes of lower product prices and productivity and higher prices of hired labor could aggravate the trade-offs of farm profitability with water use and soil quality.

In a meso-level analysis in the IGP, Erenstein and Thorpe (2011) found a low-to-high gradient of food insecurity moving from west-to-east. They highlighted that the apparent homogeneity masks significant diversity. Our study demonstrated large heterogeneity among the districts, but did not find a clear geographical gradient. From Figure 2.2 and Figure 2.4 it can be derived that Patiala (Punjab) and Karnal (Haryana) showed similarities. Farms in these districts were larger, with higher incomes, more livestock and often higher milk yields compared to the other districts. In combination with the socio-economic conditions of these districts (especially the number of vehicles and energy per person), these characteristics could be associated with more wealth. A 'gradient' could not be extended towards the eastern IGP and Rajasthan. Although not directly related to wealth, a striking difference when comparing Patiala (Punjab) and Karnal (Haryana) with the other study districts, was the dominance of wheat and rice. In these western districts almost $100 \%$ of the land was dedicated to wheat and rice cultivation whereas the median was not more than $50 \%$ for the other districts (Figure 2.2f, g). The Punjab and Karnal, in which Patiala and Karnal are located, have been the heartland of the Green Revolution efforts and, especially here, improved seeds, irrigation, pesticides and fertilizers were promoted to improve yields, with as a consequence, adverse effects on the biophysical environment (Aryal et al., 2018). Development efforts nowadays aim at sustainable intensification focusing on profit and production maximization while conserving the natural resource base (Behera and France, 2016; Jat et al., 2020b; Mishra et al., 2020).

It may be questioned for how long the aim could realistically be to intensify: farmers indicated to be challenged by labor availability, low soil fertility, unpredictable climate, land fragmentation, land availability, crop pests and diseases and water availability. These challenges are recognized in literature: Chauhan et al. (2012) stated that increasing labor shortages and deteriorating soil and water resources made the wheat-rice cropping system uneconomical and unsustainable 
and Kuchimanchi et al. (2019) stressed that non-climate related risks like depletion of ground water and land fragmentation aggravate vulnerability and crop diseases affected production, but also affected human and livestock health when spoiled cereals are consumed. On top of these farm-internal challenges, climate change will put pressure on these smallholder farming systems (Jat et al., 2020a; Khatri-Chhetri et al., 2017).

Insights into the objectives and challenges of farmers is of importance in order to understand priorities and development needs (Darnhofer et al., 2016; Michalscheck et al., 2020). In this study, we visualized the changes in a farm's window of opportunities for favorable and unfavorable scenarios. We found that unfavorable circumstances (reduced product prices, crop productivity and soil organic matter inputs) gradually reduced the window of opportunities while favorable circumstances increased the window. Trade-offs and synergies did not change for the different scenarios, but the severity was affected (Figure $2.5 \mathrm{~b}$ and $2.5 \mathrm{c}$ ) as the water use efficiency decreased.

Changes in the size of the window of opportunities and its positioning give information about the system's vulnerability, resilience and buffer capacity (Groot et al., 2016). A larger window of opportunities indicates more leeway to improve in favorable directions, and can generally be associated with more resilience and buffer capacity. We assumed here that challenges impacted the system proportionally, but it can be expected that (policy) changes that directly influence one part of the system (e.g. price setting or a subsidy), influence the shape and size of the window of opportunities. Model-based explorations, as done in this study, can be of use to predict and foresee the impacts of changes induced by e.g. policies, socio-economic conditions, market opportunities or a new (cultivation) technique (Groot et al., 2016; Tittonell et al., 2007).

Wiek and Binder (2005) explored sustainable solution spaces for decision making and identification of synergies and trade-offs based on normative (determining problems and targets), systemic (target-related assessment of the system) and procedural (involving stakeholders) aspects. Their methodology shows similarities with the Describe-Explain-Explore-Design (DEED) cycle for farming systems analysis, in which FarmDESIGN is often used (Cortez-Arriola et al., 2016; Michalscheck et al., 2018; Timler et al., 2020). This study focused on the first three phases of the DEED-cycle and covered the systemic and normative aspects of Wiek and Binder (2005). However, we here did not elaborate on the 'design' phase of the DEED-cycle, or the procedural aspects such as transdisciplinarity from Wiek and Binder 
(2005). As farming systems are embedded in a food system and influenced by local governance, more attention to cross-sectoral integrated planning and decision-making would be valuable.

To obtain insight in the objectives for farmers and the challenges perceived, farmers were asked to rank (objectives) or label (challenges) predefined statements that were formulated by local researchers. This could be seen as a first step to understand priorities, but requires follow up. Further elaboration on coping strategies and positive deviant behavior could give insights in possible development pathways.

The modelling illustrated a change in the size of the window of opportunities for different scenarios. In these scenarios, the farm's labor costs, product price and productivity all were affected in the same direction: the unfavorable scenarios examine 'the worst case', where the costs rise while product price and productivity fall, while the opposite was done in the favorable scenario. This is a simplification which should be considered when interpreting the results. The percentages chosen $(-15 \%,-25 \%,+15 \%)$ were arbitrary and could be supplemented with more in-depth analysis on the size of the window of opportunities.

This study focuses on smallholder farmers in northern India. Five out of the six districts where this study was conducted belong to the IGP. Kota (Rajasthan) which does not belong to the IGP, deviated when comparing climate: the humidity was lower, there were less rainy days and temperatures were higher, especially from March-June (zaid season) (Supplementary Materials 2C). As water availability was perceived an important threat, further comparison with districts that are already water constraint, like Kota (Rajasthan), may be relevant. This could entail comparison of cropping patterns and coping strategies used in case of droughts.

\section{Conclusion}

The primary objectives identified were improving income, water availability, family labor balance and animal health. The differences in objectives between the six districts ((Patiala (Punjab), Karnal (Haryana), Muzaffarnagar (UP West), Faizabad (UP East), Patna (Bihar) and Kota (Rajasthan)) were correlated to the differences in climatic conditions, but not with demography or farm structure. The most pressing challenges, that were seen as acute problems, were related to low labor availability, fluctuating market prices, low soil fertility and high seed prices, while land fragmentation, water availability and unpredictable climate were identified as threats. The challenges were not correlated with climate, demography, or farm structure, 
but were uniform over five out of the six districts. A model-based analysis showed that the anticipated, associated changes of lower product prices and productivity and higher prices of hired labor could aggravate the trade-offs of farm profitability with water use and soil quality. We conclude that, due to continued farm fragmentation and increased price volatility and resource constraints, the window of opportunities for smallholder farmers in northern India is strongly reduced and more fundamental changes in farming and supporting policies are needed to address the challenges that farmers are facing.

\section{Acknowledgements}

We acknowledge the financial and technical support from CGIAR Research Programs on Climate Change, Agriculture and Food Security (CCAFS), Wheat Agri-food Systems (WHEAT), Indian Council of Agri- cultural Research (ICAR), and all donors who supported this research through their contributions to the CGIAR Fund. For a list of Fund donors please see: http://www.cgiar.org/our-funders/. This study would only have been possible with the help of Jagdish Tertarwal, Jashanjot Kaur, Deepak Bijarniya, Asish Kumar Prusty, Luis Barba-Escoto, Chaitanya Kakad, Jelle van den Akker, Hannah Fisher, Angelica Marchetti, we are thankful for their dedication. Furthermore, we thank the farmers for their time and for sharing their experiences and expertise. The contribution of JCJG was supported by the Senior Expert program of the Dutch Science Council (NWO), grant number 17222. 


\section{References}

Adelhart Toorop, R., Ceccarelli, V., Bijarniya, D., Jat, M. L., Jat, R. K., Lopez-Ridaura, S., and Groot, J. C. (2020a), Using a positive deviance approach to inform farming systems redesign: A case study from Bihar, India. Agricultural Systems. 185(February): p. 102942.

Adelhart Toorop, R., Lopez-Ridaura, S., Bijarniya, D., Kalawantawanit, E., Jat, R. K., Prusty, A. K., Jat, M. L., and Groot, J. C. (2020b), Farm-level exploration of economic and environmental impacts of sustainable intensification of rice-wheat cropping systems in the Eastern Indo-Gangetic plains. European Journal of Agronomy. 121: p. 126157.

Aryal, J. P., Jat, M. L., Sapkota, T. B., Khatri-Chhetri, A., Kassie, M., Rahut, D. B., and Maharjan, S. (2018), Adoption of multiple climate-smart agricultural practices in the Gangetic plains of Bihar, India. International Journal of Climate Change Strategies and Management. 10(3): p. 407-427.

Behera, U. K. and France, J. (2016), Integrated Farming Systems and the Livelihood Security of Small and Marginal Farmers in India and Other Developing Countries. Advances in Agronomy. 138: p. 235-282.

Chauhan, B. S., Mahajan, G., Sardana, V., Timsina, J., and Jat, M. L. (2012), Productivity and sustainability of the rice-wheat cropping system in the indo-gangetic plains of the indian subcontinent: Problems, opportunities, and strategies. Vol. 117. Elsevier, p. 315-369.

Cortez-Arriola, J., Groot, J. C. J., Rossing, W. A. H., Scholberg, J. M. S., Massiotti, R. D. A., and Tittonell, P. (2016), Alternative options for sustainable intensification of smallholder dairy farms in North-West Michoacán, Mexico. Agricultural Systems. 144: p. 22-32.

Darnhofer, I., Lamine, C., Strauss, A., and Navarrete, M. (2016), The resilience of family farms: Towards a relational approach. Journal of Rural Studies. 44: p. 111-122.

Davis, K. F., Chhatre, A., Rao, N. D., Singh, D., Ghosh-Jerath, S., Mridul, A., Poblete-Cazenave, M., Pradhan, N., and DeFries, R. (2019), Assessing the sustainability of post-Green Revolution cereals in India. Proceedings of the National Academy of Sciences of the United States of America. 116(50): p. 25034-25041.

Deb, K., Agrawal, S., and Pratap, M. (2002), A fast elitist non-dominated sorting genetic algorithm for multi-objective optimization: NSGA-II. IEEE Transactions in Evolutionary Computation. 6: p. 182-197.

Ditzler, L., Komarek, A. M., Chiang, T.-W., Alvarez, S., Chatterjee, S. A., Timler, C., Raneri, J. E., Carmona, N. E., Kennedy, G., and Groot, J.C. J. (2019), A model to examine farm household trade-offs and synergies with an application to smallholders in Vietnam. Agric. Syst. 173(1): p. 49-63.

Erenstein, O., Hellin, J., and Chandna, P. (2010), Poverty mapping based on livelihood assets: A meso-level application in the Indo-Gangetic Plains, India. Applied Geography. 30(1): p. 112-125.

Erenstein, O. and Thorpe, W. (2011), Livelihoods and agro-ecological gradients: A meso-level analysis in the Indo-Gangetic Plains, India. Agricultural Systems. 104(1): p. 42-53.

Estrada-Carmona, N., Raneri, J. E., Alvarez, S., Timler, C., Chatterjee, S. A., Ditzler, L., Kennedy, G., Remans, R., Brouwer, I., van den Berg, K. B., Talsma, E. F., and Groot, J. C. (2020), A model-based exploration of farm-household livelihood and nutrition indicators to guide nutrition-sensitive agriculture interventions. Food Security. 12(1): p. 59-81.

Groot, J. C. J., Cortez-Arriola, J., Rossing, W. A. H., Améndola Massiotti, R. D., and Tittonell, P. (2016), Capturing agroecosystem vulnerability and resilience. Sust. 8(11): p. 1206.

Groot, J. C. J., Oomen, G. J. M., and Rossing, W. A. H. (2012), Multi-objective optimization and design of farming systems. Agric. Syst. 110: p. 63-77.

Groot, J. C. J. and Rossing, W. A. H. (2011), Model-aided learning for adaptive management of natural resources: an evolutionary design perspective. Methods Ecol. Evol. 2(6): p. 643-650.

Jat, M. L., Jat, H. S., Agarwal, T., Bijarniya, D., Kakraliya, S. K., Choudhary, K. M., Kalvaniya, K. C., Gupta, N., Kumar, M., Singh, L. K., Kumar, Y., Jat, R. K., Sharma, P. C., Sidhu, H. S., Choudhary, M., Datta, A., Shirsath, P. B., and Ridaura, S. L. (2020a), A Compendium of Key Climate Smart Agriculture Practices in Intensive Cereal Based Systems of South Asia. (December): p. 42.

Jat, M. L., Chakraborty, D., Ladha, J. K., Rana, D. S., Gathala, M. K., McDonald, A., and Gerard, B. (2020b), Conservation agriculture for sustainable intensification in South Asia. Nature Sustainability. 3(4): p. 336-343.

Khatri-Chhetri, A., Aggarwal, P. K., Joshi, P. K., and Vyas, S. (2017), Farmers' prioritization of climate-smart agriculture (CSA) technologies. Agricultural systems. 151: p. 184-191.

Kuchimanchi, B. R., Nazareth, D., Bendapudi, R., Awasthi, S., and D’Souza, M. (2019), Assessing differential vulnerability of communities in the agrarian context in two districts of Maharashtra, India. Climate and Development. 11(10): p. 918-929.

Laik, R., Sharma, S., Idris, M., Singh, A. K., Singh, S. S., Bhatt, B. P., Saharawat, Y., Humphreys, E., and Ladha, J. K. (2014), Integration of conservation agriculture with best management practices for improving system performance of the rice-wheat rotation in the Eastern Indo-Gangetic Plains of India. Agriculture, Ecosystems and Environment. 195: p. 68-82. 
Lopez-Ridaura, S., Frelat, R., Van Wijk, M. T., Valbuena, D., Krupnik, T. J., and Jat, M. L. (2018), Climate smart agriculture, farm household typologies and food security: An ex-ante assessment from Eastern India. Agric. Syst. 159(September 2016): p. 57-68.

Manjunatha, A. V., Anik, A. R., Speelman, S., and Nuppenau, E. A. (2013), Impact of land fragmentation, farm size, land ownership and crop diversity on profit and efficiency of irrigated farms in India. Land Use Policy. 31: p. $397-405$.

Michalscheck, M., Groot, J. C., Kotu, B., Hoeschle-Zeledon, I., Kuivanen, K., Descheemaeker, K., and Tittonell, P. (2018), Model results versus farmer realities. Operationalizing diversity within and among smallholder farm systems for a nuanced impact assessment of technology packages. Agricultural Systems. 162(February): p. 164-178.

Michalscheck, M., Groot, J. C., Fischer, G., and Tittonell, P. (2020), Land use decisions: By whom and to whose benefit? A serious game to uncover dynamics in farm land allocation at household level in Northern Ghana. Land Use Policy. 91(October 2019): p. 104325.

Mishra, J. S., Bhatt; B., Aranachalam, A., and Jat, M. (2020), Conservation Agriculture for Sustainable Intensification in Eastern India. Tech. rep. New Delhi, p. 8.

Price, K. and Storn, R. (1997), Differential Evolution - A Simple and Efficient Heuristic for Global Optimization over Continuous Spaces. Journal of Global Optimization. (11): p. 341-359.

Rufino, M. C., Quiros, C., Boureima, M., Desta, S., Douxchamps, S., Herrero, M., Kiplimo, J., Lamissa, D., Mango, J., Moussa, A. S., Naab, J., Ndour, Y., Sayula, G., Silvestri, S., Singh, D., Teufel, N., and Wanyama, I. (2013), Developing generic tools for characterizing agricultural systems for climate and global change studies (IMPACTlite - phase 2). Copenhagen: CGIAR Research Program on Climate Change, Agriculture and Food Security (CCAFS). (January): p. $1-42$.

Singh, R. B. (2000), Environmental consequences of agricultural development: a case study from the Green Revolution state of Haryana, India. Tech. rep.

Timler, C., Alvarez, S., DeClerck, F., Remans, R., Raneri, J., Estrada Carmona, N., Mashingaidze, N., Abe Chatterjee, S., Chiang, T. W., Termote, C., Yang, R. Y., Descheemaeker, K., Brouwer, I. D., Kennedy, G., Tittonell, P. A., and Groot, J. C. (2020), Exploring solution spaces for nutrition-sensitive agriculture in Kenya and Vietnam. Agricultural Systems. 180(1): p. 102774.

Tittonell, P., Van Wijk, M. T., Rufino, M. C., Vrugt, J. A., and Giller, K. E. (2007), Analysing trade-offs in resource and labour allocation by smallholder farmers using inverse modelling techniques: a case-study from Kakamega district, western Kenya. Agric. Syst. 95(1-3): p. 76-95.

Wiek, A. and Binder, C. (2005), Solution spaces for decision-making - A sustainability assessment tool for city-regions. Environmental Impact Assessment Review. 25(6): p. 589-608. 


\section{Supplemental Materials}

\section{Supplementary Materials 2A: FarmDESIGN parameterization}

Table S1: Characteristics of the selected farm in Punjab that was used in the bio-economic farm modelling.

\begin{tabular}{ll}
\hline & Punjab \\
\hline Farm size (ha) & 6.46 \\
\hline Livestock presence (TLU) & 2.4 \\
\hline Milk production (L/year) & 7300 \\
\hline Cropping patterns & Wheat-Fallow-Rice $(66 \%)$ \\
& $\begin{array}{l}\text { Sugarcane }(31 \%) \\
\text { Green fodder }(3 \%)\end{array}$ \\
\hline
\end{tabular}

Table S2: Decision variables, constraints, and objectives.

\begin{tabular}{|c|c|c|c|}
\hline \multicolumn{4}{|l|}{ DECISION VARIABLES } \\
\hline Description & Minimum & Maximum & Initial \\
\hline Arable land.Alt_Mustard_Yam_Cn Area & 0 & 6.46 & 0 \\
\hline Arable land.Alt_Wheat_Mung_Maize Area & 0 & 6.46 & 0 \\
\hline Arable land.Plot2_Sugarcane Area & 0 & 6.46 & 2 \\
\hline Arable land.Plot4_Rice(k)_Wheat(r) Area & 0 & 6.46 & 4.26 \\
\hline Arable land.Plot4_green fodder Area & 0 & 6.46 & 0.2 \\
\hline Cotton seed cake ToAnimals & 0 & 5000 & 0 \\
\hline Oats ToAnimals & 0 & 5000 & 0 \\
\hline mustard cake ToAnimals & 0 & 5000 & 2500 \\
\hline Maize grain ToAnimals & 0 & 5000 & 1000 \\
\hline Wheat straw ToAnimals & 0 & 10000 & 3000 \\
\hline Sugarcane tops ToAnimals & 0 & 9000 & 1000 \\
\hline Maize residue ToAnimals & 0 & 1 & 0 \\
\hline Wheat straw ToAnimals & 0 & 100 & 0 \\
\hline Wheat straw ToSoil & 0 & 30000 & 0 \\
\hline Rice straw ToSoil & 0 & 42000 & 0 \\
\hline Maize residue ToSoil & 0 & 1 & 1 \\
\hline Wheat straw ToSoil & 0 & 100 & 0 \\
\hline Rice straw ToBurning & 0 & 42000 & 29723.2 \\
\hline Wheat straw ToBurning & 0 & 30000 & 0 \\
\hline Economics HiredRegularLabor & 0 & 7000 & 3985.15 \\
\hline \multicolumn{4}{|l|}{ OBJECTIVES } \\
\hline Description & Direction & & \\
\hline Water balance WaterRequiredPerHa & Minimize & & \\
\hline Organic matter balance Balance & Maximize & & \\
\hline EconomicResults OperatingProfit & Maximize & & \\
\hline \multicolumn{4}{|l|}{ CONSTRAINTS } \\
\hline Description & Minimum & Maximum & Value \\
\hline NonGrazingPeriod.Deviation Intake & -9999 & 0 & -5.55 \\
\hline NonGrazingPeriod.Deviation Energy & -5 & 10 & 5.65 \\
\hline NonGrazingPeriod.Deviation Protein & 0 & 30 & 27.88 \\
\hline Arable land Area & 6.4 & 6.5 & 6.46 \\
\hline Rice(k)_Wheat(r).Wheat straw SelfSupply & 1 & 99999 & 7.12 \\
\hline Sugarcane.Sugarcane tops SelfSupply & 1 & 99999 & 11.45 \\
\hline LabourBalance.Balance Regular & 0 & 99999 & 0.02 \\
\hline
\end{tabular}


Table S3: Parameters of scenarios.

\begin{tabular}{|c|c|c|c|c|}
\hline \multirow[t]{2}{*}{ Variable } & \multicolumn{4}{|l|}{ Scenario } \\
\hline & $-25 \%$ & $-15 \%$ & Baseline & $15 \%$ \\
\hline \multicolumn{5}{|l|}{ ECONOMICS } \\
\hline Regular labour price (INR) & 25 & 23 & 20 & 17 \\
\hline \multicolumn{5}{|c|}{ ANIMAL PRODUCTS - Price (INR) } \\
\hline Buffalo milk & 15 & 17 & 20 & 23 \\
\hline \multicolumn{5}{|c|}{ CROPS - Effective organic matter $(\mathrm{kg} / \mathrm{ha})$} \\
\hline Sugarcane & 829.5 & 940.1 & 1106 & 1271.9 \\
\hline Green fodder & 364.5 & 413.1 & 486 & 558.9 \\
\hline Rice(k)_Wheat(r) & 657.75 & 745.45 & 877 & 1008.55 \\
\hline Alt_Mustard_Yam_Cn & 285 & 323 & 380 & 437 \\
\hline Alt_Wheat_Mung_Maize & 505.5 & 572.9 & 674 & 775.1 \\
\hline \multicolumn{5}{|c|}{ CROP PRODUCTS - Price (INR/kg) } \\
\hline Sugarcane stems & 2.325 & 2.635 & 3.1 & 3.565 \\
\hline Sugarcane tops & 1.5 & 1.7 & 2 & 2.3 \\
\hline Pearl millet & 0 & 0 & 0 & 0 \\
\hline Sorghum & 0 & 0 & 0 & 0 \\
\hline Maize fodder & 11.25 & 12.75 & 15 & 17.25 \\
\hline Maize grain & 7.5 & 8.5 & 10 & 11.5 \\
\hline Cotton seed cake & 15 & 17 & 20 & 23 \\
\hline Mustard cake & 22.5 & 25.5 & 30 & 34.5 \\
\hline Oats & 9.75 & 11.05 & 13 & 14.95 \\
\hline Rice straw & 0.75 & 0.85 & 1 & 1.15 \\
\hline Wheat straw & 0.75 & 0.85 & 1 & 1.15 \\
\hline Wheat grain & 13.0125 & 14.75 & 17.35 & 19.95 \\
\hline Rice grain & 12.2625 & 13.9 & 16.35 & 18.8 \\
\hline Mustard & 22.5 & 25.5 & 30 & 34.5 \\
\hline Yam & 12 & 13.6 & 16 & 18.4 \\
\hline Wheat straw & 0.75 & 0.85 & 1 & 1.15 \\
\hline Mung grain & 45 & 51 & 60 & 69 \\
\hline Mung straw & 0 & 0 & 0 & 0 \\
\hline Maize grain & 9.75 & 11.05 & 13 & 14.95 \\
\hline Maize residue & 0 & 0 & 0 & 0 \\
\hline Wheat grain & 11.25 & 12.75 & 15 & 17.25 \\
\hline \multicolumn{5}{|c|}{ CROP PRODUCTS - Yield (kg/ha) } \\
\hline Sugarcane stems & 81000 & 91800 & 108000 & 124200 \\
\hline Sugarcane tops & 16200 & 18360 & 21600 & 24840 \\
\hline Pearl millet & 949.5 & 1076.1 & 1266 & 1455.9 \\
\hline Sorghum & 816 & 924.8 & 1088 & 1251.2 \\
\hline Maize fodder & 1457.25 & 1651.55 & 1943 & 2234.45 \\
\hline Maize grain (imported) & 0 & 0 & 0 & 0 \\
\hline Cotton seed cake (imported) & 0 & 0 & 0 & 0 \\
\hline Mustard cake (imported) & 0 & 0 & 0 & 0 \\
\hline Oats (imported) & 0 & 0 & 0 & 0 \\
\hline Rice straw & 5760 & 6528 & 7680 & 8832 \\
\hline Wheat straw & 4320 & 4896 & 5760 & 6624 \\
\hline Wheat grain & 4320 & 4896 & 5760 & 6624 \\
\hline Rice grain & 5760 & 6528 & 7680 & 8832 \\
\hline Mustard & 1200 & 1360 & 1600 & 1840 \\
\hline Yam & 22500 & 25500 & 30000 & 34500 \\
\hline Wheat straw & 4320 & 4896 & 5760 & 6624 \\
\hline Mung grain & 450 & 510 & 600 & 690 \\
\hline Mung straw & 1575 & 1785 & 2100 & 2415 \\
\hline Maize grain & 3375 & 3825 & 4500 & 5175 \\
\hline Maize residue & 3375 & 3825 & 4500 & 5175 \\
\hline Wheat grain & 4320 & 4896 & 5760 & 6624 \\
\hline
\end{tabular}




\section{Supplementary Materials 2B: Farmers objectives and challenges perceived}

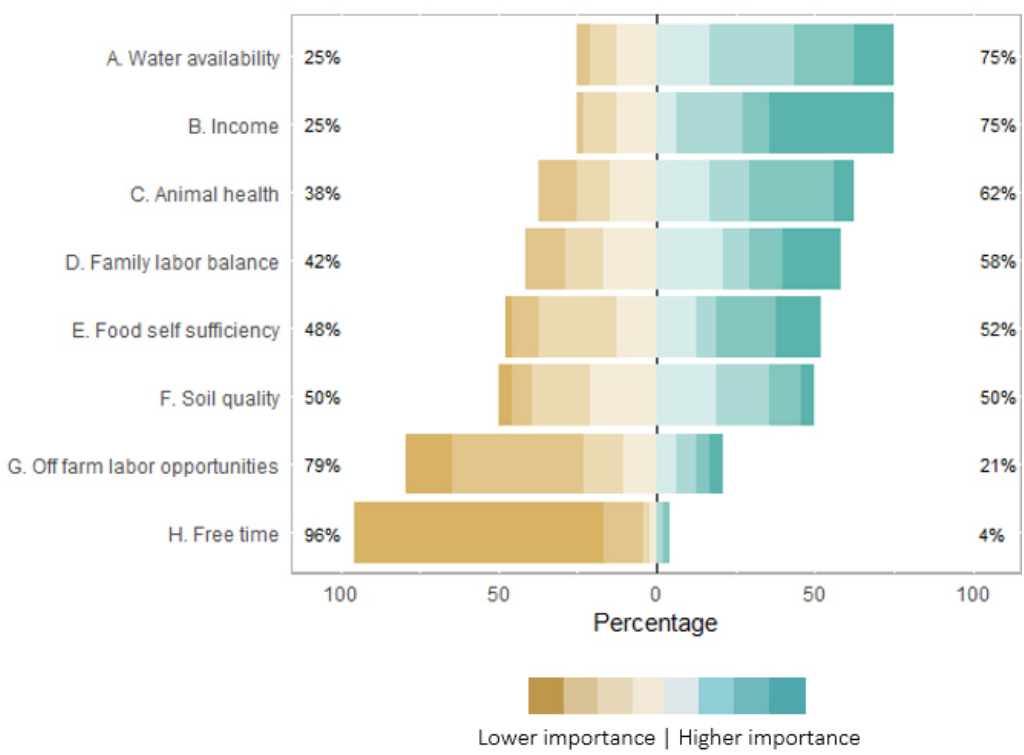

Figure S1: Farmers' objectives ordered with data from the districts of Patiala (Punjab, n=8), Karnal (Haryana, n=9), Muzaffanagar (UP-West, n=6), Faizabad (UP-East, n=8), Patna (Bihar, n=9) and Kota (Rajasthan, n=8).

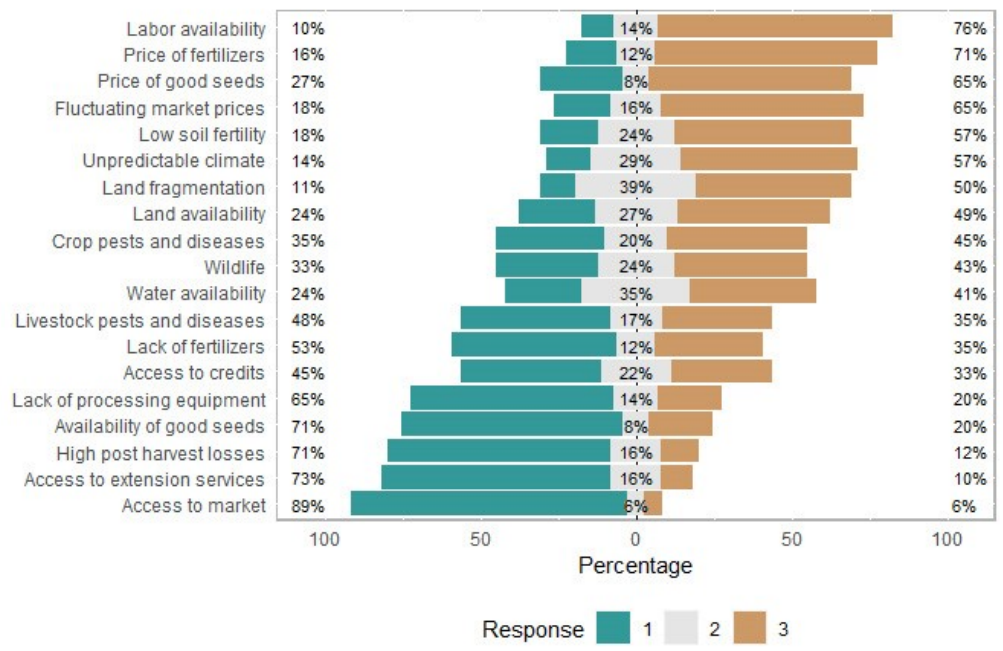

Figure S2: Challenges perceived by farmers in Patiala (Punjab, n=8), Karnal (Haryana, n=9), Muzaffanagar (UP-West, n=6), Faizabad (UP-East, $n=8$ ), Patna (Bihar, n=9) and Kota (Rajasthan, n=8). Scores: $1=$ no problem, $2=$ threat, $3=$ problem. Note: land fragmentation and access to market were only assessed in Faizabad (UP-East) and Patna (Bihar) districts. 


\section{Supplementary Materials 2C: Climatic parameters of six case-study districts}

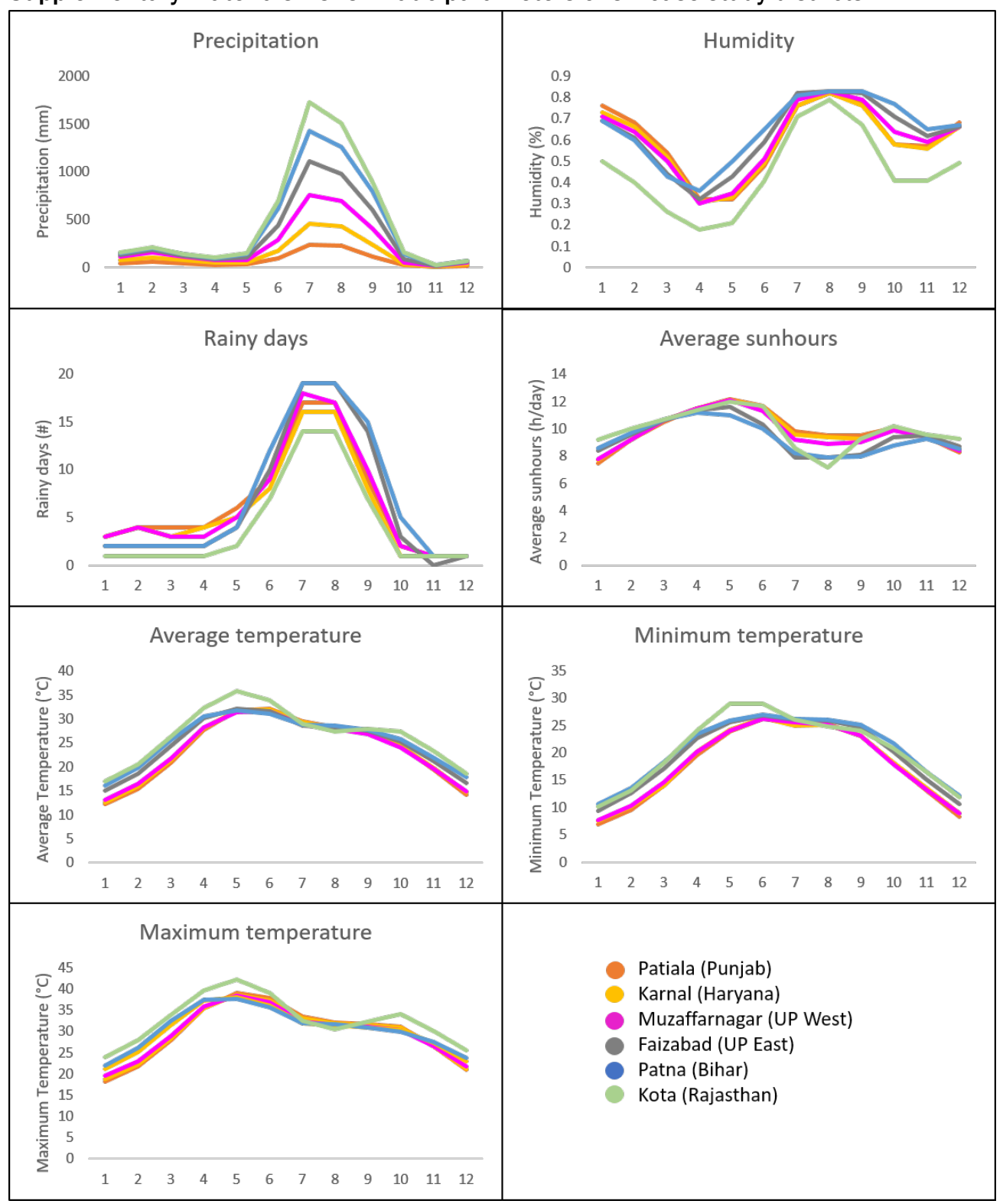

Figure S3: Climatic parameters of six case-study districts. 



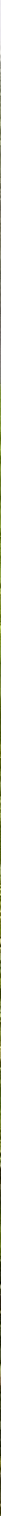

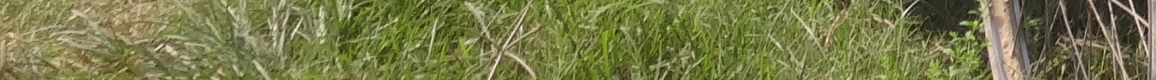
-

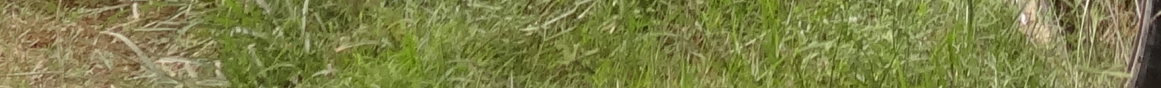
S.

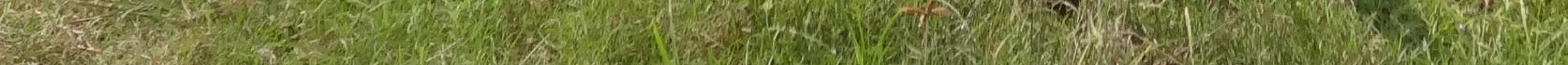




\section{Chapter 3}

Farm-level exploration of economic and environmental impacts of sustainable intensification of rice-wheat cropping systems in the Eastern Indo-Gangetic plains

Roos de Adelhart Toorop, Santiago Lopez-Ridaura, Deepak Bijarniya, Eakapat Kalawantawanit, Raj Kumar Jat, Asish Kumar Prusty, Mangi Lal Jat, Jeroen C.J. Groot

Published as: Adelhart Toorop, R., Lopez-Ridaura, S., Bijarniya, D., Kalawantawanit, E., Jat, R. K., Prusty, A. K., Jat, M. L., and Groot, J. C. (2020), Farm-level exploration of economic and environmental impacts of sustainable intensification of rice-wheat cropping systems in the Eastern Indo-Gangetic plains. European Journal of Agronomy. 121: p. 126157 


\section{Abstract}

Agriculture in rural Bihar needs to maintain its productivity while enhancing its biophysical sustainability. To sustainably intensify the predominant rice-wheat systems, alternative cropping patterns with short duration legumes, planted in the usually fallow summer season, were developed. The addition of the legume ensures near-permanent soil cover, breaks the cereal-cereal cycle, and aims to improve soil quality while yielding between 0.6 and $1.2 \mathrm{Mg} \mathrm{ha}^{-1}$ of protein-rich dry matter. On-station experiments previously demonstrated the agronomical feasibility of the alternative cropping patterns while this study addresses the implications of such field-level changes at farm-level for different types of smallholders. We used the model FarmDESIGN to 1) assess current farm performance, 2) explore options to rearrange cropping patterns and 3) assess the impact of cropping patterns with mung bean. We found diverse farm performances, indicating a heterogenous farming community. Re-arranging current cropping patterns gave all farms possibilities to save water, increase soil organic matter content and decrease nitrogen losses but showed trade-offs with operating profit. Higher resource endowed farms had most potential to favourably rearrange the farm and improve multiple performance indicators. Two out of the five farms assessed did not benefit from including the alternative cropping patterns. We conclude that the impact of innovations greatly depends on farm type and current farm features and performance, described by a farm typology.

Keywords: Redesign, multi-objective optimization, India, rotation, typology, mung bean 


\section{Introduction}

Smallholder farms represent a large proportion of farms around the world and produce a substantial share of commodities and human nutrients (Herrero et al., 2017). The livelihoods of these farmers and their households strongly depend on farm activities for food security and income. Drivers at different levels (macro, meso and micro) affect the farms and their diversity, and shape their trajectories of change (Herrero et al., 2014). Macro-level factors such as population growth and climate change are important drivers of very localised changes in farming systems. Population growth leads to an increasing demand for food and it generates pressure on agricultural productivity due to fragmentation of land and resource scarcity (e.g. through depletion of water for irrigation). Resource availability can also be affected by climate change, moreover, changing temperatures, irradiation and rainfall patterns could also impair crop growth and development and animal performance which all reduce farm productivity.

There is great pressure on farmers to sustainably intensify their production however the impacts of climatic changes are experienced strongly in South Asia. In the Indo-Gangetic Plains (IGP), which are an important agricultural area for cereal production in India, rice-wheat cropping systems cover a large proportion of the cultivated land (12.3 million hectares (Sharma et al., 2018)) and contribute substantially to food consumed. However, the continuous intensive cultivation of these crops has led to soil degradation and over-exploitation of fresh water resources, resulting in challenges to sustain crop productivity whilst also ensuring environmental sustainability (Erenstein, 2011; Parihar et al., 2016). The IGP are characterized by a poverty gradient from low poverty in the north-west increasing eastwards to high poverty in eastern IGP. Bihar, located in the eastern IGP, is India's third most populous state, with over $90 \%$ of inhabitants living in rural areas. The majority of the population depends on agriculture and food insecurity is common (Krishna and Kumari, 2014). It is vulnerable to climate change due to heat, drought and flood risks, and also to increasingly erratic monsoon precipitation (Chhabra and Haris, 2015; Sehgal et al., 2013). Especially rice cultivation demands the use of large quantities of inputs and water, with its costs both in financial and environmental terms. In order to sustainably develop the livelihoods of smallholders in Bihar, there is an urgent need to address the major challenges that farmers face while simultaneously strengthening the natural resource base and avoiding pollution of air, water and soils (R. Jat et al., 2018; Lopez-Ridaura et al., 2018; Saharawat et al., 2010). 
Governmental policies aim to sustainably intensify the agricultural productivity, particularly for cereals and livestock (Laik et al., 2014; Singh et al., 2009), by promoting Climate Smart Agriculture (CSA) and Conservation Agriculture (CA) practices to enhance soil and water quality and reduce water use (M. L. Jat et al., 2013; R. K. Jat et al., 2014; Parihar et al., 2016). On-station research projects have investigated combinations of alternative methods for tillage, planting and residue management as well as for diversification and intensification options at field level, for instance by incorporating legume crops like mung bean (Vigna radiata), black gram (Vigna mungo) and dhaincha (Sesbania bispinosa) (Hossain et al., 2016) in the summer (zaid) season which is usually kept fallow (Choudhary et al., 2018; Hossain et al., 2016; H. Jat et al., 2018). These field experiments show promising results regarding soil quality improvement and water productivity when alternative practices are combined (Choudhary et al., 2018; R. Jat et al., 2018; Parihar et al., 2016). Choudhary et al. (2018), Hossain et al. (2016), H. Jat et al. (2018) and R. D. Jat et al. (2018) also found positive biophysical effects when the legume crop was added within conventional management (i.e. no CA). This seems an easy addition to these cropping patterns as it does not require new skills and machinery.

To assess the impact of the integration of legumes, an evaluation at the farm level is required in addition to field-level experimentation. A whole-farm analysis informs decisions on farm resource allocation and aids in determining consequences for the household's livelihood objectives associated with income, nutrition, labour use, and the overall environmental impact. When performing a whole-farm analysis, the diversity of farming systems needs to be considered. Changes at the plot level affect both the farm systems' biophysical environment and the socio-economic conditions but the extent of change may depend on the original farm configuration and assets (Michalscheck et al., 2018). Grouping farms based on functional and structural characteristics is a common way to deal with diversity within farming communities (Alvarez et al., 2018; K. S. Kuivanen et al., 2016; K. Kuivanen et al., 2016; Lopez-Ridaura et al., 2018; Tittonell et al., 2010). The heterogeneity of these communities can be studied by in-depth characterization of farms representing a type in a typology.

In this study we did an in-depth assessment of five farms from different farm types, followed by a whole-farm exploration with multi-objective optimization model FarmDESIGN (Ditzler et al., 2019; Groot et al., 2016; Groot et al., 2012; Timler et al., 2020) to assess the potential impact of reallocation of cropping patterns and inclusion of mung bean in cereal-based cropping systems. A systems approach was adopted to arrive at integrated assessment of economic 
and environmental performance, and to explore potential synergies and trade-offs among objectives.

\section{Materials and Methods}

\subsection{Objectives and case study area}

In this study, we explore options to maximize operating profit, water saving and soil organic matter balance, and to minimize the nitrogen balance. Soil organic matter balance, water saving and nitrogen balance function as proxy for environmental health.

The farms for this study were selected from the villages Kuboli and Digambra in Samastipur, Bihar, located in Eastern India, which is part of the IGP (Figure 3.1). The state has a sub-humid climate with temperatures ranging from 6 to $45^{\circ} \mathrm{C}$, with June as hottest month $\left(32{ }^{\circ} \mathrm{C}\right.$ average $)$ and January as coldest month $\left(15^{\circ} \mathrm{C}\right.$ average). The average annual rainfall is $1176 \mathrm{~mm}$ per year (Chhabra and Haris, 2015). The dominant cropping pattern is rice in kharif (monsoon, June-Oct) followed by wheat in rabi (November-April) and by a fallow period during the summer (zaid) season (April-June/July).

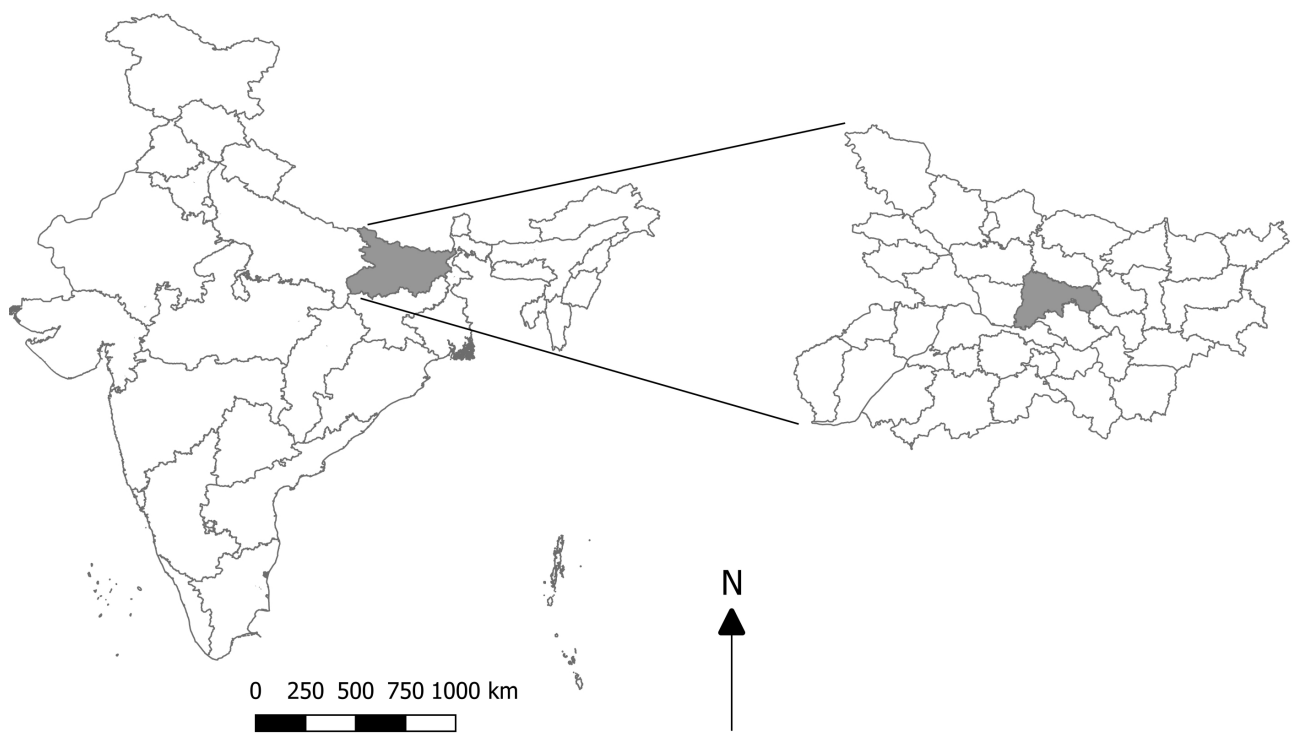

Figure 3.1: Map of India with the Indio Gangetic Plains in grey and in detail the state Bihar with the study area Samastipur in the center of the state. 


\subsection{Farm selection and on-farm data collection}

Lopez-Ridaura et al. (2018) characterized the diversity of farming systems in Bihar based on a household survey on farming systems and livelihood pursuits among 269 farms in Bihar. Farms were classified into five farm types which for this study were named the Farm Manager, Wealthy Farmer, Arable Farmer, Small Farmer, and Marginal Farmer. The relation between the selected farms and the farm types described by Lopez-Ridaura et al. (2018) is presented in Supplementary Materials 3A. In 2016, we performed short household surveys to select one farm for each type. For detailed analysis of these farms we used a customized survey based on the IMPACTLite survey tool that facilitates the collection of household information on key farm-household performance and livelihoods indicators (Rufino et al., 2013). A total of five surveys were completed collecting data on household composition, labour allocation, farm structure (land size, animal numbers, cultivation of crops and trees, use of organic resources, fertilizers and pesticides, owned assets and equipment), productivity of crops and livestock, and imports and exports of products and resources. This provided data for a detailed analysis of farm configuration, resource allocation (land use and residue destination), productivity, environmental impact and socio-economic performance for each farm type.

\subsection{Alternative cropping patterns with a legume crop}

System intensification through the integration of a short duration legume may provide an opportunity to improve environmental health while also producing a protein rich grain. Enhanced soil quality can be expected through the prolonged soil cover contributing to aggregate stability; moderated soil temperature favouring root growth and biomass production; and sequestered carbon (H. Jat et al., 2018). Thereby residual NO3-N will be taken up from the surface soil layers before it is leached to aquifers, preventing loss of nutrients and ground water pollution. Choudhary et al. (2018) and R. D. Jat et al. (2018) reported an increase in profitability of about $15 \%$.

To assess the impact of short duration mung bean (Vigna radiata) in the summer season, three alternative cropping patterns were constructed in combination with common kharif (rice, maize) and rabi (wheat, mustard) crops: rice-wheat-mung bean; maize-wheat-mung bean; and maize-mustard-mung bean. These cropping patterns have been field-tested in the Borlaug Institute for South Asia (BISA) station in Pusa, Bihar, in a long-term experiment that started in 2012 (Borlaug Institute for South Asia, 2015). The time window for cultivation of the mung 
bean was 90 days between harvest of the rabi crop and sowing of the kharif crop, which allows two picking moments. Input-data regarding the alternative cropping patterns were derived from these field experiments. Supplementary Materials 3B shows these alternative cropping patterns with the outcomes on the objectives calculated using data from the field experiment in $2014 / 2015$.

\subsection{Model-based analysis}

We used the bio-economic whole-farm model FarmDESIGN (Ditzler et al., 2019; Groot et al., 2012) for a diagnosis of the productive, environmental and socio-economic baseline performance of the five selected farms. FarmDESIGN is a static model that quantifies farm performance in terms of annual resource flows and balances. The model is equipped with an evolutionary algorithm, i.e. Pareto-based Multi-Objective Differential Evolution (P-MODE) (Deb et al., 2002; Price and Storn, 1997), to explore options to improve performance of the baseline of the five selected farms for the four objectives and to determine the interrelations among these farm objectives. The relations among objectives are captured by the shape of the outcome space, and can be synergetic if objectives change in a desirable direction simultaneously, but might also be conflicting hence implying trade-offs in farm performance (Groot et al., 2010). The P-MODE algorithm generates a set of alternative farm configurations (solutions) that is iteratively improved using Pareto-based ranking (Groot et al., 2012; Groot et al., 2010; Groot et al., 2007; Groot and Rossing, 2011). A multi-objective design problem can be generally stated as follows.

$$
\begin{gathered}
\operatorname{Max} / \operatorname{Min} U(x)=(U 1(x), U 2(x), \ldots, U k(x)) T \\
x=\left(x_{1}, x_{2}, \ldots, x_{n}\right) T
\end{gathered}
$$

Subject to i constraints:

$$
g_{i}(x) \geq h_{i}
$$

Where, $\mathrm{U} 1(\mathrm{x}), \ldots, \mathrm{Uk}(\mathrm{x})$ are the objective functions that are either maximized or minimized, and $(\mathrm{x} 1, \ldots, \mathrm{xn})$ are the decision variables that represent the farm-specific adjustable parameters, to 
define alternative farm configurations. The decision variables can take on an array of values, $\mathrm{x} \in \mathrm{S}$, where $\mathrm{S}$ is the outcome or parameter space. Constraints in equation (3) can arise from the problem formulation, for instance by limitations on farm model results related to a specific configuration of decision variables.

In our study, the objectives were to maximize the soil organic matter balance, farm operating profit and the water balance, and to minimize the farm nitrogen balance as these indicators align with the objectives and challenges of farms in Bihar. These objectives were calculated as follows:

1. Operating profit (i.e. income) (USD/year) is the main farm economics indicator which is quantified as the difference between the gross margins obtained for crop and animal production, and the costs incurred for manures and fertilizers, assets, hired labour, and general costs for farm maintenance and administration.

2. Soil organic matter balance $(\mathrm{kg} / \mathrm{ha} /$ year $)$ is calculated as the difference between inputs of organic matter into the soil (from crop roots and residues, mulch, and farm-produced and imported manures) and losses by degradation of active soil organic matter, added manure and erosion.

3. Water balance for irrigation $\left(\mathrm{m}^{3} /\right.$ ha/year) measures the depletion of available water resources and the amount of water applied to each of the crops. A positive water balance indicates a surplus of water, a negative value represents an irrigation water deficit. In this study the water balance for each current farm configuration was $0 \mathrm{~m}^{3}$, indicating neither a water surplus nor a deficit. Positive scores on this objective indicate water saving, negative scores indicate potential deficit as the water demand is higher than with the baseline configuration.

4. Farm nitrogen balance $(\mathrm{kg} \mathrm{N} / \mathrm{ha} /$ year) is quantified by subtracting the nitrogen exported in managed products (animal and crop products and manures) from the sum of inputs of nitrogen into the farm in crop products (e.g. purchased or off-farm collected feeds), animal products, manures and fertilizers, deposition, symbiotic fixation (by leguminous plants) and non-symbiotic fixation (by free-living soil biota). The farm nitrogen balance is a proxy for losses, while a negative balance would imply reliance on soil nitrogen delivery.

In addition to these objectives, we assessed the current farm performance in terms of the indicators operating profit per unit of area (USD/ha), water use efficiency (operating profit/water 
use; $\left.\mathrm{USD} / \mathrm{m}^{3}\right)$, active ingredients in pesticides per unit of area $(\mathrm{kg} / \mathrm{ha})$, the number of different crops cultivated, and the dietary energy production (expressed in number of people that can obtain sufficient calories from on-farm produced food based on Dietary Reference Intake (Otten et al., 2006).

Table 3.1 lists the decision variables and constraints set in this modelling exercise. We configured the P-MODE optimization to yield 500 outcomes representing alternative farm management and resource allocation options after 10,000 iterations of recombination, evaluation and selection of alternatives in the Pareto-based evolutionary algorithm. The parameter settings of Differential Evolution algorithm of P-MODE were a cross-over probability $\mathrm{CR}=0.85$ and amplitude of mutations F=0.15 (cf. Groot et al., 2012; Groot et al., 2007).

Table 3.1: Decision variables and constraints set for the optimization routine for each of the five farms. Decision variables indicate which parameters may be adjusted with the evolutionary algorithm. Constraints give a minimum and maximum value in which specific objective should fall in alternative farm configurations.

\begin{tabular}{|c|c|c|}
\hline & Minimum & Maximum \\
\hline \multicolumn{3}{|l|}{ Decision variables } \\
\hline Land use arable crop rotations (ha) & 0 & Total area arable land (ha) \\
\hline Land use alternative crops (ha) & 0 & Total area arable land (ha) \\
\hline Animal feed to animals $(\mathrm{kg})$ & 0 & Yield $(\mathrm{kg} / \mathrm{ha}) *$ total area arable land (ha) \\
\hline Animal feed to market $(\mathrm{kg})$ & 0 & Yield $(\mathrm{kg} / \mathrm{ha}) *$ total area arable land (ha) \\
\hline Crop residues to soil $(\%)$ & 0 & 100 \\
\hline Crop residues to animals (\%) & 0 & 100 \\
\hline Dairy cows (\#) & 0 & 5 \\
\hline \multicolumn{3}{|l|}{ Constraints } \\
\hline Farm area (ha) & Current area -0.1 ha & Current area \\
\hline Saturation deviation ruminants $(\%)$ & $-\infty$ & 0 \\
\hline Energy deviation ruminants (\%) & -5 & 5 \\
\hline Protein deviation ruminants $(\%)$ & 0 & 30 \\
\hline Organic matter balance (kg/ha/year) & -310 & $\infty$ \\
\hline Regular labour surplus (h/year) & 0 & $\infty$ \\
\hline Casual labour (h/year) & 0 & $\infty$ \\
\hline Self-reliance household consumed crops & 1 & $\infty$ \\
\hline
\end{tabular}




\section{Results}

\subsection{Current farm performance}

The five farms differed in terms of land, crops, household size, livestock types and numbers which led to different farm performance. Table 3.2 gives an overview of the current farm characteristics and performance on environmental and economic indicators allowing comparison across indicators and among farms.

The Farm Manager had the largest farm (3.0 ha) with the largest number of family members (17) and the most time available for working on- or off-farm (3832 hours) (Table 3.2). Half of the area was used as arable land with cereals for human consumption and feed, fodder, banana and vegetables altogether making up for $65 \%$ of the gross margin crops with nine different crops. The remaining of the land was allocated to (scattered) trees, which made up $23 \%$ of the gross margin crops. Of the total operating profit $8 \%$ was generated through sales of animal products. This farm had highest operating profit overall, with largest contribution of animals and scattered trees. In addition, operating profit per hectare (total) and per hectare of arable land were highest. This farm outperformed the other farms in terms of operating profit, water use, dietary energy, SOM balance and pesticide use.

The Wealthy Farmer was characterized by large land and livestock holding ( 2.9 ha, 2 cows, 2 heifers). This farm had 13 household members with 1953 hours available for on- or off-farm work. Nine crops were cultivated: a variety of cereals (for human consumption and feed), oilseed crops and vegetables were cultivated, often in combination with mung bean as an intercrop. In addition, tobacco was cultivated as a cash crop, both as a monoculture and as an intercrop with maize. Animal products and fruits from scattered trees contributed to the total operating profit for only $2 \%$ and $8 \%$, respectively. This farm did not outcompete other farms and performed poorly on objectives related to water use and nitrogen losses.

The Arable Farmer had no livestock and was, with a farm size of 2.8 ha, comparable to the Farm Manager and the Wealthy Farmer. On the majority of the land (1.6 ha) mango trees were grown, which contribute $54 \%$ of the operating profit from fruit sales. On the remaining 1.2 hectares, cereals were mainly cultivated with minimal labor inputs: the household contributed with 32 hours, which was supplemented with a 50 hours of hired labor. This farm performed comparatively well with regards to environmental objectives (water saving, nitrogen efficiency, pesticide use) while economic performance, soil organic matter balance and dietary energy 
per hectare were poor in comparison to other farms (Table 3.2). With only maize and pea (intercropped), wheat and rice cultivated the crop diversity was low.

Table 3.2: Characteristics of modeled farms.

\begin{tabular}{|c|c|c|c|c|c|}
\hline & & & Farm type & & \\
\hline Farm characteristics & $\begin{array}{c}\text { Farm } \\
\text { manager }\end{array}$ & $\begin{array}{l}\text { Wealthy } \\
\text { farm }\end{array}$ & Arable farm & Small farm & $\underset{\text { farm }}{\text { Marginal }}$ \\
\hline Farm size (ha) & 3 & 2.9 & 2.8 & 0.9 & 0.33 \\
\hline Cultivated area (ha) & 1.6 & 2.6 & 1.2 & 0.74 & 0.32 \\
\hline $\begin{array}{l}\text { Fraction allocated to } \\
\text { trees }\end{array}$ & 0.24 & 0.08 & 0.54 & 0.12 & 0 \\
\hline Number of heifers (no) & 2 & 3 & 0 & 2 & 0 \\
\hline Number of cows (no) & 2 & 2 & 0 & 1 & 2 \\
\hline $\begin{array}{l}\text { Number of family } \\
\text { members (no) }\end{array}$ & 17 & 13 & 5 & 4 & 10 \\
\hline $\begin{array}{l}\text { Household labour } \\
\text { (hours/year) }\end{array}$ & 3832 & 1953 & 32 & 2513 & 1256 \\
\hline $\begin{array}{l}\text { Contract work costs } \\
\text { (USD/year) }\end{array}$ & 360 & 580 & 435 & 215 & 44 \\
\hline Number of crops (no) & 9 & 9 & 4 & 9 & 3 \\
\hline Arable crops & $\begin{array}{c}\text { Wheat, } \\
\text { yam+sorghum, } \\
\text { maize+potato, } \\
\text { oat+berseem, } \\
\text { gourds, } \\
\text { banana }\end{array}$ & $\begin{array}{l}\text { Wheat, mung, } \\
\text { rice+maize, } \\
\text { tobacco+maize, } \\
\text { potato, } \\
\text { mustard, } \\
\text { mung+sorghum, } \\
\text { tobacco, } \\
\text { gourds+mung }\end{array}$ & $\begin{array}{l}\text { Maize+pea, } \\
\text { wheat, rice }\end{array}$ & $\begin{array}{l}\text { Wheat+mustard, } \\
\text { rice, } \\
\text { maize+potato, } \\
\text { cauliflower, } \\
\text { tobacco+maize, } \\
\text { sorghum, } \\
\text { gourds }\end{array}$ & $\begin{array}{c}\text { Wheat, maize, } \\
\text { sorghum }\end{array}$ \\
\hline Scattered trees & $\begin{array}{l}\text { Mango (1.1 } \\
\text { ha), guava, } \\
\text { lemon, litchi, } \\
\text { palm, timber }\end{array}$ & $\begin{array}{c}\text { Mango (0.2 } \\
\text { ha), banana, } \\
\text { jackfruit, } \\
\text { lemon, guava, } \\
\text { timber }\end{array}$ & $\underset{\text { ha) }}{\text { Mango (1.6 }}$ & $\begin{array}{l}\text { Mango (0.09 } \\
\text { ha), banana, } \\
\text { palm tree, } \\
\text { timber }\end{array}$ & $\begin{array}{l}\text { Guava, } \\
\text { banana }\end{array}$ \\
\hline $\begin{array}{l}\text { Operating profit } \\
\text { (USD/year) }\end{array}$ & 13232 & 6473 & 4349 & 2088 & 1189 \\
\hline $\begin{array}{l}\text { Operating profit/ha } \\
\text { (USD/ha/year) }\end{array}$ & 4387 & 2219 & 1553 & 2317 & 3567 \\
\hline $\begin{array}{l}\text { Gross margin animals } \\
\text { (USD/ha/year) }\end{array}$ & 683 & 58 & 0 & 331 & 3357 \\
\hline $\begin{array}{l}\text { Gross margin crops } \\
\text { (USD/ha/year) }\end{array}$ & 4091 & 2570 & 1714 & 2296 & 483 \\
\hline $\begin{array}{l}\text { Organic matter balance } \\
(\mathrm{kg} / \mathrm{ha} / \text { year) }\end{array}$ & 76 & -27 & -309 & -135 & -27 \\
\hline Water use $\left(\mathrm{m}^{3} /\right.$ ha/year) & 3873 & 7147 & 3721 & 5961 & 3858 \\
\hline $\begin{array}{l}\text { Pesticide use (g } \\
\text { AI/ha/year) }\end{array}$ & 699 & 1056 & 700 & 1899.2 & 1113 \\
\hline $\mathrm{N}$ balance $(\mathrm{kg} / \mathrm{ha} /$ year $)$ & 181 & 281 & 99 & 131 & 335 \\
\hline $\begin{array}{l}\text { Farm } \mathrm{N} \text { use efficiency } \\
(\%)\end{array}$ & 40 & 21 & 56 & 49 & 26 \\
\hline $\begin{array}{l}\text { Dietary energy } \\
\text { (persons/ha/year) }\end{array}$ & 25.2 & 18 & 15 & 28 & 38 \\
\hline
\end{tabular}


The Small Farmer managed 0.9 hectares, of which 0.74 hectares was cultivated, and owned 2 heifers and 1 cow. This farm belongs to the smaller households with four household members having 2513 hours available for on- or off-farm activities. Cropping systems were based on cereals, with and without mustard, potato or tobacco as intercrop, and vegetables. Animal products and fruits from trees made up $12 \%$ of the total operating profit each. Although this farm did not outcompete other farms on any of the objectives, performance on nitrogen efficiency, dietary energy and water saving per hectare were relatively high (Table 3.2).

The Marginal Farmer had the smallest farm with 0.33 hectares, and with 10 household members (1256 hours) the greatest density people-land. The entire farm area was cultivated with wheat and maize for home consumption and crop residues were used as feed for 2 cows. The majority of the farm income was derived from sales of livestock products $(88 \%)$. Being the smallest farm, absolute operating profit and dietary energy were lowest but when expressed per hectare, their performance was comparatively good (2nd highest operating profit per hectare). Nitrogen use efficiency, nitrogen balance and crop diversity were low.

\subsection{Trade-offs and synergies}

Figure 3.2 shows the comparative positions of the five farms analysed and their outcome spaces delimited by the four objectives to maximize operating profit, soil organic matter balance and water saving and to minimize $\mathrm{N}$ balance. By presenting alternative configurations in two-dimensional spaces we assessed the relations between these objectives.

The results of the multi-objective optimization present clear differences in size and positioning of the 'outcome space' for each farm (Figure 3.2). The exploration of the Farm Manager yielded the largest room to manoeuvre, which was 10 times as large as the volume of the Wealthy Farmer and more than 1000 times larger than the volumes of the Arable Farmer, Small Farmer and Marginal Farmer (Table 3.3). The Arable Farmer, Small Farmer and Marginal Farmer were close to the boundary of the outcome space with respect to operating profit and water saving: the reconfigurations showed limited improvement for these objectives. However, soil organic matter balance and nitrogen balance could improve after reallocation of current cropping patterns for all farms (Figure 3.2c). Soil organic matter balances of $1000 \mathrm{~kg} / \mathrm{ha} / \mathrm{year}$ could be reached for all farms except the Arable Farmer. N balances could be lowered by $88 \%$ for the Farm Manager, 45\% for the Arable Farmer and approximately 20\% for the Wealthy Farmer, 
Small Farmer and Marginal Farmer. Water saving (up to 30\%) and increasing operating profit (up to 20\%) were in particular substantial for the Farm Manager and Wealthy Farmer.

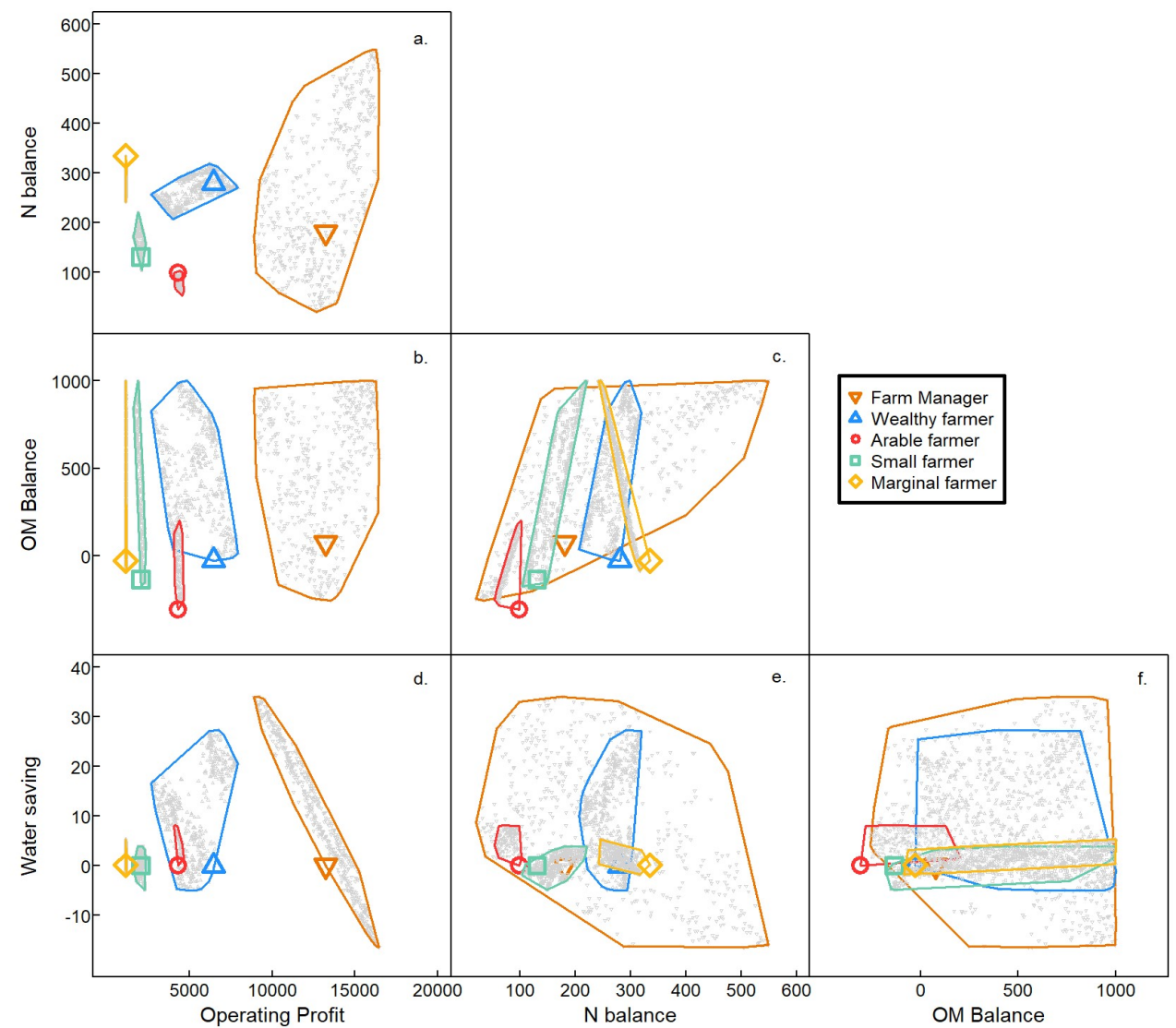

Figure 3.2: Relations among objectives of minimizing nitrogen $(\mathrm{N})$ balance $(\mathrm{kg} / \mathrm{ha} / \mathrm{year}$; $\mathrm{a}, \mathrm{c}, \mathrm{e})$ and maximizing organic matter (OM) balance (kg/ha/year; b, c, f), water saving (\%; d, e, f) and operating profit (USD/year; a, b, d) resulting from the multi-objective optimization. Each grey dot represents a farming system configuration, resulting in a set of alternatives for each of the case study farms in Bihar, India. The symbols (triangle, circle, square, diamond) represent the original performance on the objectives.

Although the potential for change was not equal for the five farms, trade-offs and synergies between objectives could be revealed from the shape of the outcome space. Figure $3.2 \mathrm{~d}$ shows trade-offs between operating profit and water saving: there is little scope to improve economic performance of farms and at the same time save water. The line-shape of the Farm Manager illustrates this most clearly. Albeit with a less clear association, trade-offs were revealed between operating profit and $\mathrm{N}$ balance (Figure 3.2a, Farm Manager and Wealthy Farmer) and between 
operating profit and SOM balance (Figure 3.2b, Farm Manager, Wealthy Farmer and Arable Farmer). Figure 3.2c illustrates that relationships among objectives could differ between farms: all showed a trade-off between the objectives $\mathrm{N}$ balance and SOM balance except the Marginal Farmer, which showed a synergy. In Figure 3.2e a synergy between $\mathrm{N}$ balance and water saving was revealed for the Small Farmer while the Farm Manager and the Marginal farmer showed an opposite (trade-off) relationship. These differences occur as result of the initial cropping patterns which eventually define the shape of the outcome space. Amongst other objectives no, or less apparent, patterns could be observed.

Figure 3.3 visualizes the prominent trade-off between operating profit and water saving and explains how land allocation defines the relationship between objectives. Land allocation for maximum profit appeared to be similar to the land allocation for minimum water saving. Configurations with greater operating profit have larger areas of the crop vegetables-potato+maize-fallow, while solutions with larger areas of this crop have low water saving. The crops yam+sorghum-wheat-fallow and fallow-maize+pea-fallow are associated with greater water saving, however have low operating profit indicating the trade-off between these two objectives.
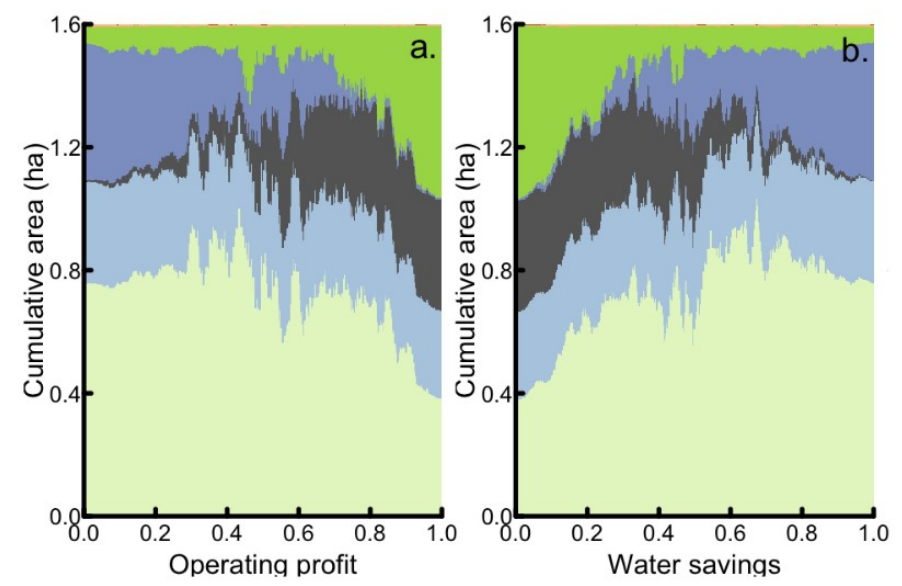

Yam+Sorghum - Wheat - Fallow

Vegetables - Oat+Berseem - Fallow

- Banana

- Fallow - Maize+Pea - Fallow

Vegetables - Potato+Maize - Fallow

Figure 3.3: Modeled land allocation to crops in relation to relative changes in operating profit (a) and water savings (b) for the Farm Manager. The values on the X-axes were normalized ( 0 for the lowest performing system reconfiguration, 1 for the best performing system reconfiguration). The Y-axes indicate total cropped area. 


\subsection{Exploration of impact of alternative cropping patterns}

Figure 3.4 compares the alternative cropping patterns with all cropping patterns currently cultivated on the five farms at the field level. We used the indicators dietary energy, economic performance and soil organic matter expressed as efficiencies in terms of water use, i.e. 'economic water use efficiency' (USD/1000 $\mathrm{m}^{3}$ ), 'food water use efficiency' $\left(\mathrm{kcal} / 1000 \mathrm{~m}^{3}\right)$ and 'SOM water use efficiency' $\left(\mathrm{kg} / \mathrm{ha} / \mathrm{year} / \mathrm{m}^{3}\right)$. The current cropping patterns "fallow-maize+pea-fallow", "vegetables-oat+berseem-fallow" and "yam+soghum-wheat-fallow" from the Farm Manager and "fallow-maize+pea-fallow" from the Arable Farmer outperformed the alternative cropping patterns in terms of the three efficiency indicators. When exploring options to enlarge the outcome space with alternative cropping patterns with FarmDESIGN, we found that these best performing crops, which outperformed the alternatives, dominated the rotations of the Farm Manager and the Arable Farmer, while the alternative cropping patterns were not allocated any area. The Farm Manager and Arable Farmer were therefore excluded from further analysis on the impact of alternative cropping patterns on the overall performance of the farms.
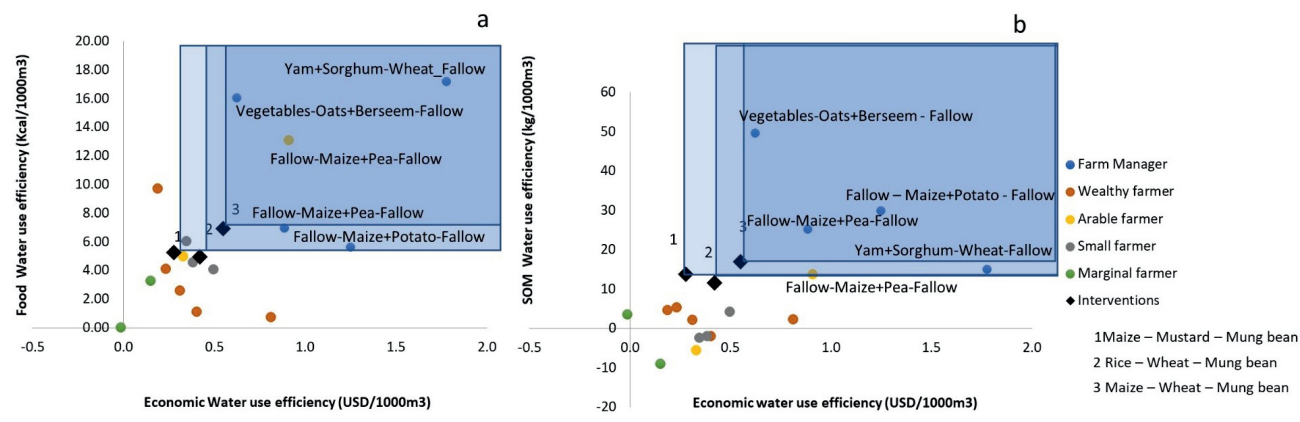

Figure 3.4: (a) Water use efficiency (WUE) for economic performance and food supply (USD and kcal per $1000 \mathrm{~m}^{3}$ water); (b) Water use efficiency for economic performance and Soil organic matter balance (USD and kg organic matter per $1000 \mathrm{~m}^{3}$ water). Blue rectangles indicate better performance on the objectives compared to the alternative cropping systems.

Figure 3.5 compares the room to manoeuvre with, and without alternative cropping patterns. The additional cropping patterns led to increased outcome spaces for the Wealthy Farmer, Small Farmer and Marginal Farmer.

In absolute terms the Wealthy Farmer had the largest increase in volume. The operating profit did not increase, but water saving and $\mathrm{N}$ balance showed potential for optimization through substitution of "fallow-potato+mung bean-fallow" by the alternative cropping pattern 
"maize - mustard - mung bean". The Marginal Farmer could achieve the largest improvement with diversification of the cropping patterns Maize-wheat-fallow and sorghum-fallow-fallow mainly because of better potential performance to maximize operating profit (up to $41 \%$ ) and to minimize $\mathrm{N}$ balance (up to $39 \%$ ) after inclusion of alternative cropping patterns "rice-wheat-mung bean" and "maize - wheat - mung bean". Nevertheless, the majority of alternative configurations for this farm used more water than the baseline (Figure 3.5). This is in contrast when compared to the potential water saving of the Wealthy Farmer (40\%) and Small Farmer (20\%), but should be seen in perspective: the Marginal Farmer initially used less water than the other farmers (Table 3.2), in absolute terms as well as per hectare. The Small Farmer could improve water saving, however options to increase operating profit remained limited.

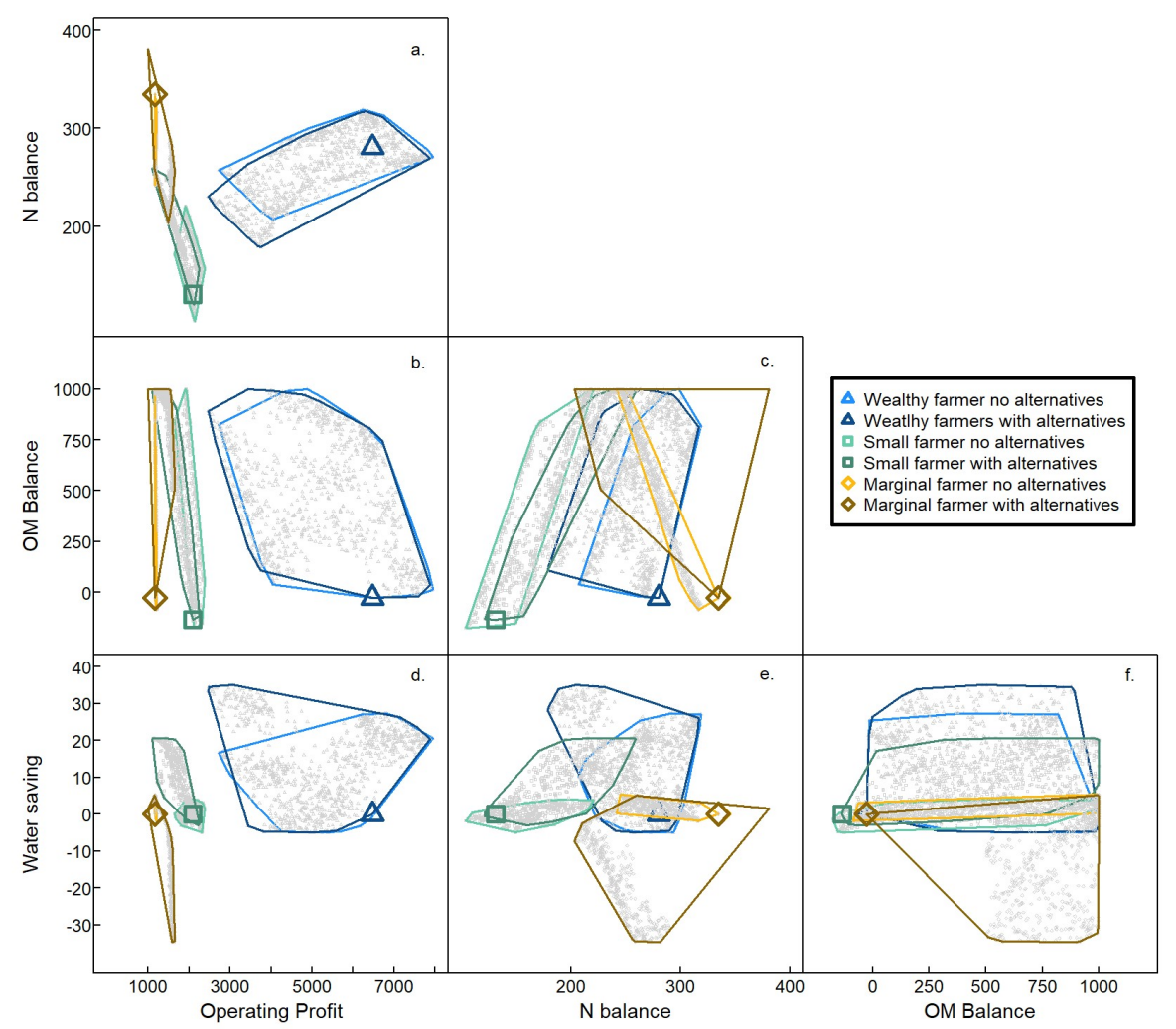

Figure 3.5: Relations among objectives after multi-objective optimization with and without the option to include alternative cropping patterns with mung bean. Objectives were minimizing nitrogen $(\mathrm{N})$ balance $(\mathrm{kg} / \mathrm{ha} / \mathrm{year}$; a, c, e) and maximizing organic matter $(\mathrm{OM})$ balance $(\mathrm{kg} / \mathrm{ha} /$ year; $b, \mathrm{c}, \mathrm{f})$, water saving $(\%$; $, \mathrm{e}, \mathrm{f})$ and operating profit (USD/year; a, b, d) Each grey dot represents a farming system configuration, resulting in two sets of alternatives for each farm: one with and one without the option to include alternative cropping patterns with mung bean. The symbols (triangle, square, diamond) represent the original performance on the objectives. 


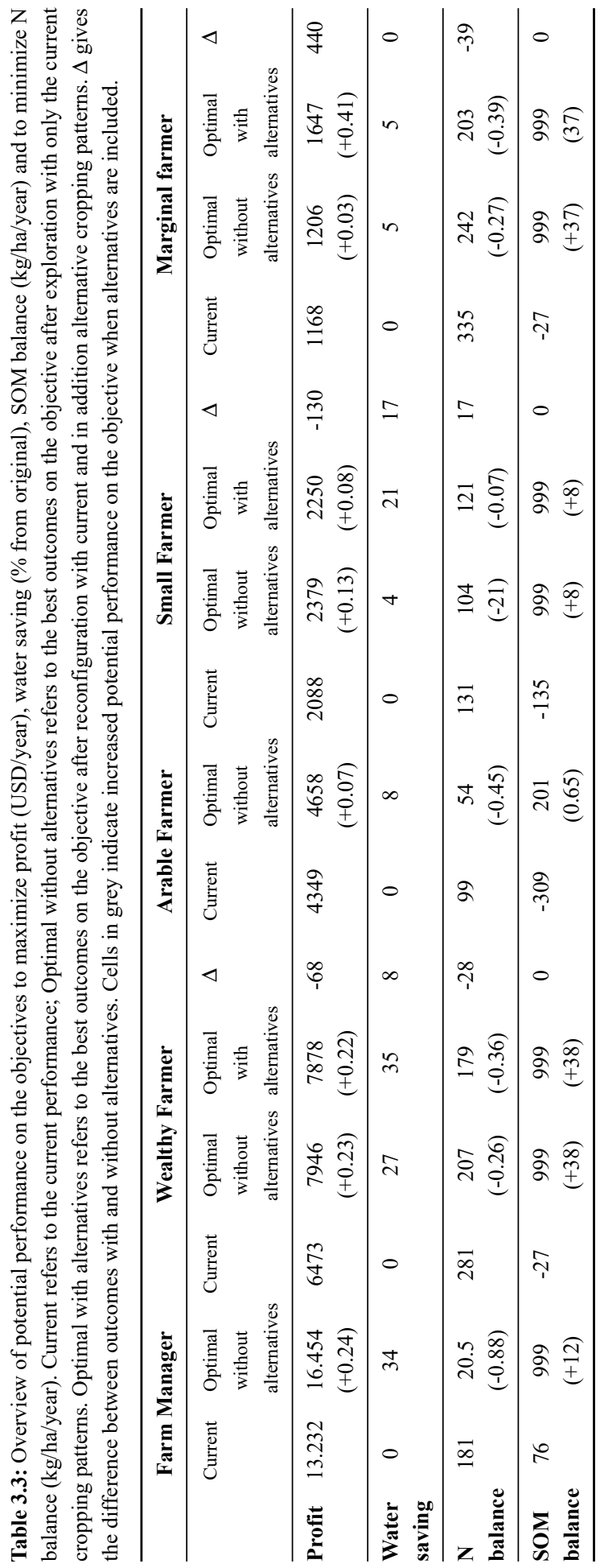




\section{Discussion}

In cereal-based systems, inclusion of short duration mung bean during the summer season showed positive results in on-station (H. Jat et al., 2018; R. D. Jat et al., 2018; Hossain et al., 2016) as well as in on-farm trials (Choudhary et al., 2018). In this study we explore the economic and environmental impact of cropping patterns with mung bean for five contrasting farm types. The multi-objective optimization model FarmDESIGN was used to generate sets of farm configurations with, and without alternative cropping systems maize-wheat-mung bean, maize-mustard-mung bean and rice-wheat-mung bean in addition to reconfiguration of land allocation for current cropping activities.

When allowing re-configuration with their current cropping patterns all farms showed potential to improve soil fertility (i.e. increased SOM balance), reduce $\mathrm{N}$ losses and improve $\mathrm{N}$ use efficiency (i.e. $\mathrm{N}$ balance). These environmental indicators could especially be improved with adjusted residue management. The Farm Manager and Wealthy Farmer showed potential to increase their profit and save water after reconfiguration with their current activities (without alternative cropping patterns) while these objectives showed limited room for improvement for the other farmers. With highest crop diversity, land size, organic matter balance and operating profit, the Farm Manager and Wealthy Farmer could be considered relatively highly resource endowed farm household. Their greater set of options together with their farm size, resulted in a larger outcome space. As Michalscheck et al. (2018) and Brown et al. (2018) point out, higher resource endowed farmers had larger room to manoeuvre: with more resources to reallocate, greater improvements in their objectives were found. The Arable, Small and Marginal Farmers were more constrained in crop diversity, labour or farm size and showed smaller outcome spaces after reconfiguration with FarmDESIGN when compared to the Farm Manager and Wealthy Farmer.

The model exploration, when given the opportunity to include alternative cropping patterns, did not result in the same magnitude of potential positive change for all farms as the field trials did. For the Farm Manager and Arable Farmer, reconfiguration with current cropping patterns led to greater outcomes on the objectives than when cropping patterns with mung bean were included. As shown in Figure 3.4, the current cropping patterns of these farms outperformed the alternatives on the objectives assessed, indicating that the configuration of the current cropping patterns in combination with farm assets, define the potential for alternative cropping patterns. For the other farm types (Wealthy Farmer, Small Farmer and Marginal Farmer) the alternative 
cropping patterns enabled larger outcome spaces, but there were no farm configurations which improved performance for all objectives. These results may nuance the findings from field-level experiments with mung bean: the potential positive impact of alternative cropping patterns with mung bean depends on farm type.

Originally, mung bean was proposed as sustainable intensification measure for the predominant cereal-based systems. However, in addition to cereals, vegetables, fodder-and cash crops were cultivated in combination with fruit trees (Table 3.2). The five farms cultivated 16 unique cropping patterns. From these 16 cropping patterns, only three combined wheat and rice (rice+maize-wheat-mung bean (Well-endowed Farmer); rice-wheat + mustard-fallow (Small Farmer) and rice-wheat-fallow (Marginal Farmer)). It can be questioned to what extent the farms assessed in this study were in need of alternative cropping patterns to diversify their cereal-cereal system. Moreover, most cereal-vegetable and cereal-legume combinations showed comparable or better performance on the objectives assessed. However, the majority of the cropping patterns (12 out of 16) had at least one fallow season, leaving room for sustainable intensification. Risk aversion may be one of the reasons to leave the summer season fallow as early onset of monsoon rains could cause yield losses.

Mung bean fits within strategies such as CSA and CA as a nitrogen fixing crop that contributes to soil fertility and provides ground cover and additional nutritional grain as crop product. CA-based management practices related to tillage (zero tillage), planting (permanent raised bed) and residue management (retention of residues on soil surface as mulch instead of burning) were promoted simultaneously with cultivating the fallow period, all to enhance systems-productivity, improve economic profitability, resource use efficiency and resilience to climatic risk (H. S. Jat et al., 2019; M. L. Jat, 2017; R. K. Jat et al., 2014). In this study, we isolated cultivation of mung bean in the summer season from other practices and assessed the potential inclusion of the modified cropping pattern. Synergistic effects of the mung bean in the succeeding crop and the effect of other CA practices when implemented simultaneously, can be expected both agronomically (H. S. Jat et al., 2019; H. Jat et al., 2018; Keil et al., 2015; Parihar et al., 2016) and managerially (e.g. less time required for land preparation). Aggregating CA practices could be a next step to assess the potential improvement in objectives and change in outcome spaces. In the design of such a modelling study the accessibility of CA-based machinery (e.g. happy seeder, multi-crop bed planters) should be taken into account as these are not accessible by all farm types given their plot-sizes and socio-economic status. Opportunities may 
however change with time, as internal agroecosystem processes as well as external drivers and influences regulate resource availability. The outcome space may expand if new technologies or knowledge becomes available as demonstrated in Figure 3.5, while it could be further modified if environmental conditions, product prices or subsidy policies change (Groot et al., 2016).

Nevertheless, it can be questioned to what extent these sustainable intensification measures with their associated (economic) risks are enough to sustainably develop this vulnerable and populous state. Farm size is likely to decrease with each generation, and with the majority of inhabitants living in rural areas, dependent on agriculture, this would likely result in an increase of small and marginal farms for which economic viability is a major challenge. Although development planners promote cereal production to make Bihar part of the 'cereal bowl of the country' (Government of India, 2016; Laik et al., 2014), it can be questioned if the growing food demand can be met, whilst also improving the livelihood of farmers and not negatively affect the farms natural resources. The Arable Farmer, Small Farmer and Marginal Farmer in this study represented the lower resource endowed farm types in this region and together made up $60 \%$ of the farms from the typology of Lopez-Ridaura et al. (2018). As our results show especially limited room to manoeuvre for these farms, more radical rethinking of these farming systems may be another way to meet the objectives of among others CSA. To inform the research agendas for on-farm experiments, future modelling studies could entail using larger sets of alternatives and using techniques that allow more complex system re-designs (Behera and France, 2016; Pretty, 2018). As part of this future research, crop-livestock interactions could also be studied as a promising livelihood strategy (Erenstein and Thorpe, 2010). Furthermore, analysis of a larger number of farms per type would also give more insight into the diversity within types, enabling better translation to farm types and better extrapolation of the results. Such improvements are still labour intensive both in the stage of data collection as in data analysis, but once the diversity of farms and the differentiated impact of alternatives is well understood, model-based explorations could contribute to more nuanced and distinct targeting of interventions at field level.

\section{Conclusions}

In this study we assessed the potential of integration of intensified cropping systems with mung bean to improve multiple objectives for five farms, each representing a farm type in Samastipur, Bihar. We found large performance variation on objective values among farms, 
indicating heterogeneity in the farming community, leading to differentiated potential to improve systems' performance. Reconfiguring cropping patterns gave all five farms options to save water, increase soil organic matter content and decrease nitrogen losses but showed trade-offs with operating profit. Larger and higher resource endowed farms (Farm Manager and Wealthy Farmer) had more options to favourably rearrange the farm resulting in the largest outcome spaces on multiple objectives. The Arable Farmer, Small Farmer and Marginal Farmer showed considerably smaller potential to improve the overall performance of the farm. Alternative cropping patterns rice-wheat-mung bean; maize-wheat-mung bean and maize-mustard-mung bean showed potential as sustainable intensification strategies for the Wealthy Farmer, Small Farmer and Marginal Farmer. The Farm Manager and Arable Farmer would not benefit from the new cropping patterns with mung bean as their initial cropping patterns outperformed the alternatives and more favourable farm configurations were obtained without these alternative cropping patterns. In practical terms, our results suggest that policies and programs aiming at the sustainable intensification of cereal-based cropping systems in Bihar should target their strategies per farm type. Along with the alternative cropping patterns with mung bean, additional efforts are needed to be carried out to sustainably intensify at the whole-farm level. Discussing options with farmers and other decision makers in a participatory fashion, might boost the potential of the model-based approach presented here and enhance further our understanding on the challenges and opportunities for farmers.

\section{Acknowledgements}

We acknowledge the financial and technical support from CGIAR Research Programs on Climate Change, Agriculture and Food Security (CCAFS) and Wheat Agri-food Systems (WHEAT), and all donors who supported this research through their contributions to the CGIAR Fund. For a list of Fund donors please see: http://www.cgiar.org/our-funders/. Furthermore, we thank the farmers for their time and for sharing their experiences and expertise, and the anonymous referees for their useful comments that helped us to improve the paper. The contribution of JCJG was supported by the Senior Expert program of the Dutch Science Council (NWO), grant number 17222. 


\section{References}

Adelhart Toorop, R., Lopez-Ridaura, S., Bijarniya, D., Kalawantawanit, E., Jat, R. K., Prusty, A. K., Jat, M. L., and Groot, J. C. (2020), Farm-level exploration of economic and environmental impacts of sustainable intensification of rice-wheat cropping systems in the Eastern Indo-Gangetic plains. European Journal of Agronomy. 121: p. 126157.

Alvarez, S., Timler, C. J., Michalscheck, M., Paas, W., Descheemaeker, K., Tittonell, P., Andersson, J. A., and Groot, J. C. (2018), Capturing farm diversity with hypothesis-based typologies: An innovative methodological framework for farming system typology development. PLoS ONE. 13(5): p. 1-24.

Behera, U. K. and France, J. (2016), Integrated Farming Systems and the Livelihood Security of Small and Marginal Farmers in India and Other Developing Countries. Advances in Agronomy. 138: p. 235-282.

Borlaug Institute for South Asia (2015), Major Accomplishments 2012-2014. Tech. rep. New Delhi: Borlaug Institute for South Asia.

Brown, P. R., Afroz, S., Chialue, L., Chiranjeevi, T., El, S., Grünbühel, C. M., Khan, I., Pitkin, C., Reddy, V. R., and Roth, C. H. (2018), Constraints to the capacity of smallholder farming households to adapt to climate change in South and Southeast Asia. Climate and Development. 0(0): p. 1-18.

Chhabra, V. and Haris, A. A. (2015), Climate Variability, Extreme Rainfall and Temperature Events over Different Agro-ecological Zones of Bihar. Journal of AgriSearch. 2(3): p. 189-194.

Choudhary, K., Jat, H., Nandal, D., Bishnoi, D., Sutaliya, J., Choudhary, M., Yadvinder-Singh, Sharma, P., and Jat, M. (2018), Evaluating alternatives to rice-wheat system in western Indo-Gangetic Plains: Crop yields, water productivity and economic profitability. Field Crops Research. 218(November 2017): p. 1-10.

Deb, K., Agrawal, S., and Pratap, M. (2002), A fast elitist non-dominated sorting genetic algorithm for multi-objective optimization: NSGA-II. IEEE Transactions in Evolutionary Computation. 6: p. 182-197.

Ditzler, L., Komarek, A. M., Chiang, T.-W., Alvarez, S., Chatterjee, S. A., Timler, C., Raneri, J. E., Carmona, N. E., Kennedy, G., and Groot, J. C. J. (2019), A model to examine farm household trade-offs and synergies with an application to smallholders in Vietnam. Agric. Syst. 173(1): p. 49-63.

Erenstein, O. (2011), Cropping systems and crop residue management in the Trans-Gangetic Plains: Issues and challenges for conservation agriculture from village surveys. Agric. Syst. 104(1): p. 54-62.

Erenstein, O. and Thorpe, W. (2010), Crop-livestock interactions along agro-ecological gradients: a meso-level analysis in the Indo-Gangetic Plains, India. Environment, Development and Sustainability. 12(5): p. 669-689.

Government of India (2016), All India Report on Input Survey 2011-12. Tech. rep., p. 521.

Groot, J. C. J., Cortez-Arriola, J., Rossing, W. A. H., Améndola Massiotti, R. D., and Tittonell, P. (2016), Capturing agroecosystem vulnerability and resilience. Sust. 8(11): p. 1206.

Groot, J. C. J., Jellema, A., and Rossing, W. A. (2010), Designing a hedgerow network in a multifunctional agricultural landscape: Balancing trade-offs among ecological quality, landscape character and implementation costs. European Journal of Agronomy. 32(1): p. 112-119.

Groot, J. C. J., Oomen, G. J. M., and Rossing, W. A. H. (2012), Multi-objective optimization and design of farming systems. Agric. Syst. 110: p. 63-77.

Groot, J. C. J. and Rossing, W. A. H. (2011), Model-aided learning for adaptive management of natural resources: an evolutionary design perspective. Methods Ecol. Evol. 2(6): p. 643-650.

Groot, J. C. J., Rossing, W. A., Jellema, A., Stobbelaar, D. J., Renting, H., and Van Ittersum, M. K. (2007), Exploring multi-scale trade-offs between nature conservation, agricultural profits and landscape quality-A methodology to support discussions on land-use perspectives. Agriculture, Ecosystems and Environment. 120(1): p. 58-69.

Herrero, M., Thornton, P. K., Bernués, A., Baltenweck, I., Vervoort, J., van de Steeg, J., Makokha, S., van Wijk, M. T., Karanja, S., Rufino, M. C., and Staal, S. J. (2014), Exploring future changes in smallholder farming systems by linking socio-economic scenarios with regional and household models. Global Environmental Change. 24(1): p. $165-182$.

Herrero, M., Thornton, P. K., Power, B., Bogard, J. R., Remans, R., Fritz, S., Gerber, J. S., Nelson, G., See, L., Waha, K., Watson, R. A., West, P. C., Samberg, L. H., van de Steeg, J., Stephenson, E., van Wijk, M., and Havlík, P. (2017), Farming and the geography of nutrient production for human use: a transdisciplinary analysis. The Lancet Planetary Health. 1(1): e33-e42.

Hossain, M. S., Hossain, A., Sarkar, M. A. R., Jahiruddin, M., da Silva, J. A. T., and Hossain, M. I. (2016), Productivity and soil fertility of the rice-wheat system in the High Ganges River Floodplain of Bangladesh is influenced by the inclusion of legumes and manure. Agriculture, Ecosystems and Environment. 218: p. 40-52.

Jat, H., Datta, A., Sharma, P. C., Kumar, V., Yadav, A. K., Choudhary, M., Choudhary, V., Gathala, M. K., Sharma, D. K., Jat, M. L., Yaduvanshi, N. P., Singh, G., and McDonald, A. (2018), Assessing soil properties and nutrient availability under conservation agriculture practices in a reclaimed sodic soil in cereal-based systems of North-West India. Archives of Agronomy and Soil Science. 64(4): p. 531-545. 
Jat, H. S., Kumar, P., Sutaliya, J., Kumar, S., Choudhary, M., Singh, Y., and Jat, M. L. (2019), Conservation agriculture based sustainable intensification of basmati rice-wheat system in North-West India. Archives of Agronomy and Soil Science. 00(00): p. 1-17.

Jat, M. L., Gathala, M. K., Saharawat, Y.S., Tetarwal, J.P., and Gupta, R. (2013), Double no-till and permanent raised beds in maize-wheat rotation of north-western Indo-Gangetic plains of India: Effects on crop yields, water productivity, profitability and soil physical properties. Field Crops Res. 149: p. 291-299.

Jat, M. L. (2017), Climate smart agriculture in intensive cereal based systems: Scalable evidence from Indo-Gangatic Plains. Belavadi, V.V., Nataraja Karaba, N., Gangadharappa, N.R. (Eds.), Book: Agriculture under Climate Change: Threats, Strategies, Policies Books, Agriculture under Climate Change: Threats, Strategies, and Policies., p. 147-154.

Jat, R. D., Jat, H.S., Nanwal, R. K., Yadav, A. K., Bana, A., Choudhary, K. M., Kakraliya, S. K., Sutaliya, J. M., Sapkota, T. B., and Jat, M. L. (2018), Conservation agriculture and precision nutrient management practices in maize-wheat system: effects on crop and water productivity and economic profitability. Field Crops Res. 222(March): p. 111-120.

Jat, R., Singh, R. G., Kumar, M., Jat, M., Parihar, C. M., Bijarniya, D., Sutaliya, J. M., Jat M.K, Parihar, M., Kakraliya, S. K., and Gupta, R. K. (2018), Ten years of conservation agriculture in a rice-maize rotation of Eastern Gangetic Plains of India: Yield trends, water productivity and economic profitability. Field Crops Research. 232(April 2018): p. $1-10$.

Jat, R. K., Sapkota, T. B., Singh, R. G., Jat, M., Kumar, M., and Gupta, R. K. (2014), Seven years of conservation agriculture in a rice-wheat rotation of Eastern Gangetic Plains of South Asia: Yield trends and economic profitability. Field Crops Research. 164(1): p. 199-210.

Keil, A., D'souza, A., and McDonald, A. (2015), Zero-tillage as a pathway for sustainable wheat intensification in the Eastern Indo-Gangetic Plains: does it work in farmers' fields? Food Security. 7(5): p. 983-1001.

Krishna, M. and Kumari, S. (2014), AGRICULTURAL SCENARIO OF BIHAR -. Jharkhand Journal of Social Development. VII(1): p. 1-11.

Kuivanen, K. S., Alvarez, S., Michalscheck, M., Adjei-Nsiah, S., Descheemaeker, K., Mellon-Bedi, S., and Groot, J. C. (2016), Characterising the diversity of smallholder farming systems and their constraints and opportunities for innovation: A case study from the Northern Region, Ghana. NJAS - Wageningen Journal of Life Sciences. 78: p. 153-166.

Kuivanen, K., Michalscheck, M., Descheemaeker, K., Adjei-Nsiah, S., Mellon-Bedi, S., Groot, J., and Alvarez, S. (2016), A comparison of statistical and participatory clustering of smallholder farming systems - A case study in Northern Ghana. Journal of Rural Studies. 45: p. 184-198.

Laik, R., Sharma, S., Idris, M., Singh, A. K., Singh, S. S., Bhatt, B. P., Saharawat, Y., Humphreys, E., and Ladha, J. K. (2014), Integration of conservation agriculture with best management practices for improving system performance of the rice-wheat rotation in the Eastern Indo-Gangetic Plains of India. Agriculture, Ecosystems and Environment. 195: p. 68-82.

Lopez-Ridaura, S., Frelat, R., Van Wijk, M. T., Valbuena, D., Krupnik, T. J., and Jat, M. L. (2018), Climate smart agriculture, farm household typologies and food security: An ex-ante assessment from Eastern India. Agric. Syst. 159(September 2016): p. 57-68.

Michalscheck, M., Groot, J. C., Kotu, B., Hoeschle-Zeledon, I., Kuivanen, K., Descheemaeker, K., and Tittonell, P. (2018), Model results versus farmer realities. Operationalizing diversity within and among smallholder farm systems for a nuanced impact assessment of technology packages. Agricultural Systems. 162(February): p. 164-178.

Otten, J. J., Hellwig, J. P., and Meyers, L. D. (2006), Dietary Energy Intakes the Essential Guide to Nutrient Requirements. National Academies Press.

Parihar, C. M., Jat, S. L., Singh, A. K., Kumar, B., Pradhan, S., Pooniya, V., Dhauja, A., Chaudhary, V., Jat, M. L., and Jat, R. K. (2016), Conservation agriculture in irrigated intensive maize-based systems of north-western India: effects on crop yields, water productivity and economic profitability. Field Crops Research. 193: p. 104-116.

Pretty, J. (2018), Intensification for redesigned and sustainable agricultural systems. Science. 362(6417): eaav0294.

Price, K. and Storn, R. (1997), Differential Evolution - A Simple and Efficient Heuristic for Global Optimization over Continuous Spaces. Journal of Global Optimization. (11): p. 341-359.

Rufino, M. C., Quiros, C., Boureima, M., Desta, S., Douxchamps, S., Herrero, M., Kiplimo, J., Lamissa, D., Mango, J., Moussa, A. S., Naab, J., Ndour, Y., Sayula, G., Silvestri, S., Singh, D., Teufel, N., and Wanyama, I. (2013), Developing generic tools for characterizing agricultural systems for climate and global change studies (IMPACTlite - phase 2). Copenhagen: CGIAR Research Program on Climate Change, Agriculture and Food Security (CCAFS). (January): p. $1-42$.

Saharawat, Y. S., Singh, B., Malik, R. K., Ladha, J. K., Gathala, M., Jat, M. L., and Kumar, V. (2010), Evaluation of alternative tillage and crop establishment methods in a rice-wheat rotation in North Western IGP. Field Crops Research. 116(3): p. 260-267. 
Sehgal, V. K., Singh, M. R., Chaudhary, A., Jain, N., and Pathak, H. (2013), Vulnerability of agriculture to climate change: District level assessment in the Indo-gangetic Plains. Tech. rep. New Delhi.

Sharma, P. C., Datta, A., Yadav, A. K., Choudhary, M., Jat, H. S., and McDonald, A. (2018), Effect of Crop Management Practices on Crop Growth, Productivity and Profitability of Rice-Wheat System in Western Indo-Gangetic Plains. Proceedings of the National Academy of Sciences, India Section B: Biological Sciences. (April): p. 1-13.

Singh, U., Sing, Y., Kumar, V., and Ladha, J. (2009), Evaluation and promotion of resource conserving tillage and crop establishment techniques in rice-wheat system in Eastern India. In: Ladha, J.K. (Ed.), Integrated Crop and Resource Management in the Rice-Wheat Systems of South Asia. International Rice Research Institute, Los Baños, Philippines, p. 151-176.

Timler, C., Alvarez, S., DeClerck, F., Remans, R., Raneri, J., Estrada Carmona, N., Mashingaidze, N., Abe Chatterjee, S., Chiang, T. W., Termote, C., Yang, R. Y., Descheemaeker, K., Brouwer, I. D., Kennedy, G., Tittonell, P. A., and Groot, J. C. (2020), Exploring solution spaces for nutrition-sensitive agriculture in Kenya and Vietnam. Agricultural Systems. 180(1): p. 102774.

Tittonell, P., Muriuki, A., Shepherd, K. D., Mugendi, D., Kaizzi, K. C., Okeyo, J., Verchot, L., Coe, R., and Vanlauwe, B. (2010), The diversity of rural livelihoods and their influence on soil fertility in agricultural systems of East Africa-A typology of smallholder farms. Agric. Syst. 103(2): p. 83-97.

\section{Supplementary Materials}

Supplementary data to this article can be found online at https://doi.org/10.1016/j.eja.2020.126157. 



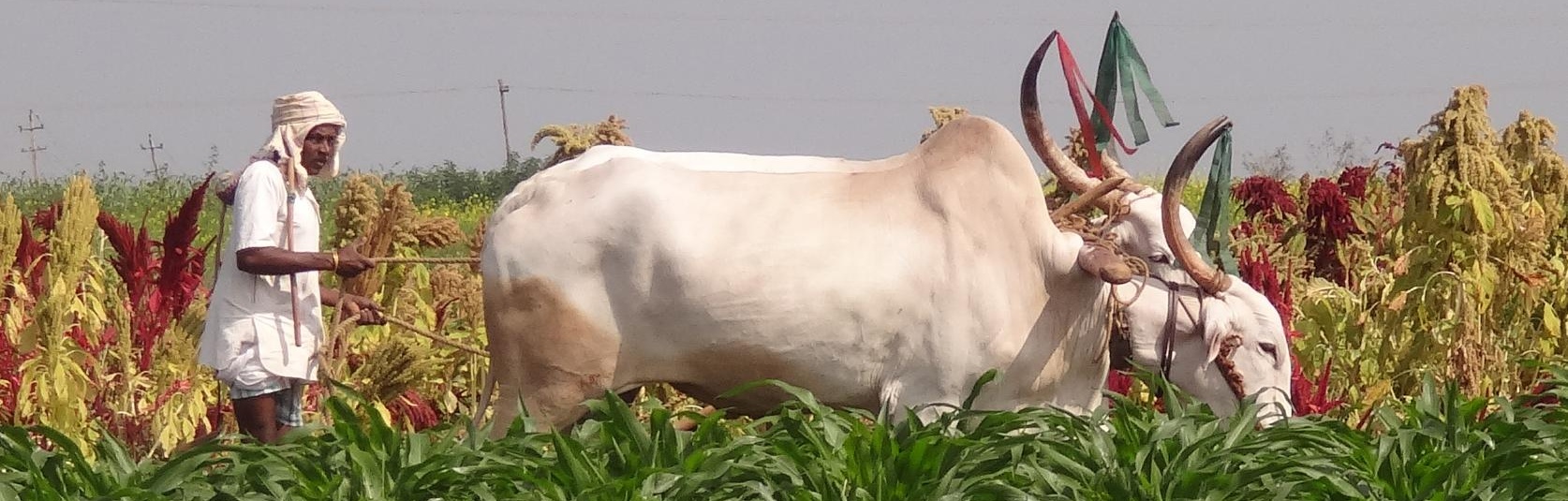

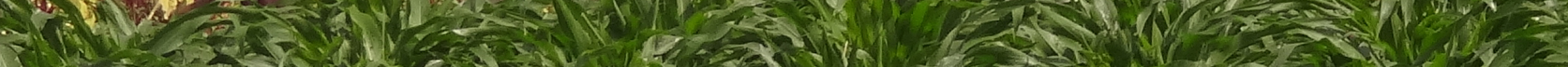

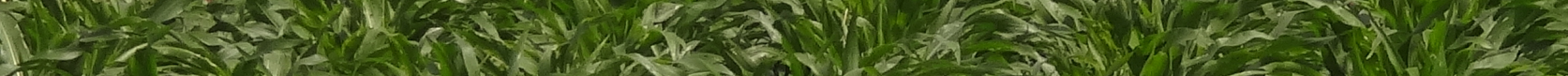

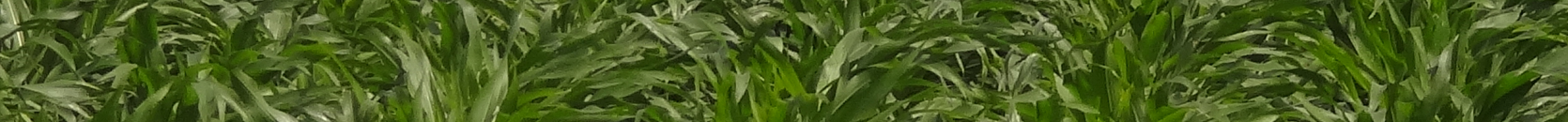

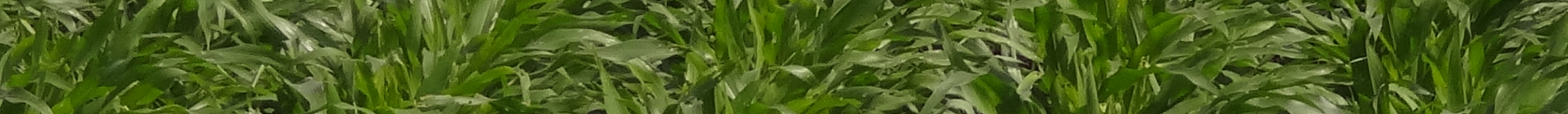

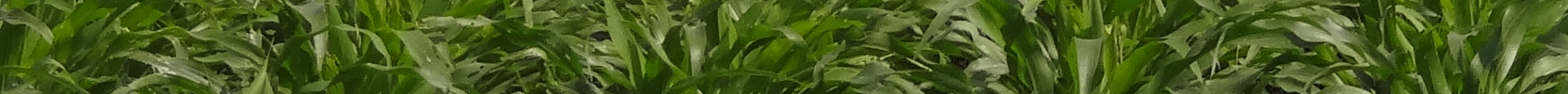

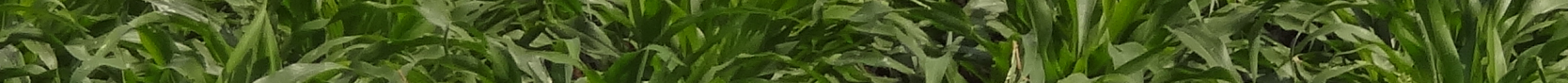
15
1

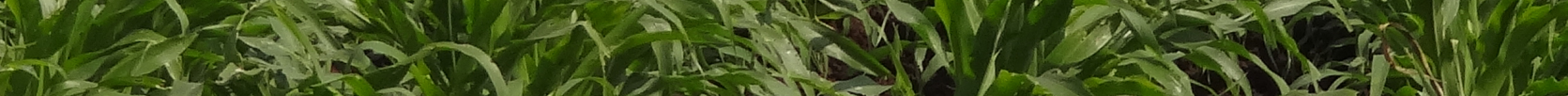

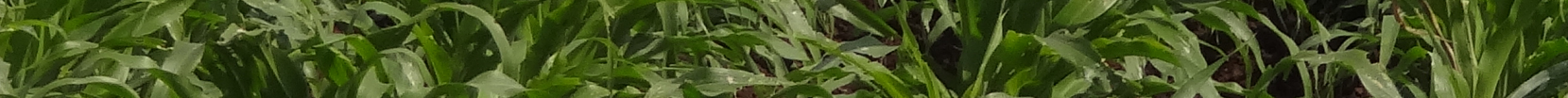
The s. s. S. 


\section{Chapter 4}

Using a positive deviance approach to inform farming systems redesign: a case study from Bihar, India

Roos de Adelhart Toorop*, Viviana Ceccarelli*, Deepak Bijarniya, Mangi Lal Jat, Raj Kumar Jat, Santiago Lopez-Ridaura, Jeroen C.J. Groot

*shared first authorship

Published as: Adelhart Toorop, R., Ceccarelli, V., Bijarniya, D., Jat, M. L., Jat, R. K., Lopez-Ridaura, S., and Groot, J.C. (2020), Using a positive deviance approach to inform farming systems redesign: A case study from Bihar, India. Agricultural Systems. 185(February): p. 102942 


\section{Abstract}

Improving farming systems in resource-poor contexts is often difficult, as farmers face multiple challenge to implement the innovations developed by researchers. On the other hand, viable solutions may be already present within local communities by positive deviant farmers This study develops a positive deviance informed methodology to support redesign of farming systems in Bihar, India, with the aim to improve farm productive, economic and environmental performances. We tested the methodology using survey data from 43 farms and the indicators of operating profit, soil organic matter balance, water use and dietary energy production. Positive deviant farms and practices were first identified and then recombined into a redesign in consultation with farmers. The FarmDESIGN model was used to calculate current farm performance and to explore potential alternative farm configurations in the redesign. We found that outstanding performance on all indicators could only be reached by integrating high livestock density with an optimal combination of crop practices, which confirms the key role of interactions among components in mixed crop-livestock systems to improve all dimensions of farm sustainability. The redesigns outperformed all real farms on the indicators assessed. Farmers confirmed the viability of the redesigns in focus group discussions and their suggestions can serve as useful input for a next cycle of farm redesign. Since all suggestions are locally practiced and have proven to be accessible, affordable and recognizable, we conclude that our methodology based on positive deviant farms and practices yields promising results with a large potential to boost agricultural development for resource-scarce smallholder farmers.

Keywords: FarmDESIGN model, Multi-objective optimization, soil organic matter balance, dietary energy, mixed crop-livestock systems, farm typology 


\section{Introduction}

The Indo-Gangetic Plains of India are the main food producing region of the country with intensive cereal-based agriculture sustaining millions of people with food and income. However, there is a strong productivity gradient from west to east, with Bihar being one of the poorest states (R. K. Jat et al., 2014; Laik et al., 2014) with about $41 \%$ of the population living below the poverty line (World Bank, 2016). The state's economy is mostly based on the agricultural sector which contributes to one fourth of its Gross Domestic Product and employs $81 \%$ of its population (Government of Bihar, 2012). Bihar's agriculture faces multiple challenges, including low farm income and substantial productivity gaps (Shirsath et al., 2017), natural resource degradation (Erenstein and Thorpe, 2011), and increasing drought occurrence due to climate change (Shirsath et al., 2017).

In recent years, the Government of India has introduced an ambitious reform agenda for Indian agriculture which includes the goals of doubling farmers' income by 2022 and further improving national food security (Chand, 2017). Given Bihar's high potential to significantly increase its agricultural production, the Government of India plans to transform this state into the 'future food bowl' of the country by boosting cereal and livestock production (Government of Bihar, 2012; Laik et al., 2014). To this aim, Climate Smart Agriculture (CSA) techniques and other sustainable intensification practices have been widely promoted in Bihar (R. K. Jat et al., 2014; Laik et al., 2014). However, despite extensive efforts and good results obtained in experimental trials, the adoption of these new technologies remains low in Bihar as farmers are hindered by multiple constraints such as small landholdings and limited access to mechanization (Aryal et al., 2018).

Model-aided redesign of farming systems can substantially improve farm performances even in the context of low resource endowment and other socio-economic constraints. Instead of relying on the introduction of new technologies, the redesign can focus on using the room to manoeuvre inside the current farms by optimizing resource allocation and redistributing practices already in use (Dogliotti et al., 2014). From this perspective, whole-farm modelling represents a powerful tool to inform farm redesign because it can explore a large set of alternative farm configurations and evaluate the impact of these changes (Thornton and Herrero, 2001; Janssen and van Ittersum, 2007; Le Gal et al., 2011; Jones et al., 2017). However, despite the fact that the redesign process can considerably benefit from large diversity of alternatives (van Noordwijk et al., 2001; Dogliotti et al., 2003), modelling studies usually focus on a rather small number of practices 
(Dogliotti et al., 2003; Dogliotti et al., 2005). On the other hand, the limited computing capacity of mathematical programming could not process large combinatorial problems and, therefore, a preliminary selection of practices is always required (Dogliotti et al., 2003; Groot et al., 2010).

The positive deviance approach can provide an interesting technique to explore the farm diversity and select a subset of efficient practices from the multitude of current farmers' practices. Positive deviants are defined as individuals that achieve better outcomes than their peers despite having the same resources and constraints. The better performance can be achieved due to an innovative use of available assets, inputs and processes (i.e. positive deviant practices) (Marsh et al., 2004; Pant and Odame, 2009). Compared to innovations developed and promoted by researchers, farmers' positive deviant practices are already used in the biophysical and socio-economic context and therefore can be assumed accessible, affordable, tailored to local conditions and possibly transferable to other farmers (Marsh et al., 2004; Bradley et al., 2009). At the same time, they also already represent the most successful practices within the population and therefore represent a good starting point for a redesign procedure. However, although the positive deviance approach has been extensively used in the field of nutrition and health (Ahrari et al., 2002; Bolles et al., 2002; Mackintosh et al., 2002; Marsh et al., 2002), its application in the agricultural context remains limited.

Existing studies on positive deviance in agriculture are mostly descriptive reviews, using normative approaches to identify positive deviants (Ochieng, 2007; Biggs, 2008; Pant and Odame, 2009; Amankwah et al., 2012). Positive deviants are broadly defined as the 'best' farmers and are named by the community or local researchers, often without quantitative verification whether their performances are indeed better than the average. Furthermore, many studies focus on the single objective of profit (Amankwah, 2013; Savikurki, 2013) while the multi-objective nature of sustainability and agriculture requires a multi-criteria assessment of positive deviance, as introduced with the Pareto-optimality based method proposed by Modernel et al. (2018) and further employed by Steinke et al. (2019). Finally, up to now, positive deviant practices have been identified by qualitative comparison of farms and, to the best of our knowledge, there are no studies which have integrated the positive deviance approach in a redesign of farming systems. As such, this approach requires methodological specifications before it can be successfully implemented in the agricultural context. 
This study develops a positive deviance informed methodology to support redesign of farming systems in Bihar on the four indicators of operating profit, water use, soil organic matter (SOM) balance and dietary energy production. The methodology is tested using 43 farms divided into five farm types and the whole-farm model FarmDESIGN. The aim is to improve overall performance on the four indicators using positive deviant farms and practices as a starting point and the methodology is divided into four steps: (1) to identify positive deviant farms, (2) to identify positive deviant practices, (3) to combine identified positive deviant practices in a positive deviance informed redesign for further improvement of the overall farm performance, and (4) to investigate the relevance of the proposed redesigns for local farmers. Positive deviant farms and practices were identified based on a quantitative methodology, with positive deviants defined as farms that perform better the population mean on each of the selected indicators. In the redesign, we aimed to further improve positive deviant farms to performances twice compared to the population mean on each of the indicators. This goal was defined in order to change the overall balance at state level of region-wise targets (such as water use or dietary energy production) and to suggest appealing improvements for all farmers, not only for the poorer part of the population.

\section{Methodology}

\subsection{Study area and data collection}

Agriculture in Bihar is characterized by mixed crop-livestock farming systems. The year is divided into three seasons: rabi (winter, October-April), zaid (spring, April-June), kharif (monsoon, June-October). The predominant rotation is wheat-rice with wheat grown in rabi and rice grown in kharif, although maize is also very common and can be grown in any of the three seasons. In zaid, the short season between the harvest of wheat and the planting of rice, farmers generally grow some fast-growing crops or leave the land fallow. Cereals represent the main staple food for household food security, but other crops are also grown such as oilseeds, pulses and vegetables. Livestock mainly comprises cows or buffalos for milk production, while goats and chickens are rare and, especially goats, are associated with the poorest that cannot afford cows or buffalos. Livestock is mostly fed wheat and rice straw obtained from cereal cultivation, possibly complemented with green fodder, collected grass and small amount of compound feed. As the straw is either sold or used on farm as feed, it has a substantial contribution to the 
farm income. In this way, it hampers the adoption of CSA techniques which require the use of straw as mulch (Erenstein et al., 2007; Singh et al., 2013). Average milk production per animal is low due to the large proportion of unproductive animals and the poor rations. In general, livestock management is largely inefficient and there is large potential for increasing livestock production (Devendra et al., 2000; Erenstein et al., 2007).

In 2010-2011, an extensive household survey was conducted on farming systems and livelihood pursuits among 269 farms in Bihar. Farms were classified into five farm types based on functional and structural characteristics: part-time farmers (type 1), wealthy farmers (type 2), small-scale crop and livestock farmers (type 3), medium-scale cereal crop farmers (type 4) and resource-poor agricultural labourers (type 5) (Table 4.1) (Lopez-Ridaura et al., 2018). For this study, 43 farms were further selected to collect input for the FarmDESIGN model. This in-depth survey was conducted by local researchers and based on the IMPACTLIte survey from Rufino et al. (2013) and included detailed quantitative information on physical components (fields, animals, crops); inputs (labour, fertilizers, pesticides, seeds); outputs (income, yields, animal products) and management (adoption of CSA techniques) (Supplementary Materials 4A). The 43 farms were located in the districts of Muzzaffapur (Bakhari $(n=4)$ and Dighra $(n=4)$ ),

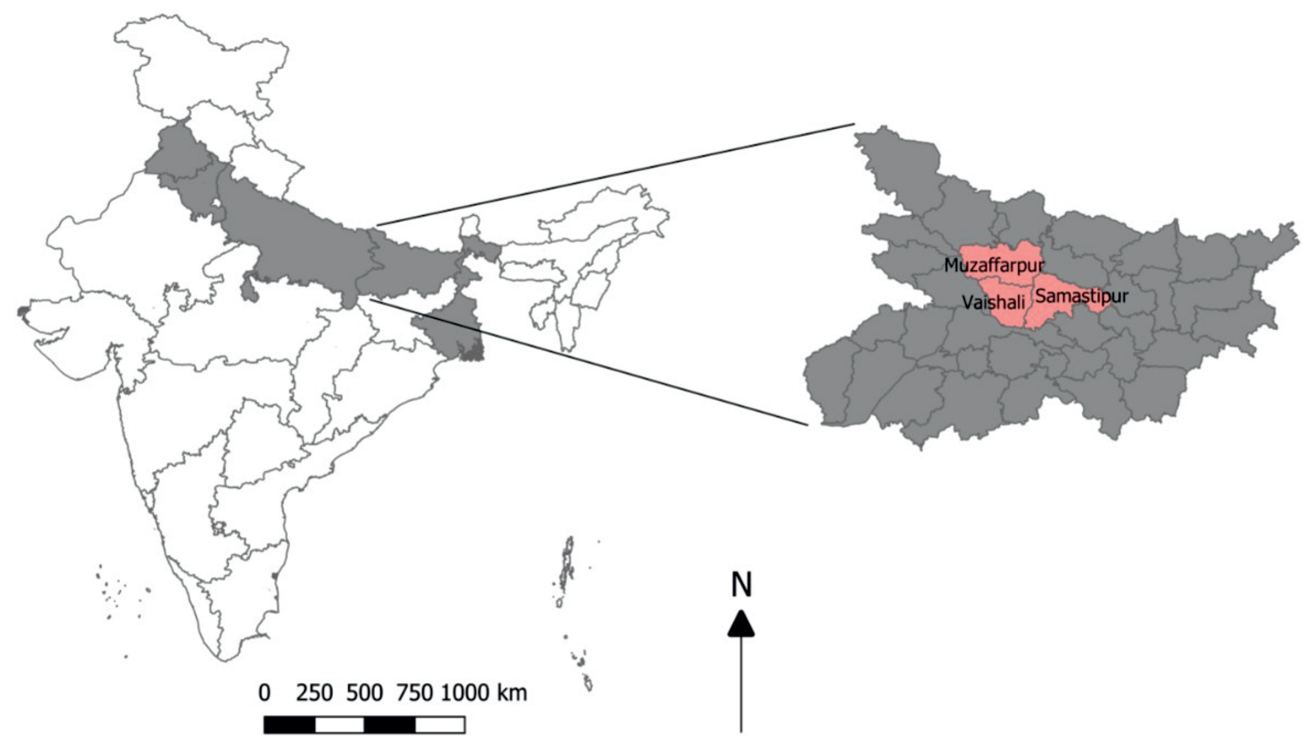

Figure 4.1: Map of India with the Indo-Gangetic Plains in grey and the state Bihar in detail with the districts Vaishali, Samastipur and Muzzaffapur in pink. 
Samastipur (Chandauli (n=5), Digambra ( $\mathrm{n}=7)$, Kuboli $(\mathrm{n}=3)$ and Repura $(\mathrm{n}=5))$ and Vaishali (Bajitpur ( $n=5)$, Bardiha $(n=5)$ and Nirpur $(n=5)$ ) (Figure 4.1). The selected villages were similar in terms of farming systems, soil and climate. We aimed to select one farm per village for each type, when this was not possible the type was omitted for the village (Table 4.2). The in-depth surveys on the 43 farms were conducted in 2016-2018.

Table 4.1: Distribution of the 43 farms entered in FarmDESIGN divided per village and farm type. We selected one farm per village for each type and when this was not possible the type was omitted for the village.

\begin{tabular}{|c|c|c|c|c|c|c|c|}
\hline \multirow[t]{2}{*}{ District } & \multirow[t]{2}{*}{ Village } & \multicolumn{5}{|c|}{ Number of farms } & \multirow[t]{2}{*}{ TOTAL } \\
\hline & & Type 1 & Type 2 & Type 3 & Type 4 & Type 5 & \\
\hline \multirow[t]{2}{*}{ Muzzaffapur } & Bakhari & 1 & 1 & 1 & 1 & 0 & 4 \\
\hline & Dighra & 1 & 0 & 1 & 1 & 1 & 4 \\
\hline \multirow[t]{4}{*}{ Samastipur } & Chaundali & 1 & 1 & 1 & 1 & 1 & 5 \\
\hline & Digambra & 1 & 1 & 2 & 1 & 2 & 7 \\
\hline & Kuboli & 1 & 1 & 0 & 1 & 0 & 3 \\
\hline & Repura & 1 & 1 & 1 & 1 & 1 & 5 \\
\hline \multirow[t]{3}{*}{ Vaishali } & Bajitpur & 1 & 1 & 1 & 1 & 1 & 5 \\
\hline & Bardiha & 1 & 1 & 1 & 1 & 1 & 5 \\
\hline & Nirpur & 1 & 1 & 1 & 1 & 1 & 5 \\
\hline TOTAL & & 9 & 8 & 9 & 9 & 8 & 43 \\
\hline
\end{tabular}

\subsection{FarmDESIGN}

FarmDESIGN is a static and exploratory whole-farm model that quantifies farm productive, economic and environmental performance on annual basis (Groot et al., 2012; Cortez-Arriola et al., 2016). The model can be used for both analysis of current farm performance and exploration of alternative management options. In the exploration process, the model performs a multi-objective optimization using a Pareto-based Differential Evolution algorithm which uses the current farm configuration as a starting point (Groot et al., 2012). The model optimizes the multiple objectives according to the indicated constraints and generates a large set (e.g., 500 , this can be specified by the user) of alternative configurations of farming systems by adjusting production activities and resource allocation, and evaluating their consequences on farm performances (Groot et al., 2012). As the Pareto-based multi-objective optimization does not present one single solution, the researcher can select one or multiple preferred farm 


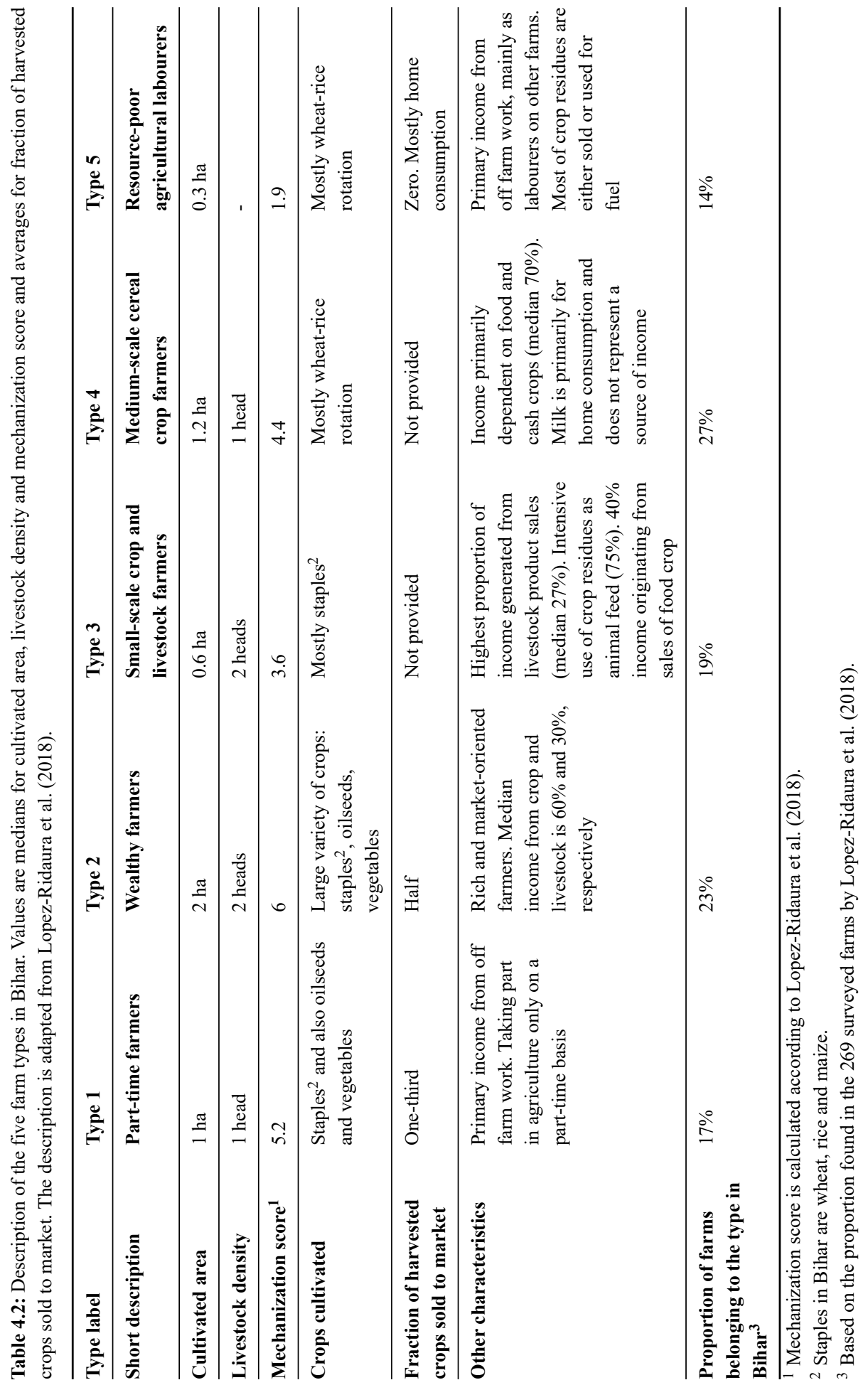


configurations according to further criteria and/or in consultation with stakeholder. A detailed description of the model is provided by Groot et al. (2012) and Ditzler et al. (2019), while applications of the model can be found in Cortez-Arriola et al. (2014), Flores-Sánchez et al. (2015), Mandryk et al. (2014), Cortez-Arriola et al. (2016), Groot et al. (2016), Michalscheck et al. (2018) and Timler et al. (2020). The model with example datasets is available online at: https://sites.google.com/site/farmdesignmodel/home.

\subsection{Selection of indicators}

1. The following four indicators were selected for the analysis: (1) operating profit, (2) soil organic matter (SOM) balance, (3) water use, and (4) dietary energy production. These indicators were chosen in consultation with local researchers and represent the main priorities for agriculture in Bihar (Erenstein and Thorpe, 2011; R. D. Jat et al., 2018; Lopez-Ridaura et al., 2018). All indicators are expressed on an annual basis and per hectare in order to allow the comparison between farms with different landholding sizes and were calculated as follows:

2. Operating profit (USD ha ${ }^{-1}$ year $^{-1}$ ) was calculated as the difference between the revenue obtained for crop and animal production and the costs including imported manure, fertilizers, pesticides, medical costs for livestock, feed costs and hired labour. All the economic data were converted from Indian rupees into USD using an exchange rate of 1 $\mathrm{USD}=71.42$ Indian rupees.

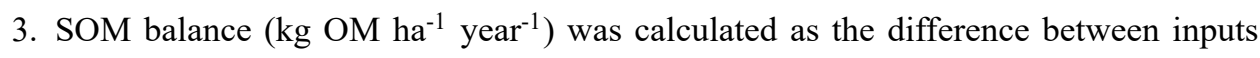
of organic matter into the soil (from crop roots and residues, green manure, and farm-produced and imported manures) and losses of organic matter (by degradation of active soil organic matter, degradation of added manure, and soil erosion).

4. Water use $\left(\mathrm{m}^{3}\right.$ water $\mathrm{ha}^{-1}$ year $\left.^{-1}\right)$ was calculated as the sum of the amount of irrigation water applied to each crop.

5. Dietary energy production (adults $\mathrm{ha}^{-1}$ year $^{-1}$ ) was calculated as the sum of dietary energy of each product used for human consumption. Dietary energy was calculated according to the Nutritional System Dietary Energy (DeFries et al., 2015) and was expressed as the number of consumer units (i.e. reference adults) who would be able to obtain $100 \%$ of their recommended Dietary Reference Intake for energy (Otten et al., 2006) from the total farm production. As indicators calculated on a kilocalorie basis are extensively used for food security (Frelat et al., 2016; Hammond et al., 2017a; Ritzema et al., 2017; 
Lopez-Ridaura et al., 2018), this study selected dietary energy production as a simple measure for national food security while it does not focus on farm food self-sufficiency or nutritional issues.

\subsection{Methodological framework}

The proposed methodological framework for positive deviance informed redesign is divided into four steps (Figure 4.2). First, positive deviant farms and practices were identified by a three-sub-steps nested assessment and, then, in subsequent steps positive deviant farms were further improved by recombination of positive deviant practices in FarmDESIGN and the results were discussed with farmers. As is typical for adaptive management and experiential learning cycles, there was a feedback-loop between design and stakeholder interaction (Kolb, 1984; Giller et al., 2008; Groot and Rossing, 2011). Each step of the methodology is described in the respective sections below.

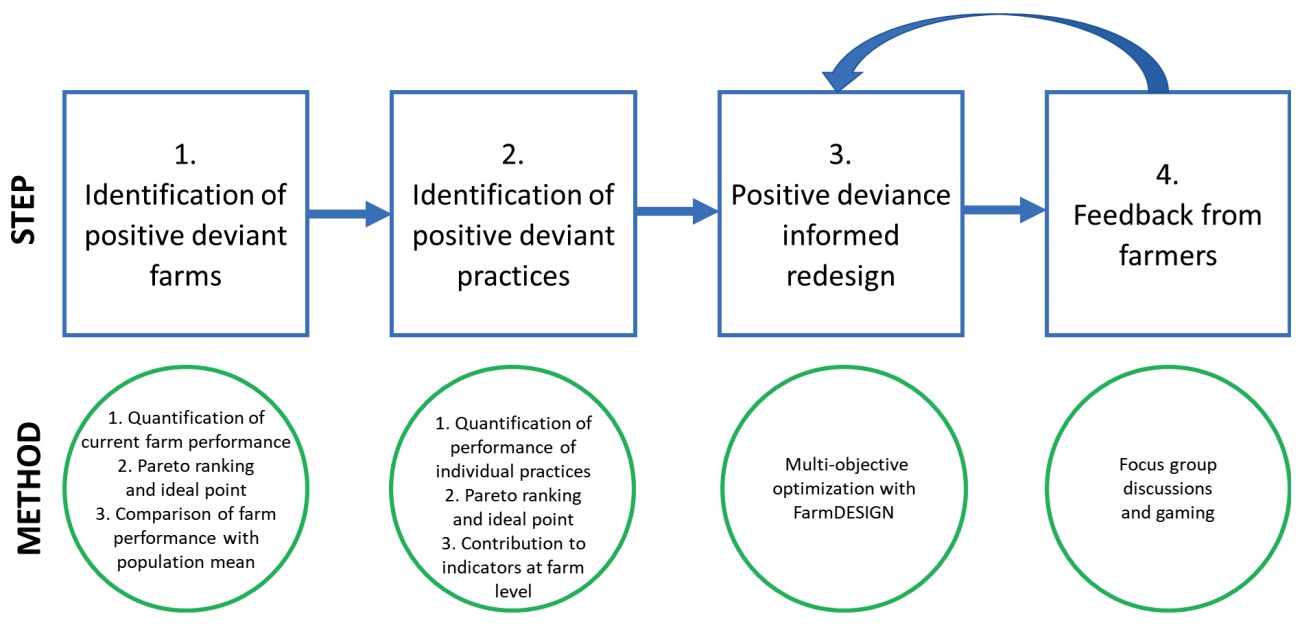

Figure 4.2: Overview of the methodological framework divided into four steps (blue squares) and respective methods (green circles). The last two steps constitute an iterative cycle in which feedback from stakeholders is used to inform a new cycle(s) of redesign (feedback arrow).

\subsubsection{Identification of positive deviant farms}

In this study, we defined positive deviants as farms that perform better than the population mean on each of the selected indicators. To identify positive deviant farms, we used a nested assessment following three subsequent sub-steps: 1) Quantification of current farm performance; 2) Pareto ranking and determination of the distance to the ideal point (see definition below); 3 ) 
Comparison of farm performance with population mean. In the nested assessment, the Pareto ranking determines farms which are operating at optimal and suboptimal level and defines the consequent scope for improvement within the population, the ordination from the ideal point sorts the Pareto-optimal farms and finds the best compromise farms, and, finally, the comparison of farm performance with the population mean identifies which farms are truly deviating from the average.

\section{Quantification of current farm performance}

First, values for the four indicators were calculated for each of the 43 farms using FarmDESIGN. Differences in performances among farm types were assessed indicator-by-indicator using General Linear Model. Homogeneity of variances and normality were verified using the Levene test and Shapiro-Wilk test on the residuals, respectively. Statistical analyses were performed using the software IBM SPSS Statistics version 23.0 (IBM Corp, 2015). Significance was established at $\mathrm{p}<0.05$.

\section{Pareto ranking and ideal point}

Second, farms were classified according to Pareto ranking and distance from the ideal point. Compared to other multi-criteria method such as Multiple Goal Linear Modelling, Pareto optimality combines multiple objectives without resorting to subjective weighting (Das, 1999; Groot and Rossing, 2011). Pareto-optimal or non-dominated solutions outperform the other solutions in at least one indicator without being outperformed in any other indicator and were identified using the algorithm described by Goldberg (1989). The set of Pareto-optimal solutions define the Pareto frontier while the solutions below the frontier are performing below the potential optimal level (i.e. suboptimal or dominated solutions). These suboptimal solutions can be still improved in multiple indicators up to the Pareto frontier and, therefore, represents the scope of improvement within the population (Modernel et al., 2018) (Figure 4.3). However, Pareto ranking usually identifies a wide array of Pareto-optimal solutions, including extreme cases (i.e. solutions which excel in one indicator but perform very poorly in all the others). For this reason, Modernel et al. (2018) who initially identified positive deviance with Pareto optimality, finally resorted to expert knowledge to rule out the win-lose and lose-win farms and to define the win-win farms among the Pareto-optimal farms. Therefore, we complemented Pareto ranking with a second approach: the ordination from the ideal point. 


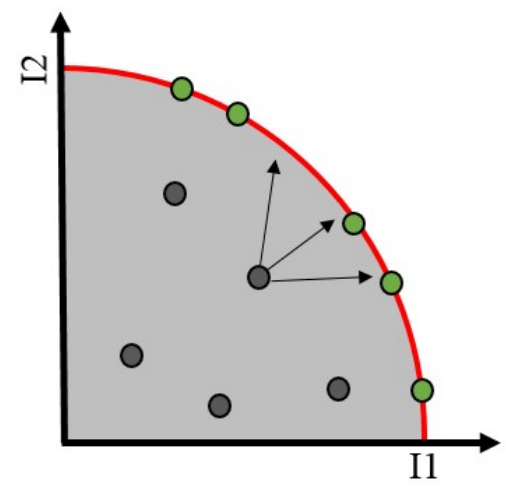

Figure 4.3: Example of Pareto optimality for the two indicators I1 and I2. Green circles represent the Pareto-optimal solutions defining the Pareto frontier (red line). Grey circles represent the suboptimal solutions that can be still improved in multiple indicators up to the Pareto frontiers (black arrows). The grey area represents the scope of improvement inside the population: in this case there are five suboptimal solutions out of ten and, therefore, there is scope for improving $50 \%$ of the solutions.

Next, farms were ordinated according to their distance from the ideal point. The ideal point was defined as the best value for each indicator attained among the 43 farms (Deb, 2014). For each farm the respective distance to the ideal point was calculated using the formula of double-scaled Euclidean distance by Barrett (2005). In addition to normalizing the variables values, this formula also rescales the Euclidean distances in a $0-1$ range:

$$
\begin{gathered}
D_{p q}=\sqrt{\sum_{k=1}^{n} \frac{\left(\frac{p_{k}-q_{k}}{m d_{k}}\right)^{2}}{n}} \\
m d_{k}=\left(\text { maximum }_{k}-\text { minimum }_{k}\right)^{2}
\end{gathered}
$$

Where $D_{p q}$ is the distance of the set of indicators of farm $p_{k}=\left(p_{1}, p_{2}, \ldots p_{n}\right)$ from the set of indicators of the ideal point $q_{k}=\left(q_{1}, q_{2}, \ldots q n\right), m d_{k}$ is the maximum discrepancy for the indicator $k$ (Equation 2), and $n$ is the number of indicators. The ideal point is unlikely to be achieved given trade-offs between target indicators but is used to further rank the solutions: the ideal point allows to rule out the extreme cases, rank the solutions on a continuous scale and identify the Pareto-optimal solutions which represent the best compromises (Piech and Rehman, 1993; Tiwari et al., 1999). However, the farms closest to the ideal point can still 
include unbalanced performances between indicators. We therefore introduce a threshold value for positive deviance in the next sub-step.

\section{Comparison of farm performance with population mean}

Finally, the farms with all indicators above the mean were defined as positive deviants. In these farms, having a high value in one indicator does not decrease the values of the other indicators, although they do not necessarily perform best on one of the indicators. As such, these are the farms with less trade-offs between indicators. This rule adds to the Pareto ranking and ideal point by defining a narrow set of positive deviants with outstanding performances for each indicator.

\subsubsection{Identification of positive deviant practices}

Positive deviant practices are the best practices which lead to positive deviant performance in a farm. To identify positive deviant practices, we used three sub-steps: 1) quantification of performance of individual practices; 2) Pareto ranking and determination of the distance to the ideal point; 3) quantification of the contribution of practices to the indicators at farm level.

Practices are defined as the combination of a production activity with a specific set of techniques and are divided into crop and animal husbandry practices. Crop practices consist of a crop with specific set of cultivation techniques, including irrigation (irrigated or non-irrigated), machinery (mechanized or manual planting/threshing), straw management $(0 \%, 50 \%$ and $100 \%$ straw left on field as mulch), CSA techniques (traditional cultivation, zero tillage wheat, direct seeded rice), fertilization and pesticide application (low or high application), season (for crops that can be grown in different seasons such as maize or sorghum). The same crop cultivated with different cultivation techniques are considered different crop practices. For instance, wheat cultivation is classified into nine practices: traditional wheat with manual threshing, traditional wheat with mechanical threshing, and zero tillage wheat, each of them with three levels of straw allocation to soil of $0 \%, 50 \%$ and $100 \%$. As a crop can last from one to several seasons, one crop practice can refer to one or more season (e.g. rice one season, yam two seasons, mango three seasons for several years). Rotations are formed of one to three successive crop practices in rabi (winter), zaid (spring) and kharif (monsoon), for instance "wheat-mungbean-rice", "wheat-yam-yam(continued)" with yam being planted in zaid and harvested in kharif, "mango-mango(continued)-mango(continued)" with mango being 
a perennial crop lasting for several years. Animal husbandry practices consist of an animal with related purpose (for milk or for meat).

\section{Quantification of performance of individual practices}

First, for each indicator the performances per hectare were calculated for crop and animal husbandry practices. For crops, practices were individually entered in FarmDESIGN; as yields, prices and cultivation costs per ha did not differ among farm types we used average values from the 43 farms for each crop practice. OM inputs were used instead of SOM balance because crop practices usually last only one season while OM outputs from soil were calculated on annual basis. The crop practice was allocated to 1 ha. No manure was applied, as this is considered as an effect of the animal component, unless the crop specifically requires manure or other organic fertilizers, and these are usually imported (e.g. for tobacco). For animal husbandry, the performances of one adult bovine on one hectare was calculated using the formulas in Supplementary Materials 4A. The performances of goats and chickens were not considered because of the negligible effect on the indicators, rare occurrence on the farms and the culturally-determined reluctance towards rearing animals other than bovines (Thorpe et al., 2007).

\section{Pareto ranking and ideal point}

Second, practices were classified according to Pareto rank and ordinated based on the distance from ideal point, using the procedure explained above for farm performances (Section 2.4.1.2). Ordination of crop practices was performed for each season separately: rabi, zaid, kharif. The coordinates of the ideal point for crop practices represented the best performances among the three seasons (see Section 3.3 and Supplementary Materials 4F). As we only evaluated the performance of bovines, we could not perform the Pareto ranking or ordination from the ideal point of this single animal husbandry practice.

\section{Contribution to the indicators at farm level}

Finally, for each farm, the four indicators were partitioned into the relative contributions of individual crop and animal husbandry practices. Formulas were adapted from the model calculation as described in Groot et al. (2012) (Supplementary Materials 4B). Contribution of individual production activities to single indicators and to the overall farm performances were compared among positive deviant and non-deviant farms. We identified the practices in positive deviant farms that contribute to improving overall farm performance i.e. contributed 
for a substantial share in several indicators without decreasing any other: these are the positive deviant practices.

\subsubsection{Positive deviance informed redesign}

In the positive deviance informed redesign, we recombined the previously identified positive deviant farms and practices in FarmDESIGN with the aim to redesign a farm which performed twice compared to the population mean for each of the indicators (i.e. around $+100 \%$; in case of water half the population mean i.e. around $-50 \%$ ). The redesign was initially performed on an individual farm and the resulting redesigned configuration was then adapted to the five farm types.

The four indicators were used as objectives to: (1) maximize operating profit, (2) maximize SOM balance, (3) minimize water use, and (4) maximize dietary energy production. The objectives were constrained to performance levels higher than either the original, or higher than twice the mean if they were already performing better. This forced the model to only consider alternative configurations with better solutions than the original (Groot et al., 2012). The decision variables were the areas allocated to crop rotations, the destination of crop residues and the amount of imported feed. Residue destination was restricted to common farmers' practices in Bihar, e.g. wheat and rice straw could not be left on the field, according to Singh et al. (2013) and results from the interviews. The constraints were: (1) whole farm crop area was fixed, (2) the feed balance was fixed to acceptable deviation (dry matter $\leq 100 \%$ of intake capacity, energy within $95-105 \%$ of the requirements and protein within $100-130 \%$ of the requirement) (Groot et al., 2012; Cortez-Arriola et al., 2016), (3) minimum feed self-reliance for animal feed was $35 \%$ for energy and $20 \%$ for protein. The optimization process was run for 2000 iterations using the default values for amplitude of mutations $\mathrm{F}=0.15$ and crossover probability $\mathrm{CR}=0.85$ (Groot et al., 2007; Groot et al., 2010).

The redesign was performed using an iterative procedure:

- One positive deviant farm was selected as a starting point for the redesign; this farm was selected in order to already present most of the positive deviant practices.

- The causes of low scores on the lowest indicator(s) in the selected farm were identified based on the results on positive deviant practices (Section 2.4.2) and by comparing the farm configuration with configurations of farms with the highest value for the 
given indicator(s) (these extreme farms are usually not positive deviants as the highest performance in one indicator often comes with poor performances for other indicators).

- Potential replacements were suggested for multi-objective optimization with FarmDESIGN i.e. replacement of an existing practice by a positive deviant practice. When introducing a new crop practice in the rotation, we took into account only rotations already present in the 43 farms thus ensuring agronomic feasibility. We did not take account of a pre-crop effect.

- The alternative farm configurations obtained with the multi-optimization were sorted in order to check if a configuration was formed which complied with the goal to have all the indicators performing twice the population mean.

- If such a configuration was not found in step 4, a new change was introduced in the farm and a new exploration was run, until a farm configuration was found with all indicators performing twice the mean. We only introduced one change at a time and kept the configuration as similar as possible to the original farm.

In order to present a recognizable example for all farm types, the obtained farm configuration was adapted for each farm type. To this aim, we repeated the procedure explained above for five model farms representing the five farm types using the obtained configuration as a starting point. Each model farm was assigned with the average area of the respective farm type as in Lopez-Ridaura et al. (2018) and the average available labour per farm type in this study. As a result, we obtained five positive deviance redesigned farms, one for each farm type.

\subsubsection{Feedback from farmers}

Fifteen focus group discussions were conducted with local farmers in the period of January-February 2019 in Nirpur (Vaishali district), Bakhari (Muzzaffapur district) and Chaundali (Samastipur district). In each village, one focus group discussion per farm type was conducted with 10 representative farmers of the farm type, making a total of 15 sessions with 150 farmers. Farmers were recruited on the basis of a short household survey in each village and were assigned to a type as identified by Lopez-Ridaura et al. (2018). The focus group discussions were divided in three parts: in part 1, the designed farm was presented and farmers were asked for feedback on each element of the configuration; in part 2, farmers conducted a serious game in which they were asked to change the decision variables of the designed farm configuration, observe the effect of these changes on the indicators as calculated by the model and choose their preferred configuration among the alternatives produced; in part 3 , farmers 
were asked for feedback on the designed farm in the view of the game's outcome. In this study, the focus group discussions served to provide an initial feedback on the redesigned farm configuration and to collect their suggestions for subsequent redesign cycles. The complete description of the focus group discussions is available in Supplementary Materials 4C.

\section{Results}

\subsection{Quantification of current farm performances}

The 43 farms had a median area of 1.5 ha and showed a wide variety of crops. The most important crops were wheat (39\% average area), rice (33\%) and maize $(23.5 \%)$ (average area in one season). Furthermore, oilseed, pulses, fodder, vegetables, fruit trees and tobacco were cultivated. Farms had a median livestock density of 1.9 Tropical Livestock Units (TLU) $\mathrm{ha}^{-1}$ (median 2.4 TLU per farm). Most farms had cows or buffalos for milk production with an average milk yield per cow of $5.5 \mathrm{~kg} \mathrm{day}^{-1}$ (calculated for the whole year) and the herd comprised on average $30 \%$ of non-productive animals (heifers or calves). Calculated average feed self-reliance was $60 \%$ for both energy and protein but decreased to $40 \%$ in farms with livestock density larger than $5 \mathrm{TLU} \mathrm{ha}^{-1}$. Farms presented a large within- and between- type variability (Figure 4.4), and values of indicators did not significantly differ among farm types. In line with the fact that villages were selected among similar farming systems, soil and climate, we did not find significant differences among villages and therefore we do not further consider them in the analyses (Supplementary Materials 4D).

\subsection{Identification of positive deviant farms}

Farms exhibited a synergy between SOM balance and dietary energy production, but trade-offs between SOM balance and water use and between water use and dietary energy production (Figure 4.5). Half of the farms (22 out of 43 farms) were classified as Pareto-optimal and occurred with similar frequencies in the different farm types (Figure 4.5B). Distance from the ideal point ranged between 0.40 and 0.83 (on a 0 to 1 scale) (Figure 4.6A). The first 16 farms closest to the ideal point were also Pareto-optimal (Supplementary Materials 4E). Farm types did not show any pattern in relation to the distance from the ideal point (Figure 4.6A). Six out of 43 farms had at the same time all indicators above the mean and were therefore assigned 
as positive deviants. They were all Pareto-optimal, among the eight closest farms to the ideal point and represented all farm types except for type 1 .

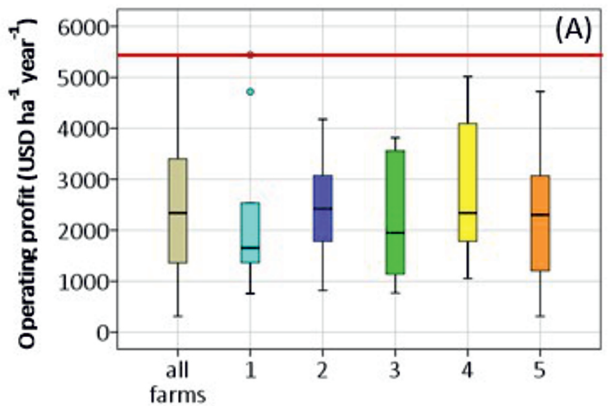

Farm type

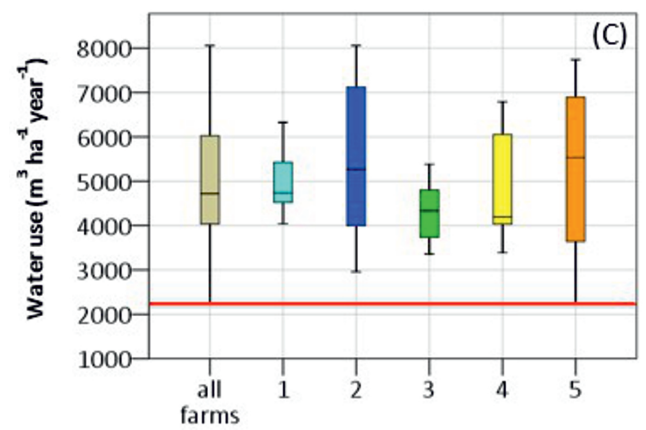

Farm type

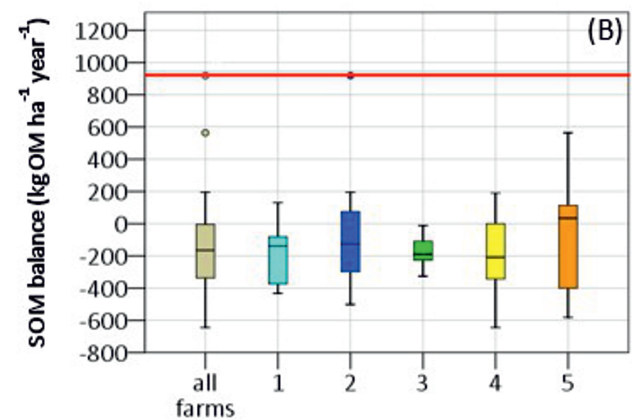

Farm type

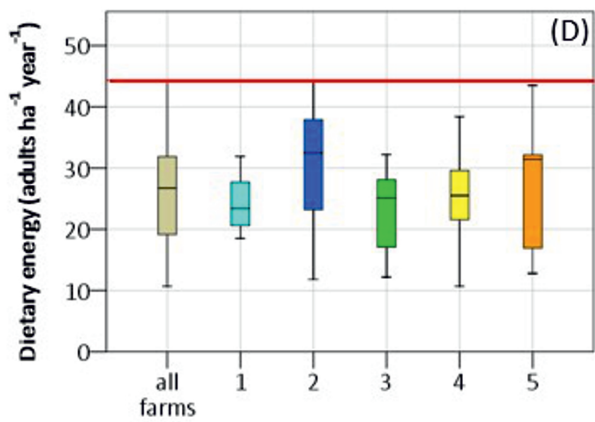

Farm type

Figure 4.4: Performances of the four indicators of the 43 farms. Colours represent performances from all the farms (grey), type 1 (part-time farmers, light blue; $n=9$ ), type 2 (Wealthy farmers, dark blue; $n=8$ ), type 3 (Small-scale crop and livestock farmers, green; $n=9$ ), type 4 (Medium-scale cereal crop farmers, yellow; $n=9$ ), type 5 (Resource poor agricultural labourers, orange, $\mathrm{n}=8)$. Dots represent outliers ( $>1.5 \mathrm{x}$ interquartile range). Red lines represent the ideal point (best value from set of 43 farms) for each indicator. Indicator performances were calculated with the model FarmDESIGN.

\subsection{Identification of positive deviant practices}

One hundred forty three crop practices (i.e. the combination of a crop with specific set of cultivation techniques) including 45 different crops were cultivated in the 43 farms. Crop practices presented large variability in the indicator values, with an operating profit of 290-5044 USD ha ${ }^{-1}$ year ${ }^{-1}$, OM inputs of 1-747 $\mathrm{kg} \mathrm{OM} \mathrm{ha}^{-1}$ year $^{-1}$, water use of 0-4550 $\mathrm{m}^{3} \mathrm{ha}^{-1}$ year $^{-1}$ and dietary energy production of 0-21.6 adults ha ${ }^{-1}$ year $^{-1}$ (Supplementary Materials 4F and 
Using a positive deviance approach to inform farming systems redesign: a case study from Bihar, India

$\widehat{\oplus}$
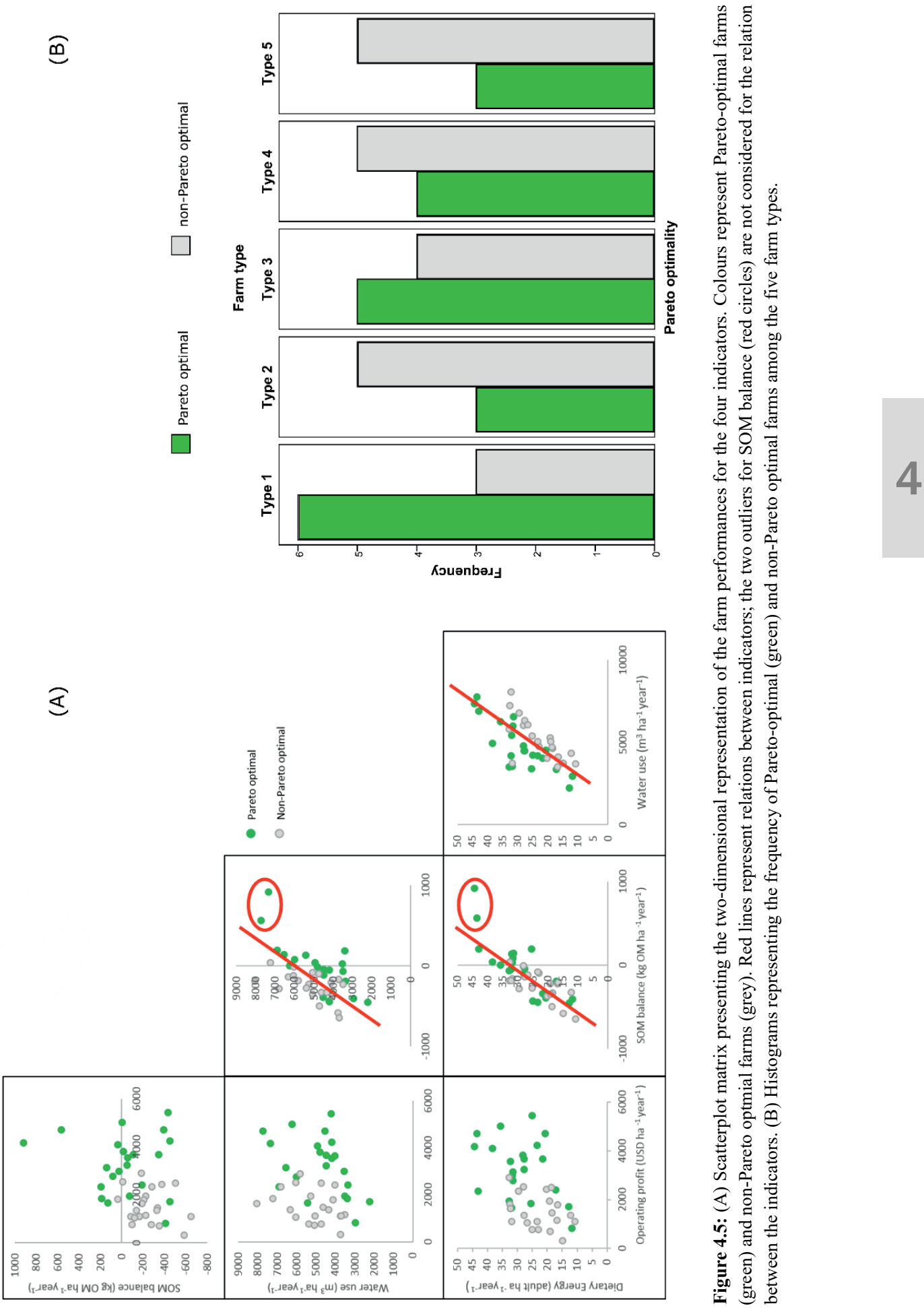


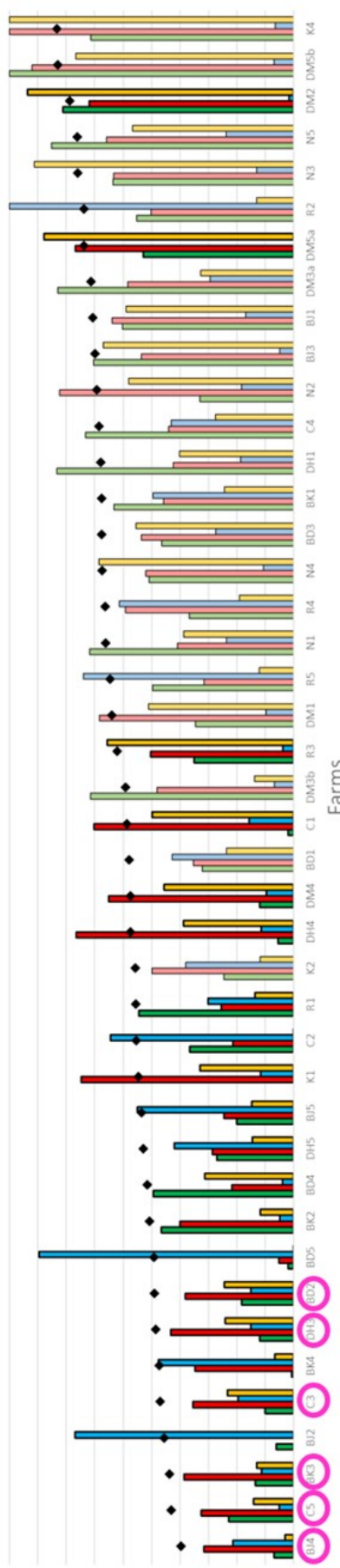

ङ

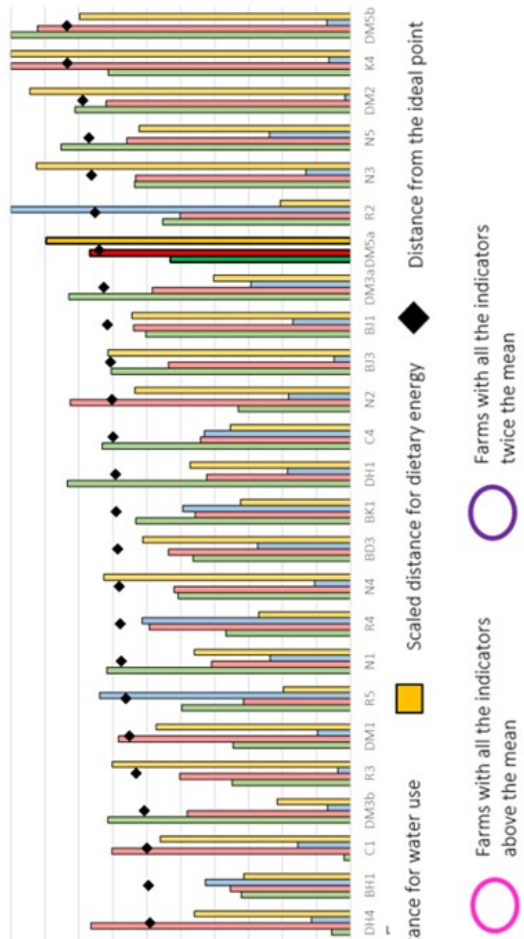

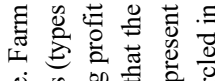

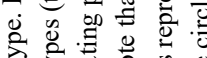

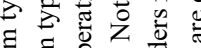

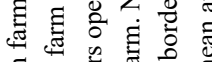

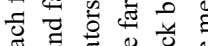

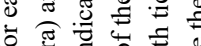

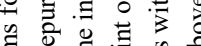

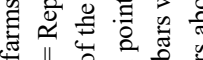
둉

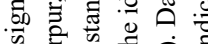

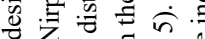

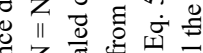
Z ङु

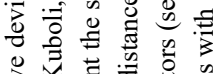

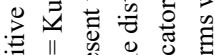

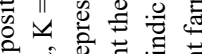

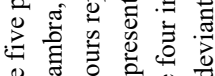
옹응 훙

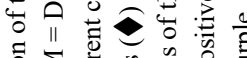

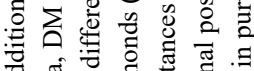

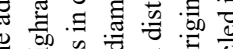

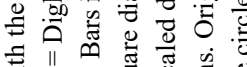

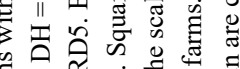

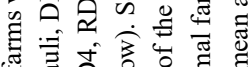

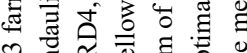

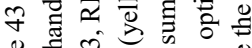

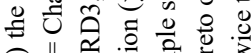

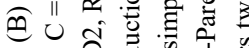

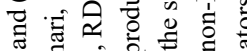

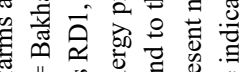

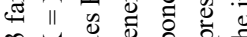
\% 능 总

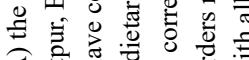

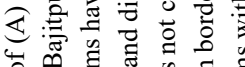

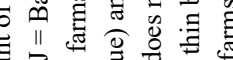

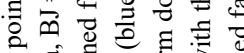

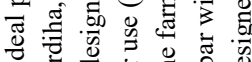
o

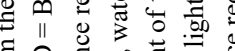

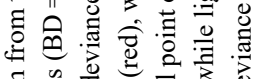
다웡

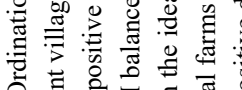

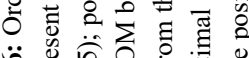

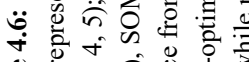
는

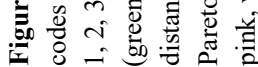


4G). The average performance of one adult bovine (1 TLU) on one hectare was 579 USD ha-1 year ${ }^{-1}$ of operating profit, $67 \mathrm{~kg} \mathrm{OM} \mathrm{ha}^{-1}$ year-1 $^{-1}$ of OM inputs, $0 \mathrm{~m}^{3} \mathrm{ha}^{-1}$ year-1 of water use and 2.1 adults ha $^{-1}$ year $^{-1}$ for dietary energy. We present an overview of the performances of the most common crop and animal husbandry practices in Table 4.3.

Eleven out of 46 in rabi, 15 out of 47 in zaid and 16 out of 51 in kharif crop practices were ranked as Pareto-optimal. At overall level, no clear trade-offs or synergies were revealed between indicators (Figure 4.7). However, comparing performances of the indicators for single crop practices, crop practices excelling in one of the indicators showed strong trade-offs with other indicators, with none having all four indicators above the mean. Crop practice distance from ideal point varied from 0.46 to 0.89 . All the Pareto-optimal crop practices closest to the ideal point were cereals (wheat and maize).

After analysis of the performances of practices, we evaluated the contributions of each practice on the indicators at farm level and identified the practices actually responsible for the highest/lowest performances for each indicator. For brevity, here we only present a summary of the main findings while the detailed analysis and bar graphs are presented in Supplementary Materials 4H. For operating profit, the most profitable farms either cultivated mango or tobacco or had high livestock density. Yam also significantly contributed to crop gross margin, despite the small dedicated area. For SOM balance, OM inputs mainly originated from crop residues, especially cereal straw and sesbania. Manure production was the most variable OM component and high manure production appeared essential to achieve positive SOM balance. For water use, high use directly correlated to the area dedicated to rice, while the lowest use related with large area of fallow and low water requiring crop practices, such as mustard, tobacco and yam. For dietary energy, the highest values were achieved in farms which combined a high cereal production with a large number of animals.

The in-depth analysis of the nine farms closest to the ideal point, which included the six positive deviant farms (i.e. farms with all the indicators above the mean), revealed the following set of positive deviant practices: high livestock density (5-6 TLU ha $\left.{ }^{-1}\right)$, low or no (0-30\%) rice, around $30 \%$ of wheat and $30 \%$ monsoon maize (average area in one season). In addition to the practices mentioned, yam and tobacco were identified as potential positive deviant practices. Yam was ranked as Pareto-optimal and received a distance to the ideal point of 0.64 being the closest crop practice after cereals. Monsoon maize without residues allocated to soil was ranked as Pareto-optimal and received an ideal point distance of 0.6. Finally, despite the relatively large 
distance to the ideal point (0.79), tobacco may also be considered a promising crop practice, because it is a Pareto-optimal crop practice and appears twice out of nine farms mentioned above. The in-depth analysis of the nine farms closest to the ideal points is presented in Supplementary Materials 4I.

Table 4.3: Indicator performance, Pareto ranking ( $N=$ non-optimal, $P O=P a r e t o-o p t i m a l)$ and distance from the ideal point of the most common crop and animal husbandry practices present in the 43 farms. Crop practices are divided into the three seasons rabi (winter), zaid (spring) and kharif (monsoon).

\begin{tabular}{|c|c|c|c|c|c|c|}
\hline Practice & $\begin{array}{c}\text { OM input } \\
\left(\mathrm{kg} \mathrm{OM}^{-1} \text { year }^{-1}\right)\end{array}$ & $\begin{array}{c}\text { Water use } \\
\left(\mathrm{m}^{3} \mathrm{ha}^{-1}\right. \\
\left.\text { year }^{-1}\right)\end{array}$ & $\begin{array}{c}\text { Operating } \\
\text { profit (USD } \\
\text { ha }^{-1} \text { year }^{-1} \text { ) }\end{array}$ & $\begin{array}{c}\begin{array}{c}\text { Dietary } \\
\text { energy } \\
\text { (adults ha }^{-1} \\
\left.\text { year }^{-1}\right)\end{array}\end{array}$ & $\begin{array}{l}\text { Pareto } \\
\text { ranking }\end{array}$ & $\begin{array}{l}\text { Distance to } \\
\text { ideal point }\end{array}$ \\
\hline \multicolumn{7}{|l|}{ Rabi (Winter) } \\
\hline Wheat $0 \% 1$ & 159 & 2100 & 584 & 15.8 & $\mathrm{~N}$ & 0.63 \\
\hline Tobacco & 266 & 1000 & 1470 & 0 & $\mathrm{PO}$ & 0.69 \\
\hline Mustard & 28 & 1000 & 394 & 8.7 & PO & 0.72 \\
\hline Mango $^{2}$ & 5 & 1333 & 541 & 1.07 & $\mathrm{~N}$ & 0.82 \\
\hline \multicolumn{7}{|l|}{ Zaid (Spring) } \\
\hline $\begin{array}{l}\text { Yam - first } \\
\text { season }^{3}\end{array}$ & 88 & 500 & 3827 & 19 & PO & 0.46 \\
\hline Sesbania & 705 & 0 & -78 & 0 & PO & 0.69 \\
\hline Sorghum 4 & 136 & 0 & -257 & 0 & $\mathrm{~N}$ & 0.69 \\
\hline Mungbean & 224 & 0 & 333 & 2.2 & $\mathrm{PO}$ & 0.72 \\
\hline Mango $^{2}$ & 5 & 1333 & 541 & 1.07 & $\mathrm{~N}$ & 0.82 \\
\hline \multicolumn{7}{|l|}{$\begin{array}{l}\text { Kharif } \\
\text { (Monsoon) }\end{array}$} \\
\hline $\begin{array}{l}\text { Yam - second } \\
\text { season }^{3}\end{array}$ & 88 & 500 & 3828 & 19 & $\mathrm{PO}$ & 0.46 \\
\hline $\begin{array}{l}\text { Monsoon maize } \\
0 \% 1\end{array}$ & 161 & 1200 & 559 & 17.6 & $\mathrm{~N}$ & 0.6 \\
\hline Rice $0 \% 1$ & 125 & 4550 & 204 & 14.6 & $\mathrm{~N}$ & 0.8 \\
\hline Sorghum & 136 & 0 & -257 & 0 & $\mathrm{~N}$ & 0.82 \\
\hline Mango $^{2}$ & 5 & 1333 & 541 & 1.07 & $\mathrm{~N}$ & 0.82 \\
\hline \multicolumn{7}{|l|}{ Animals } \\
\hline Dairy cow & 73 & 0 & 579 & 2.1 & - & - \\
\hline
\end{tabular}

${ }^{1} 0 \%$ indicates that no residues are left on field as mulch

2 Mango lasts for several years. The performance per season was obtained by dividing the overall yearly performance by the three seasons.

${ }^{3}$ Yam lasts for two seasons (it is planted in zaid and harvested in kharif) and therefore appears in both seasons. The performance per season was obtained by dividing the overall two-season performance by the two seasons.

${ }^{4}$ Sorghum lasts one season and can be grown both in zaid and in kharif. 


\subsection{Positive deviance informed redesign}

Based on the crop practice analysis, the following crop rotations were proposed for the positive deviance redesigned farms: Mustard-Yam-Cn ('Cn' indicates that yam continues for two seasons), Wheat-Mungbean-Maize, and Tobacco-Sorghum-Maize. The shares of each crop rotation were comparable between the types (Table 4.4). Livestock density ranged from 4.7 TLU ha-1 (type 2) to $6.3 \mathrm{TLU} \mathrm{ha}^{-1}$ (type 3). Farm types 1, 2 and 4 required hiring additional labour for livestock management.

The five positive deviance redesigned farms performed twice the mean for each indicator. When adding them to the 43 farms, six farms out of 48 were ranked as Pareto-optimal and the distance from the ideal point ranged from 0.26 to 0.83 (Supplementary Materials 4J). The five farms were closest to the ideal point (distance 0.26-0.30, Figure 4.6B), and for types 1,3 and 5 the designs were classified as Pareto-optimal. The detailed steps for the design procedure are presented in Supplementary Materials 4K. 


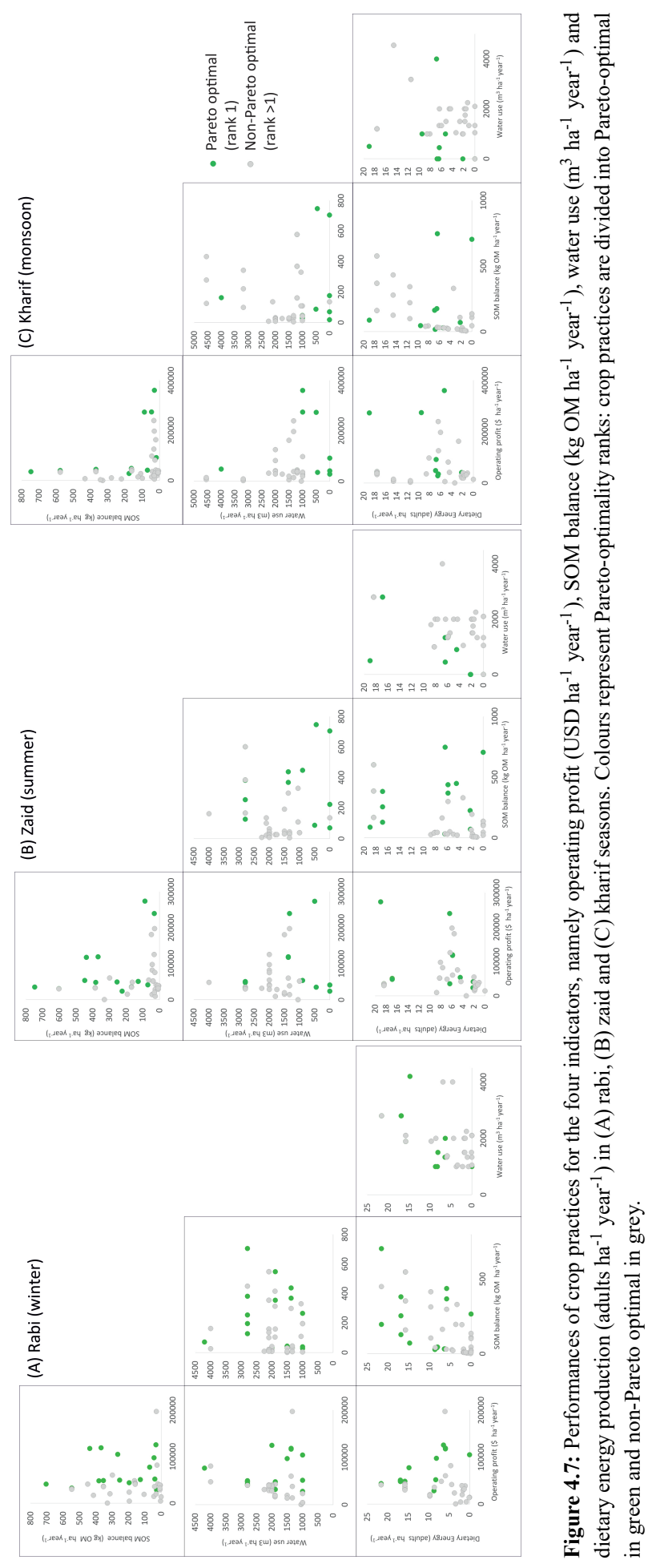




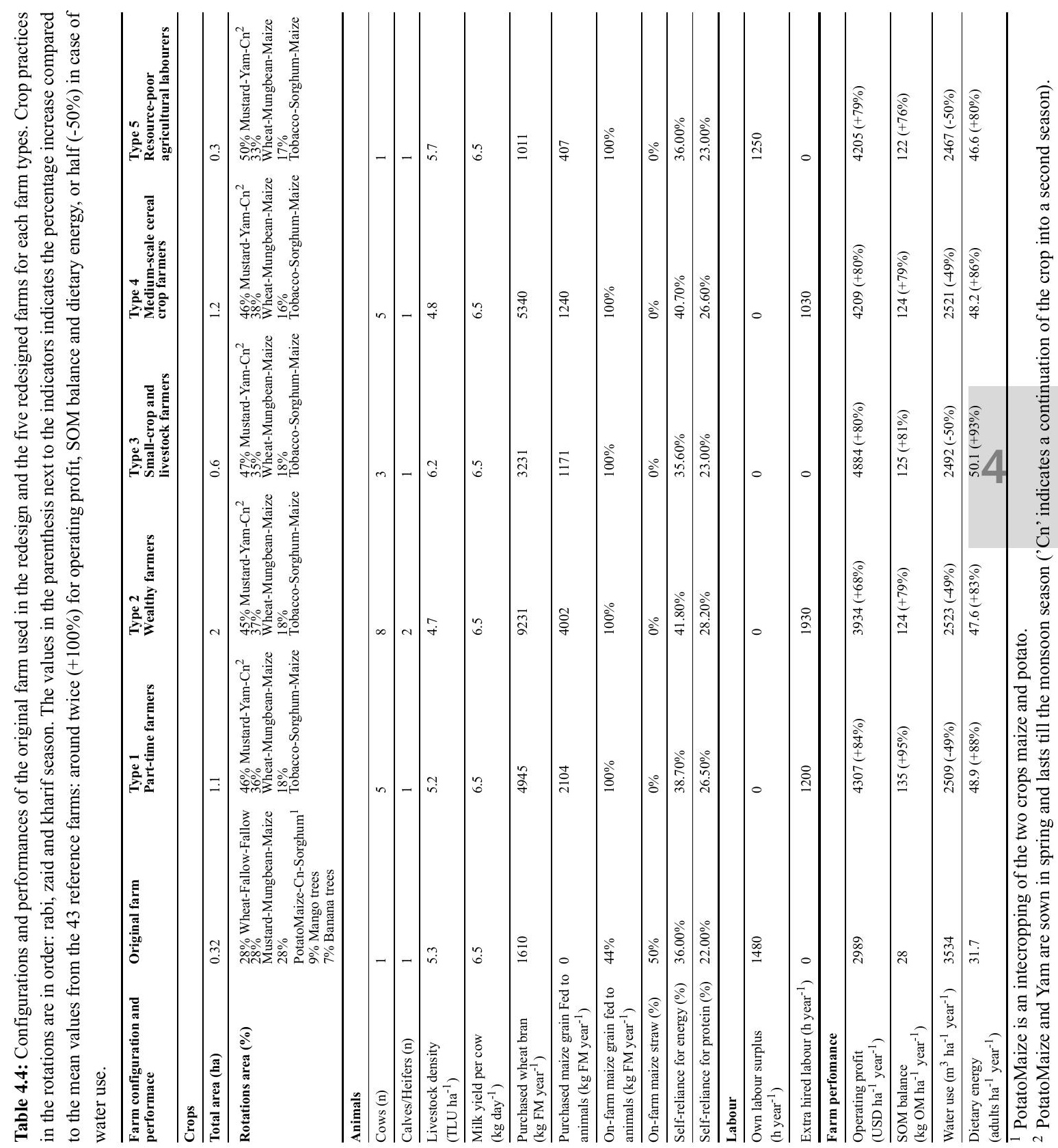




\subsection{Feedback from farmers}

The focus group discussions yielded consistent results among villages (Table 4.5): farmers from the same farm type attending different focus groups made similar remarks and some major comments were repeated among all farm types.

Table 4.5: Summary of farmers' feedback on the components of the positive deviance redesigned farm configurations during the focus group discussions (part 3). The table summarizes the results for each farm type by reporting the comments which were consistent in the three focus groups of the same farm type. Only elements which rewarded negative comments are listed while components which farmers consistently agreed on in all the workshops are not listed.

\begin{tabular}{|c|c|c|c|c|c|}
\hline \multirow{2}{*}{$\begin{array}{l}\text { Configuration } \\
\text { of redesigned } \\
\text { farm }\end{array}$} & Type 1 & Type 2 & Type 3 & Type 4 & Type 5 \\
\hline & $\begin{array}{l}\text { Part-time } \\
\text { farmers }\end{array}$ & Wealthy farmers & $\begin{array}{l}\text { Small-crop } \\
\text { and livestock } \\
\text { farmers }\end{array}$ & $\begin{array}{l}\text { Medium-scale } \\
\text { cereal crop } \\
\text { farmers }\end{array}$ & $\begin{array}{l}\text { Resource-poor } \\
\text { agricultural } \\
\text { labourers }\end{array}$ \\
\hline Livestock & $\begin{array}{l}\text { Not considered } \\
\text { feasible: } \\
\text { constrained by } \\
\text { feed import and } \\
\text { labour }\end{array}$ & $\begin{array}{l}\text { Not considered } \\
\text { feasible: } \\
\text { constrained by } \\
\text { feed import and } \\
\text { labour }\end{array}$ & Agree & $\begin{array}{l}\text { Not considered } \\
\text { feasible: } \\
\text { constrained by } \\
\text { feed import }\end{array}$ & Agree \\
\hline Yam & Willing & $\begin{array}{l}\text { Willing but in less } \\
\text { area in order to } \\
\text { have more cereals }\end{array}$ & $\begin{array}{l}\text { Willing but in less } \\
\text { area in order to } \\
\text { have more cereals }\end{array}$ & $\begin{array}{l}\text { Willing but in less } \\
\text { area in order to } \\
\text { have more cereals }\end{array}$ & $\begin{array}{l}\text { Willing but in less } \\
\text { area in order to } \\
\text { have more cereals }\end{array}$ \\
\hline Wheat & Willing & Undecided & $\begin{array}{l}\text { Would prefer a } \\
\text { slightly larger } \\
\text { wheat area }\end{array}$ & $\begin{array}{l}\text { Not willing to } \\
\text { decrease wheat } \\
\text { area }\end{array}$ & $\begin{array}{l}\text { Not willing to } \\
\text { decrease wheat } \\
\text { area because they } \\
\text { need it for food } \\
\text { security }\end{array}$ \\
\hline Monsoon maize & $\begin{array}{l}\text { Willing but } \\
\text { constrained in } \\
\text { the lowlands }\end{array}$ & $\begin{array}{l}\text { Willing but they } \\
\text { also want some } \\
\text { rice }\end{array}$ & $\begin{array}{l}\text { Willing but } \\
\text { constrained in } \\
\text { the lowlands }\end{array}$ & $\begin{array}{l}\text { Willing but } \\
\text { constrained in } \\
\text { the lowlands }\end{array}$ & $\begin{array}{l}\text { Some of the } \\
\text { farmers might be } \\
\text { willing but they } \\
\text { also need some } \\
\text { rice in monsoon } \\
\text { season for food } \\
\text { security }\end{array}$ \\
\hline Tobacco & $\begin{array}{l}\text { Willing as soon } \\
\text { as the good price } \\
\text { will be back }\end{array}$ & $\begin{array}{l}\text { Not willing } \\
\text { because of } \\
\text { governmental } \\
\text { ban }\end{array}$ & $\begin{array}{l}\text { Willing as soon } \\
\text { as the good price } \\
\text { will be back }\end{array}$ & $\begin{array}{l}\text { Willing as soon } \\
\text { as the good price } \\
\text { will be back }\end{array}$ & $\begin{array}{l}\text { Not willing } \\
\text { because of } \\
\text { high input } \\
\text { requirements }\end{array}$ \\
\hline Missing crops & $\begin{array}{l}\text { Rice and possibly } \\
\text { vegetables should } \\
\text { be added }\end{array}$ & $\begin{array}{l}\text { Rice should be } \\
\text { added. More crop } \\
\text { diversification is } \\
\text { required for their } \\
\text { farm }\end{array}$ & $\begin{array}{l}\text { Rice and } \\
\text { eventually potato } \\
\text { should be added }\end{array}$ & $\begin{array}{l}\text { Rice and potato } \\
\text { should be added. } \\
\text { Eventually mango } \\
\text { orchard and } \\
\text { vegetables should } \\
\text { be added too }\end{array}$ & $\begin{array}{l}\text { Rice and } \\
\text { eventually potato } \\
\text { and vegetables } \\
\text { should be added }\end{array}$ \\
\hline
\end{tabular}


When introducing the positive deviance redesigned farm (part 1), farmers agreed in all the focus groups that the configuration was familiar and realistic. The performance in terms of operating profit, water use and dietary energy production of the designed positive deviants were above their expectations.

During the game (part 2), farmers chose their preferred configuration almost exclusively according to the profit and the degree of similarity with their own current farms. Despite farmers mentioning decreasing water tables and rainfall and high irrigation costs during the sessions, water use rarely informed their choices. Farmers never included SOM balance as a selection criterion, but said that they would cope with negative SOM balance by adding organic amendments.

In the discussion after the game (part 3), farmers stated that they were interested in the high profit offered by the redesigned farm, but multiple components were considered undesirable (Table 4.5). Only type 3 farmers found the suggested farm configuration entirely feasible and useful. High livestock density represented the main issue for types 1,2 and 4 that were constrained by feed import and labour. Type 4 farmers were not willing to reduce wheat because this is their main crop and type 5 farmers did not agree to reduce wheat and rice for food security reasons. Farmers were interested in replacing rice with monsoon maize but stated that this is not feasible in the lowlands. The recent price drop in tobacco forced farmers to stop cultivating the crop, but they were willing to grow it again if the price would recover. Finally, farmers asked for more crop diversification.

\section{Discussion}

This study aimed to identify and redesign positive deviant farming systems in Bihar, using data from 43 farms classified in five farm types. Because of large within-type variability, farm types did not significantly differ in terms of average indicator performances nor frequencies of exceptionally good performances when expressed per hectare. This suggests that the different performances in terms of profit and potential food availability between farm types found by Lopez-Ridaura et al. (2018) were mostly driven by farm size while farm efficiency (i.e. performance per ha) was similar across farm types. Exceptional performances across different farm types were also reported in other studies and suggest that focusing on farm typology might limit the identification of options to improve farm performances (Ondersteijn et al., 2003; 
Flores-Sanchez et al., 2011; Cortez-Arriola et al., 2015; Hammond et al., 2017b; Michalscheck et al., 2018; Modernel et al., 2018; Steinke et al., 2019). These findings justify the decision in our methodology to use average performances from all farm types and identify positive deviant farms and practices across all farms instead of focusing on individual farm types.

The nested assessment allowed to identify six positive deviant farms. While Pareto ranking and calculating the distance to the ideal point were sub-steps that added useful information, the comparison with the population mean was finally required to narrow down the selection to a small number of best performing farms for all indicators. Pareto ranking identified more than half of the farms as Pareto-optimal; this is a significantly larger percentage than the 41 Pareto-optimal farms out of 280 in Modernel et al. (2018) and 12 out of 521 in Steinke et al. (2019), also considering that more indicators were used in those studies, thereby increasing the probability of equal Pareto ranks (Groot et al., 2010). Although the ideal point distance successfully ruled out Pareto-optimal farms with extreme performances (i.e. farms which excel in one indicator but perform very poorly in all the others), all farms were relatively far from the ideal point. In line with the largely widespread Pareto optimality and the far distance from the ideal point, even the six positive deviant farms with all the indicators above the mean were not substantially deviating from the population mean on each indicator. This suggests that all farms, including the six positive deviants, were locked into strong trade-offs among indicators and perfomances can be still substantially improved in the redesign.

The diverse practices in the 43 farms presented widely differential performances with some practices showing very high performances for single indicators, but without clear trends among the four indicators (Figure 4.5). Crop practices had widespread Pareto optimality and far distances to the ideal point, and no practices were found with all indicators above the mean. As such, none of the crop practices could be the single success factor for positive deviance. Nevertheless, livestock could solve these trade-offs as it increases operating profit, SOM balance and dietary energy production from a given area with negligible additional water use. High livestock density (5-6 TLU ha ${ }^{-1}$ ) seemed the key feature of the six positive deviant farms, even though it needs to be complemented with a specific set of crop practices to achieve best performances. Livestock is often pointed as the way forward to achieve overall farm sustainability as it can simultaneously improve productive, economic and environmental performances (Devendra et al., 2000; Petersen et al., 2007; Wilkins, 2008; Herrero et al., 2010; 
Thornton and Herrero, 2015) and was suggested as positive deviant practice by Steinke et al. (2019).

During the redesign step, the selected positive deviant farms could be further improved when high livestock density was combined with an optimal combination of crop practices. This is in line with the idea that interactions and complementarity among practices are more important than the practices themselves (Tittonell, 2014a; Thornton and Herrero, 2015; Altieri, 2018; Lopez-Ridaura et al., 2018). Adding the positive deviance redesigned farms to the set of actual farms reduced the number of Pareto-optimal cases. As the Pareto frontier moved forward, the scope for improvement within the farms increased from $50 \%$ to $86 \%$ when including the redesigns (Figure 4.8). All the redesigned farms scored the closest distance to the ideal point, decreasing the minimum distance from 0.40 to 0.26 . This demonstrates that the designed configurations had a superior overall performance. However, increasing livestock density reduced farm feed self-reliance: SOM balance and dietary energy seemed to originate more from the net feed import rather than the internal recycling of residues or positive interactions among farm components (Cortez-Arriola et al., 2014; Flores-Sánchez et al., 2015; Cortez-Arriola et al., 2016).
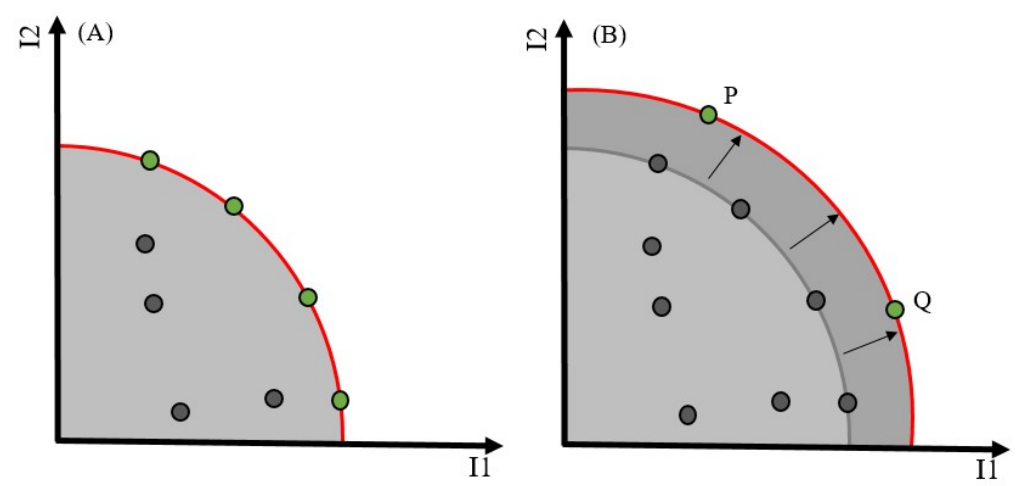

Figure 4.8: Example of shift of the Pareto frontier for two indicators I1 and I 2 when adding superior solutions to the initial set of solutions. Green circles represent the Pareto-optimal solutions defining the Pareto frontier (red line). Grey circles represent the suboptimal solutions. (A) In the initial situation, there are four suboptimal solutions out of eight: there is scope for improving 50\% of the population. (B) The addition of superior solutions P and Q moves the Pareto frontier forward and the previously Pareto-optimal solutions are now suboptimal. There are eight suboptimal solutions out of ten: the scope for improvement increased to $80 \%$ of the population.

During the focus group discussions, farmers showed interest in the considerably higher profit offered by the positive deviance redesigned farms, but some farm types also raised concerns 
regarding the elements that were different from their current farms. For example, types 1 (part-time farmers), type 2 (well-endowed farmers) and type 4 (cereal-crop farmers) showed concerns about higher labour and feed import costs when livestock density would increase. While farmers raised concrete concerns, implicit but inherent goals and values also contributed to their decision making (Van der Ploeg, 1994). For instance, the underlying causes of these concerns may be risk and vulnerability aversion related to dependency on feed import for livestock. These implicit goals (e.g. increasing farm resilience) combined with intrinsic drivers, activities and their social and market network define the farming style of a farmer (Renting et al., 2009; Van der Ploeg et al., 2009). Farmers tend to adhere to their current farming style: for example, type 4 (medium-scale cereal crop farmers) favoured larger wheat area and type 5 (resource poor agricultural labourers) preferred staple crops and did not like tobacco because of its high input requirements. As such, the redesigned farm appeared to be most suitable for type 3 farmers which already base their livelihood strategy on livestock, while it would require some adjustments to better fit other farm types.

The three innovative aspects of the proposed methodology in this study are: (1) three-sub-steps assessment for identification of positive deviant farms; (2) quantitative analysis for identification of positive deviant practices; (3) integration of redesign component into the positive deviance approach. First, based on a clear definition of positive deviance, the proposed nested assessment for positive deviance expands the Pareto-optimality based method by Modernel et al. (2018) and identifies positive deviants without relying on subjective weighting or expert knowledge. Second, positive deviant practices were identified by quantifying the contribution of individual practices and their interactions. Compared to the common use in the field of nutrition of statistical inference (e.g. correlation or chi-square test between positive deviant performances and practices) (Ahrari et al., 2002; Mackintosh et al., 2002; Bradley et al., 2009), the use of a detailed farm survey combined with a modelling approach has two advantages: it tests for the underlying causes of positive deviance and works with a smaller sample size. Finally, the integration of the redesign component allowed to explore the multitude of practices (143 in total) from the community to find the most efficient combination. Because of computational limits, a similar exploration could not be performed by the model alone with (iterative) Linear Programming or Multiple Goal Linear Programming and would otherwise require resorting to preselection of practices by experts (cf. Dogliotti et al., 2005; Dogliotti et al., 2014). This application expands the potential of FarmDESIGN with respect to other studies which only optimize within the current farm configuration (Cortez-Arriola et al., 2016; Ditzler et al., 2019) 
or after adding a limited set of new alternatives (Flores-Sánchez et al., 2015; Mandryk et al., 2014; Michalscheck et al., 2018; Timler et al., 2020). To the best of our knowledge, this is the first study to integrate the positive deviant approach in a redesign of farming systems. Farm redesign may be in conflict with the idea that positive deviants are powerful agents of change because they are real and thus proved to be realistic (Marsh et al., 2004; Bradley et al., 2009). However, the redesign is based on existing positive deviant farms and practices used among farmers while the feedback-loop was added to guarantee sensible and feasible suggestions.

Future studies could use our results from focus group discussions to inform a second cycle of redesign. General improvements include risk analysis for tobacco, more crop diversification and selection of suitable crops to replace rice in the lowlands. Other indicators and objectives could be assessed, such as increasing feed self-reliance and reducing the labor burden (as mentioned by farmers), and reducing greenhouse gas emissions from animals. In addition, the preliminary redesigned configuration should be further tailored to each farm type (Landais, 1998; Ojiem et al., 2006; Andersen et al., 2007; Tittonell et al., 2010; Righi et al., 2011; Tittonell, 2014b; Descheemaeker et al., 2016; Haileslassie et al., 2016). We acknowledge that livestock density may not be appropriate for all farm types but, given the governmental goal to increase milk production in Bihar (Government of Bihar, 2012; Laik et al., 2014), it would be relevant to further discuss the implications and drawbacks of such a change with farmers and other stakeholders. Given the current low efficiency of the livestock component (Devendra et al., 2000; Erenstein et al., 2007), significant gains could be achieved by exploring options to optimize livestock density and reduce feed import (e.g. better herd management, higher feed quality and protein intake, increased on-farm feed production, etc.). The game could be further improved to include both farmers and other stakeholders in the redesign process (Vervoort et al., 2010). As last step, pilot positive deviant farms could be implemented in the villages to test and showcase the positive deviance redesigned farms in reality.

\section{Conclusions}

This study identified and redesigned farming systems in Bihar departing from existing, well-performing farms and based on best practices from the community. Using this positive deviance approach, we were able evaluated the multitude of practices present and selected few effective practices for the redesign. We found that outstanding performance for all indicators could only be reached by integrating high livestock with an optimal combination 
of crop practices, which confirms the key role of interactions among components in mixed crop-livestock systems to improve multiple dimensions of farm sustainability. The redesigns outperformed all real farms in terms of the indicators assessed and showed inspiring examples for the community as they were configured out of viable interventions which already showed their validity. Focus group discussions revealed that the redesign was especially interesting for farm type 3 (small-scale crop and livestock farmers), while we recommend a second design cycle for the other farm types. We conclude that it is possible to simultaneously improve farm productive, economic and environmental performances by focusing on the room for manoeuvre inside the diversity of current farmers' practices. These results show that the methodology could yield valuable suggestions for farm optimization to support sustainable development in agroecosystems and improvements of smallholder farmer livelihoods.

\section{Acknowledgements}

We acknowledge the financial and technical support from CGIAR Research Programs on Climate Change, Agriculture and Food Security (CCAFS) and Wheat Agri-food Systems (WHEAT), and all donors who supported this research through their contributions to the CGIAR Fund. For a list of Fund donors please see: http://www.cgiar.org/our-funders/. Furthermore, we thank the farmers for their time and for sharing their experiences and expertise. The contribution of JCJG was supported by the Senior Expert program of the Dutch Science Council (NWO), grant number 17222 . 


\section{References}

Adelhart Toorop, R., Ceccarelli, V., Bijarniya, D., Jat, M. L., Jat, R. K., Lopez-Ridaura, S., and Groot, J. C. (2020), Using a positive deviance approach to inform farming systems redesign: A case study from Bihar, India. Agricultural Systems. 185(February): p. 102942.

Ahrari, M., Kuttab, A., Khamis, S., Farahat, A. A., Darmstadt, G. L., Marsh, D. R., and Levinson, F. J. (2002), Factors associated with successful pregnancy outcomes in upper Egypt: a positive deviance inquiry. Food Nutr. Bull. 23(1): p. 83-88.

Altieri, M. A. (2018), Agroecology: the science of sustainable agriculture. Boca Raton: CRC Press.

Amankwah, K., Klerkx, L., Oosting, S. J., Sakyi-Dawson, O., Van Der Zijpp, A. J., and Millar, D. (2012), Diagnosing constraints to market participation of small ruminant producers in northern Ghana: An innovation systems analysis. NJAS - Wageningen Journal of Life Sciences. 60-63: p. 37-47.

Amankwah, K. (2013), Enhancing food security in Northern Ghana through smallholder small ruminant production and marketing. Wageningen UR.

Andersen, E., Elbersen, B., Godeschalk, F., and Verhoog, D. (2007), Farm management indicators and farm typologies as a basis for assessments in a changing policy environment. J. Environ. Manag. 82(3): p. 353-362.

Aryal, J. P., Jat, M. L., Sapkota, T. B., Khatri-Chhetri, A., Kassie, M., Rahut, D. B., and Maharjan, S. (2018), Adoption of multiple climate-smart agricultural practices in the Gangetic plains of Bihar, India. International Journal of Climate Change Strategies and Management. 10(3): p. 407-427.

Barrett, P. (2005), Euclidean distance: Raw, normalised, and double-scaled coefficients.

Biggs, S. (2008), Learning from the positive to reduce rural poverty and increase social justice: Institutional innovations in agricultural and natural resources research and development. Experimental Agriculture. 44(1): p. 37-60.

Bolles, K., Speraw, C., Berggren, G., and Lafontant, J. G. (2002), Ti Foyer (Hearth) community-based nutrition activities informed by the positive deviance approach in Leogane, Haiti: a programmatic description. Food Nutr. Bull. 23(4 Suppl): p. 11 .

Bradley, E. H., Curry, L. A., Ramanadhan, S., Rowe, L., Nembhard, I. M., and Krumholz, H. M. (2009), Research in action: using positive deviance to improve quality of health care. Implement. Sci. 4(1): p. 25.

Chand, R. (2017), Doubling farmers income. Rationale, strategy, prospects and action plan. National Institution for Transforming India. 91: p. 399-404.

Cortez-Arriola, J., Groot, J. C. J., Massiotti, R. D. A., Scholberg, J. M. S., Aguayo, D. V. M., Tittonell, P., and Rossing, W. A. H. (2014), Resource use efficiency and farm productivity gaps of smallholder dairy farming in North-west Michoacán, Mexico. Agricultural Systems. 126: p. 15-24.

Cortez-Arriola, J., Groot, J. C. J., Rossing, W. A. H., Scholberg, J. M. S., Massiotti, R. D. A., and Tittonell, P. (2016), Alternative options for sustainable intensification of smallholder dairy farms in North-West Michoacán, Mexico. Agricultural Systems. 144: p. 22-32.

Cortez-Arriola, J., Rossing, W. A. H., Massiotti, R. D. A., Scholberg, J. M. S., Groot, J. C. J., and Tittonell, P. (2015), Leverages for on-farm innovation from farm typologies? An illustration for family-based dairy farms in north-west Michoacán, Mexico. Agric. Syst. 135: p. 66-76.

Das, I. (1999), A preference ordering among various Pareto optimal alternatives. Structural optimization. 18(1): p. $30-35$.

Deb, K. (2014), Multi-objective optimization. In: Search Methodologies. Springer, p. 403-449.

DeFries, R., Fanzo, J., Remans, R., Palm, C., Wood, S., and Anderman, T. L. (2015), Metrics for land-scarce agriculture. Science. 349(6245): p. 238-240.

Descheemaeker, K., Ronner, E., Ollenburger, M., Franke, A. C., Klapwijk, C. J., Falconnier, G. N., Wichern, J., and Giller, K. E. (2016), Which Options Fit Best? Operationalizing the Socio-Ecological Niche Concept. Experimental Agriculture. 55(S1): p. 169-190.

Devendra, C., Thomas, D., Jabbar, M. A., and Zerbini, E. (2000), Improvements of livestock production in crop-animal Systems in agro-ecological zones of South Asia. Nairobi, Kenya: ILRI, p. 1-108.

Ditzler, L., Komarek, A. M., Chiang, T.-W., Alvarez, S., Chatterjee, S. A., Timler, C., Raneri, J. E., Carmona, N. E., Kennedy, G., and Groot, J.C. J. (2019), A model to examine farm household trade-offs and synergies with an application to smallholders in Vietnam. Agric. Syst. 173(1): p. 49-63.

Dogliotti, S., Rossing, W. A. H., and Van Ittersum, M. K. (2003), ROTAT, a tool for systematically generating crop rotations. European Journal of Agronomy. 19(2): p. 239-250.

Dogliotti, S., Van Ittersum, M. K., and Rossing, W. A. H. (2005), A method for exploring sustainable development options at farm scale: a case study for vegetable farms in South Uruguay. Agricultural systems. 86(1): p. $29-51$.

Dogliotti, S., García, M. C., Peluffo, S., Dieste, J. P., Pedemonte, A. J., Bacigalupe, G. F., Scarlato, M., Alliaume, F., Alvarez, J., Chiappe, M., and Rossing, W. A. (2014), Co-innovation of family farm systems: A systems approach to sustainable agriculture. Agricultural Systems. 126: p. 76-86. 
Erenstein, O. and Thorpe, W. (2011), Livelihoods and agro-ecological gradients: A meso-level analysis in the Indo-Gangetic Plains, India. Agricultural Systems. 104(1): p. 42-53.

Erenstein, O., Thorpe, W., Singh, J., and Varma, A. (2007), Crop-livestock interactions and livelihoods in the Indo-Gangetic Plains, India: A regional synthesis. CIMMYT.

Flores-Sanchez, D., Koerkamp-Rabelista, J. K., Navarro-Garza, H., Lantinga, E. A., Groot, J. C. J., Kropff, M. J., and Rossing, W. A. H. (2011), Diagnosis for ecological intensification of maize-based smallholder farming systems in the Costa Chica, Mexico. Nutr. Cycl. Agroecosyst. 91(2): p. 185.

Flores-Sánchez, D., Groot, J. C., Lantinga, E. A., Kropff, M. J., and Rossing, W. A. (2015), Options to improve family income, labor input and soil organic matter balances by soil management and maize-livestock interactions. Exploration of farm-specific options for a region in Southwest Mexico. Renewable Agriculture and Food Systems. 30(4): p. 373-391.

Frelat, R., Lopez-Ridaura, S., Giller, K. E., Herrero, M., Douxchamps, S., Djurfeldt, A. A., Erenstein, O., Henderson, B., Kassie, M., Paul, B. K., Rigolot, C., Ritzema, R. S., Rodriguez, D., Van Asten, P. J., and Van Wijk, M. T. (2016), Drivers of household food availability in sub-Saharan Africa based on big data from small farms. Proceedings of the National Academy of Sciences of the United States of America. 113(2): p. 458-463.

Giller, K. E., Leeuwis, C., Andersson, J. A., Andriesse, W., Brouwer, A., Frost, P., Hebinck, P., Heitkönig, I., Van Ittersum, M. K., Koning, N., Ruben, R., Slingerland, M., Udo, H., Veldkamp, T., Van de Vijver, C., Van Wijk, M. T., and Windmeijer, P. (2008), Competing claims on natural resources: What role for science? Ecology and Society. 13(2).

Goldberg, D. (1989), Genetic algorithms in search. In: Optimization and machine learning. Reading: Addison-Wesley, p. 142.

Government of Bihar (2012), State Action Plan on Climate Change: Building Resilience through Development. Government of Bihar.

Groot, J. C. J., Cortez-Arriola, J., Rossing, W. A. H., Améndola Massiotti, R. D., and Tittonell, P. (2016), Capturing agroecosystem vulnerability and resilience. Sust. 8(11): p. 1206.

Groot, J. C. J., Jellema, A., and Rossing, W. A. (2010), Designing a hedgerow network in a multifunctional agricultural landscape: Balancing trade-offs among ecological quality, landscape character and implementation costs. European Journal of Agronomy. 32(1): p. 112-119.

Groot, J. C. J., Oomen, G. J. M., and Rossing, W. A. H. (2012), Multi-objective optimization and design of farming systems. Agric. Syst. 110: p. 63-77.

Groot, J. C. J. and Rossing, W. A. H. (2011), Model-aided learning for adaptive management of natural resources: an evolutionary design perspective. Methods Ecol. Evol. 2(6): p. 643-650.

Groot, J. C. J., Rossing, W. A., Jellema, A., Stobbelaar, D. J., Renting, H., and Van Ittersum, M. K. (2007), Exploring multi-scale trade-offs between nature conservation, agricultural profits and landscape quality-A methodology to support discussions on land-use perspectives. Agriculture, Ecosystems and Environment. 120(1): p. 58-69.

Haileslassie, A., Craufurd, P., Thiagarajah, R., Kumar, S., Whitbread, A., Rathor, A., Blummel, M., Ericsson, P., and Kakumanu, K. R. (2016), Empirical evaluation of sustainability of divergent farms in the dryland farming systems of India. Ecol. Indic. 60: p. 710-723.

Hammond, J., Fraval, S., van Etten, J., Suchini, J. G., Mercado, L., Pagella, T., Frelat, R., Lannerstad, M., Douxchamps, S., and Teufel, N. (2017a), The Rural Household Multi-Indicator Survey (RHoMIS) for rapid characterisation of households to inform climate smart agriculture interventions: Description and applications in East Africa and Central America. Agric. Syst. 151: p. 225-233.

Hammond, J., van Wijk, M. T., Smajgl, A., Ward, J., Pagella, T., Xu, J., Su, Y., Yi, Z., and Harrison, R. D. (2017b), Farm types and farmer motivations to adapt: Implications for design of sustainable agricultural interventions in the rubber plantations of South West China. Agricultural Systems. 154: p. 1-12.

Herrero, M., Thornton, P. K., Notenbaert, A. M., Wood, S., Msangi, S., Freeman, H. A., Bossio, D., Dixon, J., Peters, M., Van De Steeg, J., Lynam, J., Rao, P., MacMillan, S., Gerard, B., McDermott, J., Seré, C., and Rosegrant, M. (2010), Smart investments in sustainable food production: Revisiting mixed crop-livestock systems. Science. 327(5967): p. $822-825$.

IBM Corp (2015), IBM SPSS Statistics for Windows. Armonk, NY.

Janssen, S. and van Ittersum, M. K. (2007), Assessing farm innovations and responses to policies: A review of bio-economic farm models. Agricultural Systems. 94(3): p. 622-636.

Jat, R. D., Jat, H. S., Nanwal, R. K., Yadav, A. K., Bana, A., Choudhary, K. M., Kakraliya, S. K., Sutaliya, J. M., Sapkota, T. B., and Jat, M. L. (2018), Conservation agriculture and precision nutrient management practices in maize-wheat system: effects on crop and water productivity and economic profitability. Field Crops Res. 222(March): p. $111-120$. 
Jat, R. K., Sapkota, T. B., Singh, R. G., Jat, M., Kumar, M., and Gupta, R. K. (2014), Seven years of conservation agriculture in a rice-wheat rotation of Eastern Gangetic Plains of South Asia: Yield trends and economic profitability. Field Crops Research. 164(1): p. 199-210.

Jones, J. W., Antle, J. M., Basso, B., Boote, K. J., Conant, R. T., Foster, I., Godfray, H. C. J., Herrero, M., Howitt, R. E., and Janssen, S. (2017), Brief history of agricultural systems modeling. Agricultural systems. 155: p. $240-254$.

Kolb, D. A. (1984), Experiential learning: Experience as the source of learning and development. New Jersey: Prentice-Hall.

Laik, R., Sharma, S., Idris, M., Singh, A. K., Singh, S. S., Bhatt, B. P., Saharawat, Y., Humphreys, E., and Ladha, J. K. (2014), Integration of conservation agriculture with best management practices for improving system performance of the rice-wheat rotation in the Eastern Indo-Gangetic Plains of India. Agriculture, Ecosystems and Environment. 195: p. $68-82$.

Landais, E. (1998), Modelling farm diversity: new approaches to typology building in France. Agric. Syst. 58(4): p. 505-527.

Le Gal, P. Y., Dugué, P., Faure, G., and Novak, S. (2011), How does research address the design of innovative agricultural production systems at the farm level? A review. Agricultural Systems. 104(9): p. 714-728.

Lopez-Ridaura, S., Frelat, R., Van Wijk, M. T., Valbuena, D., Krupnik, T. J., and Jat, M. L. (2018), Climate smart agriculture, farm household typologies and food security: An ex-ante assessment from Eastern India. Agric. Syst. 159(September 2016): p. 57-68.

Mackintosh, U. A., Marsh, D. R., and Schroeder, D. G. (2002), Sustained positive deviant child care practices and their effects on child growth in Viet Nam. Food Nutr. Bull. 23(4 Suppl): p. 18

Mandryk, M., Reidsma, P., Kanellopoulos, A., Groot, J. C. J., and van Ittersum, M. K. (2014), The role of farmers' objectives in current farm practices and adaptation preferences: a case study in Flevoland, the Netherlands. Regional Environmental Change. 14(4): p. 1463-1478.

Marsh, D. R., Schroeder, D. G., Dearden, K. A., Sternin, J., and Sternin, M. (2004), The power of positive deviance. Br. Med. J. 329(7475): p. 1177.

Marsh, D. R., Sternin, M., Khadduri, R., Ihsan, T., Nazir, R., Bari, A., and Lapping, K. (2002), Identification of model newborn care practices through a positive deviance inquiry to guide behavior-change interventions in Haripur, Pakistan. Food Nutr. Bull. 23(4 Suppl): p. 107-116.

Michalscheck, M., Groot, J. C., Kotu, B., Hoeschle-Zeledon, I., Kuivanen, K., Descheemaeker, K., and Tittonell, P. (2018), Model results versus farmer realities. Operationalizing diversity within and among smallholder farm systems for a nuanced impact assessment of technology packages. Agricultural Systems. 162(February): p. 164-178.

Modernel, P., Dogliotti, S., Alvarez, S., Corbeels, M., Picasso, V., Tittonell, P., and Rossing, W. (2018), Identification of beef production farms in the Pampas and Campos area that stand out in economic and environmental performance. Ecological Indicators. 89(May 2017): p. 755-770.

Van Noordwijk, M., Tomich, T., and Verbist, B. (2001), Negotiation Support Models for Integrated Natural Resource Management in Tropical Forest Margins. Conservation Ecology. 5(2): p. 21.

Ochieng, C. M. O. (2007), Development through positive deviance and its implications for economic policy making and public administration in Africa: The case of Kenyan agricultural development, 1930-2005. World Development. 35(3): p. $454-479$.

Ojiem, J. O., de Ridder, N., Vanlauwe, B., and Giller, K. E. (2006), Socio-ecological niche: A conceptual framework for integration of legumes in smallholder farming systems. International Journal of Agricultural Sustainability. 4(1): p. 79-93.

Ondersteijn, C. J. M., Beldman, A. C. G., Daatselaar, C. H. G., Giesen, G. W. J., and Huirne, R. B. M. (2003), Farm structure or farm management: effective ways to reduce nutrient surpluses on dairy farms and their financial impacts. Livest. Prod. Sci. 84(2): p. 171-181.

Otten, J. J., Hellwig, J. P., and Meyers, L. D. (2006), Dietary Energy Intakes the Essential Guide to Nutrient Requirements. National Academies Press.

Pant, L. P. and Odame, H. H. (2009), The promise of positive deviants: bridging divides between scientific research and local practices in smallholder agriculture. Knowl. Manag. Dev. J. 5(2): p. 160-172.

Petersen, S. O., Sommer, S. G., Béline, F., Burton, C., Dach, J., Dourmad, J. Y., Leip, A., Misselbrook, T., Nicholson, F., and Poulsen, H. D. (2007), Recycling of livestock manure in a whole-farm perspective. Livest. Sci. 112(3): p. 180-191.

Piech, B. and Rehman, T. (1993), Application of multiple criteria decision making methods to farm planning: A case study. Agric. Syst. 41(3): p. 305-319.

Renting, H., Rossing, W. A. H., Groot, J. C. J., Van der Ploeg, J. D., Laurent, C., Perraud, D., Stobbelaar, D. J., and Van Ittersum, M. K. (2009), Exploring multifunctional agriculture. A review of conceptual approaches and prospects for an integrative transitional framework. J. Environ. Manage. 90(SUPPL. 2): S112-S123. 
Righi, E., Dogliotti, S., Stefanini, F. M., and Pacini, G. C. (2011), Capturing farm diversity at regional level to up-scale farm level impact assessment of sustainable development options. Agric. Ecosyst. Environ. 142(1-2): p. 63-74.

Ritzema, R. S., Frelat, R., Douxchamps, S., Silvestri, S., Rufino, M. C., Herrero, M., Giller, K. E., López-Ridaura, S., Teufel, N., and Paul, B. K. (2017), Is production intensification likely to make farm households food-adequate? A simple food availability analysis across smallholder farming systems from East and West Africa. Food Secur. 9(1): p. 115-131.

Rufino, M. C., Quiros, C., Boureima, M., Desta, S., Douxchamps, S., Herrero, M., Kiplimo, J., Lamissa, D., Mango, J., Moussa, A. S., Naab, J., Ndour, Y., Sayula, G., Silvestri, S., Singh, D., Teufel, N., and Wanyama, I. (2013), Developing generic tools for characterizing agricultural systems for climate and global change studies (IMPACTlite - phase 2). Copenhagen: CGIAR Research Program on Climate Change, Agriculture and Food Security (CCAFS). (January): p. $1-42$.

Savikurki, A. (2013), Positive deviance in small holder crop-livestock farming systems in Northern Ghana. PhD thesis.

Shirsath, P. B., Aggarwal, P. K., Thornton, P. K., and Dunnett, A. (2017), Prioritizing climate-smart agricultural land use options at a regional scale. Agricultural Systems. 151: p. 174-183.

Singh, K., Singh, R., Jha, A., Kumar, A., Kumar, A., and Meena, M. S. (2013), Feed and Fodder Value Chains in Bihar: Some Empirical Evidences. SSRN.

Steinke, J., Mgimiloko, M. G., Graef, F., Hammond, J., van Wijk, M. T., and van Etten, J. (2019), Prioritizing options for multi-objective agricultural development through the Positive Deviance approach. PLoS ONE. 14(2): p. 1-20.

Thornton, P. K. and Herrero, M. (2001), Integrated crop-livestock simulation models for scenario analysis and impact assessment. Agricultural systems. 70(2-3): p. 581-602.

Thornton, P. K. and Herrero, M. (2015), Adapting to climate change in the mixed crop and livestock farming systems in sub-Saharan Africa. Nat. Clim. Chang. 5(9): p. 830.

Thorpe, W., Erenstein, O., Singh, J., and Varma, A. (2007), Crop-livestock interactions and livelihoods in the Gangetic Plains of Bihar, India. Vol. 12. ILRI.

Timler, C., Alvarez, S., DeClerck, F., Remans, R., Raneri, J., Estrada Carmona, N., Mashingaidze, N., Abe Chatterjee, S., Chiang, T. W., Termote, C., Yang, R. Y., Descheemaeker, K., Brouwer, I. D., Kennedy, G., Tittonell, P. A., and Groot, J. C. (2020), Exploring solution spaces for nutrition-sensitive agriculture in Kenya and Vietnam. Agricultural Systems. 180(1): p. 102774.

Tittonell, P. (2014a), Ecological intensification of agriculture—sustainable by nature. Curr. Opin. Environ. Sustain. 8: p. 53-61.

Tittonell, P. (2014b), Livelihood strategies, resilience and transformability in African agroecosystems. Agricultural Systems. 126: p. 3-14.

Tittonell, P., Muriuki, A., Shepherd, K. D., Mugendi, D., Kaizzi, K. C., Okeyo, J., Verchot, L., Coe, R., and Vanlauwe, B. (2010), The diversity of rural livelihoods and their influence on soil fertility in agricultural systems of East Africa-A typology of smallholder farms. Agric. Syst. 103(2): p. 83-97.

Tiwari, D. N., Loof, R., and Paudyal, G. N. (1999), Environmental-economic decision-making in lowland irrigated agriculture using multi-criteria analysis techniques. Agric. Syst. 60(2): p. 99-112.

Van der Ploeg, J. D., Laurent, C., Blondeau, F., and Bonnafous, P. (2009), Farm diversity, classification schemes and multifunctionality. J. Environ. Manage. 90: S124-S131.

Van der Ploeg, J. D. (1994), Styles of farming: an introductory note on concepts and methodology. In: Endogenous regional development in Europe, HJ de Haan, JD van der Ploeg (eds.). Vila Real, Portugal 1991. Luxembourg (1994) 7-31. Ook in: Born from within. Practice and perspectives of endogenous rural development, JD van der Ploeg, A. Long (eds.). Van Go, p. 7-31.

Vervoort, J. M., Kok, K., van Lammeren, R., and Veldkamp, T. (2010), Stepping into futures: exploring the potential of interactive media for participatory scenarios on social-ecological systems. Futures. 42(6): p. 604-616.

Wilkins, R. J. (2008), Eco-efficient approaches to land management: A case for increased integration of crop and animal production systems. Philosophical Transactions of the Royal Society B: Biological Sciences. 363(1491): p. $517-525$.

World Bank (2016), Bihar - Poverty, growth and inequality (English). India state briefs. Tech. rep. Washington, D.C.

\section{Supplementary Materials}

Supplementary data to this article can be found online at https:// doi.org/10.1016/j.agsy.2020.102942. 



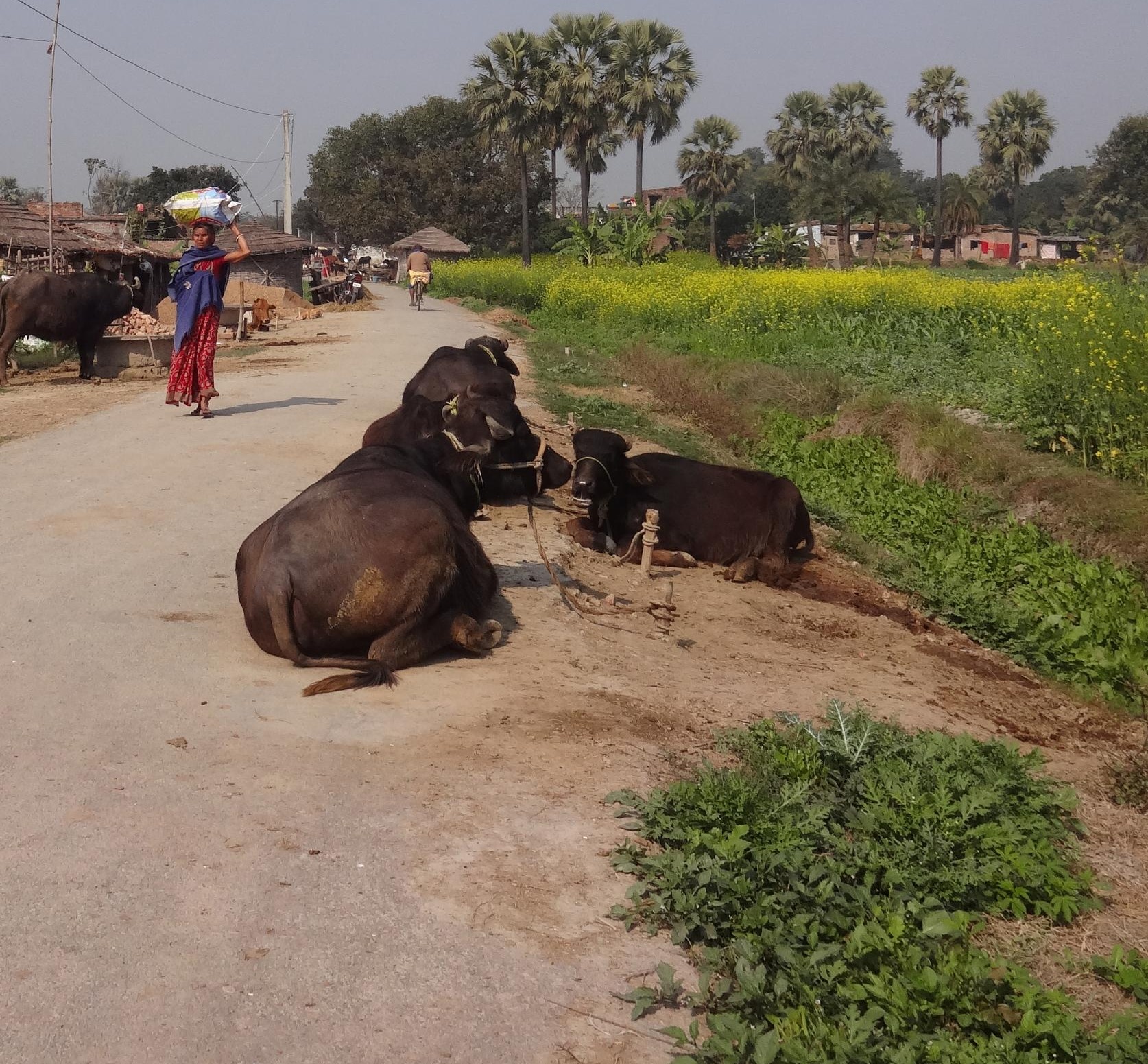




\section{Chapter 5}

Analysing antifragility among smallholder farmers in Bihar, India: an assessment of farmers' vulnerability and the strengths of positive

deviants

Roos de Adelhart Toorop, Santiago Lopez-Ridaura, Mangi Lal Jat, Pauline Eichenseer, Deepak Bijarniya, Raj Kumar Jat, Jeroen C.J. Groot 


\section{Abstract}

Farmers around the world are increasingly vulnerable: climate variability is identified as the primary stressor, but also unfavorable biophysical circumstances and disturbances in the socio-economic domain (labor dynamics, price volatility) affect farm management and production. To deal with these disturbances, adaptations are recognized as essential. Antifragility acknowledges that adaptations and volatility are inherent characteristics of complex systems, and abandons the idea of returning to the pre-disturbance system state. Instead, antifragility recognizes that disturbances can trigger reorganization, within the field or farm, enabling selection and removal of weaker system features, allowing the system to evolve towards a better state. In this study we assessed the vulnerability of different types of smallholder farmers in Bihar, India, and explored the scope for more antifragile farming systems. Accumulation of stocks and redundancies, creation of optionality and strengthening of autonomy were identified as criteria for antifragility. We had focus group discussions with in total 92 farmers and found that most expressed to be vulnerable: they experienced challenges and constraints but had limited adaptive capacity to change their situation. They mostly made short-term decisions to cope with or mitigate urgent challenges but did not engage in strategic planning driven by longer term objectives. Instead, they waited for governmental support to improve their livelihoods. Despite being confronted with similar challenges, four positive deviants showed to be more antifragile: their diverse farming systems were abundant in stocks and optionality, and the farmers distinguished in terms of autonomy, competence and connectedness. To support antifragility among regular farmers, adaptations at policy-level may be required, e.g. by shifting from a top-down towards a bottom-up adaptation and innovation regime where initiative and cooperation are endorsed. With a more autonomous orientation, farmers' intrinsic motivation will increase, enabling transitions at the farm-level. In this way connected systems can be developed which are socio-economically and biophysically adaptive. When practices, knowledge and skills are continuously developed an antifragile system with ample optionality, redundancies and stocks may evolve over time.

Keywords: Autonomy, adaptive capacity, smallholder farmers, policy, Bihar 


\section{Introduction}

During the second half of the 20th century agricultural practice has radically changed throughout South Asia: mechanization, intensification and specialization driven by the Green Revolution policy objectives and advancing technology led to major changes in farm management (Behera and France, 2016; Erenstein and Thorpe, 2011). Introduction of chemical fertilizers, improved crop varieties and animal breeds, irrigation and mechanization induced changes in both biophysical and socio-economic environment, aiming for improved yields, profit or labor productivity. Although yields increased and economy grew from these efforts (M. L. Jat et al., 2020), the gains were distributed unequally. Nowadays, poverty and undernourishment are still reality, amongst others in Bihar, one of India's most populous states. Continuous intensive cultivation led to soil degradation and over-exploitation of natural resources which, in combination with the changes in the biophysical and climatic environment, high degree of farm fragmentation, inadequate infrastructure, and weak institutions and markets, resulted in a challenge to sustain the livelihoods of smallholder farmers (Laik et al., 2014; Lopez-Ridaura et al., 2018).

Climate variability is identified as primary stressor (Singh et al., 2020), but also unfavorable biophysical circumstances and disturbances in the socio-economic domain (e.g. labor dynamics, price volatility) impact farm management and likely affect production. Farming activities are often exposed to unpredictable perturbations, e.g. floods, labor shocks or the recent COVID-19 pandemic cannot be anticipated. To act upon the watchword to 'expect the unexpected', the ability to make changes and adaptations are recognized as essential. As farming is subjected to the dynamics of complex systems the focus should be on managing farms towards adaptive capacity; creating conditions that enable productive, but largely unspecified, future states. It is about defining the conditions for an adaptive system that benefits and evolves from disturbances (Taleb, 2012; Darnhofer, 2020).

The objective to optimize production systems drives the development direction towards high-yielding mechanized agriculture, often based on capital-intensive inputs, making smallholder farmers increasingly dependent, for instance on external inputs, machinery and financing. The consequence optimization, homogenization and fragilization of these systems: the system impairs in suboptimal circumstances (Altieri et al., 2015; Meynard et al., 2018; Urruty et al., 2016). Although there has been an increasing social and political pressure for enhanced robustness (withstanding) and resilience (recovery) of these systems, it can be 
questioned whether the current system needs enhancement or a thorough transformation (Hendrickson, 2015). Instead of aiming for highly productive and efficient systems here we propose to investigate ways to become antifragile: the opposite of fragile.

We here define antifragility as a system state which gains from disturbances. The average performance of an antifragile system increases as perturbations trigger selection and removal of under-performing system-features, while the strongest survive. The response to the disturbance could start with a temporary decline of performance followed by recovery exceeding the initial performance of the system. Antifragility can be developed in all systems (natural, human, financial, social or socio-economical, biophysical, natural, political) and at all levels (molecules, organisms, people, companies, markets).

In this paper we focus on the vulnerability of smallholder farmers in Bihar and explore options to become more antifragile. The objectives are to: i) identify their main challenges and coping strategies; ii) define the scope and first attention points to make them more antifragile; and iii) describe positive deviants which already transformed their farming systems towards more antifragile systems. In the discussion we elaborate attention points to enhance antifragility among farmers in Bihar.

\section{Methodology}

\subsection{Conceptual framework}

In the past decades concepts like vulnerability, robustness, and resilience have been used to better grasp the sustainability and understand the dynamics of socio-ecological systems (Berkes, 2007; Darnhofer, 2014; Folke, 2006; Folke et al., 2010; Lopez-Ridaura et al., 2002; Urruty et al., 2016; Walker et al., 2004). The vulnerability of a farming system can be conceptualized as its exposure to changing conditions and its adaptive capacity to deal with those conditions (Gallopín, 2006; McCubbin et al., 2015; Smit and Wandel, 2006). In case of a disturbance, performance of a fragile system is impaired, and the system is not able to return to the original state over time (Figure 5.1a). In contrast, a robust system withstands shocks and maintains performance within the normal variation around the mean (Figure 5.1b) and a resilient system is affected but recovers over time (Figure 5.1c). In this study, we add antifragility to these concepts. Opposed to the fragile response, the antifragile system (Figure 5.1d) improves its performance over time due to reorganization after a disturbance (Taleb, 2012). The disturbance 
then triggers reorganization, within the field or farm or even at higher levels, enabling selection and removal of less-adapted system-features. This response could start with a temporary decline of performance followed by recovery exceeding the initial performance of the system.
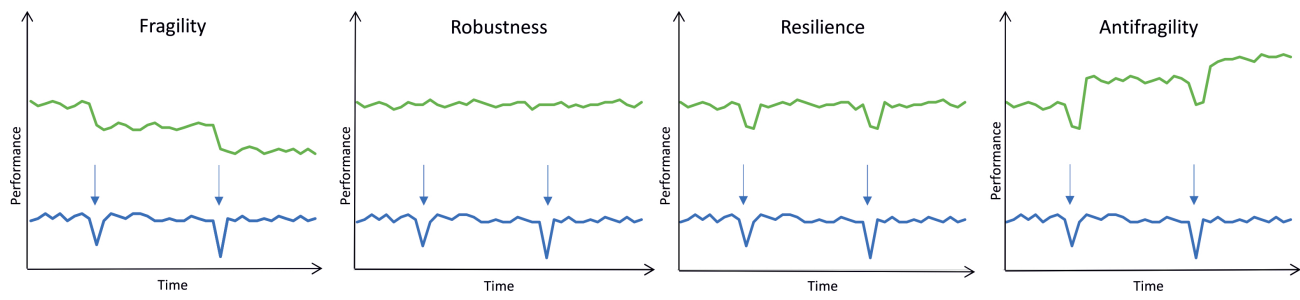

Figure 5.1: Responses of systems performance (green line) in response to variability over time (blue line). The arrows indicate disturbances.

We present antifragility here rather as a set of features enabling an antifragile response than a 'testable body of theory'. Based on Taleb (2012) we identified the following strategies as key to allow antifragile responses of farming systems:

- Accumulating stocks and redundancies: Reserves or storage capacity to use a resource when needed. These resources are part of the subunits which may be of use when the system reorganizes after a disturbance. This also entails keeping debts (negative stocks) at a low level relative to the assets of the farm.

- Creating optionality (i.e., multiple options): Employing multiple activities and skills (e.g., diversity of crops grown, biodiversity, multiple sources of income, diversity of resources, multiple sources of information) which enable new opportunities. Experimentation is necessary to develop new skills and try new practices which can be upscaled if they prove to be successful.

- Strengthening autonomy: Self-organization rather than relying on external help. Increasing self-determination to enable autonomous decisions on external input use and within value chains. This includes the ability (creativity) to see opportunities and tune these to the local context, and to disengage from activities which are no longer opportune.

\subsection{Study area}

This study focused on farmers in the villages Chaundali (district of Samastipur) and Nirpur (district of Vaishali), located in Northern Bihar (Figure 5.2) which were visited in January 
and February 2020. Previous studies from the same research team (Adelhart Toorop et al., 2020a; Adelhart Toorop et al., 2020b) were conducted in the these villages and strong contacts were already established. The villages were $20 \mathrm{~km}$ apart from each other and considered comparable in terms of farming systems, soils and climate. Both villages were located at a distance of $+/-6 \mathrm{~km}$ from the nearest market, with poor access roads. At a weather station in Pusa, Samastipur ( $<20 \mathrm{~km}$ from study sites), the yearly rainfall ranged from 787 to $2390 \mathrm{~mm}$ in the time period between 2007 and 2017 with an average of $1344 \mathrm{~mm} /$ year. July-September were typically the hottest $\left(33.5\right.$ to $\left.38.5^{\circ} \mathrm{C}\right)$ and most humid months receiving up to $70 \%$ of annual precipitation, while the lowest temperatures were recorded in January with mean temperatures ranging from $7-10^{\circ} \mathrm{C}$ ( $\mathrm{R}$. Jat et al., 2018). The dominant cropping pattern is rice in kharif (monsoon, June-Oct) followed by wheat in rabi (November-April) and a fallow period during zaid (summer, April-June/July).

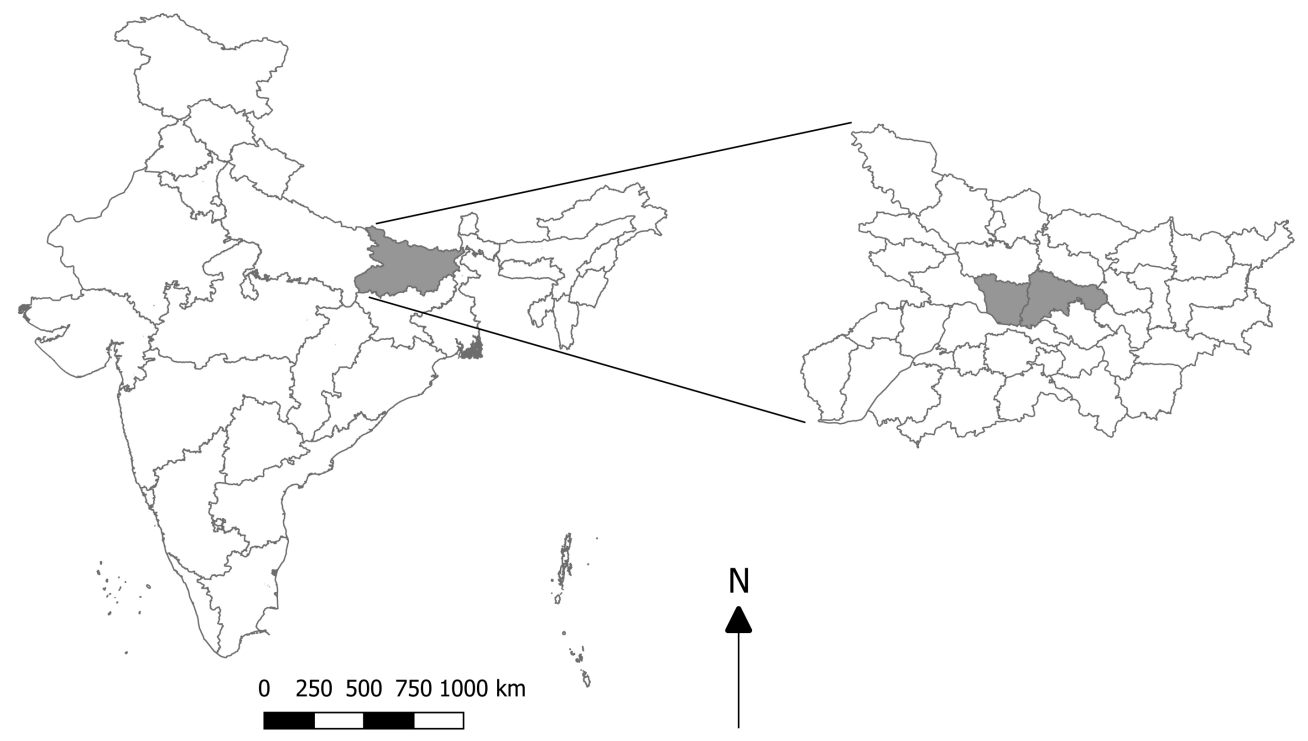

Figure 5.2: Map of India with Bihar in grey (left) and detail of Bihar with its 38 districts (right). Data was collected in Samastipur and Vaishali districts (in grey on detailed map).

\subsection{Methodological framework}

This study was built around two central questions: 1) how vulnerable are different types of smallholder farmers in Bihar and 2) what are attention points to promote antifragility among smallholder farmers? These questions led to a three-step approach where first challenges 
and coping strategies of farmers were identified in order to assess their vulnerability, then, the options to become more antifragile were explored in focus group discussions (FGDs) with farmers and interviews with policy informers (step 2) and in interaction with positively deviating farmers (step 3). The last two steps constitute an iterative cycle where the learnings from positive deviants could be discussed with and valued by farmers. Positive deviants are defined as individuals that achieve better outcomes than their peers despite having the same resources and constraints (Pant and Odame, 2009). The viewpoints of farmers, positive deviants, and policy informers enable the formulation of attention points to increase the antifragility among farmers.

For clarity: in this study we refer to farmers and to positive deviants. Farmers are regular farmers, while positive deviants are the farmers that were specifically selected as excellent farmers (§2.3.1). Positive deviants cannot be grouped in one of the farm types as their farm structure and management strongly deviates from the average. Both farmers and positive deviants were smallholders.

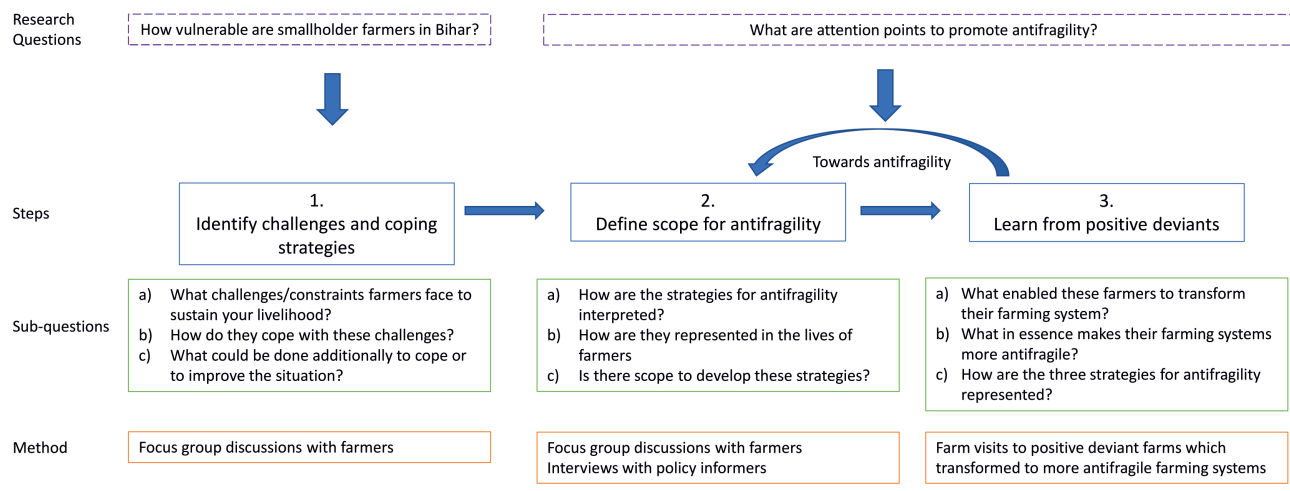

Figure 5.3: Methodological framework with main research questions (purple dashed boxes) to be carried out as three subsequent steps (blue boxes) with sub-questions (green boxes) and method (orange boxes).

\subsubsection{Participant selection}

Farmers were recruited on the basis of willingness to participate in the study and farm type. The typology constructed by Lopez-Ridaura et al. (2018) was used as their extensive household-survey on farming systems and livelihood pursuits among 269 households in Northern Bihar was suitable. Based on functional and structural characteristics five smallholder farm types were distinguished (part-time farmers, wealthy farmers, small-scale crop and livestock farmers, medium-scale cereal crop farmers and resource poor agricultural laborers) 
(Lopez-Ridaura et al., 2018). Two FGDs were organized for these five farm types, one in Chaundali and one in Nirpur, each with 10-15 farmers. In the days prior to the FGDs, quick surveys were conducted to assign farmers a type.

To understand policy making and dissemination we aimed at interviewing 'policy informers' at all levels. Policy informers could be both governmental and non-governmental and were involved in policy making, often through an advisory role. The snowball-technique was used to get in touch with people from village to state level. At the end of each interview, participants were asked to nominate positively deviating farmers which they thought to be autonomous and rich in optionality and stocks. Those farmers were visited as antifragile farmers (§2.3.5).

Supplementary Materials 5A gives an overview of characteristics of the five farm types and Supplementary Materials 5B presents the format of the quick survey.

\subsubsection{Statements on strategies for antifragility}

Farmers who attended the FGDs $(n=92)$ and policy informers $(n=13)$ were asked to rank the following five statements based on importance: 'I aim for a diversified income'; 'I am dependent on advice'; 'Limiting the use of fertilizers and inputs is important'; 'Water storage is essential in case of a drought'; 'Storage facilities to store produce is important to get a good price on the market'. To ensure that all respondents understood the exercise an individual explanation was given, and each statement was written in Hindi and depicted with an icon on a card. Each of the statements was used to trigger discussions about autonomy, optionality and stocks and we compared differences between farmers and policy informers using one-way analysis of variance (ANOVA). In case of significance a Tukey Honest Significance test was performed for multiple pairwise-comparison between the means of the groups. Likert scale data r-packages were used for visualization (http://www.bryer.org/project/likert/).

\subsubsection{Focus Group Discussions}

The FGDs were divided in three parts: first, farmers were asked to list all challenges regarding sustaining their livelihoods; second, they were asked for coping strategies and potential solutions for the listed challenges; finally, they were introduced to antifragility ('gaining from an unfortunate situation') and the three strategies. Starting from the statements ranked (\$2.3.2) farmers were asked how these strategies were represented within their lives. 
For the second part, where farmers shared their coping strategies and potential solutions, each response was assigned the label 'coping', 'buffering' or 'adapting'. The response got the label 'coping' in case it implied continuation of the business as usual (i.e. no new skills or knowledge required); 'buffering' when management was adjusted to mitigate the effect; and 'adapting' when the response required new knowledge and skills and implied transformation at systems level. To reduce perception bias two researchers assigned the labels independently.

See Supplementary Materials 5C for the format of the FGDs.

\subsubsection{Interviews with policy-informers}

To understand how farmers are supported and directed in their decision making we interviewed people which had a stake in the development of policies (i.e. policy informers). Figure 5.4 presents the policy structure in Bihar with the research, training and extension organizations ('knowledge generators') in green and the governmental policy system in grey. The knowledge generators inform the policy system and are in direct touch with farmers as part of research and through extension of $\mathrm{KVKs}^{1}$ which are under their direction. Within the policy system, we distinguish 'vision makers', who plan and design development programs and 'implementers' who disseminate those through extension services. Supplementary Materials 5D gives a description of the roles of the actors.

In semi-structured interviews we asked knowledge generators (4), vision makers (3), implementers (4) and extension workers (2) for their responsibilities, goals and vulnerability ('what is the worst that can happen') of the position of the interviewee and the organization. This was followed by the ranking of the strategies for antifragility and elaboration on each of the strategies. As part of this we discussed to what extent their work contributed to the development of the three strategies (i.e. stock, optionality, autonomy) at farm level and what their outlook was on agriculture for the coming 5-10 years. At last, we asked if they could nominate a positive deviant farm with strong performance on the three strategies.

\subsubsection{Farm visits to positive deviant farmers}

Based on the nominations from policy informers positively deviating farmers were visited. During a farm tour structural (farm assets and resources) and functional (livelihood pursuits)

\footnotetext{
${ }^{1} \mathrm{KVK}$ stands for Krishi Vigyan Kendra, meaning 'farm science center', and.is an agricultural extension center in India. KVKs are usually associated with a local agricultural university, and serve as link between the Indian Council of Agricultural Research (ICAR) and farmers.
} 
characteristics of the farm were listed (Supplementary Materials 5E). A semi-structured interview followed in which the farmer was asked for his trajectory of change and reflection on the three strategies for antifragility. Farmers which showed to be exemplar in the combination of optionality, stocks and independence were described as positive deviants.

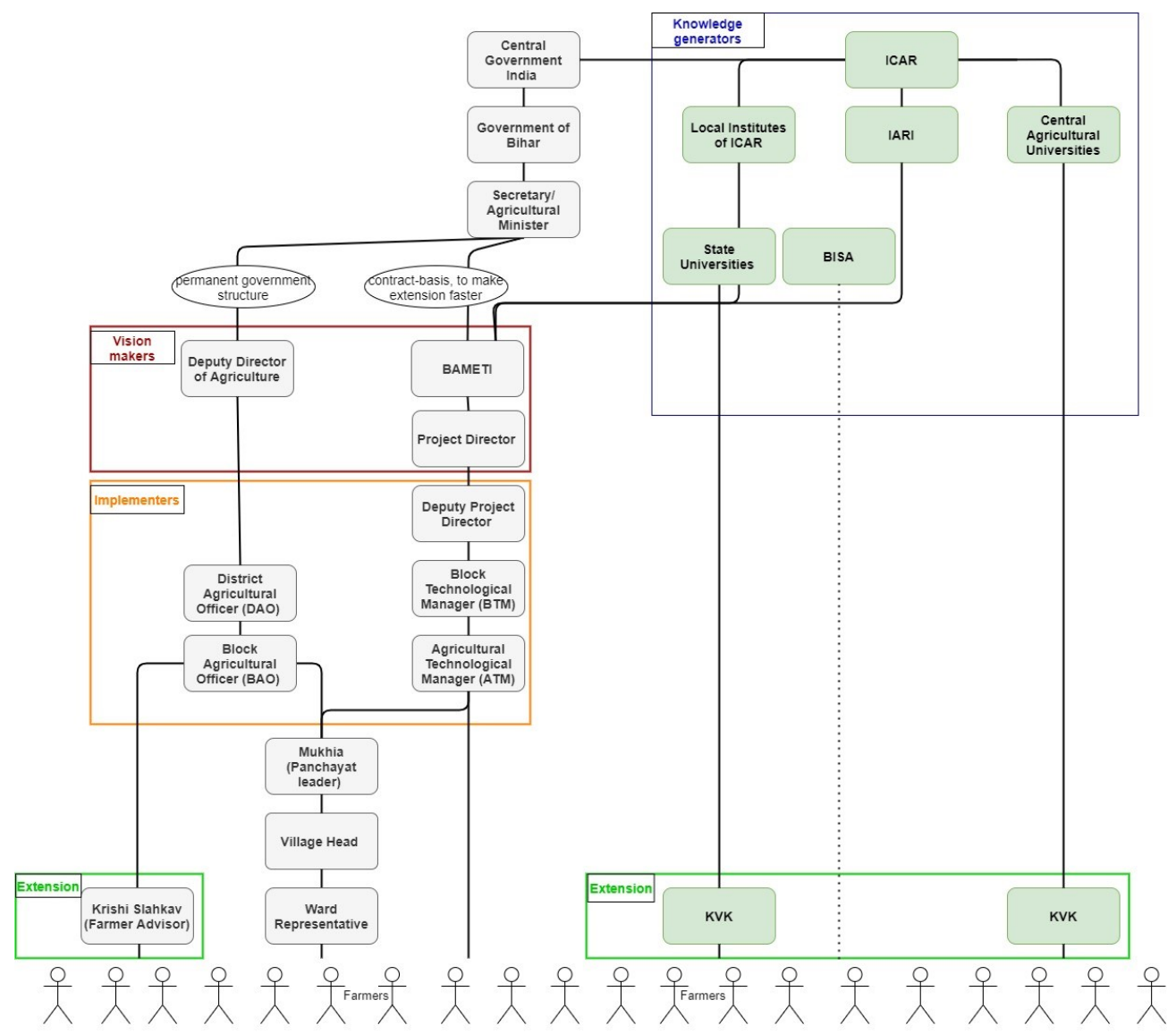

Figure 5.4: Institutional web of policy informers, with knowledge generators, vision makers, implementers and extension workers. Functions in grey are part of the governmental policy-system, functions in green are research, training and extension organizations. 


\section{Results}

\subsection{Challenges and constraints}

Farmers across all farm types listed a broad array of challenges as problematic to sustain livelihoods: water and labor scarcity; low market prices; low quality and access to inputs (Table 5.1). Farmers coped with the majority of the problems by bearing higher costs, leaving land fallow or postponing farm management practices. Pointing at the government for support was common. The consequences and room to manoeuvre differed among farm types. For the Part-time farmers and Wealthy farmers, water or labor scarcity mainly resulted in higher cultivation costs: they had the means to pay higher diesel prices to use borewells or machinery. Farmers from other farm types often had to 'queue' to use a community borewell or to hire laborers. These farmers would eventually also bear the costs of being late with their practices due to reduced farm productivity. High quality inputs were expensive and scarce resulting in inevitable yield penalties for farmers without access to credits (often Cereal crop farmers and Resource poor farmers). They either bought low quality seeds or were late with the purchase of seeds as they did not have credits until the harvest of the previous season was sold.

In some cases, the impact of the problem was buffered through deviation from the business as usual. Labor scarcity could be buffered through including family labor or using mechanization instead of hiring labor; lack of seeds was partly solved by saving wheat seeds; and low market prices were less of a problem when produce was primarily for self-consumption. In addition to the coping and buffering responses, some solutions implied a systems transformation, i.e. re-thinking of the farming system and its management. Farmers mentioned switching crops (especially replacing vegetables and rice), use of organic instead of artificial fertilizers and starting a machinery cooperative as potential options to overcome constraints. However, apart from the use of organic fertilizers, these transformative changes were not practiced among the participants of the FGDs. Not all challenges were unanimously experienced by all farm types. Poor soil quality and lack of credits, were examples of challenges that were felt mostly by lower resource endowed farmers. In addition to the constraints summarized in Table 5.1, land fragmentation, damage by wild animals, lack of off-farm working opportunities and poor water quality were listed as problems, but no solutions were raised. For these points, the farmers pointed at the government to take action. 
Table 5.1: Most frequently mentioned challenges with potential coping strategies. In italics strategies which were already (widely) practiced. Colors categorize the responses as coping (orange), buffering (yellow) or adaptation (green). White fields indicate that the challenge was not (unanimous) recognized by the farm type.

\begin{tabular}{|c|c|c|c|c|c|}
\hline Challenge & Part time farmer & Wealthy farmer & $\begin{array}{l}\text { Crop-livestock } \\
\text { farmer }\end{array}$ & Cereal crop farmer & $\begin{array}{l}\text { Resource poor } \\
\text { farmer }\end{array}$ \\
\hline \multirow[t]{4}{*}{ Water scarcity } & $\begin{array}{l}\text { Irrigate more, bear } \\
\text { increased costs }\end{array}$ & $\begin{array}{l}\text { Gov. should invest } \\
\text { in borewells and } \\
\text { ponds }\end{array}$ & Deepen borewell & $\begin{array}{l}\text { Gov. should invest } \\
\text { in community } \\
\text { borewell }\end{array}$ & \multirow[t]{2}{*}{$\begin{array}{l}\text { Gov. should invest } \\
\text { in community } \\
\text { borewell and ponds }\end{array}$} \\
\hline & \multirow{3}{*}{$\begin{array}{l}\text { Substitute vegetables } \\
\text { and rice }\end{array}$} & Leave land fallow & \multirow{3}{*}{$\begin{array}{l}\text { Switch to green } \\
\text { fodder }\end{array}$} & Leave land fallow & \\
\hline & & & & $\begin{array}{l}\text { Change to short } \\
\text { duration varieties }\end{array}$ & Leave land fallow \\
\hline & & $\begin{array}{l}\text { Switch to green } \\
\text { manure or sesbania }\end{array}$ & & $\begin{array}{l}\text { Switch to green } \\
\text { fodder }\end{array}$ & \\
\hline \multirow[t]{3}{*}{ Labor scarcity } & Delayed seeding & Leave land fallow & Leave land fallow & \multirow{2}{*}{$\begin{array}{l}\text { Pay high price to get } \\
\text { labor }\end{array}$} & \multirow[t]{2}{*}{ Work harder } \\
\hline & Include family labor & $\begin{array}{l}\text { Replace paddy with } \\
\text { sesbania }\end{array}$ & Delayed seeding & & \\
\hline & Use mechanization & Use mechanization & $\begin{array}{l}\text { Include family } \\
\text { labor }\end{array}$ & $\begin{array}{l}\text { Start machinery } \\
\text { cooperative }\end{array}$ & Include family labor \\
\hline \multirow{3}{*}{$\begin{array}{l}\text { Low quality and } \\
\text { access to inputs } \\
\text { (seeds, fertilizers, } \\
\text { pesticides) }\end{array}$} & $\begin{array}{l}\text { Bear higher costs and } \\
\text { lower yields }\end{array}$ & \multirow[t]{3}{*}{$\begin{array}{l}\text { Gov. should own } \\
\text { shops with licensed } \\
\text { products }\end{array}$} & $\begin{array}{l}\text { Bear higher costs } \\
\text { and lower yields }\end{array}$ & \multirow[t]{3}{*}{$\begin{array}{l}\text { Gov. should own } \\
\text { shops with licensed } \\
\text { products }\end{array}$} & $\begin{array}{l}\text { Bear higher costs } \\
\text { and lower yields }\end{array}$ \\
\hline & $\begin{array}{l}\text { Use organic } \\
\text { fertilizers }\end{array}$ & & $\begin{array}{l}\text { Pay higher price } \\
\text { to get scarce }\end{array}$ & & Use vermicompost \\
\hline & Save seeds for wheat & & quality inputs & & \\
\hline \multirow[t]{2}{*}{ Low market prices } & \multirow[t]{2}{*}{ No solution } & $\begin{array}{l}\text { MSP* should be in } \\
\text { place for vegetables }\end{array}$ & $\begin{array}{l}\text { Gov. should } \\
\text { invest in storage } \\
\text { for vegetables }\end{array}$ & $\begin{array}{l}\text { Gov. should invest } \\
\text { in storage for } \\
\text { vegetables }\end{array}$ & \multirow[t]{2}{*}{$\begin{array}{l}\text { Only cultivate for } \\
\text { home consumption }\end{array}$} \\
\hline & & $\begin{array}{l}\text { Change to cash } \\
\text { crops which do well } \\
\text { on the market }\end{array}$ & $\begin{array}{l}\text { Only enter the } \\
\text { market for a part } \\
\text { of the income }\end{array}$ & $\begin{array}{l}\text { MSP* should be in } \\
\text { place for vegetables }\end{array}$ & \\
\hline Lack of advice & & $\begin{array}{l}\text { Approach neighbors, } \\
\text { researchers and call } \\
\text { centers }\end{array}$ & & $\begin{array}{l}\text { Approach neighbors, } \\
\text { researchers and call } \\
\text { centers }\end{array}$ & \\
\hline \multirow[t]{3}{*}{ Poor soil quality } & & & $\begin{array}{l}\text { Level the fields to } \\
\text { avoid ponding }\end{array}$ & $\begin{array}{l}\text { Move clay from } \\
\text { lowlands to poor } \\
\text { highlands }\end{array}$ & \\
\hline & & & & $\begin{array}{l}\text { Use organic } \\
\text { fertilizers }\end{array}$ & \\
\hline & & & & $\begin{array}{l}\text { Grow mung bean } \\
\text { and sesbania }\end{array}$ & \\
\hline \multirow[t]{2}{*}{ Lack of credits } & & & & $\begin{array}{l}\text { Bank should provide } \\
\text { credits }\end{array}$ & Save seeds \\
\hline & & & & & $\begin{array}{l}\text { Do more off-farm } \\
\text { work }\end{array}$ \\
\hline $\begin{array}{l}\text { No suitable } \\
\text { mechanization }\end{array}$ & & $\begin{array}{l}\text { Start machinery } \\
\text { cooperative }\end{array}$ & & & \\
\hline Heat stress & & $\begin{array}{l}\text { Bear losses when } \\
\text { seeding was not } \\
\text { done in time }\end{array}$ & & & \\
\hline $\begin{array}{l}\text { Low crop } \\
\text { productivity }\end{array}$ & & & & & $\begin{array}{l}\text { Purchase better } \\
\text { seeds }\end{array}$ \\
\hline
\end{tabular}




\subsection{Farmers' views on strategies contributing to antifragility}

Farmers interpreted optionality as diversification of marketable crops and this strategy was valued as way to spread risks in case of climatic disasters. Although not acknowledged as optionality, most farmers owned cattle and produced dairy products, crops (cereals) and fruit for home consumption. Especially cereal production was highly valued by all farm types, bothfor home consumption and for sales. Livestock had a subordinate role because of the high labor demand and competition between food and feed crops. Only the farm type with livestock as livelihood strategy (Crop-livestock farmer) mentioned milk as continuous source of income, with a low, but stable price. The Part-time farmers and Resource poor farmers relied on their income from off-farm activities to sustain their way of farming, and a lack of off-farm job opportunities for the Resource poor agricultural laborers was mentioned as problematic. For the other farm types an off-farm job was undesirable but considered an option if necessary, to continue farming. They however wished the next generation futures outside agriculture.

There was little response to peak prices on the market. Farmers reasoned that other farmers would respond quicker and that good price in one year did not guarantee a good price for the next year. Moreover, there was a general reluctance towards change: experimentation was not common, and changes were implemented after others (e.g., neighbors) showed to be successful. This conservative attitude is also expressed in Table 5.1, most challenges were endured.

Stocks were mostly interpreted as storage capacity for products and acknowledged as important to better regulate supply and demand. On-farm storage was limited to cereals for home consumption and wheat seeds. Few redundancies were built into the production systems and although farmers understood the benefits (of e.g. rainwater storage and soil organic matter stocks) little priority was given to invest in these. Communal water ponds were not seen as stocks as they were mainly beneficial for wealthier farmers which had the means to pump.

When talking about autonomy farmers referred to the freedom to say no to advisors and shopkeepers. Although this freedom was felt, farmers expressed to be locked in. They acknowledged the need for change but did not take any action themselves as they expected the government to support them with the right techniques and financial support. Although there were high expectations towards the government, they in general felt disadvantaged compared to farmers in other states and thought that their governmental support was less opportune 
than in the neighboring states. They mentioned that in Bihar the minimum support price ${ }^{2}$ was not working and that they lacked 'good' markets where they could get good prices. When discussing collectiveness versus independence farmers expressed a strong sense of community with neighbors and family for daily life but that farming was restricted to the household. Village meetings were organized where also farm related issues were discussed and farmers were informed if there were governmental projects and schemes. Despite these village meetings there was little (collective) power to address the challenges at hand. Farmers relied heavily on inputs of all sorts and argued that these gave the best chance to get the highest attainable yield. With these high yields the high costs of cultivation would pay off.

\subsection{Policy-views on strategies contributing to antifragility}

When discussing the importance of advice, diversified income, use of inputs, storage and water availability with policy informers, various solutions to the challenges of farmers were mentioned. Conservation agriculture and integrated farming systems were recurrently mentioned as the development directions which could integrally solve the problems at hand. When talking about antifragility all policy informers acknowledged the need of optionality, often referred to as diversity to spread risks. Nevertheless cereals, and in particular rice, were still seen as most important crops of which the cultivation needed to be enhanced through improved technology. Increasing stocks of water and soil quality were seen as crucial for sustainable development of farming systems. The goal was however not to minimize inputs. Use of vermicompost and manure was promoted but artificial fertilizers, pesticides and purchased seeds were seen as inevitable. Autonomy and independence were less familiar concepts and not seen as positive assets. Enhancing farmers' livelihoods was seen as a governmental responsibility, as one of the vision makers said: 'It is our responsibility to bring changes in their behavior. To enhance their income, quality of life.' Being successful as governmental organization implied having farmers adopting the promoted practices. At the higher level, policy informers were skeptical about antifragility as a concept, especially in case of shocks. In their opinion mild and medium-sized disturbances need to be anticipated by becoming more robust (mostly referred to as resilient). Heavy disturbances could not be avoided and were not seen as desirable drivers for change.

\footnotetext{
${ }^{2}$ Based on the recommendations of the Commission for Agricultural Costs and Prices, the Department of Agriculture and Co-operation, Government of India, declares Minimum Support Prices (MSP) for 22 crops before their sowing seasons.
} 


\subsection{Towards antifragile farmers}

\subsubsection{Priorities based on ranking of features of antifragility}

Farmers and policy informers did not indicate clear priorities in development directions when asked to rank features of antifragility (Figure 5.5). No significant differences were found between farmers and policy-informers (Supplementary Materials 5F). All statements received both low and high ranks, indicating that stakeholders were divided within and among groups. Interviews and FGDs revealed that low ranks indicate lower importance but were not perceived unimportant. The only statement that received more low than high ranks by both farmers and policy informers concerned limiting the use of inputs in order to become independent. In general, increasing optionality and stocks were understood as important to further develop, but autonomy and independence were not seen as important characteristics to support an effective response to disturbances.

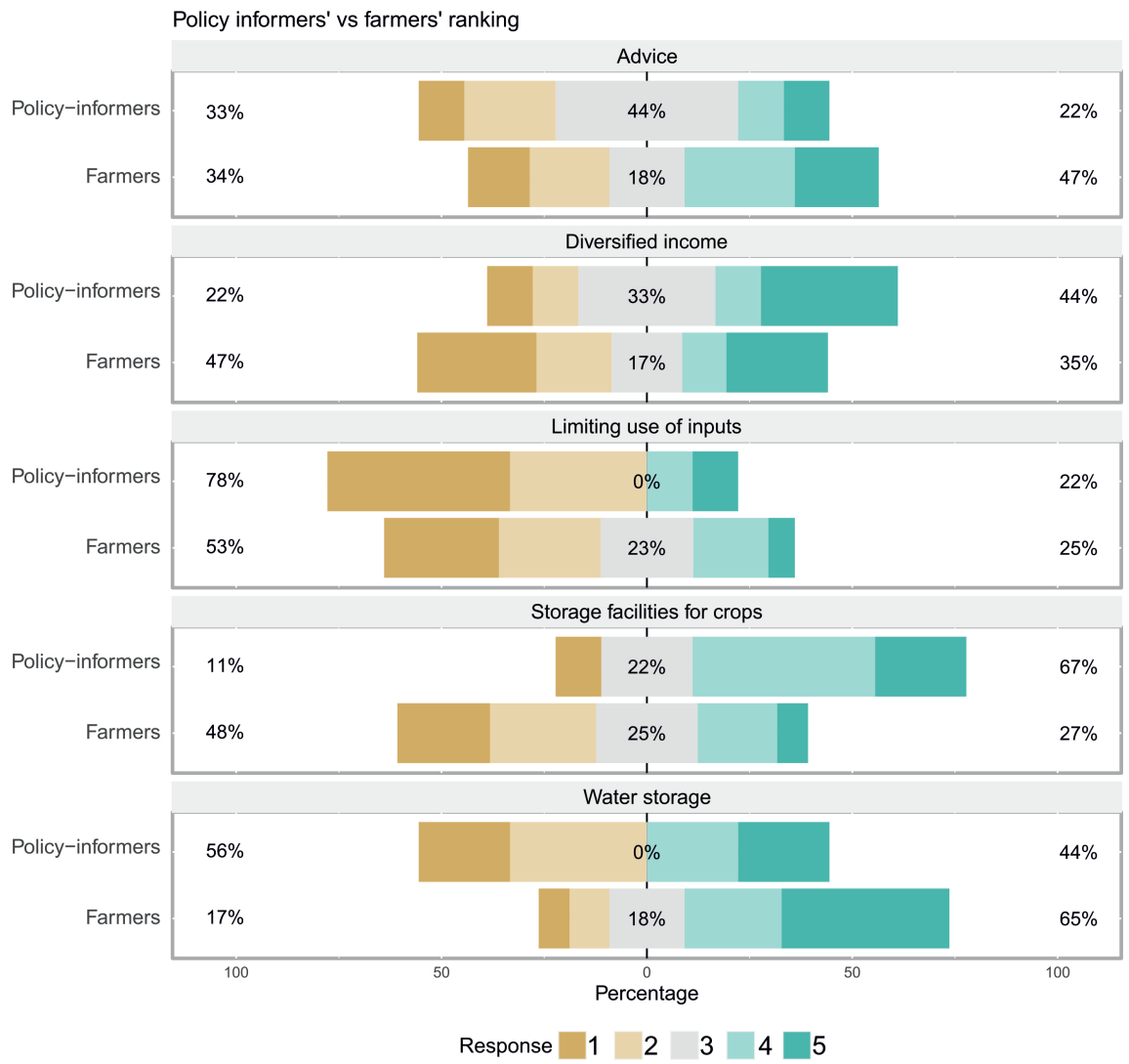

Figure 5.5: Results of ranking of statements regarding importance of features of antifragility by farmers and policy-informers. Response 1 (yellow) indicates lowest importance, 5 (green) highest importance. 


\subsubsection{Positive deviants as examples of antifragile farming systems}

Table 5.2 gives an overview of four farming systems that were nominated by the interviewed policy informers as deviating from the farmer population on the basis of the three strategies. They motivated that structural long-term challenges and constraints rather than by unpredictable shocks triggered them to change their farm management. Opportunities arose through their professional network, which helped to acquire knowledge and skills. These positive deviants started with a phase of experimenting at low costs in which new practices were developed next to the business as usual. Only in case of success, the practice was expanded. With the products (e.g. mushrooms, fish, organic vegetables) a niche market could be entered. The four antifragile farmers made the deliberate choice to increase their optionality (greater diversity) and independence but were nevertheless still dependent on inputs (e.g., seeds).

\section{Box 1: Personal stories about the trajectories of positive deviant farmers}

Mushrooms, biogas, fish, service provider: “Eight years ago I didn't have a positive outlook on agriculture. I asked a researcher who came to the village regularly: 'should I quit farming and look for a job in the city?'. He did not give any advice, but offered me a training to install and use a biogas installation. I liked it very much. When I was familiar with the biogas I wanted to explore something new. I got a training in growing mushrooms. I can sell them easily and there is demand for spores, so I also started to sell spores. These activities boosted my enthusiasm to farm. I invested in machinery which I also use to work as a contractor. I like to say that money is a good teacher; if you earned, you learned!"

Fish collective: "Before 2010 the area was often fallow: the lowlands of Saray Ranjan had unfavorable conditions for good crop growth. Fish cultivation was stimulated by the government and I got the opportunity to follow a course on fishery in Andhra Pradesh. Together with 5 farmers I started the first pond. It went well and we wanted to expand. We asked farmers with their fields adjacent to the pond to join our collective. Now farmers ask us if they can join. Then they are offered a training. These ponds are like an ATM. If members need money, they call a fisherman, there are always customers and in all stages of the growth there is return. On the sides of the ponds, vegetables are cultivated and fruit trees are abundant. With the collective labor is not a problem. We are now 37 farmers with in total 95 acres (38 ha). It is good to be bigger, there are always people around to watch and to guard. The government is also helpful because we are a group, there is now electricity. We also get monthly visits from an expert who advises, but by now we know what to do with most of the challenges." 
Table 5.2: Description of production and management systems of antifragile examples.

\begin{tabular}{|c|c|c|c|c|}
\hline Production system & Stocks & Optionality & Independence & Notes \\
\hline $\begin{array}{l}\text { Organic farm, } \\
\text { diversified } \\
\text { production }\end{array}$ & $\begin{array}{l}200 \text { trees for timber, } \\
\text { harvested when } \\
\text { needed, usually } \\
\text { after } 15 \text { y; chili } \\
\text { can be stored; Soil } \\
\text { improvement with } \\
\text { vermicompost led } \\
\text { to lower irrigation } \\
\text { demand. }\end{array}$ & $\begin{array}{l}\text { Wide variety of crops } \\
\text { (incl. flowers and } \\
\text { medicinal herbs } \\
\text { which are rare); } \\
\text { vermicompost }\end{array}$ & $\begin{array}{l}\text { Direct sales; uses } \\
\text { mainly organic } \\
\text { fertilizers; cereals } \\
\text { for home consumption }\end{array}$ & $\begin{array}{l}\text { At the moment no } \\
\text { market for organic } \\
\text { produce but expects } \\
\text { this soon, expects to } \\
\text { benefit from a head } \\
\text { start. Already inspired } \\
30 \text { nearby farmers } \\
\text { who are also (partly) } \\
\text { organic now. Satisfied } \\
\text { with income. }\end{array}$ \\
\hline $\begin{array}{l}\text { Mushroom } \\
\text { production \& arable } \\
\text { production }\end{array}$ & $\begin{array}{l}\text { Mushroom residue } \\
\text { goes to soil; } \\
\text { vermicompost gives } \\
\text { good results }\end{array}$ & $\begin{array}{l}\text { Wide variety of crops } \\
\& \text { mushrooms }\end{array}$ & $\begin{array}{l}\text { Direct sales; network } \\
\text { of 'innovative } \\
\text { farmers' for } \\
\text { knowledge exchanges }\end{array}$ & $\begin{array}{l}\text { Satisfied with income } \\
\text { and way of farming }\end{array}$ \\
\hline
\end{tabular}

Learns from doing:

if an experiment is successful, he increases area. Now trials with capsicum.

\begin{tabular}{|c|c|c|c|c|}
\hline $\begin{array}{l}\text { Mushrooms } \\
\text { (oyster \& spores), } \\
\text { biogas, fish, service } \\
\text { provider, rents out } \\
\text { tube-well (box 1) }\end{array}$ & $\begin{array}{l}\text { Manure is source } \\
\text { of biogas, digestate } \\
\text { used as fertilizer; } \\
\text { has stock of biogas; } \\
\text { cereal stock; dries } \\
\text { mushrooms to store; } \\
\text { family members all } \\
\text { work on farm and } \\
\text { replace each other. }\end{array}$ & $\begin{array}{l}\text { Different agricultural } \\
\text { 'enterprises' } \\
\text { generating income } \\
\text { throughout the year. } \\
\text { Cultivation and } \\
\text { service provision } \\
\text { (tube-well and } \\
\text { contract work with } \\
\text { own machinery) }\end{array}$ & $\begin{array}{l}\text { Has own input-shop } \\
\text { and own machinery; } \\
\text { Direct sales - } \\
\text { negotiates price with } \\
\text { customers who come } \\
\text { to the farm. }\end{array}$ & $\begin{array}{l}\text { Received training but } \\
\text { no/little monetary } \\
\text { support. Proud to be a } \\
\text { teacher in mushroom } \\
\text { cultivation. }\end{array}$ \\
\hline $\begin{array}{l}\text { Fish collective (box } \\
\text { 1) }\end{array}$ & $\begin{array}{l}\text { Always produce; } \\
\text { safety increases } \\
\text { with more members } \\
\text { (more people to } \\
\text { watch/guard); }\end{array}$ & $\begin{array}{l}\text { Different types of } \\
\text { fish; wide variety of } \\
\text { fruits and vegetables } \\
\text { for members of the } \\
\text { collective; labor tasks } \\
\text { are divided }\end{array}$ & $\begin{array}{l}\text { Direct sales; no } \\
\text { employees, hire } \\
\text { temporary labor when } \\
\text { needed. }\end{array}$ & $\begin{array}{l}\text { All members of the } \\
\text { collective also have } \\
\text { their own farming } \\
\text { activities. Manure is } \\
\text { collected and used } \\
\text { as fertilizer for the } \\
\text { ponds. } \\
\text { As collective they } \\
\text { have more power, } \\
\text { government provided } \\
\text { electricity. }\end{array}$ \\
\hline
\end{tabular}

\section{Discussion}

In this study we assessed the fragility of different types of smallholder farmers in Bihar and explored the scope for more antifragile farming systems. We found that farmers across all farm types were challenged by water and labor scarcity; low market prices; low quality and access to inputs; limited access to inputs; land fragmentation; and damage by wild animals. Farmers made mostly short-term decisions to cope with or mitigate the urgent challenges at hand but did not 
engage in strategic planning driven by longer term objectives. Spreading risks was a motivation to diversify the dominant rice-wheat system with other marketable crops, and increased optionality. Other than this, the strategies for antifragility were not consciously incorporated in the current way of farming: few redundancies were built into the system and farmers showed strong dependence on the government to improve their production systems and livelihoods, which was interpreted as limited autonomy. Four positive deviant farmers showed that complex and abundant farming systems with ample optionality and redundancies are possible and can be profitable. These positive deviants received initial help from governmental programs, and their inherent characteristics (e.g., autonomy, engagement, self-organization) allowed a process of tinkering (evolutionary improvement through experimentation and selection) which resulted in more antifragile farming systems.

Our results show that farmers across all farm types were vulnerable and locked-in with limited adaptive capacity to improve their situation (Table 5.1). The level of vulnerability however differed across farm types as adaptive capacity and exposure to challenges depended on resource endowment. Many challenges implied either increased cultivation costs or delayed crop management practices leading to yield penalties. Farmers that were more resource endowed (Part-time farmers, Wealthy farmers, Cereal crop farmers) also had more adaptive capacity. They often could afford the higher costs while the less resource endowed farmers (Crop-livestock farmers and Resource poor farmers) had no means to manage higher costs or the social context did not allow them first access to the resource. Lower resource endowed farmers were more and often earlier exposed to challenges as they simply ran out of resources quicker. As an example, farmers with no means to irrigate were earlier challenged by a drought (i.e. water scarcity) than farmers who could initially irrigate.

FDGs and interviews with policy informers revealed a strong top-down community governance and policy structure with little encouragement for autonomous, bottom-up initiatives. For farmers, as lowest level entities (Figure 5.4), the available money and information streams were translated into concrete and systematic programs. These programs aimed for uniformity which determined the inputs (types of seeds, fertilizers, pesticides) and advice given by extension workers and shopkeepers. Especially the higher resource endowed farmers, the target group for many development programs, showed little pro-activeness: they were well-informed about potential solutions for their challenges but pointed at the government to start programs or initiate a transition, mainly in the form of subsidies and training. 
The ability to take initiative (i.e. decision-making, agency) is not purely a rational process (Moller et al., 2006; Pacilly et al., 2016; Ryan and Deci, 2000). Adoption and adaptation of new practices and technologies are related to farmers' motivations, that can range in their degree of autonomy and control (Jambo et al., 2019; Moller et al., 2006). Self-determination theory recognizes autonomy, competence and connectedness as the basis on which motivation is build (Ryan and Deci, 2000). In our study, these characteristics distinguished the positive deviants from the farmers in the FGDs. Although farms within a farm type were very similar in their resources and livelihood strategies, there was no collective power (i.e. connectedness) to enhance the constrained situation, neither to share knowledge or practical work. In contrast, the positive deviants formed strong ties with others for production and marketing which stimulated learning and continuous adaptations of the farming systems management and beyond. They indicated engagement and satisfaction with their systems, their daily activities and their income.

The self-determination theory explains that coercive and external pressures tend to minimize (intrinsic) motivation (Moller et al., 2006; Ryan and Deci, 2000). We observed this in the strong reliance on governmental interventions. Triggering farmers' intrinsic motivation and connectedness is crucial to increase autonomous functioning (Stobbelaar et al., 2009). Greater autonomy will enable initiative and development of competences (Moller et al., 2006), e.g. through a dual strategy where something new is explored (Barbell Strategy) or tinkering. When practices, knowledge and skills are continuously developed, complexity will evolve over time (Clancy, 2010; Urruty et al., 2016), and increase in optionality, stocks and redundancy can be expected (Altieri et al., 2015; Gliessman, 2015). As a result of these assets, adaptiveness increases. Figure 5.6 schematically represents this rationale which could ultimately lead to more antifragility at farm level. To support such a shift, transformation and adaptation at policy-level may be required. This can for example start with formulation of goal-oriented and adaptive policies that promote cooperation (Stobbelaar et al., 2009). In this way we can aim for connective systems which are socio-economically and biophysically adaptive.

When interpreting the results presented here, the consequences of our approach should be considered. In this study we organized FGDs to identify challenges and coping strategies of different types of smallholder farmers. In order to have farmers available, the FGDs were planned in the middle of the rabi season (January and February) which is a relatively quiet moment in the year. Our results and analysis are based on a snapshot in time while the perception of challenges may be dynamic (Nikolaski et al., 2018). The challenges listed in Table 5.1 can 
be identified as structural problems or long-term stressors. Although Bihar is known for its vulnerability in case of climatic anomalies (Chhabra and Haris, 2015; Erenstein et al., 2007; R. Jat et al., 2018; Shirsath et al., 2017) sudden disturbances and shocks were hardly mentioned. This can be explained by the lower frequency of the shocks compared to the continuous stress of the daily challenges and the age of the participants. Only challenges that were shared among all participants of the FDG were listed, and younger farmers may not have been exposed to rarer shocks. Although the list of challenges may not be exhaustive, understanding of the stressors is an indispensable first step towards increasing the systems' vulnerability to shocks (Tendall et al., 2015).

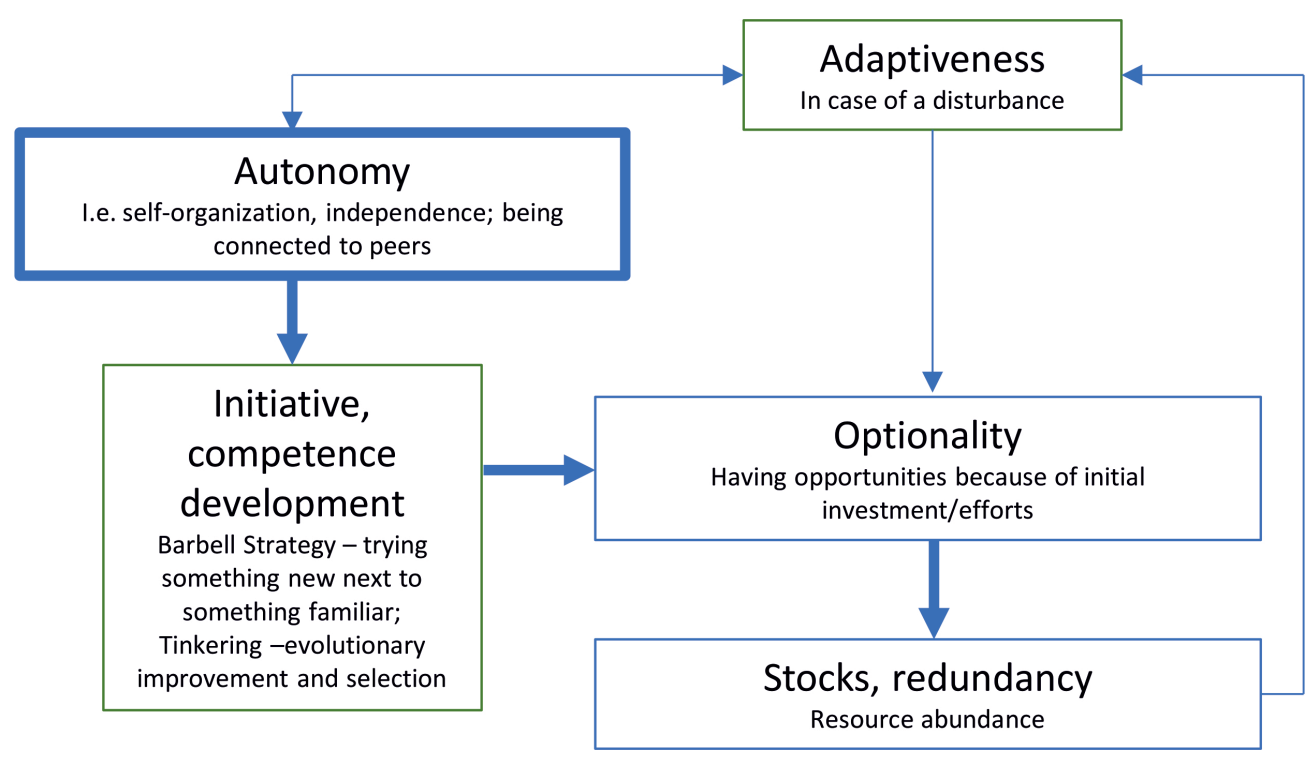

Figure 5.6: Relationship between autonomy and the ability to develop optionality and stocks, to reinforce adaptiveness in case of a disturbance.

Four positive deviant farms showed that it was feasible to deviate from the dominating wheat-rice production systems. We did not collect data on performance indicators and were therefore not able to show quantitative (statistical) deviance compared to average farmers. Because the positive deviant farmers showed optionality, stocks and independence, we expect them to be more antifragile but we do not have direct evidence in terms of differences in systems dynamics between farms. Moreover, it was difficult to single out success factors with this small and normatively selected sample of farmers. To go beyond the explorative nature of this study, the social and agronomical performance and development should be better understood for more 
positive deviants with different types of farming systems. Clear indicators for positive deviance should then be developed. These positive deviants received help from governmental programs, which probably made that they were known by the policy informers who nominated them. Although they showed higher levels of autonomy and seemed not to lean on the attention they got, the flagship position may have helped them to develop.

In this study we introduced the term antifragility as a dynamic system property in socio-ecological systems. The features contributing to antifragility are not new to the literature, on the contrary: it is too abundant to be complete. A few examples: optionality, especially in the form of diversity, is widely acknowledged to foster adaptation. Ecological, social and political diversity are promoted to increase options and reduce risks (Altieri et al., 2015; Berkes, 2007; Hoy, 2015; MacFall et al., 2015). Stocks in various forms contribute as buffer against failure: redundancy and diversity avoid that loss of critical system components trigger dramatic changes in the system-dynamics (Altieri et al., 2015; Hodbod and Eakin, 2015). Fraser et al. (2015) and Stave and Kopainsky (2015) relate the importance of stocks to food security. Autonomy or self-organization in biological, social and ecological systems should avoid top-down suppression and reliance, and supports the self-organizing properties of diverse entities at local scales (Berkes, 2007; Hoy, 2015).

To what extent are we, with introducing antifragility as a new concept, giving different words to ideas that have been discussed in the literature as adaptive management, adaptation, resilience, and transformation literature? To a certain extent: antifragility requires adaptation and transformation to benefit from disturbances and evolve. Antifragility however aims to use disturbances to improve the system and to increase its performance. It does not aim at stability, coping or recovery, instead, it entails long-term learning, trial and adaptation to structurally gain from disorder. The resilient system-dynamics described by for example Darnhofer (2014) (i.a. transformation after unexpected shocks) and Tendall et al. (2015) (i.a. eradicate weaknesses to build capacities) could therefore be recognized as antifragile responses. Moreover, movements like agroecology and organic agriculture claim to reduce vulnerability and increase resilience because of attention for crop and animal diversification, maintenance of local genetic diversity, crop rotations and organic matter-and nutrient cycles (Altieri et al., 2015) and these systems may often have antifragile responses.

This study explored the scope to increase antifragility at farm level. Farmers are, as primary producers, however influenced by commercial (traders, breeders, financers) and public institutes 
(Figure 5.4) all with their own objectives (Pacilly et al., 2016). True antifragility extends to this whole system. That would require rigorous rethinking of the hierarchical structures and desirable size of food systems. In the light of antifragility at different levels, we are in a unique moment in time: the COVID-19 pandemic affects all actors in the food system. This gives ample opportunity to study system-dynamics.

\section{Conclusions}

We conclude that farmers across all farm types were vulnerable and locked-in with limited adaptive capacity to improve the challenges at hand. Although challenges were often not jeopardizing the continuity of the farms, farmers acknowledged a need for change. They however did not take action as they expected governmental support. Four positive deviant farmers deviated in terms of autonomy, competence and connectedness and showed highly divers farming systems, rich in optionality and stocks. They formed strong ties with others for production and marketing which stimulated learning and continuous adaptations of the farming systems management and beyond.

Focus group discussions with farmers and interviews with policy informers revealed strong top-down community governance and policy structure with little encouragement for autonomous, bottom-up initiatives. To support a shift towards more antifragile farming systems, adaptation at policy-level may be required. This could start with formulation of goal-oriented and adaptive policies that promote cooperation. When practices, knowledge and skills are continuously developed, complexity will evolve over time, allowing an evolutionary process of reconfiguration and selection that leads to improvements in farm performance and adaptive capacity. In this way we can aim for socio-economically and biophysically adaptive farming systems that become antifragile over time.

\section{Acknowledgements}

We acknowledge the financial and technical support from CGIAR Research Programs on Climate Change, Agriculture and Food Security (CCAFS), Wheat Agri-food Systems (WHEAT), Indian Council of Agricultural Research (ICAR), and all donors who supported this research through their contributions to the CGIAR Fund. For a list of Fund donors please 
see: http://www.cgiar.org/our-funders/. We thank the farmers for their time and for sharing their experiences and expertise. The contribution of JCJG was supported by the Senior Expert program of the Dutch Science Council (NWO), grant number 17222. 


\section{References}

Adelhart Toorop, R., Ceccarelli, V., Bijarniya, D., Jat, M. L., Jat, R. K., Lopez-Ridaura, S., and Groot, J. C. (2020a), Using a positive deviance approach to inform farming systems redesign: A case study from Bihar, India. Agricultural Systems. 185(February): p. 102942.

Adelhart Toorop, R., Lopez-Ridaura, S., Bijarniya, D., Kalawantawanit, E., Jat, R. K., Prusty, A. K., Jat, M. L., and Groot, J.C. (2020b), Farm-level exploration of economic and environmental impacts of sustainable intensification of rice-wheat cropping systems in the Eastern Indo-Gangetic plains. European Journal of Agronomy. 121: p. 126157.

Altieri, M. A., Nicholls, C. I., Henao, A., and Lana, M. A. (2015), Agroecology and the design of climate change-resilient farming systems. Agron. Sustain. Dev. 35(3): p. 869-890.

Behera, U. K. and France, J. (2016), Integrated Farming Systems and the Livelihood Security of Small and Marginal Farmers in India and Other Developing Countries. Advances in Agronomy. 138: p. 235-282.

Berkes, F. (2007), Understanding uncertainty and reducing vulnerability: Lessons from resilience thinking. Natural Hazards. 41(2): p. 283-295.

Chhabra, V. and Haris, A. A. (2015), Climate Variability, Extreme Rainfall and Temperature Events over Different Agro-ecological Zones of Bihar. Journal of AgriSearch. 2(3): p. 189-194.

Clancy, T. R. (2010), Diamonds in the rough: Positive deviance and complexity. Journal of Nursing Administration. 40(2): p. 53-56.

Darnhofer, I. (2014), Resilience and why it matters for farm management. European Review of Agricultural Economics. 41(3): p. 461-484.

Darnhofer, I. (2020), Farm resilience in the face of the unexpected: lessons from the COVID-19 pandemic. Agriculture and Human Values. 37(3): p. 605-606.

Erenstein, O. and Thorpe, W. (2011), Livelihoods and agro-ecological gradients: A meso-level analysis in the Indo-Gangetic Plains, India. Agricultural Systems. 104(1): p. 42-53.

Erenstein, O., Thorpe, W., Singh, J., and Varma, A. (2007), Crop-livestock interactions and livelihoods in the Indo-Gangetic Plains, India: A regional synthesis. CIMMYT.

Folke, C. (2006), Resilience: The emergence of a perspective for social-ecological systems analyses. Global Environmental Change. 16(3): p. 253-267.

Folke, C., Carpenter, S. R., Walker, B., Scheffer, M., Chapin, T., and Rockström, J. (2010), Resilience thinking: Integrating resilience, adaptability and transformability. Ecology and Society. 15(4).

Fraser, E. D., Legwegoh, A., and KC, K. (2015), Food stocks and grain reserves: evaluating whether storing food creates resilient food systems. Journal of Environmental Studies and Sciences. 5(3): p. 445-458.

Gallopín, G. C. (2006), Linkages between vulnerability, resilience, and adaptive capacity. Global Environmental Change. 16(3): p. 293-303.

Gliessman, S. (2015), Agroecology: The Ecology of Sustainable Food Systems. Ed. by E. W. Engles. 3rd ed. Santa Cruz: CRC Press Taylor \& Francis Group, p. 351.

Hendrickson, M. K. (2015), Resilience in a concentrated and consolidated food system. Journal of Environmental Studies and Sciences. 5(3): p. 418-431.

Hodbod, J. and Eakin, H. (2015), Adapting a social-ecological resilience framework for food systems. Journal of Environmental Studies and Sciences. 5(3): p. 474-484.

Hoy, C. W. (2015), Agroecosystem health, agroecosystem resilience, and food security. Journal of Environmental Studies and Sciences. 5(4): p. 623-635.

Jambo, I. J., Groot, J. C., Descheemaeker, K., Bekunda, M., and Tittonell, P. (2019), Motivations for the use of sustainable intensification practices among smallholder farmers in Tanzania and Malawi. NJAS - Wageningen Journal of Life Sciences. 89: p. 100306.

Jat, M. L., Chakraborty, D., Ladha, J. K., Rana, D. S., Gathala, M. K., McDonald, A., and Gerard, B. (2020), Conservation agriculture for sustainable intensification in South Asia. Nature Sustainability. 3(4): p. 336-343.

Jat, R., Singh, R. G., Kumar, M., Jat, M., Parihar, C. M., Bijarniya, D., Sutaliya, J. M., Jat M.K, Parihar, M., Kakraliya, S. K., and Gupta, R. K. (2018), Ten years of conservation agriculture in a rice-maize rotation of Eastern Gangetic Plains of India: Yield trends, water productivity and economic profitability. Field Crops Research. 232(April 2018): p. $1-10$.

Laik, R., Sharma, S., Idris, M., Singh, A. K., Singh, S. S., Bhatt, B. P., Saharawat, Y., Humphreys, E., and Ladha, J. K. (2014), Integration of conservation agriculture with best management practices for improving system performance of the rice-wheat rotation in the Eastern Indo-Gangetic Plains of India. Agriculture, Ecosystems and Environment. 195: p. 68-82.

Lopez-Ridaura, S., Frelat, R., Van Wijk, M. T., Valbuena, D., Krupnik, T. J., and Jat, M. L. (2018), Climate smart agriculture, farm household typologies and food security: An ex-ante assessment from Eastern India. Agric. Syst. 159(September 2016): p. 57-68. 
Lopez-Ridaura, S., O., M., and Astier, M. (2002), Evaluating the sustainability of com-plex socio-environmental systems. Ecological Indicators. 2((1-2)): p. 135-148.

MacFall, J., Lelekacs, J. M., LeVasseur, T., Moore, S., and Walker, J. (2015), Toward resilient food systems through increased agricultural diversity and local sourcing in the Carolinas. Journal of Environmental Studies and Sciences. 5(4): p. 608-622.

McCubbin, S., Smit, B., and Pearce, T. (2015), Where does climate fit? Vulnerability to climate change in the context of multiple stressors in Funafuti, Tuvalu. Global Environmental Change. 30: p. 43-55.

Meynard, J. M., Charrier, F., Fares, M., Le Bail, M., Magrini, M. B., Charlier, A., and Messéan, A. (2018), Socio-technical lock-in hinders crop diversification in France. Agronomy for Sustainable Development. 38(5).

Moller, A. C., Ryan, R. M., and Deci, E. L. (2006), Self-determination theory and public policy: Improving the quality of consumer decisions without using coercion. Journal of Public Policy and Marketing. 25(1): p. 104-116.

Nikolaski, Z., Christiaensen, L., and Hill, R. (2018), Household shocks and coping mechanism: evidence from Sub-Saharan Africa. Telling Myths from Facts. Directions in Development-Agriculture and Rural Development. (November 2017): p. 123-134.

Pacilly, F. C., Groot, J. C., Hofstede, G. J., Schaap, B. F., and van Bueren, E. T. (2016), Analysing potato late blight control as a social-ecological system using fuzzy cognitive mapping. Agronomy for Sustainable Development. $36(2)$.

Pant, L. P. and Odame, H. H. (2009), The promise of positive deviants: bridging divides between scientific research and local practices in smallholder agriculture. Knowl. Manag. Dev. J. 5(2): p. 160-172.

Ryan, R. M. and Deci, E. L. (2000), Self-determination theory and the facilitation of intrinsic motivation, social development, and well-being. American Psychologist. 55(1): p. 68-78.

Shirsath, P. B., Aggarwal, P. K., Thornton, P. K., and Dunnett, A. (2017), Prioritizing climate-smart agricultural land use options at a regional scale. Agricultural Systems. 151: p. 174-183.

Singh, R. K., Singh, A., Kumar, S., Sheoran, P., Sharma, D. K., Stringer, L. C., Quinn, C. H., Kumar, A., and Singh, D. (2020), Perceived Climate Variability and Compounding Stressors: Implications for Risks to Livelihoods of Smallholder Indian Farmers. Environmental Management: p. 1-19.

Smit, B. and Wandel, J. (2006), Adaptation, adaptive capacity and vulnerability. Global Environmental Change. 16(3): p. 282-292.

Stave, K. A. and Kopainsky, B. (2015), A system dynamics approach for examining mechanisms and pathways of food supply vulnerability. Journal of Environmental Studies and Sciences. 5(3): p. 321-336.

Stobbelaar, D. J., Groot, J. C., Bishop, C., Hall, J., and Pretty, J. (2009), Internalization of agri-environmental policies and the role of institutions. Journal of Environmental Management. 90(SUPPL. 2): S175-S184.

Taleb, N. N. (2012), Antifragile - things that gain from disorder. Vol. 53. 9, p. 1689-1699. arXiv: arXiv: 1011.1669v3.

Tendall, D. M., Joerin, J., Kopainsky, B., Edwards, P., Shreck, A., Le, Q. B., Kruetli, P., Grant, M., and Six, J. (2015), Food system resilience: Defining the concept. Global Food Security. 6: p. 17-23.

Urruty, N., Tailliez-Lefebvre, D., and Huyghe, C. (2016), Stability, robustness, vulnerability and resilience of agricultural systems. A review. Agronomy for Sustainable Development. 36(1): p. 1-15.

Walker, B., Holling, C. S., Carpenter, S. R., and Kinzig, A. (2004), Resilience, adaptability and transformability in social-ecological systems. Ecology and Society. 9(2). 


\section{Supplemental Material}

\section{Supplementary Materials 5A: : Characteristics of farm-types}

Lopez-Ridaura et al. (2018) constructed a typology based on a farm household survey on farming systems and livelihood pursuits. Table 1 gives an overview of the farm characteristics of each of the types. This table has been derived from Adelhart Toorop et al. (2020a).

Table S1: Description of the five farm types in Bihar. Values are medians for cultivated area, livestock density and mechanization score, and averages for fraction of harvested crops sold to markets.

\begin{tabular}{|c|c|c|c|c|c|}
\hline Type label & Type 1 & Type 2 & Type 3 & Type 4 & Type 5 \\
\hline $\begin{array}{l}\text { Short } \\
\text { description }\end{array}$ & $\begin{array}{l}\text { Part-time } \\
\text { farmers }\end{array}$ & Wealthy farmers & $\begin{array}{l}\text { Small-scale crop } \\
\text { and livestock } \\
\text { farmers }\end{array}$ & $\begin{array}{l}\text { Medium-scale } \\
\text { cereal crop } \\
\text { farmers }\end{array}$ & $\begin{array}{l}\text { Resource-poor } \\
\text { agricultural } \\
\text { labourers }\end{array}$ \\
\hline Cultivated area & 1 ha & 2 ha & 0.6 ha & $1.2 \mathrm{ha}$ & $0.3 \mathrm{ha}$ \\
\hline TLU on farm & 1 & 2 & 3 & 1 & $\begin{array}{l}\text { No significant } \\
\text { production }\end{array}$ \\
\hline $\begin{array}{l}\text { Mechanization } \\
\text { score }^{1}\end{array}$ & 5.2 & 6 & 3.6 & 4.4 & 1.9 \\
\hline Crops cultivated & $\begin{array}{l}\text { Staples }^{2} \text { and } \\
\text { also oilseeds and } \\
\text { vegetables }\end{array}$ & $\begin{array}{l}\text { Large variety } \\
\text { of crops: } \\
\text { staples }{ }^{2} \text {, oilseeds, } \\
\text { vegetables }\end{array}$ & Mostly staples ${ }^{2}$ & $\begin{array}{l}\text { Mostly wheat-rice } \\
\text { rotation }\end{array}$ & $\begin{array}{l}\text { Mostly wheat-rice } \\
\text { rotation }\end{array}$ \\
\hline $\begin{array}{l}\text { Fraction of } \\
\text { harvested crops } \\
\text { sold to market }\end{array}$ & One-third & Half & Not provided & Not provided & $\begin{array}{l}\text { Mostly home } \\
\text { consumption }\end{array}$ \\
\hline $\begin{array}{l}\text { Other } \\
\text { characteristics }\end{array}$ & $\begin{array}{l}\text { Primary income } \\
\text { from off farm } \\
\text { work. Taking part } \\
\text { in agriculture only } \\
\text { on a part-time } \\
\text { basis }\end{array}$ & $\begin{array}{l}\text { Rich and } \\
\text { market-oriented } \\
\text { farmers. Median } \\
\text { income from crop } \\
\text { and livestock is } \\
60 \% \text { and } 30 \% \text {, } \\
\text { respectively }\end{array}$ & $\begin{array}{l}\text { Highest } \\
\text { proportion of } \\
\text { income generated } \\
\text { from livestock } \\
\text { product sales } \\
\text { (median } 27 \% \text { ). } \\
\text { Intensive use of } \\
\text { crop residues } \\
\text { as animal } \\
\text { feed ( } 75 \% \text { ). } \\
40 \% \text { income } \\
\text { originating from } \\
\text { sales of food } \\
\text { crops. Large } \\
\text { families ( } 12 \text { adult } \\
\text { equivalents per } \\
\text { ha }->\text { on a } 0.6 \\
\text { ha farm }+/-5 \\
\text { adults). Low in } \\
\text { mechanization. }\end{array}$ & $\begin{array}{l}\text { Income primarily } \\
\text { dependent on } \\
\text { food and cash } \\
\text { crops (median } \\
70 \% \text { ). Milk } \\
\text { is primarily } \\
\text { for home } \\
\text { consumption } \\
\text { and does not } \\
\text { represent a source } \\
\text { of income }\end{array}$ & $\begin{array}{l}\text { Primary income } \\
\text { from off farm } \\
\text { work, mainly as } \\
\text { laborers on other } \\
\text { farms. Most of } \\
\text { crop residues are } \\
\text { either sold or used } \\
\text { for fuel }\end{array}$ \\
\hline $\begin{array}{l}\text { Proportion of } \\
\text { farms belonging } \\
\text { to the type in } \\
\text { Bihar }\end{array}$ & $17 \%$ & $23 \%$ & $19 \%$ & $27 \%$ & $14 \%$ \\
\hline
\end{tabular}

${ }^{1}$ Mechanization score is calculated according to Lopez-Ridaura et al. (2018).

${ }^{2}$ Staples in Bihar are wheat, rice and maize.

${ }^{3}$ Based on the proportion found in the 269 surveyed farms by Lopez-Ridaura et al. (2018). 


\section{Supplemenary Materials 5B: Quick-survey to allocate types to farmers.}

In the days prior to the FGDs, quick surveys were conducted to assign farmers a type. Table 2 gives an overview of the quick-survey used.

Table S2: Survey on houshold characteristics to allocate farms a type.

\begin{tabular}{|c|c|c|}
\hline Farm type & $1-2-3-4-5$ & \\
\hline \multicolumn{3}{|l|}{ Farmer name } \\
\hline \multicolumn{3}{|l|}{ Fathers name } \\
\hline \multicolumn{3}{|l|}{ Phone number } \\
\hline \multicolumn{3}{|l|}{ Farm size (mention unit) } \\
\hline \multicolumn{3}{|l|}{ Number of adults in household (>16y) } \\
\hline \multicolumn{3}{|l|}{ Number of 'youngsters' (10-16 years) } \\
\hline \multicolumn{3}{|l|}{ Household members involved in farming (n) } \\
\hline \multicolumn{3}{|l|}{ Household members involved in off-farm work (n) } \\
\hline \multicolumn{3}{|l|}{ Number of cows/buffalo (n) } \\
\hline \multicolumn{3}{|l|}{ Number of goats $(\mathrm{n})$} \\
\hline \multicolumn{3}{|l|}{ Number of chickens (n) } \\
\hline Crops grown in kharif season (excl. homegarden) & Crop: & INR/Self cons. \\
\hline Crops grown in rabi season (excl. homegarden) & Crop: & INR/Self cons. \\
\hline \multicolumn{3}{|l|}{$\begin{array}{l}\text { Crops grown in zaid (list crops }+ \text { size; excl. } \\
\text { homegarden) }\end{array}$} \\
\hline \multicolumn{3}{|l|}{ Income from livestock (INR) } \\
\hline \multicolumn{3}{|l|}{ Income from off-farm sources (INR) } \\
\hline Do you own a rainwater storage? & Yes/No* & \\
\hline Do you have storage facilities for farm products? & Yes/No* & \\
\hline
\end{tabular}

*Delete as appropriate

\section{Supplemenary Materials 5C: Format Focus group discussions}

Introduction (5 min): Facilitator introduces research team and expectations for the session.

\section{Vulnerability - disturbances, challenges and constraints (30 $\mathrm{min})$}

- Do you remember an especially good year? Why was it good?

- Which events were disastrous in the past? Did this lead to a change in management?

- What disturbances do you fear for?

- What is the effect of the disturbance?

- What is the worst disturbance? (why?)

- How often does this disturbance occur?

Based on the discussion that followed from the questions, we together make a list with disturbances, challenges and constraints, the frequencies and the effects. 


\section{Coping and Prevention (20 min)}

- From all these disturbances, challenges and constraints, are there ways to prevent them, and to cope?

- Per disturbance/challenge/constraint we ask if there is a strategy to prevent and to cope

On a flipchart each of the disturbances/challenges/constraints with 1) prevention strategies and 2) coping strategies - check: Does everyone agree?

\section{Three strategies $(20 \mathrm{~min})$}

We identified three strategies to reduce vulnerability: (i) Optionality: Having multiple options to choose from, (ii) Stocks: Reserves or storage capacity to use a resource when needed and (ii) Independence: Can people follow their own ideas and interests? Or do they have to follow people in their surroundings, rules or regulations?

- How do participants interpret these strategies?

- What are examples of optionality, stocks and independence in their enterprises? (five ranked statements as starter for the discussion)

- Do participants recognize these strategies as buffering strategies? Do we miss strategies?

- What could be other ways to enlarge optionality, stocks and independence?

\section{Supplemenary Materials 5D: Network of policy-informers in Bihar, description of actors} (corresponds with Figure 5.4).

\begin{tabular}{|c|c|c|c|}
\hline Category & Stakeholder & Type & Description \\
\hline Policy maker & $\begin{array}{l}\text { Central } \\
\text { governement } \\
\text { of India }\end{array}$ & Gov. & $\begin{array}{l}\text { Policy planning, investments on centrally sponsored schemes, research } \\
\text { and development through central government managed agricultural } \\
\text { institutes (ICAR, IARI, central agricultural universities), input subsidies } \\
\text { to farmers }\end{array}$ \\
\hline Policy maker & $\begin{array}{l}\text { Government of } \\
\text { Bihar }\end{array}$ & Gov. & $\begin{array}{l}\text { Policy planning, investments on state sponsored schemes, research and } \\
\text { development through state government managed agricultural institutes } \\
\text { (state universities), input subsidy shares to farmers }\end{array}$ \\
\hline Policy maker & $\begin{array}{l}\text { Secretary/ } \\
\text { agricultural } \\
\text { minister }\end{array}$ & Gov. & $\begin{array}{l}\text { Policy planning, investment prioritization and overall leadership for } \\
\text { execution of the agriculture }\end{array}$ \\
\hline $\begin{array}{l}\text { Program } \\
\text { developers }\end{array}$ & $\begin{array}{l}\text { Deputy Director of } \\
\text { Agriculture }\end{array}$ & Gov. & $\begin{array}{l}\text { Supervision/monitoring of the specific scheme/programs of the } \\
\text { governments (for example climate change) through liasoning with } \\
\text { district agricultural officers as well as research and development } \\
\text { organizations of the government (ICAR, IARI, central agricultural } \\
\text { universities) }\end{array}$ \\
\hline Implementor & $\begin{array}{l}\text { District } \\
\text { agricultural officer } \\
\text { (DAO) }\end{array}$ & Gov. & $\begin{array}{l}\text { Execution of the agricultural developmental schemes of the Government } \\
\text { at district level, implementing subsidy schemes for the farmers at district } \\
\text { level, overall responsibility for execution of the agricultural development } \\
\text { schemes of the government }\end{array}$ \\
\hline $\begin{array}{l}\text { Execution/ } \\
\text { extension }\end{array}$ & $\begin{array}{l}\text { Block agricultural } \\
\text { officer (BAO) }\end{array}$ & Gov. & $\begin{array}{l}\text { Execution of the agricultural developmental schemes of the Government } \\
\text { at block (sub-district) level, implementing subsidy schemes for the } \\
\text { farmers, overall responsibility for facilitation and execution of the } \\
\text { agricultural development schemes of the government at the block level }\end{array}$ \\
\hline $\begin{array}{l}\text { Execution/ } \\
\text { extension }\end{array}$ & $\begin{array}{l}\text { Krishi Slahkav } \\
\text { (farmer advisor) }\end{array}$ & Gov. & $\begin{array}{l}\text { The local level extension person who advises farmers regarding new } \\
\text { technologies and Government schemes }\end{array}$ \\
\hline $\begin{array}{l}\text { Execution } \\
\text { /extension }\end{array}$ & $\begin{array}{l}\text { Mukhia } \\
\text { (Panchayat } \\
\text { leader)* }\end{array}$ & & $\begin{array}{l}\text { Elected head of the village/cluster of village level local government. } \\
\text { Responsible for implementation of the rural development schemes of the } \\
\text { government at village/cluster of village level. }\end{array}$ \\
\hline $\begin{array}{l}\text { Execution/ } \\
\text { extension }\end{array}$ & $\begin{array}{l}\text { Village head } \\
\text { (Sarpanch)* }\end{array}$ & & $\begin{array}{l}\text { An elected representative responsible to implement different community } \\
\text { welfare activities and government schemes at village level. }\end{array}$ \\
\hline
\end{tabular}




\begin{tabular}{|c|c|c|c|}
\hline $\begin{array}{l}\text { Execution/ } \\
\text { extension }\end{array}$ & $\begin{array}{l}\text { Ward } \\
\text { representative } \\
\text { (Ward panch)* }\end{array}$ & & $\begin{array}{l}\text { An elected representative in one segment of the village panchayat who is } \\
\text { responsible for village development program of that particular segment } \\
\text { he/she represents (falls under Sarpanch and part of state-government } \\
\text { structure) }\end{array}$ \\
\hline $\begin{array}{l}\text { Program } \\
\text { developers }\end{array}$ & $\begin{array}{l}\text { BAMETI (Bihar } \\
\text { agriculture } \\
\text { management \& } \\
\text { extension training } \\
\text { institute) }\end{array}$ & State gov. & $\begin{array}{l}\text { An apex institute at state level for implementing all the training and } \\
\text { extension schemes of the state government through training of trainers } \\
\text { and other related activities in coordination with various departments and } \\
\text { schemes of the Government }\end{array}$ \\
\hline $\begin{array}{l}\text { Program } \\
\text { developers }\end{array}$ & Project Director & State gov. & $\begin{array}{l}\text { The person responsible for overall implementation/execution of a } \\
\text { particular project at state level. Financing from state government? }\end{array}$ \\
\hline $\begin{array}{l}\text { Execution/ } \\
\text { extension }\end{array}$ & $\begin{array}{l}\text { Deputy Project } \\
\text { Director }\end{array}$ & State gov. & $\begin{array}{l}\text { In each district a deputy project director is placed for } \\
\text { implementation/execution of projects at district level. Collaborates } \\
\text { with Project Director and Block Technology Managers }\end{array}$ \\
\hline Extension & $\begin{array}{l}\text { Block Technical } \\
\text { Manager (BTM) }\end{array}$ & State gov. & $\begin{array}{l}\text { Dissemination: intermediary of Dep. Proj. Dir. and ATMs, works at } \\
\text { block level }\end{array}$ \\
\hline Intermediary & $\begin{array}{l}\text { Agricultural } \\
\text { Technical Manager } \\
\text { (ATM) }\end{array}$ & State gov. & Intermediary of BTM and farmers. \\
\hline $\begin{array}{l}\text { Research } \\
\text { organization } \\
\text { Extension }\end{array}$ & $\begin{array}{l}\text { ICAR (Indian } \\
\text { Council of } \\
\text { Agricultural } \\
\text { Research) } \\
\end{array}$ & Gov. & $\begin{array}{l}\text { Basic and strategic as well as applied research in core areas identifies } \\
\text { for the specific domain and delivery of the technologies through } \\
\text { collaborations with various agencies. Capacity development of } \\
\text { stakeholders in core areas of competence. Part of central government. }\end{array}$ \\
\hline $\begin{array}{l}\text { Research } \\
\text { organization }\end{array}$ & $\begin{array}{l}\text { Central } \\
\text { Agricultural } \\
\text { Universities } \\
\end{array}$ & Gov. & $\begin{array}{l}\text { Agricultural research, teaching and extension in specific geography and } \\
\text { fully financed by the government of India }\end{array}$ \\
\hline $\begin{array}{l}\text { Research } \\
\text { organization }\end{array}$ & State Universities & State gov. & $\begin{array}{l}\text { Agricultural research, teaching and extension in specific geography and } \\
\text { primarily financed by the state government with specific support from } \\
\text { state Government of India through ICAR }\end{array}$ \\
\hline $\begin{array}{l}\text { Research } \\
\text { organization } \\
\text { Extension }\end{array}$ & $\begin{array}{l}\text { CIMMYT/BISA } \\
\text { (Borlaug Institute } \\
\text { for South Asia) }\end{array}$ & Non gov. & $\begin{array}{l}\text { Basic, strategic and applied research and capacity development in core } \\
\text { areas of competence in maize and wheat-based farming systems and } \\
\text { facilitate smallholder farmers reach to new technologies and innovations } \\
\text { through value chain actions and partnerships Non-governmental? }\end{array}$ \\
\hline $\begin{array}{l}\text { Training \& } \\
\text { Extension }\end{array}$ & $\begin{array}{l}\text { KVK (Krishi } \\
\text { Vigyan Kendra) }\end{array}$ & Gov./ State gov. & $\begin{array}{l}\text { District level agency for research in extension, capacity development } \\
\text { and a bridge between research and extension/delivery Financed by } \\
\text { central government? Collaborating with research organizations and ??? }\end{array}$ \\
\hline
\end{tabular}

NB: Green are primarily the research, training and extension organizations whereas grey are developmental/policy organization/system. Gov. stands for central government; state gov. stands for state government; non-gov for non-governmental.

*On the village structures:

Inhabitants of rural areas are part of wards, which are structured communities of about 250 households. The inhabitants of the ward are represented by an elected ward representative (the ward panch) who is responsible for village development programs in the ward and communication to 'higher levels'. About eight wards make a village, with an elected village head (the sarpanch). The community welfare activities and development program in the village implemented through the village head who is directly associated with the district administration. Several villages form a panchayat, headed by the mukhiya, who is the elected head of the panchayat and part of the local government. The mukhiya is responsible for implementation of the rural development schemes of the government at village level. 


\section{Supplemenary Material E: Semi-structured interview positive deviant farmers}

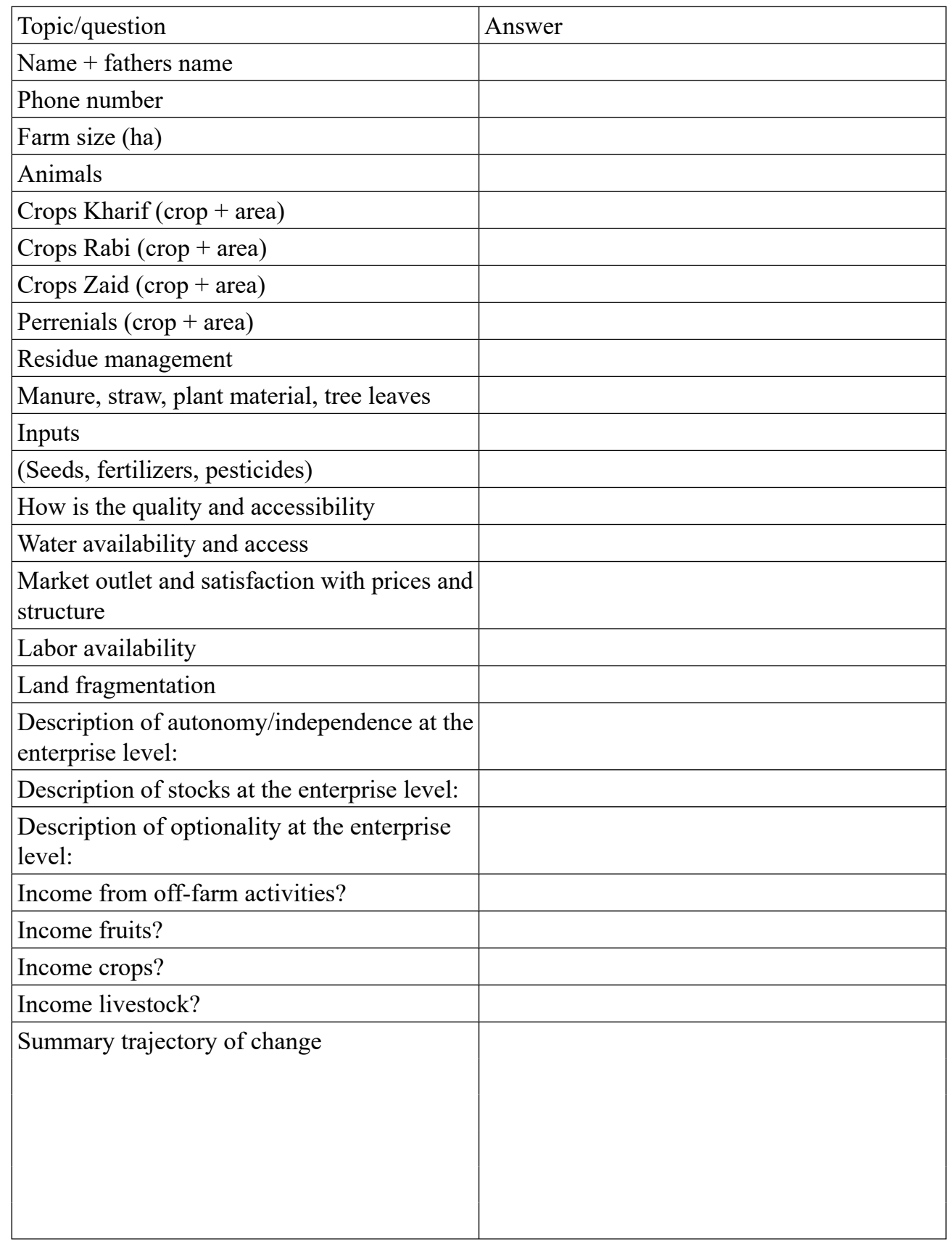




\section{Supplemenary Materials 5F: ANOVA}

Farmers who attended the FGDs $(n=92)$ and policy informers $(n=13)$ were asked to rank the following five statements based on importance: 'I aim for a diversified income'; 'I am dependent on advice'; 'Limiting the use of fertilizers and inputs is important to be independent'; 'Water storage is essential in case of a drought'; 'Storage facilities to store produce is important to get a good price on the market'. We compared differences between farmers and policy informers using one-way analysis of variance (ANOVA). In case of significance Tukey Honest Significant Differences test would have been performed for multiple pairwise-comparison between the means of the groups. There was however no significant difference.

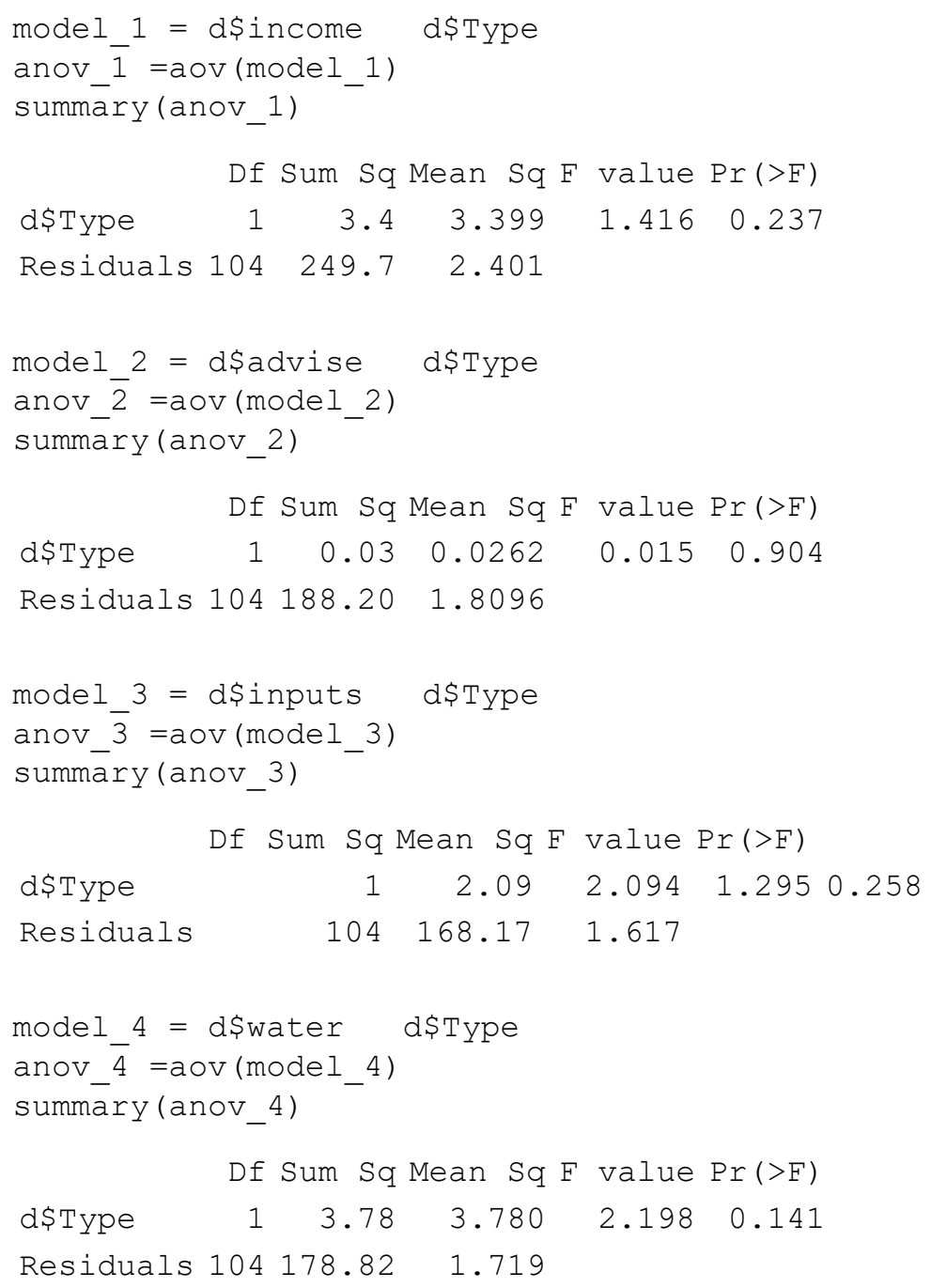




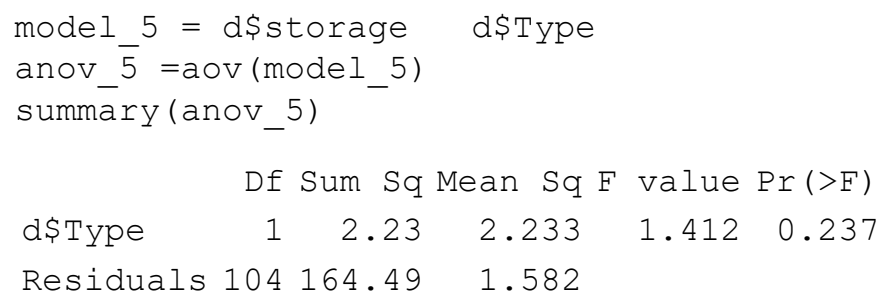

\section{References}

Adelhart Toorop, R., Ceccarelli, V., Bijarniya, D., Jat, M. L., Jat, R. K., Lopez-Ridaura, S., and Groot, J. C. (2020a), Using a positive deviance approach to inform farming systems redesign: A case study from Bihar, India. Agricultural Systems. 185(February): p. 102942

Lopez-Ridaura, S., Frelat, R., Van Wijk, M. T., Valbuena, D., Krupnik, T. J., and Jat, M. L. (2018), Climate smart agriculture, farm household typologies and food security: An ex-ante assessment from Eastern India. Agric. Syst. 159(September 2016): p. 57-68 



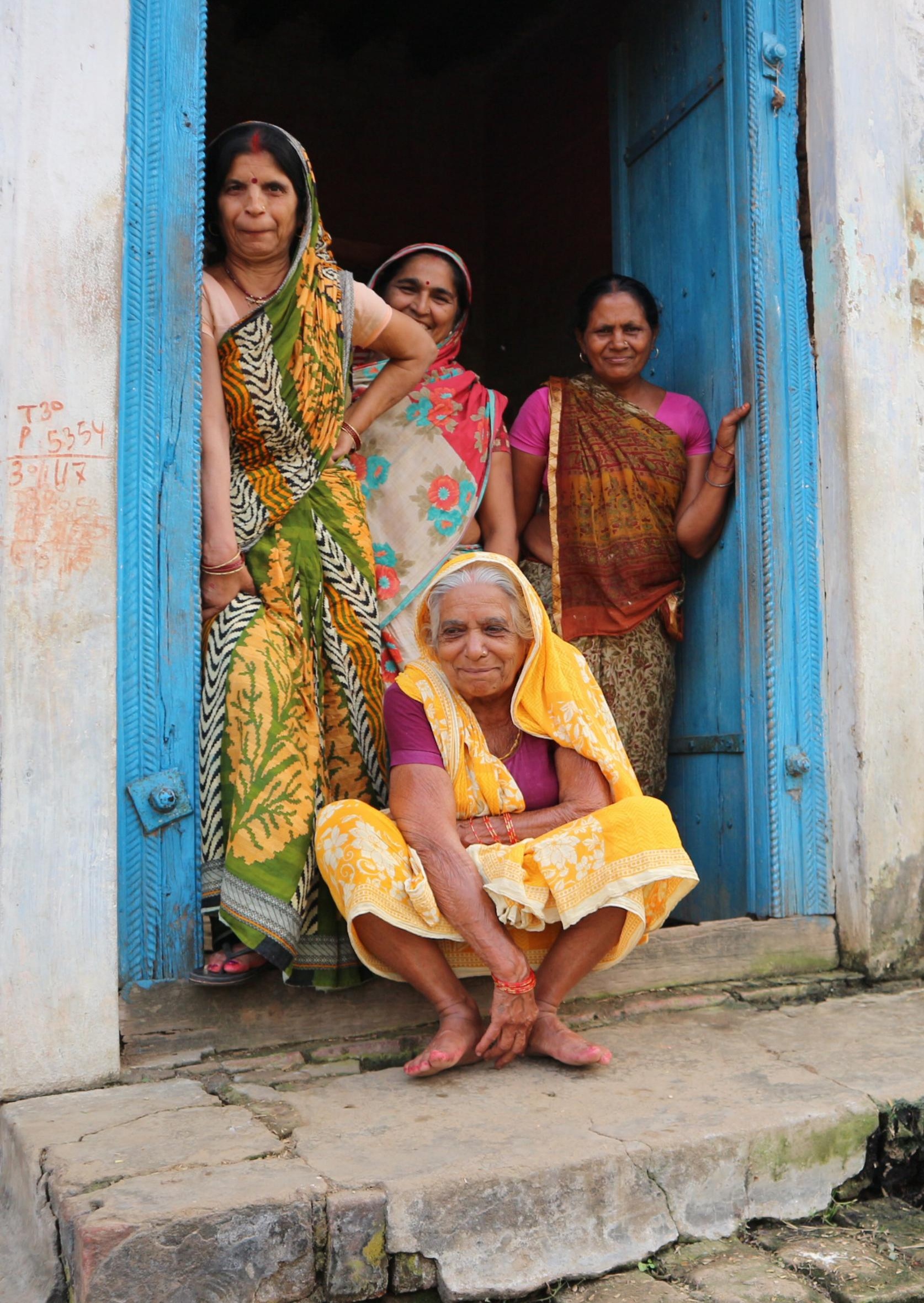




\section{Chapter 6}

General Discussion 


\section{Overview of the Main Findings}

The main objectives of this thesis were to understand and capture the characteristics and diversity of smallholder farming systems in northern India, and to assess the drivers and challenges determining the windows of opportunities for improving whole-system performance. A summary of the main findings is presented in Figure 6.1.

Chapter 2 captured the main characteristics of farming systems across the Indo-Gangetic Plains (IGP), and their diversity in terms of structural and functional features. This included an assessment of the objectives and perceived challenges for farmers in various districts throughout the IGP (located in the states Punjab, Haryana, West and East parts of Uttar Pradesh, Bihar and Rajasthan) and a model-based exploration to determine the potential effects of anticipated constraints on their options to improve profitability, soil quality, labor use and water use. We found that the most acute problems were related to low labor availability, fluctuating market prices, low soil fertility and high seed prices. The model-based analysis showed that the lower product prices, lower productivity and higher prices of hired labor could aggravate the trade-offs of farm profitability with water use and soil quality.

Chapters 3, 4 and 5 zoomed in on Bihar, a state in the Eastern IGP. Chapter 3 investigated windows of opportunities for sustainable intensification. The higher resource endowed farms had larger windows of opportunities: they showed greater optionality with more land, labor and assets available. The impact of cultivating mung bean in the usually fallow zaid (summer) season was not related to resource endowment, but rather to the current portfolio of cropping patterns. The benefits of mung bean were most visible in the environmental indicators (nitrogen (N) use efficiency and soil organic matter (SOM) balance); whereas mung bean did not expand the opportunity window towards increased income or water saving.

Chapter 4 identified farms that could be characterized as positive deviants and investigated their practices. These farms are located in the most promising areas of the window of opportunities because they performed better than the population mean on each of the selected indicators. Redesigning by using positive deviant practices expanded the window of opportunities: it allowed for a doubling of performance indicator, relative to the population mean. To do so, combining high livestock density with specific (3-season, intensive) cropping patterns (maize-yam-yam; tobacco-sorghum-maize; wheat-mung bean-maize) appeared necessary, confirming the key role of interactions among components in mixed crop-livestock systems to improve multiple dimensions of farm sustainability. Focus group discussions revealed that the 
redesign was especially interesting for small-scale crop and livestock farmers, while for the other farm types we recommend a second design cycle.

Chapter 5 revealed that farmers across all farm types were vulnerable and locked-in with limited adaptive capacity to address the challenges at hand. Water and labor scarcity, low quality and limited access to inputs and low market prices were examples of challenges that may not be jeopardizing the continuity of the average farms, but according to farmers might require change. Four positive deviants found ways to transform their farming systems to overcome these challenges. They showed strong autonomy, connectedness throughout the food chain and were rich in optionality and stocks. This chapter highlights that achieving better whole-system farm performance requires skills beyond the development of purely agronomical competences. Autonomy and community engagement are key elements for pathways towards more antifragile systems.

Which general lessons can we distil from these findings? In this discussion I first reflect on the implications of this study for farming system developments in the Indo-Gangetic Plains. In the next sections, I elaborate on evolution within agroecosystems and the role positive deviants can play. Finally, I discuss the limitations of the study and address issues for further research.

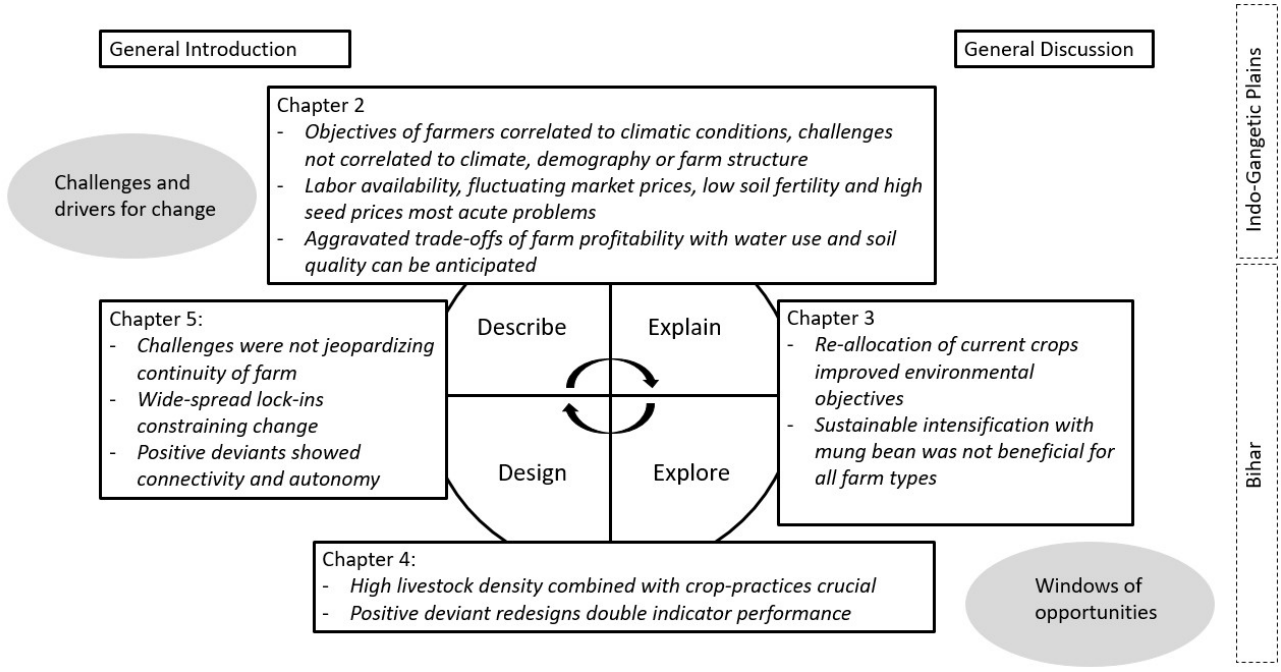

Figure 6.1: Summary of thesis findings (boxes) and cross-cutting themes (grey circles) (summary for chapter 2 needs to be adjusted). 


\section{Learnings from Bihar}

Chapters 3, 4 and 5 focused on Bihar, one of the poorest and most populous states of India. This state has comparatively low productivity and is considered vulnerable to climate change. The results from Bihar could be relevant for other states in the IGP, especially as the challenges perceived did not differ across the IGP (Chapter 2). Here, I reflect on the findings regarding livestock, the role of rice and sustainable intensification through continuous cropping.

\subsection{Role of livestock}

With 302 million bovines (National Dairy Development Board, 2019), India is known for its high livestock numbers (Chhabra et al., 2013; O’Mara, 2011). Bovines are generally an integrated part of the livelihood strategy, providing draft power, manure and milk (Erenstein and Thorpe, 2010). Ideally, the role of livestock is to intensify the system at a low cost and in a labor efficient way through their role in nutrient cycling (Behera et al., 2008). In Chapter 4 we found that high livestock density, in combination with specific cropping patterns, was an important element in positive deviance redesigned farms. Livestock was necessary to double performance of the objectives to maximize operating profit, SOM balance, dietary energy, and reduce water use by $50 \%$. However, livestock was also mentioned as a challenge, because feeding is laborious and feed is often not readily available (Chapter 4 and 5). Farmers indicated a trade-off between producing milk and providing labor. Only the farm type with livestock production as livelihood strategy ('small crop and livestock farmers') was dedicated to producing milk for sale. In addition to the trade-off between labor and milk production, greenhouse gas emissions emitted by livestock are of environmental concern in systems with high livestock density (Chhabra et al., 2013; O’Mara, 2011; Patra, 2017; Paul et al., 2018). This drawback seems to be underrepresented in the debate about climate change mitigation in India, possibly because of the sacred status of bovines in Hindu theology and the fact that slaughtering bovines is prohibited by law in most Indian states (Erenstein and Thorpe, 2011; Patra, 2017). Although methane and ammonia emissions could be mitigated through management changes regarding feeding, animal breeding, stable-regimes and manure management, this was not mentioned as an ambition. Additionally, while the high number of unproductive animals is a driver of low production per TLU (Chapter 2), an efficiency gain could be made by increasing productivity thereby lowering the greenhouse gas emissions per unit output. A first gain could be to improve the feeding regime of the animals which are already productive. Furthermore, an improved integration of crops and livestock could provide higher quality feed (in addition to straw). This 
would benefit the ration as well as soil quality (Erenstein and Thorpe, 2010; Thorpe et al., 2007).

\subsection{Role of rice}

The IGP are often associated with intensive cereal-based farming systems (Erenstein et al., 2010; Lopez-Ridaura et al., 2018). In Patiala (Punjab) and Karnal (Haryana) we found that wheat and rice covered almost $100 \%$ of the farm area. Farmers in Muzaffarnagar (Western Uttar Pradesh) cultivated predominantly sugarcane and wheat, and had limited crop diversity. The case-study sites towards the east had much greater crop diversity. In Faizabad (Eastern Uttar Pradesh) and Patna (Bihar) wheat and rice covered about 50\% of the farm area. Furthermore, the data collected on 43 farms in Patna (Bihar) revealed that farmers grew 45 different crops and applied 143 different cropping practices (i.e., crop in combination with cultivation technique). Although rice and wheat often covered the largest area, the farms showed large numbers of different crops, indicating optionality and a diversified skills set. Nevertheless, cereal (wheat, rice, maize) production is being promoted as development planners aim to convert Bihar to India's 'cereal belt' (Laik et al., 2014).

The redesigns based on positive deviance practices in Chapter 4 did not include rice in the cropping pattern. Rice cultivation correlated strongly with high water use, while the lowest water use was found in mustard, tobacco and yam, which were for that reason selected as part of the cropping patterns maize-yam-yam; tobacco-sorghum-maize and wheat-mung bean-maize. Rice appeared not to be Pareto-optimal when looking at the objectives operating profit, dietary energy production, SOM balance and water use. However, farmer suggestions in focus group discussions revealed a strong preference to cultivate rice and potato for home-consumption. For the smallholders assessed in this thesis, a focus on dietary diversification may be more desirable than boosting cereal, and in particular rice, production.

\subsection{Sustainable intensification through continuous cropping}

The need for Sustainable Intensification (SI) and Climate Smart Agriculture (CSA) is widely acknowledged among the local research and development community in the IGP in order to combat environmental degradation and promote the conservation of resources, while sustaining productivity (R. Jat et al., 2018; Laik et al., 2014; Parihar et al., 2016). Conservation Agriculture (CA) is based on the principles of minimal soil disturbance, crop rotations and permanent soil cover and fits the aims of SI and CSA. Especially for large farms with access to machinery, 
inputs and technology in the Americas and Australia, the approach has been widely adopted and has proven to be beneficial in terms of production, resource use efficiencies and soil and water conservation (Giller et al., 2015). Although contested for resource-constrained environments (Giller et al., 2015; Pittelkow et al., 2015), it has been tested in large scale (mostly on-station) experiments to examine the principles in the Indian context (M. L. Jat et al., 2020).

M. L. Jat et al. (2020)M. L. Jat et al. (2020) stressed that partial implementation of the CA principles could benefit crop yield, water use efficiency and economic returns. This thesis supports this statement with regard to the principle of (nearly) permanent soil cover. Leguminous crops like mung bean (Vigna radiata), black gram (Vigna mungo) and dhaincha (Sesbania bispinosa) have received attention as suitable zaid crops because of their potential for enhanced soil quality, nitrogen fixation, extra income/food and break of cereal-cereal cycle (Hossain et al., 2016; H. Jat et al., 2018). In Chapter 3 we found that inclusion of mung bean in zaid enlarged the window of opportunities for most farms, especially due to potential gains in SOM balance and $\mathrm{N}$ use efficiency and reduced water use. In addition to mung bean, Chapter 4 showed yam and sorghum as suitable alternatives that were received positively by farmers. A common concern, however, was the labor demand and, particularly for lower resource endowed farmers, the uncertainty around water availability in the dry zaid season.

\section{Reflections on the Methodology}

\subsection{Addressing heterogeneity for farming systems development in the Indo-Gangetic} Plains

Diversity is intrinsic to agriculture, farms and farmers. Farm diversity can be better understood through classification of, for example, the differences between regions (to extract distinctive regional features) or within a region (to understand what diversity looks like when ecological and institutional variables are eliminated) (Van der Ploeg et al., 2009). Farm typologies are a common way of grouping farming systems within a region. This can be done through statistical methods (e.g., for structural typologies), participatory methods (e.g., for functional typologies), or combinations of both (Kuivanen et al., 2016; Tittonell et al., 2020). Ideally, the groups show small intra-group variation, and large inter-group differences (Alvarez et al., 2018; Berre et al., 2016; Tittonell et al., 2010). One or multiple farmers from the groups can act as representative(s), and can be studied in-depth (e.g., through interviews and whole-farm 
modelling) as a cost-effective way to gain insights about the farm type. This method is often applied to target technologies and interventions for a specific farm type, which is also how the method was used in Chapter 3 (Douxchamps et al., 2016; Hammond et al., 2020). While interventions may be promising in-silico and on-station, however, this does not necessarily lead to their adoption (Descheemaeker et al., 2019; Ojiem et al., 2006; Ronner et al., 2016).

Typologies based on predominantly structural variables, such as the size and configuration of the farm, are farm-centred, rather than farmer-centred. Farm-centred typologies may be less suitable to capture decision making and predict behavior in changing situations (Tittonell et al., 2020). As individual farmers' objectives and challenges are important when identifying development options (Almekinders et al., 2019; Darnhofer et al., 2016), this raises the question: should the farmer be prioritized instead of the farming system when addressing heterogeneity? Chapters 3, 4 and 5 used a farm typology constructed by Lopez-Ridaura et al. (2018). This typology was based on structural (farm assets and resources) and functional (livelihood pursuits) farm characteristics. Although the typology distinguished farms rather than farmers, the types were assigned names such as 'the wealthy farmer' or 'the crop-livestock farmer'. In this thesis, quick surveys were conducted to assign farms to a type, whereupon farmers were asked if they recognized their farms in the assigned type (e.g. land holding, crops, sources of income). There was no correlation between the typologies and the objectives and challenges: no significant differences were found when testing whether the types could be distinguished when based exclusively on the ranking of objectives and challenges (Chapter 2). Also in focus group discussions, farmers within the same type exhibited substantial variation in their objectives and values.

Alternative methods to investigate heterogeneity within a community include $\mathrm{Q}$ methodology (Amaruzaman et al., 2017; C. J. Timler, 2020; Watts and Stenner, 2005), farming styles (Van der Ploeg, 1994; Van der Ploeg and Ventura, 2014) and archetypical analysis (Oberlack et al., 2019; Sietz et al., 2017; Tittonell et al., 2020). These methods aim at understanding decision making and behavior. Farmers are grouped based on their aspirations, acknowledging that these are shaped by farm assets, the biophysical environment, and socio-economic and geo-political conditions (C. J. Timler, 2020; Tittonell et al., 2020). Especially in the light of ever-changing farm conditions, where volatility and disturbances should be expected, addressing heterogeneity in such a way may be more suitable because it focuses on responses and behavior. 
These alternative ways to address farm heterogeneity still aim at clustering farms and farmers, and delineating the community. Outliers are often discarded to achieve small intra-group variation and large inter-group variation in typologies. However, looking at positive and negative extremes can provide insights in 'what works' and what is less successful. Franke et al. (2014) and Lopez-Ridaura et al. (2018) combined construction of statistical typologies with an analysis of distributions of outcomes among the households surveyed. Looking at distributions (e.g. food availability), and extreme performances in terms of critical indicators can identify out-of-the-box farming practices.

\subsection{Windows of opportunities}

The 'window of opportunities' can be defined as a set of potential farm configurations that differ in the performance on selected objectives. In thesis I looked at the windows of opportunities of smallholder farms from different perspectives to yield potential development pathways. Figure 6.2 presents three pathways to expand the window of opportunities: Figure 6.2 a shows how increased optionality (i.e., adding promising development options like new cropping patterns or practices) expands the area (Chapter 3). Figure $6.2 \mathrm{~b}$ demonstrates how the positive deviance approach selects the best-performing farms and redesigns these with best practices to expand the area (Chapter 4). Figure 6.2c illustrates the concept of antifragility, which looks beyond the farms represented in farm types and expands the area by including the outliers (Chapter 5). In this simplified figure, the window of opportunities is two-dimensional and delineated by two objectives. The window of opportunities can however be a volume ( 3 objectives) or a hyper volume (>3 objectives) (Groot et al., 2016). The size of the model-based window of opportunities can be calculated and can provide comparative indications of the potential scope for improvement within and among farming systems. The larger the window of opportunities, the more room to manoeuvre to a new and more desirable farm configuration. The size can be misleading because not all solutions may be relevant. Furthermore, the dynamic nature of the window of opportunities should be considered (Cortez-Arriola et al., 2016). Changes in policies and price, for example, may shift or reshape the outcome space.

In line with Brown et al. (2018) and Michalscheck et al. (2018) we found in Chapter 3 that higher resource endowed farms had larger windows of opportunities. Land as a resource and initial crops were particularly important factors yielding large windows of opportunities in Pareto-based whole-farm explorations. Additionally, these high resource-endowed farms demonstrated less vulnerability in cases of disturbance (Chapter 5) because they had more 
(financial) resources to buffer disruptive situations. However, while their modelled windows of opportunities were larger than those of lower resource-endowed farms, their low pro-active attitude hampered change, i.e., a move towards the Pareto-frontier. This discrepancy of having the resources to improve the system and at the same time being hampered asks for iterative research cycles to arrive at relevant solutions. In a co-learning process, the feasible and relevant options within the window of opportunities can be selected, while options that are perceived as not feasible can be discarded. This selection should start at farm-type level, to illuminate a certain corner of the window of opportunities as the starting point for a new design cycle. The focus group discussions described in Chapter 4 provided concrete feedback on the scenarios derived from the model-based redesign. For example, tobacco was suggested as a promising crop, but not found reasonable for some farm types because of high input requirements and a governmental ban. Furthermore, whereas the scenarios did not include rice and potatoes in the crop rotations, farmers indicated that these crops should be included as they were important for home consumption. With this feedback, the window of opportunities would evolve and eventually include more desirable solutions. After the cycles of model-based explorations, a process of tailoring and finetuning solutions should further improve the fit to the practical situation on- farm.

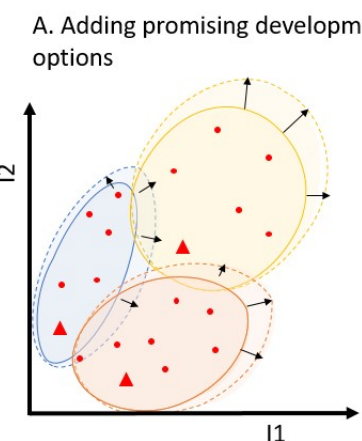

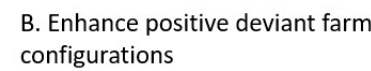

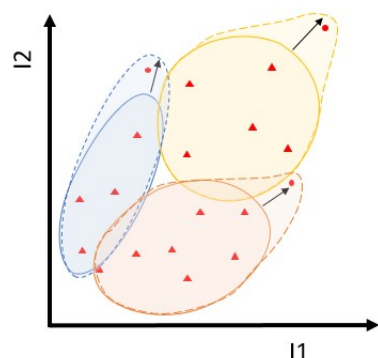

C. Searching 'outside the box': looking for positive outliers

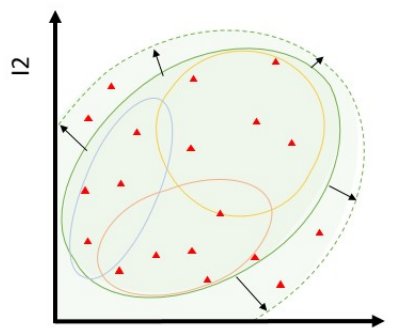

I1

Figure 6.2: Visualization of windows of opportunities and options to expand these windows as illustrated in this thesis. The outcome space is delineated by two objectives (I1 and I2). Red, blue and yellow circles indicate the windows of opportunities for different farm types, triangles represent farms, the dots alternative farm configurations, arrows indicate the direction of the expansion. A. Adding promising development options expands the window of opportunities in several directions; B. Enhancing positive deviant farm configurations expands the window of opportunities in a specific direction; C. Focusing on outliers expands the window of opportunities by looking beyond farm types and including outliers. 


\subsection{Positive deviants}

Positive deviants are individuals who achieve better outcomes than their peers, despite having comparable resources and constraints. Within a selected target area, positive deviant practices are already implemented and used in the biophysical and socio-economic context and therefore likely to be transferable to other farmers. The concept has gained ground in the 2000 s, initially in the field of health care and nutrition (Ahrari et al., 2002; Bolles et al., 2002; Mackintosh et al., 2002; Marsh et al., 2004), but more recently also in agronomy (Biggs, 2008; Biggs, 2007; Modernel et al., 2018; Ochieng, 2007; Pant and Odame, 2009; Steinke et al., 2019). So far, procedures to identify positive deviants have not been standardized.

In Chapters 4 and 5, we apply different methods to identify positive deviants: in Chapter 4, positive deviant farms were selected based on performance on predefined productive, economic and environmental objectives. In Chapter 5, on the other hand, we used a normative approach to select positive deviants by asking local experts to identify farmers that in their view were autonomous were rich in optionality and stocks. The selection process in Chapter 4 relied on quantitative indicators rather than on potentially subjective expert knowledge, and may thus seem objective and reproducible. However, whether or not a farmer was considered a positive deviant strongly depended on indicator choice. Choosing other indicators (e.g. reducing labor or greenhouse gas emissions) would have resulted in a different selection of positive deviants and thus in different redesigns. When we asked farmers to identify inspiring peers during focus group discussions, no one mentioned the farmers identified as positive deviants based on indicator performance. Additionally, having livestock was not identified as an inspiring practice even though it was the common denominator among positive deviants. Instead, farmers who owned machinery, adopted technology, or had a high social position, were listed as examples.

The normatively defined positive deviants in Chapter 5 were all actively engaged with the community through communities of practice or teaching. Although 'social position' was not among the selection criteria, it was inherent in the selection procedure, as they were shortlisted by experts in agricultural research. Pant and Odame (2009) state that "positive deviants are the ones who make their voice heard through various direct and indirect mechanisms". Positive deviants with a strong social position are found to be especially powerful communicators (Biggs, 2008), raising the question if communication capacity should be part of the identification procedure of positive deviance. To answer this question ethics regarding equity and the social context should be leading. For the Indian context where society is still hierarchically organized in 
castes, this is an important point. Social network analysis may be helpful to map formal and informal interactions among farmers and their communities by indicating linkages to other farmers, extension organizations, NGOs, research organizations, input providers, etc. (Hermans et al., 2017; Vishnu et al., 2019). Positive deviant farms and practices may be sought among farmers with many strong connections, while isolated farmers could be actively approached in the process of dissemination. With such a strategy, the criteria for positive deviance should be clearly defined to assure that farms and practices are indeed positively deviating, and not only assigned as positive deviants because of their network and connections.

\section{Evolution in Agroecosystems}

The ability to adapt is a key characteristic of sustainable systems. This is widely acknowledged in biology, starting with Darwin, who showed accumulating differences over generations of populations with genealogically related individuals. Darwinian evolution can be defined as 'gradual and continuous adaptation through natural selection, where variation (mutation, recombination, crossover) and selection are seen as the fundamental base on which natural selection can take place' (Rammel and Van Den Bergh, 2003). Selection happens as abiotic and biotic conditions inevitably change, and with time, the system expresses a chain of gradual adaptations. Similar to biological systems, agroecosystems evolve through mutation and selection to arrive at systems that fit the local context.

The concepts of adaptive capacity, transformation and antifragility imply adaptation and all focus on systems' ability to evolve, as opposed to robustness and resilience, which imply withstanding or recovery to the original state. A compromise between withstanding and adaptation has been recognized as important to balance in order to achieve systems sustainability (Darnhofer et al., 2016). In other words: the system should have sufficient robustness to maintain integrity over time, but simultaneously be adaptive to changes or disturbances and to interact with other systems (Lopez-Corona and Padilla, 2019; Ramírez-Carrillo et al., 2018; Ulanowicz et al., 2009). Too much focus on maintaining a status quo risks lock-ins. Locked-in systems can become vulnerable as they lead to fragility and hamper evolution (Taleb, 2012).

Chapters 2 and 5 give insights in the challenges experienced by farmers. Such insights can help to avoid or resolve lock-ins. Challenges were mainly at farm level, rather than caused by external drivers. Nevertheless, farmers pointed at the government as the actor responsible 
for improving the situation. Furthermore, lack of resources such as water, labor, inputs, good quality soil caused challenges for both low- and high resource endowed farms. The strategies to deal with these challenges were mostly coping and showed that farmers were already locked-in. Several solutions for the challenges that farmers mentioned implied changes at the farming systems level (e.g., substitute high water-demanding cash crops with green manure). These solutions would, however, have major effects on farm economics and management, and were therefore farmers' last resort. In focus group discussions, especially the high resource endowed farmers showed little autonomy and transformative power. The low resource endowed farmers expressed ownership of the challenges faced and expected less from governmental interventions. A type of 'survival mode' kept these low resource endowed farmers in a lock-in: they lacked the resources (e.g., time) and optionality to evolve.

From a farmer's perspective, a focus on maintaining the system and enduring may be a logical goal because it likely will not require new skills, resources, or market re-orientation. Change, on the other hand, is inherently associated with uncertainty, transaction costs, and learning time. Also, from a food systems perspective, aiming for stability is a logical primary policy objective: predictability in production and food availability is a strong trait of sustainable food systems (Hodbod and Eakin, 2015). The food system, however, needs to step away from an efficiency and optimization paradigm, and shift focus to fostering evolution to support sustainable production at farm level. This involves an assessment of how actors or entities in the system enable or constrain change, and balance flexibility, efficiency, and redundancy (Fath, 2015; Ulanowicz, 2012). When lower-level entities such as farmers are disproportionally dominated by and dependent on higher-level entities (e.g., large corporations), the lower-level entities become increasingly fragile. Such power-asymmetries in the food system should be solved to support evolution at lower levels.

Primary producers hold a vulnerable position in the food system. They are increasingly driven and challenged by, among others: international trade, technology, finance, demography and climate (Nyström et al., 2019). As farmers are made responsible for a large part of the environmental impact of the products traded in the system, they are pressured by policies to adopt more environmentally and societally just production methods. In the debate about sustainability, farmers are often seen as independent agents who can and should be adaptive. However, Chapters 2, 4 and 5 show that farmers' ability to adapt depends on context. Farmers' windows of opportunities narrow when challenges are experienced. Farmers tend to look at 
each other, and are influenced in their choices by a broad 'support' system (subsidies, minimum support prices, governmental procurement policy, extension services, post-harvest facilities).

We are now in the beginning of the 21 st century, entering an era where we have evidence of systems' behavior in the face of shock. Recent studies on the impact of COVID-19 on the food system suggested that long supply chains are more vulnerable (Kumar et al., 2021; Meuwissen et al., 2021; Rivera-Ferre et al., 2021) and that connectedness, flexibility and diversity throughout the supply chain were beneficial in dealing with the crisis. These lessons need to be made concrete for different contexts to ensure that farmers are embedded in sustainable supply chains. This must go hand in hand with the agronomic (biophysical) adaptations required. Approaches and concepts as conservation agriculture, regenerative agriculture, agroecology and organic agriculture are gaining terrain, and they all stress good agronomic practice. These approaches might need further adaptation to avoid all adverse environmental impact, as this is a prerequisite for sustainable food systems.

\section{Implications for Future Research}

The findings in this thesis contribute to the current knowledge on smallholder farmers' windows of opportunities, taking into account their diversity, drivers, and challenges.

The iterative Describe-Explain-Explore-Design (DEED) research cycle combines analysisand design-oriented approaches. As in many other studies (e.g. Cortez-Arriola et al., 2016; Michalscheck et al., 2018; C. Timler et al., 2020), the cycle was applied only once. The results would gain rigour if at least one more research cycle would be applied to incorporate the feedback received from farmers. A second cycle should focus on maintaining promising system elements while unsuitable elements should be discarded. As part of this second DEED-cycle, concrete farm configurations could be designed, from which farmers can select elements. Given the complexity and diversity of farming systems and differences in farmers' perceptions, objectives, and challenges, I believe that a focus on fostering change for instance by supporting adoption and adaptation of development options is more meaningful than further tweaking and tailoring development options per farm type through more iterations of the research cycle. As part of fostering change, it would be of interest to follow up on farmers who initially adopted interventions, but have quit after having tried. Adopting, adapting and disengaging are signs of autonomy and flexibility, and were recognized in this thesis as important for antifragility. 
Similar to resilience thinking, antifragility is still a paradigm rather than a testable concept. This thesis introduced the term for farming systems, but did not develop a framework for collecting empirical evidence for antifragility in agroecosystems. Lopez-Corona and Padilla (2019) connected antifragility and a balance between self-organization and randomness, and used Fisher Information as a unifying concept. Fisher Information gives a measure for the variability of the systems' performance, low variability leads to high Fisher Information and is associated with higher antifragility. Ramírez-Carrillo et al. (2018) also use Fisher Information in their attempt to measure 'sustainability' (defined as not losing or gaining Fisher Information over time) with indicators: ecosystem health (when systems' fluctuations are invariant there is a balance between robustness and adaptability), and stability (measured through Fisher Information and entropy). These novel ways of measuring systems' states may provide evidence for the optimal trade-off between robustness and flexibility, and order and disorder. Simultaneously to further research on this in farming and food systems, attention should be given on the development of these system properties in a holistic way.

As last point, I would like to highlight the necessity for research on equity and equality, with respect to gender and castes. The development of pathways to reach (policy) goals that benefit one part of society should not marginalize others. This seems to be an obvious objective, but requires specific attention and additional research to inform development efforts. 


\section{References}

Ahrari, M., Kuttab, A., Khamis, S., Farahat, A. A., Darmstadt, G. L., Marsh, D. R., and Levinson, F. J. (2002), Factors associated with successful pregnancy outcomes in upper Egypt: a positive deviance inquiry. Food Nutr. Bull. 23(1): p. 83-88.

Almekinders, C. J., Beumer, K., Hauser, M., Misiko, M., Gatto, M., Nkurumwa, A. O., and Erenstein, O. (2019), Understanding the relations between farmers' seed demand and research methods: The challenge to do better. Outlook on Agriculture. 48(1): p. 16-21.

Alvarez, S., Timler, C. J., Michalscheck, M., Paas, W., Descheemaeker, K., Tittonell, P., Andersson, J. A., and Groot, J. C. (2018), Capturing farm diversity with hypothesis-based typologies: An innovative methodological framework for farming system typology development. PLoS ONE. 13(5): p. 1-24.

Amaruzaman, S., Leimona, B., van Noordwijk, M., and Lusiana, B. (2017), Discourses on the performance gap of agriculture in a green economy: a Q-methodology study in Indonesia. International Journal of Biodiversity Science, Ecosystem Services and Management. 13(1): p. 233-247.

Behera, U. K., Yates, C. M., Kebreab, E., and France, J. (2008), Farming systems methodology for efficient resource management at the farm level: A review from an Indian perspective. The Journal of Agricultural Science. 146(5): p. 493-505.

Berre, D., Baudron, F., Menale, K., Craufurd, P., and Lopez-Ridaura, S. (2016), Different ways to cut a cake: Comparing expert-based and statistical typologies to target sustainable intensification technologies, a case-study in Southern Ethiopia. Experimental Agriculture. (2014): p. 1-17.

Biggs, S. (2007), Building on the positive: an actor innovation systems approach to finding and promoting pro poor natural resources institutional and technical innovations. International Journal of Agricultural Resources, Governance and Ecology. 6(2): p. 144-164.

Biggs, S. (2008), Learning from the positive to reduce rural poverty and increase social justice: Institutional innovations in agricultural and natural resources research and development. Experimental Agriculture. 44(1): p. 37-60.

Bolles, K., Speraw, C., Berggren, G., and Lafontant, J. G. (2002), Ti Foyer (Hearth) community-based nutrition activities informed by the positive deviance approach in Leogane, Haiti: a programmatic description. Food Nutr. Bull. 23(4 Suppl): p. 11.

Brown, P. R., Afroz, S., Chialue, L., Chiranjeevi, T., El, S., Grünbühel, C. M., Khan, I., Pitkin, C., Reddy, V. R., and Roth, C. H. (2018), Constraints to the capacity of smallholder farming households to adapt to climate change in South and Southeast Asia. Climate and Development. 0(0): p. 1-18.

Chhabra, A., Manjunath, K. R., Panigrahy, S., and Parihar, J. S. (2013), Greenhouse gas emissions from Indian livestock. Climatic Change. 117(1-2): p. 329-344.

Cortez-Arriola, J., Groot, J. C. J., Rossing, W. A. H., Scholberg, J. M. S., Massiotti, R. D. A., and Tittonell, P. (2016), Alternative options for sustainable intensification of smallholder dairy farms in North-West Michoacán, Mexico. Agricultural Systems. 144: p. 22-32.

Darnhofer, I., Lamine, C., Strauss, A., and Navarrete, M. (2016), The resilience of family farms: Towards a relational approach. Journal of Rural Studies. 44: p. 111-122.

Descheemaeker, K., Ronner, E., Ollenburger, M., Franke, A. C., Klapwijk, C. J., Falconnier, G. N., Wichern, J., and Giller, K. E. (2019), Which Options Fit Best? Operationalizing the Socio-Ecological Niche Concept. Experimental Agriculture. 55(S1): p. 169-190.

Douxchamps, S., Van Wijk, M.T., Silvestri, S., Moussa, A. S., Quiros, C., Ndour, N. Y. B., Buah, S., Somé, L., Herrero, M., Kristjanson, P., Ouedraogo, M., Thornton, P. K., Van Asten, P., Zougmoré, R., and Rufino, M. C. (2016), Linking agricultural adaptation strategies, food security and vulnerability: evidence from West Africa. Regional Environmental Change. 16(5): p. 1305-1317.

Erenstein, O., Hellin, J., and Chandna, P. (2010), Poverty mapping based on livelihood assets: A meso-level application in the Indo-Gangetic Plains, India. Applied Geography. 30(1): p. 112-125.

Erenstein, O. and Thorpe, W. (2010), Crop-livestock interactions along agro-ecological gradients: a meso-level analysis in the Indo-Gangetic Plains, India. Environment, Development and Sustainability. 12(5): p. 669-689.

Erenstein, O. and Thorpe, W. (2011), Livelihoods and agro-ecological gradients: A meso-level analysis in the Indo-Gangetic Plains, India. Agricultural Systems. 104(1): p. 42-53.

Fath, B. D. (2015), Quantifying economic and ecological sustainability. Ocean and Coastal Management. 108: p. 13-19.

Franke, A. C., van den Brand, G. J., and Giller, K. E. (2014), Which farmers benefit most from sustainable intensification? An ex-ante impact assessment of expanding grain legume production in Malawi. European Journal of Agronomy. 58: p. 28-38.

Giller, K. E., Andersson, J. A., Corbeels, M., Kirkegaard, J., Mortensen, D., Erenstein, O., and Vanlauwe, B. (2015), Beyond conservation agriculture. Frontiers in Plant Science. 6(OCTOBER).

Groot, J. C. J., Cortez-Arriola, J., Rossing, W. A. H., Améndola Massiotti, R. D., and Tittonell, P. (2016), Capturing agroecosystem vulnerability and resilience. Sust. 8(11): p. 1206. 
Hammond, J., Rosenblum, N., Breseman, D., Gorman, L., Manners, R., van Wijk, M. T., Sibomana, M., Remans, R., Vanlauwe, B., and Schut, M. (2020), Towards actionable farm typologies: Scaling adoption of agricultural inputs in Rwanda. Agricultural Systems. 183(May): p. 102857.

Hermans, F., Sartas, M., Van Schagen, B., Van Asten, P., and Schut, M. (2017), Social network analysis of multi-stakeholder platforms in agricultural research for development: Opportunities and constraints for innovation and scaling.

Hodbod, J. and Eakin, H. (2015), Adapting a social-ecological resilience framework for food systems. Journal of Environmental Studies and Sciences. 5(3): p. 474-484.

Hossain, M. S., Hossain, A., Sarkar, M. A. R., Jahiruddin, M., da Silva, J. A. T., and Hossain, M. I. (2016), Productivity and soil fertility of the rice-wheat system in the High Ganges River Floodplain of Bangladesh is influenced by the inclusion of legumes and manure. Agriculture, Ecosystems and Environment. 218: p. 40-52.

Jat, H., Datta, A., Sharma, P. C., Kumar, V., Yadav, A. K., Choudhary, M., Choudhary, V., Gathala, M. K., Sharma, D. K., Jat, M. L., Yaduvanshi, N. P., Singh, G., and McDonald, A. (2018), Assessing soil properties and nutrient availability under conservation agriculture practices in a reclaimed sodic soil in cereal-based systems of North-West India. Archives of Agronomy and Soil Science. 64(4): p. 531-545.

Jat, M. L., Chakraborty, D., Ladha, J. K., Rana, D. S., Gathala, M. K., McDonald, A., and Gerard, B. (2020), Conservation agriculture for sustainable intensification in South Asia. Nature Sustainability. 3(4): p. 336-343.

Jat, R., Singh, R. G., Kumar, M., Jat, M., Parihar, C. M., Bijarniya, D., Sutaliya, J. M., Jat M.K, Parihar, M., Kakraliya, S. K., and Gupta, R. K. (2018), Ten years of conservation agriculture in a rice-maize rotation of Eastern Gangetic Plains of India: Yield trends, water productivity and economic profitability. Field Crops Research. 232(April 2018): p. $1-10$

Kuivanen, K. S., Alvarez, S., Michalscheck, M., Adjei-Nsiah, S., Descheemaeker, K., Mellon-Bedi, S., and Groot, J. C. (2016), Characterising the diversity of smallholder farming systems and their constraints and opportunities for innovation: A case study from the Northern Region, Ghana. NJAS - Wageningen Journal of Life Sciences. 78: p. $153-166$.

Kumar, P., Singh, S. S., Pandey, A. K., Singh, R. K., Srivastava, P. K., Kumar, M., Dubey, S. K., Sah, U., Nandan, R., Singh, S. K., Agrawal, P., Kushwaha, A., Rani, M., Biswas, J. K., and Drews, M. (2021), Multi-level impacts of the COVID-19 lockdown on agricultural systems in India: The case of Uttar Pradesh. Agricultural Systems. 187(September 2020): p. 103027.

Laik, R., Sharma, S., Idris, M., Singh, A. K., Singh, S. S., Bhatt, B. P., Saharawat, Y., Humphreys, E., and Ladha, J. K. (2014), Integration of conservation agriculture with best management practices for improving system performance of the rice-wheat rotation in the Eastern Indo-Gangetic Plains of India. Agriculture, Ecosystems and Environment. 195: p. 68-82.

Lopez-Corona, O. and Padilla, P. (2019), Fisher Information as unifying concept for Criticality and Antifragility. (September): p. 1-6.

Lopez-Ridaura, S., Frelat, R., Van Wijk, M. T., Valbuena, D., Krupnik, T. J., and Jat, M. L. (2018), Climate smart agriculture, farm household typologies and food security: An ex-ante assessment from Eastern India. Agric. Syst. 159(September 2016): p. 57-68.

Mackintosh, U. A., Marsh, D. R., and Schroeder, D. G. (2002), Sustained positive deviant child care practices and their effects on child growth in Viet Nam. Food Nutr. Bull. 23(4 Suppl): p. 18.

Marsh, D. R., Schroeder, D. G., Dearden, K. A., Sternin, J., and Sternin, M. (2004), The power of positive deviance. Br. Med. J. 329(7475): p. 1177.

Meuwissen, M., Feindt, P., Slijper, T., Spiegel, A., Finger, R., de Mey, Y., Paas, W., Termeer, K., Poortvliet, P., Peneva, M., Urquhart, J., Vigani, M., Black, J., Nicholas-Davies, P., Maye, D., Appel, F., Heinrich, F., Balmann, A., Bijttebier, J., Coopmans, I., Wauters, E., Mathijs, E., Hansson, H., Lagerkvist, C., Rommel, J., Manevska-Tasevska, G., Accatino, F., Pineau, C., Soriano, B., Bardaji, I., Severini, S., Senni, S., Zinnanti, C., Gavrilescu, C., Bruma, I., Dobay, K., Matei, D., Tanasa, L., Voicilas, D., Zawalińska, K., Gradziuk, P., Krupin, V., Martikainen, A., Herrera, H., and Reidsma, P. (2021), Impact of Covid-19 on farming systems in Europe through the lens of resilience thinking. Agricultural Systems. 191: p. 103152.

Michalscheck, M., Groot, J. C., Kotu, B., Hoeschle-Zeledon, I., Kuivanen, K., Descheemaeker, K., and Tittonell, P. (2018), Model results versus farmer realities. Operationalizing diversity within and among smallholder farm systems for a nuanced impact assessment of technology packages. Agricultural Systems. 162(February): p. 164-178.

Modernel, P., Dogliotti, S., Alvarez, S., Corbeels, M., Picasso, V., Tittonell, P., and Rossing, W. (2018), Identification of beef production farms in the Pampas and Campos area that stand out in economic and environmental performance. Ecological Indicators. 89(May 2017): p. 755-770.

National Dairy Development Board (2019), Livestock Population in India by Species.

Nyström, M., Jouffray, J. B., Norström, A. V., Crona, B., Søgaard Jørgensen, P., Carpenter, S. R., Bodin, Galaz, V., and Folke, C. (2019), Anatomy and resilience of the global production ecosystem. Nature. 575(7781): p. 98-108. 
O’Mara, F. P. (2011), The significance of livestock as a contributor to global greenhouse gas emissions today and in the near future. Animal Feed Science and Technology. 166-167: p. 7-15.

Oberlack, C., Sietz, D., Bonanomi, E. B., De Bremond, A., Dell’ Angelo, J., Eisenack, K., Ellis, E. C., David, M., Giger, M., Heinimann, A., Kimmich, C., Kok, M. T., Navarrete, D. M., Messerli, P., Meyfroidt, P., Václavík, T., and Villamayor-Tomas, S. (2019), Archetype analysis in sustainability research: meanings, motivations, and evidence-based policy making. Ecology and Society. 24(2).

Ochieng, C. M. O. (2007), Development through positive deviance and its implications for economic policy making and public administration in Africa: The case of Kenyan agricultural development, 1930-2005. World Development. 35(3): p. $454-479$.

Ojiem, J. O., de Ridder, N., Vanlauwe, B., and Giller, K. E. (2006), Socio-ecological niche: A conceptual framework for integration of legumes in smallholder farming systems. International Journal of Agricultural Sustainability. 4(1): p. 79-93.

Pant, L. P. and Odame, H. H. (2009), The promise of positive deviants: bridging divides between scientific research and local practices in smallholder agriculture. Knowl. Manag. Dev. J. 5(2): p. 160-172.

Parihar, C. M., Jat, S. L., Singh, A. K., Kumar, B., Pradhan, S., Pooniya, V., Dhauja, A., Chaudhary, V., Jat, M. L., and Jat, R. K. (2016), Conservation agriculture in irrigated intensive maize-based systems of north-western India: effects on crop yields, water productivity and economic profitability. Field Crops Research. 193: p. 104-116.

Patra, A. K. (2017), Accounting methane and nitrous oxide emissions, and carbon footprints of livestock food products in different states of India. Journal of Cleaner Production. 162: p. 678-686.

Paul, B. K., Frelat, R., Birnholz, C., Ebong, C., Gahigi, A., Groot, J. C., Herrero, M., Kagabo, D. M., Notenbaert, A., Vanlauwe, B., and van Wijk, M. T. (2018), Agricultural intensification scenarios, household food availability and greenhouse gas emissions in Rwanda: Ex-ante impacts and trade-offs. Agricultural Systems. 163: p. 16-26.

Pittelkow, C. M., Liang, X., Linquist, B. A., Van Groenigen, L. J., Lee, J., Lundy, M. E., Van Gestel, N., Six, J., Venterea, R. T., and Van Kessel, C. (2015), Productivity limits and potentials of the principles of conservation agriculture. Nature. 517(7534): p. 365-368.

Ramírez-Carrillo, E., López-Corona, O., Toledo-Roy, J. C., Lovett, J. C., de León-González, F., Osorio-Olvera, L., Equihua, J., Robredo, E., Frank, A., Dirzo, R., and Perez-Cirera, V. (2018), Assessing sustainability in North America's ecosystems using criticality and information theory. bioRxiv: p. 1-24.

Rammel, C. and Van Den Bergh, J. C. (2003), Evolutionary policies for sustainable development: Adaptive flexibility and risk minimising. Ecological Economics. 47(2-3): p. 121-133.

Rivera-Ferre, M. G., López-i-Gelats, F., Ravera, F., Oteros-Rozas, E., di Masso, M., Binimelis, R., and El Bilali, H. (2021), The two-way relationship between food systems and the COVID19 pandemic: causes and consequences. Agricultural Systems. 191: p. 103134.

Ronner, E., Franke, A. C., Vanlauwe, B., Dianda, M., Edeh, E., Ukem, B., Bala, A., van Heerwaarden, J., and Giller, K. E. (2016), Understanding variability in soybean yield and response to P-fertilizer and rhizobium inoculants on farmers' fields in northern Nigeria. Field Crops Research. 186: p. 133-145.

Sietz, D., Ordoñez, J.C., Kok, M. T., Janssen, P., Hilderink, H. B., Tittonell, P., and Van Dijk, H. (2017), Nested archetypes of vulnerability in african drylands: Where lies potential for sustainable agricultural intensification. Environmental Research Letters. 12(9).

Steinke, J., Mgimiloko, M. G., Graef, F., Hammond, J., van Wijk, M. T., and van Etten, J. (2019), Prioritizing options for multi-objective agricultural development through the Positive Deviance approach. PLoS ONE. 14(2): p. 1-20.

Taleb, N. N. (2012), Antifragile - things that gain from disorder. Vol. 53. 9, p. 1689-1699. arXiv: arXiv: 1011.1669v3.

Thorpe, W., Erenstein, O., Singh, J., and Varma, A. (2007), Crop-livestock interactions and livelihoods in the Gangetic Plains of Bihar, India. Vol. 12. ILRI.

Timler, C., Alvarez, S., DeClerck, F., Remans, R., Raneri, J., Estrada Carmona, N., Mashingaidze, N., Abe Chatterjee, S., Chiang, T. W., Termote, C., Yang, R. Y., Descheemaeker, K., Brouwer, I. D., Kennedy, G., Tittonell, P. A., and Groot, J. C. (2020), Exploring solution spaces for nutrition-sensitive agriculture in Kenya and Vietnam. Agricultural Systems. 180(1): p. 102774.

Timler, C. J. (2020), Exploring and synergies and diversity for smallholder agriculture agriculture.

Tittonell, P., Bruzzone, O., Solano-Hernández, A., López-Ridaura, S., and Easdale, M. (2020), Functional farm household typologies through archetypal responses to disturbances. Agricultural Systems. 178(September 2019): p. 102714.

Tittonell, P., Muriuki, A., Shepherd, K. D., Mugendi, D., Kaizzi, K. C., Okeyo, J., Verchot, L., Coe, R., and Vanlauwe, B. (2010), The diversity of rural livelihoods and their influence on soil fertility in agricultural systems of East Africa-A typology of smallholder farms. Agric. Syst. 103(2): p. 83-97.

Ulanowicz, R. E. (2012), Quantitative Methods for Ecological Network Analysis and Its Application to Coastal Ecosystems. In: Treatise on Estuarine and Coastal Science. Vol. 9. Elsevier Inc., p. 35-57. 
Ulanowicz, R. E., Goerner, S. J., Lietaer, B., and Gomez, R. (2009), Quantifying sustainability: Resilience, efficiency and the return of information theory. Ecological Complexity. 6(1): p. 27-36.

Van der Ploeg, J. D., Laurent, C., Blondeau, F., and Bonnafous, P. (2009), Farm diversity, classification schemes and multifunctionality. J. Environ. Manage. 90: S124-S131.

Van der Ploeg, J. D. (1994), Styles of farming: an introductory note on concepts and methodology. In: Endogenous regional development in Europe, HJ de Haan, JD van der Ploeg (eds.). Vila Real, Portugal 1991. Luxembourg (1994) 7-31. Ook in: Born from within. Practice and perspectives of endogenous rural development, JD van der Ploeg, A. Long (eds.). Van Go, p. 7-31.

Van der Ploeg, J. D. and Ventura, F. (2014), Heterogeneity reconsidered. Current Opinion in Environmental Sustainability. 8: p. 23-28.

Vishnu, S., Gupta, J., and Subash, S. P. (2019), Social network structures among the livestock farmers vis a vis calcium supplement technology. Information Processing in Agriculture. 6(1): p. 170-182.

Watts, S. and Stenner, P. (2005), Doing Q methodology: Theory, method and interpretation. Qualitative Research in Psychology. 2(1): p. 67-91. 



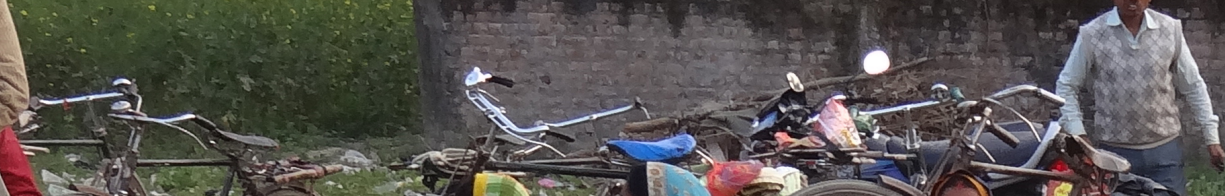

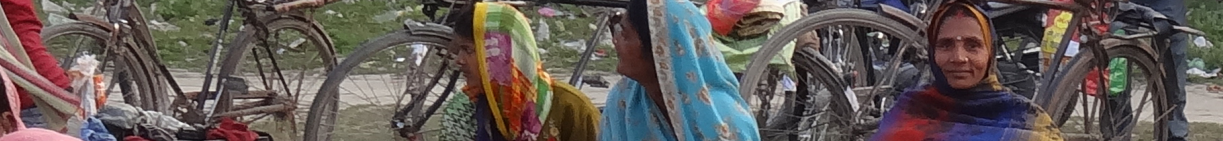

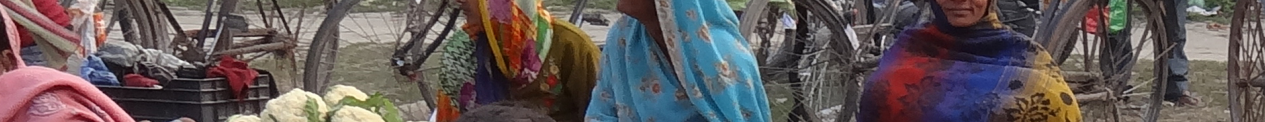

\section{renes \\ $2,-1 \times 2$}

(3.

$\cos 39$

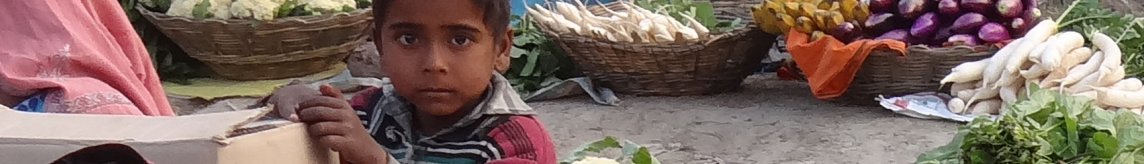

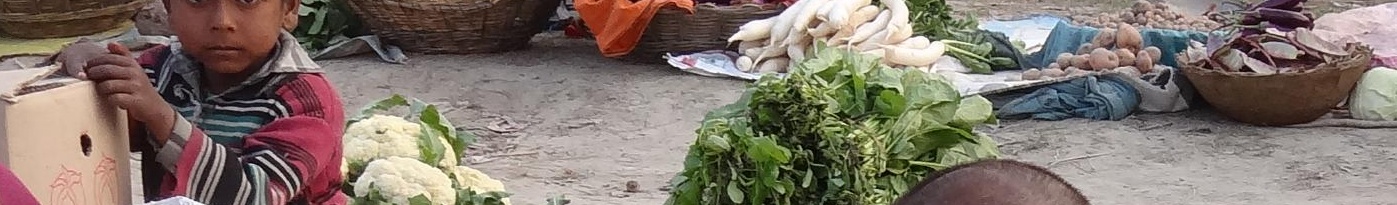

)

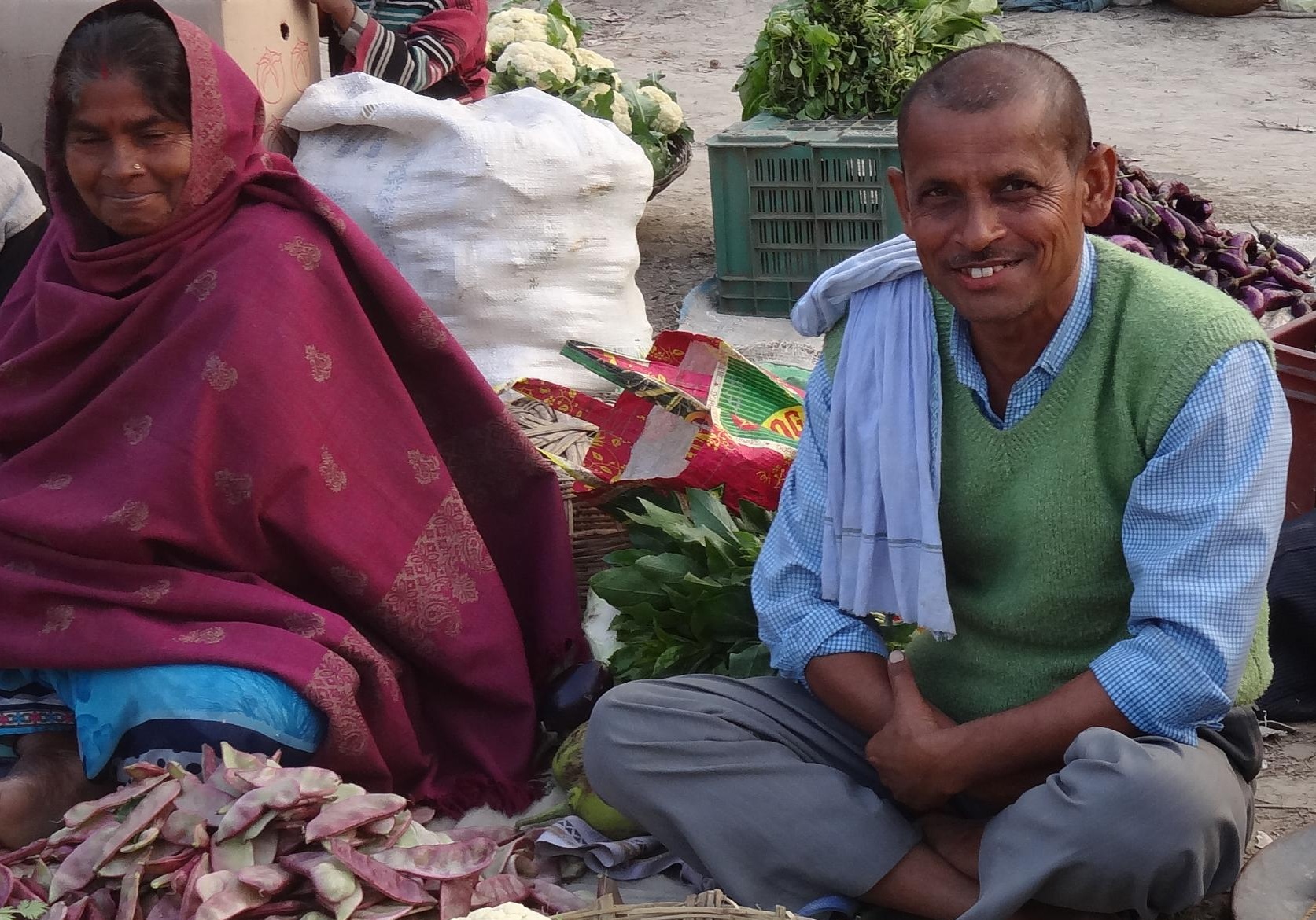

2.

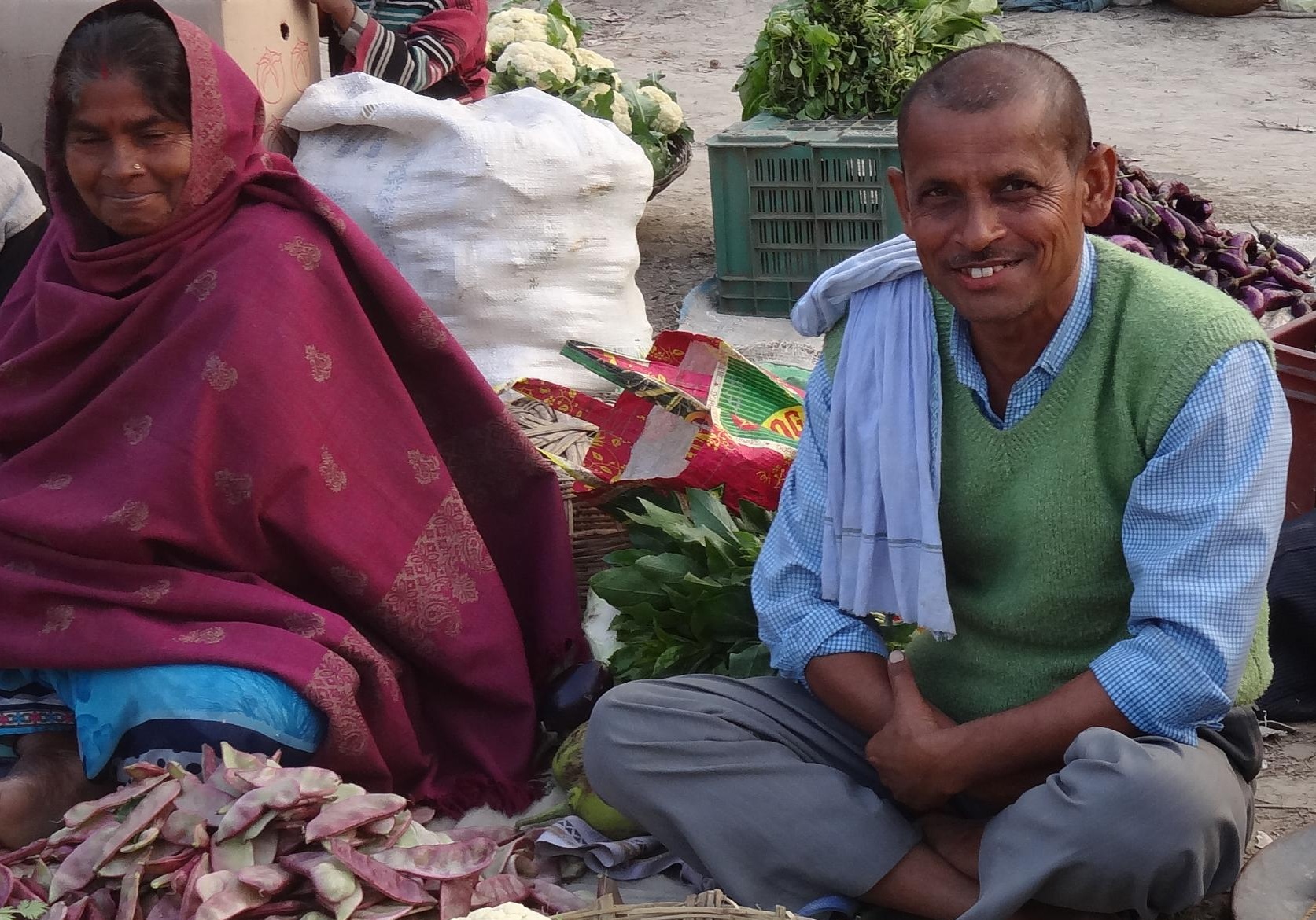

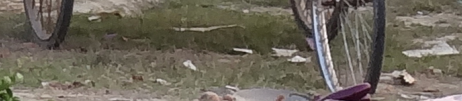

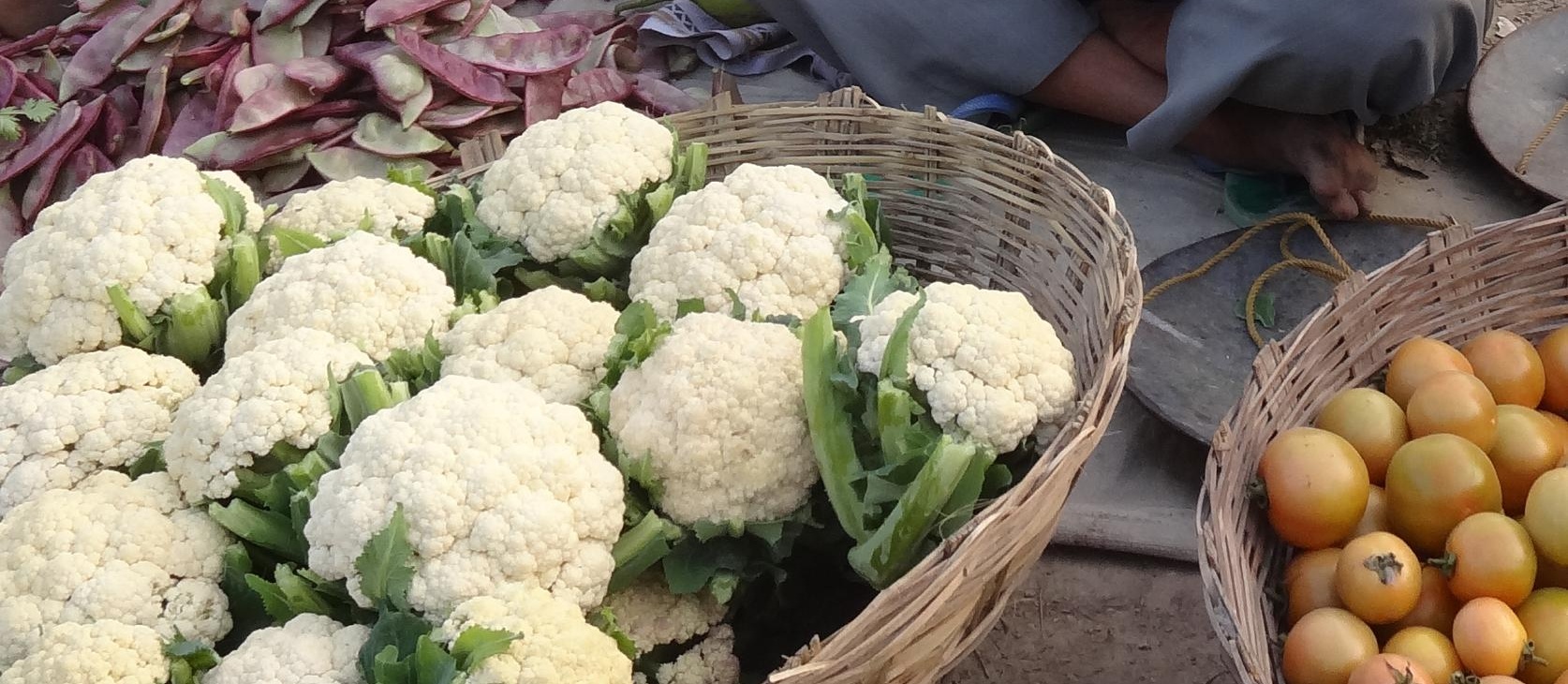




\section{Summary | Samenvatting | सारांश}





\section{Summary}

Agriculture is being questioned for its biophysical and socio-economic sustainability. While intensification, homogenization, and specialization were seen as a sign of progress in the 1950s, industrial agriculture is now being associated with a strong focus on productivity maximization with its adverse effects on the environment (soils, water, biodiversity), animal welfare, exploitive labor demands and power of multi-national companies. There is great pressure on farmers to sustainably intensify their production, amongst others in northern India. The Indo-Gangetic Plains (IGP) in northern India are the main food producing region of the country with intensive cereal-based agriculture sustaining millions of people with food and income. Continuous intensive cultivation of these cereals has led to soil degradation and over-exploitation of freshwater resources, resulting in challenges to sustain crop productivity whilst also endangering environmental sustainability. In addition, rapid population growth increases the demand for food while the impacts of climate change are experienced strongly. These challenges call for farming systems redesign. This thesis aims to understand and capture the diversity of farming systems based on their main components, characteristics, and interrelationships in order to identify windows of opportunities to inform redesign towards better whole-system farm performance for smallholder farms in the Indo Gangetic Plains.

Chapter 1 ("General introduction") describes the need for systems redesign, presents the research objective and questions and methods used to address these.

Chapter 2 ("Challenges experienced by smallholder farmers shape the window of opportunities for farm development in northern India”) presents an inventory of smallholder farmer perceptions in terms of the different objectives that farmers have and the various problems, threats and challenges they may face. I analysed whether the socio-economic and biophysical contrasts between localities are reflected in these differences in stated perceptions. Moreover, I assessed to what extent the perceived challenges could affect the outcome spaces and trade-offs that farmers must navigate. The differences in objectives between the six districts Patiala (Punjab), Karnal (Haryana), Muzaffarnagar, Faizabad (UP East), Patna (Bihar) and Kota (Rajasthan) were correlated to the differences in climatic conditions. In contrast, the challenges were not correlated with climate, demography, or farm structure, but were uniform over five out of the six districts. The most frequently mentioned challenges that were seen as acute problems were related to low labor availability, fluctuating market prices, low soil fertility and high seed prices. A model-based analysis showed that the anticipated, associated changes 
of lower product prices and productivity and higher prices of hired labor could aggravate the trade-offs of farm profitability with water use and soil quality. I conclude that due to continued farm fragmentation and increased price volatility and resource constraints the outcome space of smallholder farmers in the IGP is strongly reduced and more fundamental changes in farming and supporting policies are needed to address the challenges that farmers are facing.

Chapter 3 ("Farm-level exploration of economic and environmental impacts of sustainable intensification of rice-wheat cropping systems in the Eastern Indo-Gangetic plains") assesses the potential impact of reallocation of cropping patterns and inclusion of mung bean in cereal-based cropping systems for five farms from different farm types. The analysis with multi-objective optimization model FarmDESIGN revealed that rearranging 'current' resources (cropping patterns and land allocation) could save water, increase soil organic matter balances, and decrease nitrogen losses but that this would be at the cost of operating profit. Higher resource endowed farms had most potential to favorably rearrange the farm and improve multiple performance indicators. Two out of the five farms assessed did not benefit from including the alternative cropping patterns with mung bean in the usually fallow zaid (summer) season. I conclude that the impact of innovations greatly depends on farm type and current farm features and performance, described by a farm typology.

Chapter 4 (“Using a positive deviance approach to inform farming systems redesign: A case study from Bihar, India”) identified positive deviant farms and practices. Positive deviants are defined as individuals that achieve better outcomes than their peers despite having the same resources and constraints. In this chapter I developed methodology to support redesign of these positive deviants to arrive at farms that stand out on all indicators assessed. All practices of these modeled farms are already used in the biophysical and socio-economic context and therefore can be assumed accessible, affordable, tailored to local conditions and possibly transferable to other farmers. I tested the methodology in Bihar, India, using survey data from 43 farms. Six out of the 43 farms performed better than the population mean on each of the selected indicators (operating profit, water use, soil organic matter (SOM) balance and dietary energy production) and where therefore assigned as positive deviants. Analysis of these six positive deviants revealed that outstanding performance on all indicators could only be reached by integrating high livestock density with an optimal combination of crop practices, which confirms the key role of interactions among components in mixed crop-livestock systems to improve all dimensions of farm sustainability. The redesigns outperformed all real farms on the indicators 
assessed. Farmers confirmed the viability of the redesigns in focus group discussions and their suggestions can serve as useful input for a next cycle of farm redesign. Since all suggestions are locally practiced and have proven to be accessible, affordable and recognizable, I conclude that our methodology based on positive deviant farms and practices yields promising results with a large potential for upscaling among resource-scarce smallholder farmers.

Chapter 5 ("Analyzing antifragility among smallholder farmers in Bihar, India: an assessment of farmers' vulnerability and the strengths of positive deviants") assesses the vulnerability of different types of smallholder farmers in Bihar, India, and explored the scope for more 'antifragile' farming systems: systems that are the opposite of fragile - they gain from disturbance. Accumulation of stocks and redundancies, creation of optionality and strengthening of autonomy were identified as criteria that enable antifragility. I found that farmers expressed little antifragility: they were vulnerable and had limited adaptive capacity to improve their situation. They acknowledged a need for change but did not take action as they expected governmental support. They mostly made short-term decisions to cope with or mitigate urgent challenges but did not engage in strategic planning driven by longer term objectives. Despite being confronted with similar challenges, four positive deviants showed to be more antifragile: their diverse farming systems were abundant in stocks and optionality, and the farmers differed from others in terms of autonomy, competence and connectedness. I argue that adaptations at policy-level may be required to support antifragility among regular farmers, e.g., by shifting from a top-down towards a bottom-up adaptation and promoting innovation regimes where initiative and cooperation are endorsed. With a more autonomous orientation, farmers' intrinsic motivation may increase, enabling transitions at the farm-level.

Chapter 6 ("General discussion") puts the findings into a broader context, reflects on the methodology and elaborates on evolution in agroecosystems. The various methods in this thesis showed that it was possible to increase farmers' windows of opportunities. However, the heterogeneity among farmers and their context beyond the farming system should be considered to formulate and guide development pathways. In a world where volatility and perturbations can be expected, farming systems and farmers should be prepared for change. The food system has a role to play here: the efficiency and optimization paradigm should shift towards a focus on fostering evolution and supporting sustainable production at farm level. 



\section{Samenvatting}

'De landbouw moet duurzamer' is een claim die al jaren frequent wordt gemaakt. Waar in de jaren vijftig intensivering en specialisatie werden gezien als teken van vooruitgang, worden nu kritische vragen gesteld bij boerenbedrijven met een sterke focus op productieoptimalisatie. Zulke bedrijven worden geassocieerd met nadelige effecten op bodem en waterkwaliteit, verlies van biodiversiteit, slecht dierenwelzijn en arbeidsomstandigheden die te wensen over laten. Vaak hebben multinationals een onevenredig grote invloed op de op de ontwikkeling van deze bedrijven, wat duurzaamheid niet in de hand werkt. De druk op boeren om duurzaam te intensiveren is groot, zo ook in Noord-India. De Ganges vlakte in Noord-India is een van de belangrijkste agrarische gebieden van het land en voorziet miljoenen mensen van voedsel en inkomen. Ondanks dat het land van oudsher vruchtbaar is, heeft de continue teelt van granen geleid tot bodemdegradatie en overexploitatie van grondwater. Dit, samen met de uitdagingen die klimaatverandering en een groeiende bevolking met zich meebrengen, vraagt erom het huidige landbouwsysteem in Noord-India onder de loep te nemen en te verkennen hoe het landbouwsysteem op een duurzame manier hervormd kan worden. In dit proefschrift beoog ik de diversiteit van kleinschalige landbouwsystemen in de Ganges vlakte in kaart te brengen door de overeenkomsten en verschillen te beschrijven en inzichtelijk te maken hoe de systemen zich tot elkaar verhouden. Op basis hiervan verken ik ontwikkelingsmogelijkheden voor deze systemen.

In hoofdstuk 1 (“General Introduction”) beschrijf ik de noodzaak van herontwerp van systemen in het algemeen. Ook presenteer ik hier mijn onderzoeksvragen en beschrijf ik de methoden die zijn gebruikt in de rest van de thesis.

Hoofdstuk 2 ("Challenges experienced by smallholder farmers shape the window of opportunities for farm development in northern India") geeft inzicht in de doelen en problemen die kleinschalige boeren in Noord India ervaren. Voor deze doelen en problemen heb ik gekeken of ze correleren met contrasten tussen regio's. Daarnaast heb ik met het computermodel FarmDESIGN gekeken hoe de problemen die boeren ervaren de ontwikkelingsmogelijkheden op bedrijfsniveau beïnvloeden, en welke dilemma's ('trade-offs') boeren daarbij moeten overkomen. De resultaten laten zien dat de doelen die boeren zich stellen gecorreleerd zijn met het klimaat in de verschillende regio's. De problemen die boeren ervaren waren daarentegen niet gecorreleerd met klimaat, demografie of bedrijfsstructuur. De belangrijkste problemen hadden te maken met arbeidsbeschikbaarheid, fluctuerende marktprijzen, slechte bodemkwaliteit 
en hoge kosten voor zaden. Mijn modelstudie laat zien dat boeren in de toekomst mogelijk moeten kiezen tussen i) het verbeteren van hun inkomen of ii) inzetten op het verbeteren van de bodemkwaliteit of minder watergebruik. Het aannemelijk dat de ontwikkelingsmogelijkheden voor kleinschalige boeren afnemen, anticiperend op meer landfragmentatie (van generatie op generatie), instabiele prijzen en beperkte toegang tot hulpbronnen, is. Al deze bevindingen vragen om fundamentele veranderingen en beleidssteun.

In hoofdstuk 3 ("Farm-level exploration of economic and environmental impacts of sustainable intensification of rice-wheat cropping systems in the Eastern Indo Gangetic Plains") wordt voor vijf landbouwbedrijven van verschillende bedrijfstypen nagegaan wat de potentiële impact is van een herverdeling van de huidige gewassen en de toevoeging van mungbonen in het teeltplan tijdens het gewoonlijk braakliggende zomerseizoen. Een analyse met optimalisatiemodel FarmDESIGN toonde aan dat het herschikken van de huidige gewassen en hun areaal kan leiden tot i) waterbesparing, ii) een betere balans van organische stof in de bodem en iii) minder stikstofverliezen, maar dat het aannemelijk is dat dit ten koste zal gaan van de winst op bedrijfsniveau. De grotere bedrijven hadden het meeste potentieel om binnen het bedrijf het teeltplan te veranderen? en meerdere indicatoren te verbeteren. Twee van de vijf bedrijven hadden geen baat bij het opnemen van de alternatieve teeltplannen met mungbonen. Ik concludeer dat de impact van innovaties sterk afhankelijk is van het bedrijfstype en de huidige bedrijfskenmerken en -prestaties.

In Hoofdstuk 4 ("Using a positive deviance approach to inform farming systems redesign: A case study from Bihar, India") heb ik excellente boeren geïdentificeerd en gekeken welke activiteiten er bijdragen aan excellentie op basis van de indicatoren winst, watergebruik, organische stof balans en voedselproductie. Vervolgens heb ik de excellente bedrijven verder geoptimaliseerd. Excellente boeren presteren ondanks vergelijkbare omstandigheden beter dan hun collega's. Het is relevant naar de activiteiten van deze boeren te kijken (bijv. welke gewassen, welke dieren, welke cultiveringstechnieken gebruiken ze) omdat ze in de praktijk al effectief en realistisch zijn bleken. Dit in tegenstelling tot innovaties die alleen op onderzoeksstations getest zijn. De excellente boeren werden geïdentificeerd uit een dataset met 43 bedrijven in Bihar, India. Zes van de 43 bedrijven presteerden beter dan het populatiegemiddelde op elk van de geselecteerde indicatoren en werden daarom als excellent beschouwd. Nadere analyse van deze zes bedrijven liet zien dat excellentie alleen kon worden bereikt door relatief veel vee te combineren met bepaalde gewassen (o.a. tarwe, mungbonen, mais, mosterd en yam). 
Het verder optimaliseren van de excellente bedrijven resulteerde in re-designs die op alle indicatoren nog beter scoorde dan de echte bedrijven. In workshops met boeren werden de re-designs geëvalueerd als haalbaar, maar er werden ook suggesties voor verbetering gedaan. Deze suggesties moeten in een volgende re-design stap geïntegreerd worden. De inzichten uit deze studie kunnen ook met andere kleinschalige boeren in de regio besproken worden en de methode kan ook op andere locaties gebruikt worden.

Hoofdstuk 5 ("Analysing antifragility among smallholder farmers in Bihar, India: an assessment of farmers' vulnerability and the strengths of positive deviants") geeft inzicht in de kwetsbaarheid van kleinschalige boeren in Bihar, India. In deze studie onderzoek ik de opties voor meer 'anti-fragiele' landbouwsystemen: systemen die het tegenovergestelde zijn van fragiel - ze worden sterker na een shock in plaats van dat ze instorten. Als criteria voor anti-fragiliteit identificeer ik 1) het hebben van reserves; 2) multifunctionaliteit (het hebben van meerdere opties); en 3) het ontwikkelen van autonomie. De gangbare boeren bleken weinig anti-fragiel; ze waren ontevreden over hun leefomstandigheden en waren het erover eens dat hun situatie verbeterd diende te worden. Desondanks lieten ze weinig vermogen zien om te veranderen; ze maakten ad-hoc beslissingen om onverwachte problemen op te lossen, maar waren weinig bezig met veranderingen die het bedrijf op de lange duur zouden doen verbeteren. Ook vonden we vier boeren die hun bedrijven substantieel anders ingericht hadden en worden daarom als excellente voorbeelden beschreven. Hun bedrijven kenmerkten zich met overvloed en multifunctionaliteit, zo hadden ze fruitbomen, gewassen, dieren en nog een andere bedrijfstak zoals bijv. het telen van champignons of het maken van compost. Deze boeren toonden zich autonoom en verbonden met afnemers en andere bedrijven in de omgeving. Voor structurele veranderingen bij gangbare boeren zou verandering op beleidsniveau kunnen helpen. Zo zouden bottom-up initiatieven en samenwerking kunnen worden gestimuleerd. Zo zou de autonomie kunnen groeien wat mogelijk transities op bedrijfsniveau in de hand werkt.

Hoofdstuk 6 ("General Discussion") plaatst de bevindingen in een bredere context, reflecteert op de methodologie en gaat dieper in op evolutie in agro-ecosystemen. De verschillende methoden in dit proefschrift laten zien dat het mogelijk is om de ontwikkelingsmogelijkheden van boeren te vergroten. Er moet echter rekening worden gehouden met onderlinge verschillen tussen bedrijven en hun context om ontwikkelingstrajecten te begeleiden. In een wereld waar volatiliteit en shocks te verwachten zijn, moeten boeren zich voortdurend aanpassen en bedrijfssystemen zo ingericht worden dat ze kunnen veranderen. Om dit te bewerkstelligen 
heeft ook het voedselsysteem als geheel een rol: het efficiëntie- en optimalisatieparadigma moet verschuiven naar een focus op het bevorderen van evolutie binnen het systeem en het ondersteunen van duurzame productie op bedrijfsniveau. 


\section{सारांश}

कृषकि आज के परदृश्य में जैव-भौतकिय और सामाजकि-आर्थकि स्थरिता पर सवाल उठाए जा रहे हैं। । जबक 1950 के दशक में गहनता, समरूपीकरण और वशिषज्जता को प्रगतकि संकेत के रूप में देखा गया था, आज औद्योगकि कृषकिो अधकितम उत्पादकता पर केन्द्रति होने के साथ साथ पर्यावरण (मट्टिी, पानी, जैव वविधिता), पशु कल्याण पर इसके प्रतक्लिल प्रभावों, श्रम शोषणकारी, बहुराष्ट्रीय कंपनयों की शक्त कि साथ जोड़ा जा रहा है। । उत्तरी भारत में कसिनों पर अपने उत्पादन को लगातार तेज करने का दबाव प्रमुख है। उत्तरी भारत में गंगा के मैदानों (आईजीपी) देश का प्रमुख खाद्य उत्पादक क्षेत्र है जहां गहन अनाज आधारति कृष्लिखों लोगों के भोजन और आय का साधन है। इन अनाजों की नरिंतर गहन खेती से मट्टि का क्षरण हुआ है और मीठे पानी के संसाधनों का अत्यधकि दोहन हुआ है, जसिके परणिामस्वरूप पर्यावरणीय स्थरिता को खतरे में डालते हुए फसल उत्पादकता को बनाए रखने की चुनौतयिं हैं। इसके अलावा, तेजी से जनसंख्या वृद्धसि भोजन की मांग बढ़ रही है जबक जिलवायु परविर्तन के प्रभावों का जोरदार असर भी इस क्षेत्र में अनुभव होता है। ये चुनौतयाँ कृषप्रिणालयों को नया स्वरूप देने की आवश्यकता की और प्रेरति करती हैं। यह थीससि का उद्देश्य भारत के गंगा के मैदानों में छोटे जोत वाले कसिनों के वविधिता को समझ कर उनके मुख्य घटकों, वशिषताओं और अंतर्संबंधों के आधार पर, अवसरों की खडिकयों की पहचान करके बेहतर फार्म प्रदर्शन की दशिा में कृषप्रिणालयों की नया स्वरूप देना है।

अध्याय 1 ("सामान्य परचिय") सस्टिम को फरि से डजिाइन करने की आवश्यकता का वर्णन करता है, शोध के उद्देश्य को प्रस्तुत करता है और इन्हें संबोधति करने के लए उपयोग कए जाने वाले प्रश्नों और वधियों को प्रस्तुत करता है।।

अध्याय 2 ("उत्तर भारत के छोटे जोत वाले कसिानों द्वारा अनुभव की गई चुनौतयाँ कृषविकिस के अवसरों की खडिकी को आकार देती हैं") कसिानों के वभिन्नि उद्देश्यों और वभिन्नि समस्याओं, संभावति खतरों और चुनौतयों का सामना करने के संदर्भ में छोटे कसिानों की धारणाओं की एक सूची प्रस्तुत करती है। मैंने वश्रिलेषण कयि कक्यिया स्थानीयताओं के बीच सामाजकि-आर्थकि और जैव-भौतकि अंतर कथति धारणाओं में परलिक्षति होते हैं। इसके अलावा, मैंने आकलन कयि की कथति चुनौतयाँ कसि हद तक अवसर और ट्रेड ऑफ को प्रभावति कर सकती हैं जनिह्हें कसिानों को नेवगिट करके आगे बढ़ना चाहएि। छह जलीं जैसे पटयिला (पंजाब), करनाल (हरयिणा), मुजफ्फरनगर (पश्चमी), फैजाबाद (पूर्वी उत्तर प्रदेश), पटना (बहिार) और कोटा (राजस्थान) के उद्देश्यों के अंतर जलवायु परस्थितियों में अंतर से संबंधति थे। इसके वपिरीत, चुनौतयिं जलवायु, जनसांख्यकिी या कृषा संरचना से संबंधति नहीं थी, बल्कछछि में से पांच जलिं में एक समान थी। सबसे अधकि बार उल्लेख की जाने वाली चुनौतयाँ जन्हिं वीकट समस्याओं के रूप में देखा गया था, वे कम श्रम उपलब्धता, बाजार की कीमतों में उतार-चढ़ाव, मट्टि की उर्वरता में कमी और बीजों के उच्च कीमतों से संबंधति थी। एक मॉडल-आधारति वश्तिलेषण से पता चला है क किम उत्पाद कीमतों और उत्पादकता तथ करिए के श्रमकीं की उच्च दर के प्रत्याशति परविर्तन, पानी के उपयोग, मट्टिी की गुणवत्ता के साथ कृष्त 
लाभप्रदता के ट्रेड ऑफ को बढ़ा सकते हैं। मैं यह नष्किर्ष नकिालती हूं कनिरितर कृषजित वखिंडन और बढ़ी हुई कीमतों में अस्थरिता तथा संसाधनों की कमी के कारण भारत के गंगा के मैदानों (आईजीपी) में छोटे कसिानों के लएि अवसर बहुत कम हो गया है और कसिानों के सामने आने वाली चुनौतयों का समाधान करने के लए खेती और सहायक नीतयों में अधकि मौलकि परविर्तनों की आवश्यकता है।

अध्याय 3 ("पूर्वी भारत के गंगा के मैदानों में चावल-गेहूं फसल प्रणालयों के स्थायी गहनता के आर्थकि और पर्यावरणीय प्रभावों का कृष-स्त्तरीय अन्वेषण") फसल चक्र के पुन: आवंटन और वभिन्न प्रकार के फार्मों से पांच फार्मों के लए अनाज आधारति फसल में मूंग को शामलि करने के संभावति प्रभाव का आकलन करता है । बहु उद्देश्य अनुकूलन मॉडल (फार्मडजिएन) के साथ वश्रिलेषण से पता चला क वि्त्तमान' संसाधनों (फसल पैटर्न और भूमआवंटन फसल ) के उलटफेर कर पानी की वचत, मट्टिी कार्बनकि पदार्थ शेष राशक की वृद्धा, और नाइट्रोजन हानक को कम कर सकता है लेकनि यह लाभ ऑपरेटगि लाभ की कीमत पर हो सकता है। उच्च संसाधन संपन्न कसिानों में खेत को अनुकूल रूप से पुनर्व्यवस्थति करने और वभिन्न प्रदर्शन संकेतकों के आधार पर सुधार करने की सबसे अधकि क्षमता थी । मूल्यांकन कए गए पांच खेतों में से दो को आमतौर पर जायद (गर्मी) के मौसम में मूंग के साथ वैकल्पकि फसल पैटर्न को शामलि करने से कोई फायदा नहीं हुआ। मैंने नष्किर्ष नकिाला है का नवाचारों का प्रभाव खेत के प्रकार और वर्तमान कृषसुिधििओं और प्रदर्शन पर नर्भिर करता है, जसिका वर्णन एक फार्म टाइपोलॉजी द्वारा कयिा जाता है।

अध्याय 4 ("कृषप्रण्रणालयों को फरि से डजिाइन करने के लए एक सकारात्मक वचिलन दृष्टक्रोण का उपयोग करना: बहिर, भारत से एक केस स्टडी") सकारात्मक वचिलन वाले खेतों और प्रथाओं की पहचान की । सकारात्मक वचिलन को ऐसे व्यक्तयों के रूप में परभिषति कयि जाता है जो समान संसाधनों और बाधाओं के बावजूद अपने साथयों की तुलना में बेहतर परणिाम प्राप्त करते हैं। इस अध्याय में मैंने सकारात्मक वचिलनों फार्मों को पुन: डजिाइन कर सभी संकेतकों पर बेहतर प्रद्रश्श स्तर पर पहुँचने के लए समर्थन करने के लए पद्धतविकिसति की । इन सकारात्मक वचिलनों के का इन मॉडल कए गए फार्मों की सभी प्रथाओं का पहले से ही जैव-भौतकि और सामाजकि-आर्थकि संदर्भ में उपयोग कयि जाता है और इसलए इसे सुलभ, सस्ती, स्थानीय परस्थितियों के अनुरूप ढाला जा सकता है और संभवतःअन्य कसिानों के लए हस्तांतरणीय माना जा सकता है। मैंने यह कार्यप्रणाली का परीक्षण बहिर (भारत) के 43 खेतों के सर्वेक्षण डेटा का उपयोग करते हुए कयि। 43 खेतों में से छह खेतों ने चयनति संकेतक ( ऑपरेटगि लाभ, पानी का उपयोग, मट्टिी कार्बनकि पदार्थ (SOM), संतुलन और आहार ऊर्जा उत्पादन ) में औसत से बेहतर प्रदर्शन कयि और इसलए इन छह फार्मों को सकारात्मक वचिलनों के रूप में माना गया। इन छह सकारात्मक वचिलनों के वश्लिषण से पता चला कसिभी संकेतकों पर उत्क्क्ट्ट प्रदर्शन केवल, उच्च पशुधन घनत्व के साथ साथ फसल प्रथाओं के इष्टतम संयोजन को एकीकृत करके प्राप्त कयि जा सकता है, जो मश्रिति फसल-पशुधन प्रणालयों में घटकों के बीच बातचीत की महत्वपूर्ण भूमकि की पुष्टकिरता है ताक किषस्थिरिता के सभी आयामों में सुधार हो सके। रडिजिएन फार्म ने मूल्यांकन कए गए संकेतकों पर सभी वास्तवकि खेतों से बेहतर प्रदर्शन कयि। कसिानों के साथ फोकस समूह चर्चाओं में पुन: डज़िएइन की व्यवहार्यता की पुष्ट हुई 
और उनके सुझाव खेत के नए स्वरूप (रडिजिएन) के अगले चक्र के लए उपयोगी इनपुट के रूप में काम कर सकते हैं। चूंकसिभी सुझावों का स्थानीय रूप से अभ्यास कयि जाता है और सुलभ, कफिायती और पहचानने योग्य साबति हुए हैं, इसलए मैं यह नष्किर्ष नकिालती हूं कसिकारात्मक वचिलन वाले खेतों और प्रथाओं पर आधारति हमारी कार्यप्रणाली संसाधन-कमी वाले छोटे कसिनों के बीच बढ़ावे के लएि एक बड़ी क्षमता के साथ आशाजनक परणिाम देती है ।

अध्याय 5 ("बहिर, भारत में छोटे कसिानों के बीच नाजुकतारोधी खेती का वश्लिषण: कसिानों के असुरक्षा का एक आकलन और सकारात्मक वचिलन की ताकत") बहिर, भारत में छोटे कसिनों के वभिन्न प्रकार के जोखमि का आंकलन के साथ नाजुकतारोधी खेती प्रणाली (जो नाजुक के वपिरीत हैं - वे गड़बड़ी से लाभान्वति होती हैं ) के गुंजाइश का पता लगाया । स्टॉक और अतरिक का संचय, वैकल्पकिता का नर्मिणाण और स्वायत्तता को मजबूत करने को नाजुकतारोधी खेती प्रणाली मानदंड के रूप में पहचाना गया जो इसे सक्षम बनाता है। मैंने पाया ककिसिनों ने अपने खेती को बहुत कम नाजुकतारोधी व्यक्त की: वे कमजोर थे और उनकी स्थतिको सुधारने के लए सीमति अनुकूलीय क्षमता थी। उन्होंने बदलाव की आवश्यकता को स्वीकार कयि लेकनि सरकारी समर्थन की अपेक्षा में अनुरूप कार्रवाई नहीं की। उन्होंने ज्यादातर तात्कालकि चुनौतयों का सामना करने या उन्हें कम करने के लए अल्पकालकि नर्णिय लएि, लेकनि दीर्घकालकि उद्देश्यों से प्रेरति रणनीतकि योजना में शामलि नहीं हुए। समान चुनौतयों का सामना करने के बावजूद, चार सकारात्मक वचिलन अधकि नाजुकतारोधी दखिाई: उनकी वविधि कृषप्रिणालयाँ स्टॉक और वैकल्पकिता में समृद्ध थी, और कसिान स्वायत्तता, क्षमता और जुड़ाव के मामले में दूसरों से भन्न थे। मेरा तर्क है क साधारण कसिानों के बीच समर्थन नाजुकतारोधी को समर्थन एवं बढ़ावा हेतु नीत-स्तिर पर रूपांतरों के आवश्यक हो सकता है, जैसे , ऊपर से नीचे की अनुकूलन से हमें नीचे-ऊपर अनुकूलन की ओर स्थानांतरण के साथ साथ और उस नवाचार को बढ़ावा देने की जरूरत है जहां नयी पहल और सहयोग का समर्थन कयि जा रहा हो। अधकि स्वायत्त अभविन्यियास से, कसिानों की आंतरकि प्रेरणा बढ़ सकती है, जसिसे कसिानों के स्तर पर परविर्तन संभव हो सकता है।

अध्याय 6 ("सामान्य चर्चा") नष्किर्षों को एक व्यापक संदर्भ में रखता है, कार्यप्रणाली को प्रतबिबिति करता है और कृष-पारस्थितिकी तंत्र में वकिास पर वस्तितर से बताता है । इस शोध में उपयोग वभिन्नि तरीकों से कसिनों की अवसरों खड़िकयों में उन्नतसिंभव होता पाया गया। हालांका वकिस पथ तैयार करने और मार्गदर्शन करने से पूर्व कसिानों के बीच वविधिता और कृषप्रिणाली से अन्य संदर्भ का भी वचिर कयि जाना चाहए । ऐसी दुनयि में जहां अस्थरिता और गड़बड़ी की उम्मीद संभावति हो, कृषप्रिणालयों और कसिानों को बदलाव के लए तैयार रहना होगा। इसमे भोजन व्यवस्था एक मुख्य भूमकिा नभि सकती है: दक्षता और अनुकूलन प्रतमिन को अपना ध्यान बदल कर वकिास को बढ़ावा देने तथा खेत स्तर पर टकिाऊ उत्पादन की और करना होगा। 



\section{Acknowledgements}




\section{Acknowledgements}

I am thankful to many people who I have met and worked within the past few years. The hours spent inside the offices and fields in Wageningen and in India, and conferences and lockdowns were all the more richer in your company.

Jeroen, thank you for your support, guidance and optimism throughout the years. You have been sharing your wisdom and skills in the most humble way, no matter how high your workload. It's not only a pleasure to work with you, you are also a very nice person to spend time with in the Indian traffic, on trains, and in airports. Among my biggest achievements of the past years is that we got you into running. The way you approach running, is a reflection of your nature as a researcher: you do literature research and experiment with dedication. It's a pleasure to run with you (always faster than I would on my own) and to take the time to talk about life. Santiago, with your fast mind and outspoken character you contributed substantially to the research process without even meeting very regularly. Especially during my time in India, you were always approachable to discuss things ad-hoc. I admire the ease with which you connect with our Indian colleagues and farmers, and the way you shape the ongoing research on sustainable intensification. Thank you for being part of my supervisory team.

ML, RK, Prusty and Deepak, thanks so much for making my stays as smooth as they were. Surveying hundreds of farmers within a few days, conducting interviews in remote villages, talking with high-level policy makers... you made it all possible and accompanied me. I am grateful that I could discover your beautiful country in this way. Angelica, Chaitanya, Eakapat, Hannah, Jelle, Nanta, Pauline and Viviana, thank you for doing your MSc thesis with us. It was nice to share the research context with you to learn from your perspectives and processes. With a few of you I spent time in the field. I thoroughly enjoyed working hard, sharing meals and spending leisure time together.

This research is about India, but most of the work has been done in Wageningen. Rogier, I am grateful to be part of FSE. Thank you for all your support, especially during the last stretch of the $\mathrm{PhD}$. Gemma, Annemieke and Wampie, you cannot be missed! Blair, we are 'buddies' since the first day of our MSc and it's nice to still be part of the same crowd and run into each other on a regular basis. Mariana, I admire your good mood and energy. The office is nicer when you are there! Thanks a lot for proof reading parts of this thesis. Hennie, it's time to get back to normal routines. I miss your noisy presence and the good laughs we had with you. To the $\mathrm{PhD}$ colleagues of the past years: it's a pity that knowing each other's pitfalls does not prevent oneself from walking into them too. I however did experience that shared sorrow is half sorrow. Thanks for sharing, listening and, just as importantly, for all the fun we had, Anne, Birthe, Carl, Elsa, Francine, Fogelina, Georges, Ghina, Heitor, Jiali, Jonas, Kari, Kristine, Loekie, Lucas, Mirja, Pablo, Qingbo, Stella, Tharic, Victoria, Walter, Yavanna and Yodit. Spending time at the farm and teaching together definitely catalyzes the process of getting to know each other. Annemiek, Dirk, Felix, Kees, Laci, Merel and Renee: it's always a pleasure to see you, and I look forward to the next farm camping trip together. Walter, thanks for employing me back in 2014. I still use insights you shared, and I am grateful that you introduced me to teaching. Gerard, you invited me several times to dig soil pits in the fields of inspiring farmers. Your enthusiasm is still contagious. Wim and Wytze, we go way back: we did the same bachelor, a comparable master, and will all finish our PhD soon. It's truly enriching to discuss our views on research, and to help each other out with practical issues. Lennart and others from the PE\&RC graduate school, thanks for all the support throughout the years. 
Lenora and Lieneke, it means a lot for me to have you on my side as paranymphs. Our friendship started in the office and intensified through the talks we had about work and life, during the conferences that we visited, the many lunches and dinners we had, and the walks around Wageningen. You are both very dear to me and I look forward to all that is ahead of us.

Next to colleagues, I had many friends that supported me throughout the years, and many hobbies that offered a healthy distraction from the work.

I feel privileged to live in the Wolfswaard in Wageningen. The daily encounters with the fellow Wolfswaarders energize me every day. Thank you so much for your continuous efforts to make this place as lively and special as it is! I am very, very grateful for the life we share. And to the marvelous kids of the Wolfswaard, to Anouk, Athziri, Inte, Inti, Jinte, Mente, Pier, Wolf and Wyke: you brighten my days. I am proud to be part of your childhood memories.

Maartje, Rozemarijn, Lena and Sophie: you are the greatest company for outdoor adventures. It's not evident to have the same pace, eat the same stuff, like the same routes, and have matching voices. Let's continue to free up time to go out. Floor, it's worth a lot to have you so close and see you so regularly. Eva, I couldn't imagine that it would be so much fun to have you back in Wageningen. Ilse, our lives are running parallel since the start of our bachelor studies. I am curious to what life will bring us in the future, I am sure that it'll be nice to discuss together. Jelle, let's continue to have dinner sessions once in a while. Roeland, after living together for 10 years we proved that it is possible to still be part of each other's life. Thank you for all the short and long, refreshing and fun phone calls, your openness, and your hospitality in Zeeland. Nele and Fabian, thank you for your friendship, for your visits to Wageningen and for always making us feel at home in Antwerp. Eva, Aafke and Nico, thank you for all early mornings and late nights we spent in nature. Without you, I wouldn't have known the names of all those birds, plants, trees and animals. Eva, I am not making an attempt to express my gratefulness in words. Thank you for your friendship and for making the cover of this thesis! Lena and Hendrik, the same goes for you two. Thank you for everything, including emergency photoshopping to get the photos and figures of this thesis in acceptable formats. Anna and Maarten, I am grateful for your unconditional love and support, your open door and bright voices. Ben and Rit, Ellen and Thijs, thank you for welcoming me in your family and for your many visits to Wageningen. Reinier and Laura, Tessel, Karin and Martin, I simply cannot remember a life without you. Thank you for always being there.

Lastly, the coauthors of my life: Els, for giving the roots and the wings - "het nest is goed, maar het heelal is ruimer ${ }^{1}$ ". Taas, "Alles was man tun muss ist die richtige Taste zum richtigen Zeitpunkt zu treffen $^{2}$ ". Niels, we both have been committed to our personal goals during the last years. Despite everything, I could always lean on you. Now it's time for a new, joint, adventure in our lives. With you on my side, I am confident to climb all mountains that are ahead of us with grace. Thank you so much for being your steady self.

Papa pasti bangga.

\footnotetext{
${ }^{1}$ H. Marsman

${ }^{2}$ J.S. Bach
} 



\section{About the author}

Selected Publications

Education statement 



\section{About the author}

Roos de Adelhart Toorop was born in Amsterdam on the 18th of November, 1987. With a father from Indonesia, the differences in livelihoods in different part of the world have always been part of the family conversations. In 2007, Roos moved to Wageningen to study International Land and Water Management at Wageningen University and Research (WUR). During her internship and thesis in the Rwandan Highlands, she discovered that she enjoyed doing research at the farm and household level. After completion of her BSc, she took time to expand her agronomical knowledge as co-founder of a commercial organic vegetable garden in Hilvarenbeek, which motivated her to continue her studies at WUR and conduct an MSc in Organic Agriculture from 2011-2013. In 2014, Walter Rossing employed her as junior researcher at the Farming Systems Ecology group where they worked on a European project related to climate change adaptation in organic arable farming. In 2018, she switched focus from large-scale European agriculture to smallholder farming in Asia. In a consortium with CIMMYT, the Indian Institute for Farming Systems Research (IIFSR) and WUR she conducted her PhD research that resulted in this thesis. Throughout her carrier at Farming Systems Ecology, Roos alternated her research work with teaching the MSc course Analysis \& Design of Organic Farming Systems and supervising student projects. Since April 2021, she works as a Postdoctoral researcher at the same chair group where, together with a team from The Alliance of Bioversity International and CIAT, she develops online learning modules on synergies and trade-offs in food and agricultural systems.

In her free time, Roos is editor of the magazine for the organic food chain 'Ekoland'.

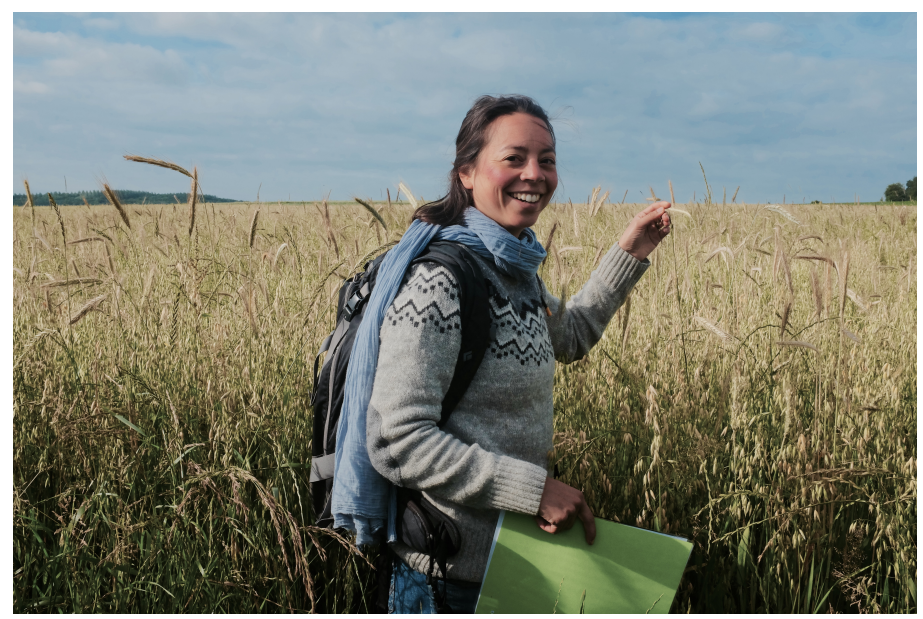





\section{Selected Publications}

Adelhart Toorop, R., Ceccarelli, V., Bijarniya, D., Jat, M.L., Jat, R.K., Lopez-Ridaura, S., Groot, J.C.J., 2020. Using a positive deviance approach to inform farming systems redesign: A case study from Bihar, India. Agric. Syst. 185, 102942. https://doi.org/10.1016/j.agsy.2020.102942.

Adelhart Toorop, R., Lopez-Ridaura, S., Bijarniya, D., Kalawantawanit, E., Jat, R.K., Prusty, A.K., Jat, M.L., Groot, J.C.J., 2020. Farm-level exploration of economic and environmental impacts of sustainable intensification of rice-wheat cropping systems in the Eastern Indo-Gangetic plains. Eur. J. Agron. 121, 126157. https://doi.org/10.1016/j.eja.2020.126157.

Schuler, J., Adelhart Toorop, R., Willaume, M., Vermue, A., Schläfke, N., Uthes, S., Zander, P., Rossing, W., 2020. Assessing Climate Change Impacts and Adaptation Options for Farm Performance Using Bio-Economic Models in Southwestern France. Sustainability 12, 7528. https://doi.org/10.3390/su12187528.

Kaur, J, Prusty, A.K., Ravisankar, N., Panwar, A.S., Shamim, M., Walia, S.S., Chatterjee S., Pasha, M.L., Babu, S., Jat, M.L., López-Ridaura, S., Groot J.C.J., Adelhart Toorop, R., Barba-Escoto, L., Noopur, K., Kashyap, P. Farm typology for planning targeted farming systems interventions for smallholders in Indo-Gangetic Plains of India. Under review.

Prusty, A.K., Ravisankar, N., Panwar, A.S., Jat, M.L., Tetarwal, J.P., López-Ridaura, S., Adelhart Toorop, R., Van den Akker, J., Kaur, J., Ghasal, P.C., Barba-Escoto, L., Groot, J.C.J. Model based assessment of farming systems prototypes and exploration of alternatives fitting farmer realities: A case study of North-Western, India. Under review.

Rossing, W.A.H., Adelhart Toorop, R., Modernel, P., Groot, J.C.J. (2019) Learning from excellence: positive deviance approaches in organic dairy and natural grassland beef farming. The 6th International Symposium for Farming Systems Design, Montevideo, Uruguay, 2019.

Adelhart Toorop, R., Bijaniya, D., Kalawantawanit, Jat, R.K., López-Ridaura, S., Jat, M.L., Groot J.C.J. (2019) Farm-level assessment of economic and environmental indicators to evaluate innovative cropping patterns in Bihar, India. The 6th International Symposium for Farming Systems Design, Montevideo, Uruguay, 2019.

Van den Akker, J., Adelhart Toorop, R., Prusty, A.K., Tetarwal, J.P., Kaur, J., López-Ridau, S., Jat, M.L., Panwar, A.S., Ravisankar, N., Groot, J.C.J. (2019) Closing the gap between research and practice: farm-level exploration towards integrated farming systems in northwest India. The 6th International Symposium for Farming Systems Design, Montevideo, Uruguay, 2019.

Adelhart Toorop, R., Van den Akker, J., Prusty, A.K., Tetarwal, J.P., Kaur, J., López-Ridaura, S., Panwar, A.S., Ravisankar, N., Jat, M.L., Groot, J.C.J. (2018) From research station to farmers field: whole farm analysis as stepping stone. National Symposium on Integrated Farming Systems for 3Es (Ecological Sustainability, Enhanced Productivity and Economic Prosperity), Bangalore, India, 2018.

Adelhart Toorop, R., De Wit, J., Rossing, W.A.H., Koopmans, C. (2017) Benefits of grass-clover in an arable crop rotation: a case study from The Netherlands. Organic World Congress, New Delhi, India, 2017. 



\section{PE\&RC Training and Education Statement}

With the training and education activities listed below the $\mathrm{PhD}$ candidate has complied with the requirements set by the C.T. de Wit Graduate School for Production Ecology and Resource Conservation (PE\&RC) which comprises of a minimum total of 32 ECTS (= 22 weeks of activities)

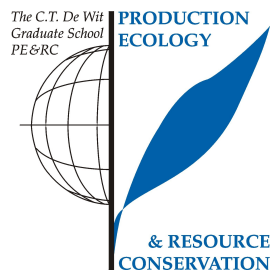

Review of literature (4.5 ECTS)

- Review of sustainable intensification of cereal-based cropping systems in the Indo-Gangetic plains of India

Post-graduate courses (3.6 ECTS)

- Companion modelling; PE\&RC (2016)

- Introduction to R for statistical analysis; PE\&RC (2018)

- Geocomputation using free and open source software; PE\&RC (2019)

\section{Invited review of journal manuscripts (1 ECTS)}

- Agricultural Systems: Assessing the vulnerability of a Mediterranean commercial rangeland to droughts by means of multidisciplinary integrated model (2020)

\section{Competence strengthening / skills courses (4.4 ECTS)}

- Scientific writing; WUR-into languages (2016)

- Workshop carousel; WUR (2018-2019)

- Making an impact: increasing the relevance of research through science-society interaction; WUR (2019)

- Supervising BSc \& MSc thesis students; WUR (2018-2021)

Scientific integrity/ethics in science activities (0.5 ECTS)

- Ethics in the social sciences; WUR (2020)

PE\&RC Annual meetings, seminars and the PE\&RC weekend (1.5 ECTS)

- PE\&RC Introduction weekend (2016)

- PE\&RC Last year weekend (2019)

Discussion groups / local seminars or scientific meetings (4.5 ECTS)

- SIAS Group meetings (2016-2018)

- Integrated farming systems for 3Es: Ecological Sustainability, Enhanced Productivity and Economic Prosperity; India)(2017-2018)

- Modelling and simulation (2019)

International symposia, workshops and conferences (7.1 ECTS)

- Organic World Congress; Delhi, India (2017)

- Farming Systems Analysis Conference; Jaipur, India (2017)

- International Symposium For Farming Systems Design; Montevideo, Uruguay (2019)

- Organization and attendance of writing workshop; Ludhiana, India (2019)

Lecturing/Supervision of practicals/tutorials (3 ECTS)

- Analysis \& design of organic farming systems (2016-2021)

BSc/MSc thesis supervision (3 ECTS)

- Exploring alternative options and feasibility for Climate Smart Agriculture (CSA) practices in whole farm scale for diverse farming system in Bihar, Eastern India

- From research centre to farmers field - farm level exploration of farm-type specific productive, economic and environmental impacts of adopting alternative cropping patterns in North West India

- The positive deviance approach to inform farming systems redesign: a case study from Bihar

- A model-based vulnerability assessment to climate shocks: an Indian case study

- Impacts of on-farm climate adaptation on households in northern India: analysis of objectives, constraints and gender equity

- Antifragility in farming systems research

- Enhancement of residue management with focus on Crop Livestock Integration in Haryana, India

- Scenario development for smallholders in Telangana 
The research described in this thesis was funded by CGIAR Research Programs on Climate Change, Agriculture and Food Security (CCAFS), Wheat Agri-food Systems (WHEAT), Indian Council of Agricultural Research (ICAR), and all donors who supported this research through their contributions to the CGIAR Fund. Financial support from Wageningen University for printing this thesis is gratefully acknowledged. 


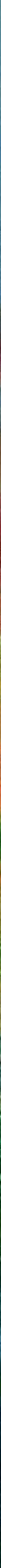

